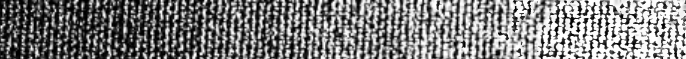

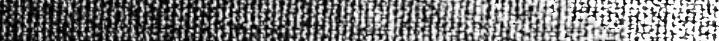

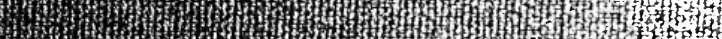

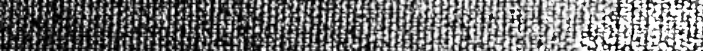
3. 130 m 6.7. H. W

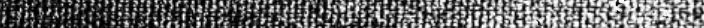

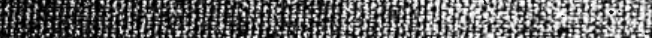

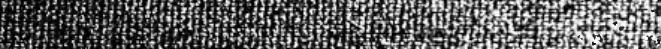

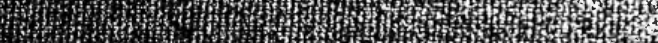

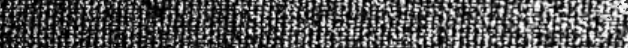

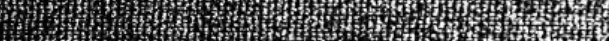

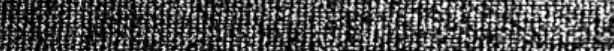

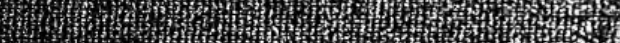

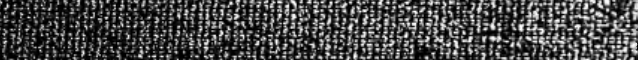
W.m, H.

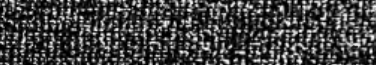
How

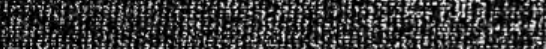

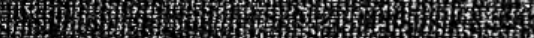
W. W 3.

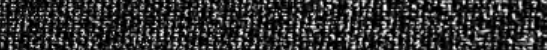
Whom H

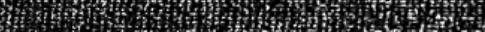

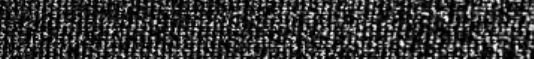

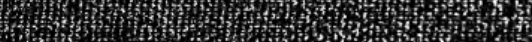
m

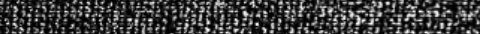

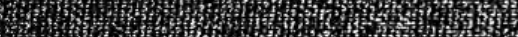
H.

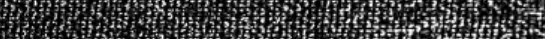
(3)

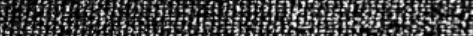
(3) W

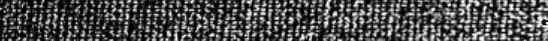

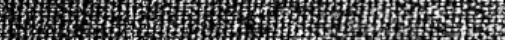
WHom

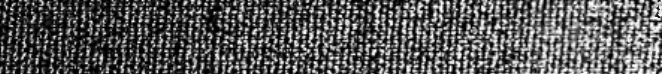

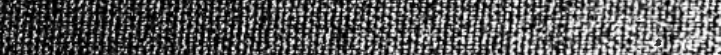

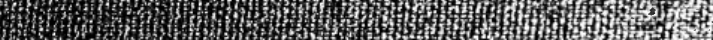
W

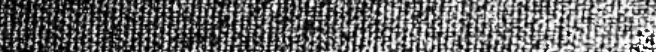

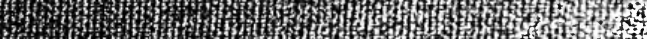

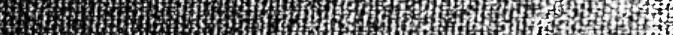

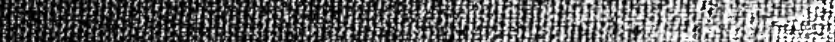
2.

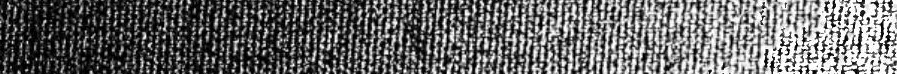
1.6.

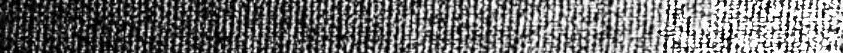

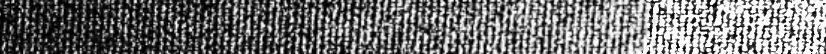
H. 
NORTH CAROLINA STATE UNIVERSITY LIBRARIES 
This book is due on the date indicated unless recalled by the Libraries. Books not returned on time are subject to replacement charges.

Borrowers may access their library accounts at: http:/www.lib.ncsu.edu/ads/borrow.html

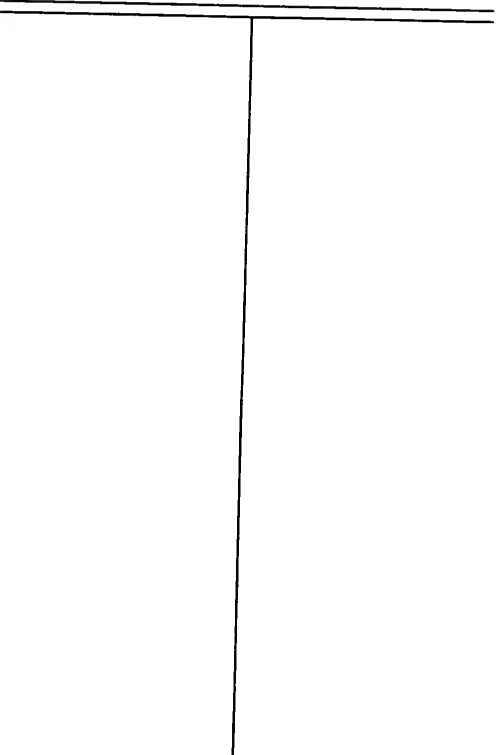



AGE AND AREA 


\section{CAMBRIDGE UNIVERSITY PRESS \\ C. F. Clay, MaNager \\ LONDON : FETTER LANE, E.C. 4}

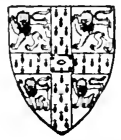

LONDON : H. K. LEWIS AND CO., LTD., 136, Gower Street, W.C. 1

LONDON: WHELDON AND WESLEY, LTD.,

28, Essex Street, Strand, W.C. 2

NEW YORK : THE MACMILLAN CO.

BOMBAY

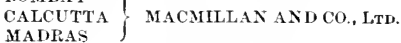

TORONTO : THE MACMILLAN CO. OF CANADA, LTD.

TOKYO : MARUZEN-KABUSHIKI.KAISHA 


\title{
AGE AND AREA
}

A S'TUDY IN GEOGRAPHICAL DISTRIBUTION AND ORIGIN OF SPECIES

\author{
BY \\ J. C. WILLIS \\ M.A., Sc.D., Hon. Sc.D. (Harvard), F.R.S. \\ European Correspondent, late Dircctor, Botanic Gardens, \\ Rio de Janeiro
}

WITH CHAPTERS BY

HUGO DE VRIES, F.M.R.S.

H. B. GUPPY, M.B., F.R.S.

Mrs E. M. REID, B.Sc., F.L.S.

JAMES SMALL, D.Sc., F.L.S.

[ These authors are not committed, by writing these chapters, to the support of all the doctrines here advanced]

\author{
CAMBRIDGE \\ AT THE UNIVERSITY PRESS
}

1922 


$$
a^{2}+x^{2 x}
$$




\section{PREFACE}

Some thirty years ago, a pupil of the strictest school of natural selection, and enthusiastic in my belief in its principles, I set out upon a course of independent observation of nature. Ten years of such work convinced me that a simpler explanation of phenomena was always to be found, and one that seemed more in accordance with the facts; and I endeavoured-with what success this book will show- to free myself from the trammels of the natural selection theory, and to work as if I had found myself in another planet where scientific investigation was just beginning. Stationed in one of the best centres in the tropics (where the phenomena of distribution are more impressive than in Europe), badly handicapped in laboratory work by a serious accident, and finding my chief pleasure in travelling about the world to see its vegetation-I took up the study of distribution, in which $I$ had always taken much interest.

Here, as elsewhere, it was soon evident that the current theories provided an explanation that was not only unnecessarily complex, but one that did not explain. As one of my critics words it, "for some reason the plant has advantages which enable it to spread"; and beyond that point we cannot go. Gradually it became clear to me that plants spread very slowly, but at an average rate determined by the various causes acting upon them, so that age forms a measure of dispersal when one is dealing with allied and similar forms.

Age as an explanation of spread is enormously simpler than natural selection, and that it is probably valid is shown by the way in which it can be used for prediction. An opponent remarks that "it is too simple to be true," but this very simplicity seems to me a strong reason in favour of its adoption, at any rate as a preliminary hypothesis. Of two explanations take the simpler, is an old rule, and as Hooker has said, "no speculation is idle or friitless, that is not opposed to truth or to probability, and which, while it coordinates a body of well-established facts, does so without violence to nature, and with a due regard to the 
possible results of future discoveries." To find explanation of the facts of distribution under the eurrent theories has always seemed a very hopeless task, and any hypothesis that offers a way out should at least receive attention. No hypothesis can, after all, alter the facts, though it may show ways in which to accumulate new ones.

In the second part of the book, I have pushed my hypothesis to what seem to me its logical conclusions, conclusions which are sometimes subversive of received opinions. To be compelled to re-examine the bases upon which those opinions are founded will do science no injury, however.

While the defects of the book are my own, I owe what is good in it very largely to the constant help, advice, and eriticism of many friends, among whom I would specially mention Dr Hugo de Vries, Dr H. B. Guppy, Mrs E. M. Reid, and Prof. James Small, all of whom have also eontributed chapters to the work. To these four I must add my friend Mr G. Udny Yule, to whose trained mathematical skill I owe much useful help and criticism. Prof. J. Stanley Gardiner has helped me very greatly in the work upon animals. In particular he was so kind as to obtain for me the help of Dr Hugh Scott, who spent hours with me in counting beetles, Mr E. Meyriek, F.R.S., who gave me figures for distribution of Micro-lepidoptera, Mr G. C. Robson, and Dr W. T. Calman, F.R.S. 'To the eriticism of Prof. E. S. Prior, A.R.A., I largely owe the present simplified form of the book, and its freedom from technieal terms; he was also so kind as to obtain for me the aid of Dr W. D. Lang. Referenees to literature, and other valuable help, I owe to Sir David Prain and Mr S. A. Skan at Kew, Mr G. Goode, M.A., at the University Library, Miss Taylor at the Balfour Library, and others, whilst I am also deeply indebted for help and criticism to (the late) Dr E. A. N. Arber, Mrs Agnes Arber, Prof. Margaret Benson, Mr E. Breakwell, Dr IV. B. Brierley, Dr N. L. Britton, Dr J. Brownlee, Mr J. BurttDavy, Dr L. Cockayne, (the late) Mr R. W. Davie, Mr C. E. Foweraker, Mr E. G. Gallop, Prof. R. Ruggles Gates, Dr B. Daydon Jackson, (the late) Dr A. Löfgren, Dr D. T. MacDougal, Dr J. H. Maiden, Miss E. R. Saunders, Dr D. H. Scott, Prof. A. C. Seward, Mr A. M. Smith, Dr Norman Taylor, Dr R. J. 
Tillyard, Prof. A. Wall, Dr J. E. B. Warming, Prof. D. M. S. Watson, and many others. That I have been able to carry out this work at all I owe to the labours of generations of systematists, botanical and zoological, foremost among whom, inasmueh as the hypothesis of Age and Area was originally founded upon their work, I must place my predecessors in Ceylon, G. H. K. Thwaites and Henry Trimen. I must also specially mention Sir Joseph Hooker, as this work forms a continuation of his labours of the fifties. Last, but not least, I am decply gratcful to my wife, and to my relatives, Mrs and Miss Steel, for much help ungrudgingly given.

For illustrations I am much indebted for loan of blocks to the Royal Society, and to the Editors of the Annals of Botany. Nature, and New Phytologist; also to my daughter Margaret, who made the drawings from which all, except those on pp. 125, 153, 173, 241 and 242 , were prepared.

J. C. WILLIS.

Cambridge,

4 April, 1922. 



\section{CON'TEN'TS}

PART I. THE PRESENT POSITION

OF AGE AND AREA

CHAP.

PAGE

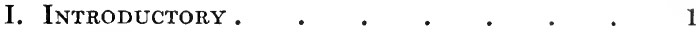

II. The Dispersal of Plants into New Areas . 10

III. The Introduction and Spread of Foreign SPECIES . . . . . . . . . 24

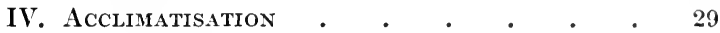

V. Causes which favour or hinder the DisPERSAL OF SPECIES $\quad . \quad$. . . . 32

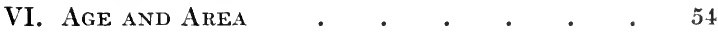

VII. Age and Area (contd.). Confirmation by

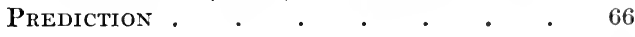

VIII. Age and Area (contd.). Invasions • • • 76

IX. Objections to tile IIypothesis . • • $\quad$ S4

PART II. THE APPLICATION OF AGE AND AREA TO THE FLORA OF THE WORLD,

\section{AND ITS IMPLICATIONS}

X. The Position of the Age and Area Theory 101 By H. B. Guppy, M.B., F.R.S.

Xi. The Further Extension of the Application or Age and Area $\quad$. $\quad . \quad$. $\quad . \quad 107$

XII. Size and Space $\quad$. $\quad$. $\quad$. 113

XiII. Age and Area, and Size and Space, in the

Compositae • • • • • •

By James Small, D.Sc., F.L.S. 
CHAP.

PAGE

XIV. Age and Area from a Palaeobotanical STANDPOINT • • • • • • • 137

By Mrs E. M. Reid, B.Sc., F.L.S.

XV. Endemism and Distribution: Species • • 148

XVI. Endemism and Distribution: Genera • • 169

XVII. The Monotypic Genera, and Genera of

LARger Size. . . . . . . 185

XViII. The Hollow Curve of Distribution • • 195

Xix. Applicability of Age and Area to Animals . 200

XX. The Origin of Species . • • • • • 204

XXI. Age and Area and the Mutation Theory • 222 By Hugo de Vries, F.M.R.S.

XXit. Geographical Distribution: General • • 228

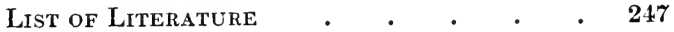

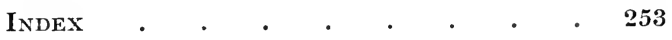

The illustrations on pp. $56,66, \tau 6, \tau 8, \tau 9,80,153$, I owe to the courtesy of the Editor, Annals of Botany. 


\section{PART I}

\section{THE PRESEN'T POSITION OF AGE AND AREA}

\section{CHAP'TER I \\ INTRODUCTORY}

$T_{\text {He existing distribution of a plant (or animal) upon the surface }}$ of the globe, which is often a very complex phenomenon, is due to the interaction of very many factors. Sometimes they are inherent to the plant itself, sometimes they are incidental to its surroundings, sometimes they partake of both qualities. At times they may be active, at others very active, and at some periods, or in some places, they may be more or less quiescent. One pulls in one direction, another in another. As a plant spreads from the place in which it originally commenced, therefore, it comes under an ever-varying pull, causing it to spread more or less rapidly, or at times not at all, according to the different and ever-altering combinations of these factors-different climates, different soils, different groups of plants that occupy the soil, presence or abscnce of such barriers as are offered by mountains, seas, changes of climate, and many other things. To all this it is obvious that age must be added-the older the species is, the more area will it have had time to cover.

But mere spreading is not all; a species may at one time be common in a certain region, and at a subsequent time may be very rare, or even non-existent there. This may be due to many things, for example, the arrival of a disease-organism to which the plant may be very subject, and to which it falls an easy prey, or which so reduces its vigour that it falls a prey to something else. Or some new competitor may appear, which is so much better suited to the local conditions that the first plant is reducel to rarity or perhaps even to extinction. In this connection by far the most important factors are those introduced by geological and other changes. In times which, geologically speaking, werc but yesterday, Britain was united to the continent of Europe, and the way was open for the passage of any species that grew 
upon the latter; now it is closed, or closed to all but a few whose seeds may be carried, by wind, birds, or man, across the dividing seas. In Tertiary times, Europe was covered with forest in which grew many things not now found there; the onset of the cold of the glacial period, and the secular changes of climate, have so altered the conditions that the Tertiary forest has disappeared.

So complicated is the interaction of all these many factors, and their continual changes, that in general it has been considered impossible to say why a given plant should be found to occupy a given area, while another species of the same genus occupies one much larger or much smaller, though it may look almost exactly like the first, and may differ from it only in characters to which we cannot, without great stretch of the imagination, attach any serious importance for life or success. We have been unable to say why, for example, Coleus barbatus should be found almost over tropical Asia and Africa, while C. elongatus, which differs chiefly in the form of the calyx and of the inflorescence, is confined to the summit of one mountain.

For sixty years we have been under the wonderful fascination of the theory of evolution by means of infinitesimal variations, or minute changes of character from individual to individual. At first, and for a long period, this theory seemed to be capable of explaining almost everything, and to it we owe what could perhaps have come in no other way, the establishment of the doctrine of evolution, now universally adopted, but which until the latter part of the last century, though 2000 years old, had met with no acceptance. To quote Iuxley (22 in List of Literature, II, pp. 180, 197), "To any one who studies the signs of the times, the emergence of the philosophy of Erolution, in the attitude of claimant to the throne of the world of thought, from the limbo of hated and, as many hoped, forgotten things, is the most portentous event of the nineteenth century." "...the publication...had the effect... of the flash of light, which to a man who has lost himself in a dark night, suddenly reveals a road which, whether it takes him straight home or not, certainly goes his way."

Under the glamour of this theory, the tendency naturally was to lay the greatest stress upon the vital factors in distribution, for these were the only oncs which could differ from individual to individual, or from species to species. The means of dispersal open to plants, their reactions to the climate, etc., and their adaptations to various ends, were therefore studied with re- 
newed and extraordısary vigour, whilst the mechanical factors, except perhaps the purely negative influences of barriers, were left comparatively neglected. For many years there was remarkable progress in our knowledge of geographical distribution, but this has now all but ceased, except in regard to the study of the purely local distribution of species in reference to the purely local changes of the different factors of climate, water-supply, associations of plants covering the ground, and the like, in which direction much work of extreme value is bcing carried on. But in regard to the wider general distribution of plants about the globe, we seem to have arrived at a period when the limiting factor, to use Blackman's words, has become the lack of a satisfactory theoretical background, which will provide efficient working hypotheses for the conduct of investigations that shall lead to real advances in our knowledge of the fascinating subject of geographical distribution. I have myself heard a leading authority upon this subject say that he thought that it was almost beyond the range of human capacity.

In this emphasising of the effects of the vital factors, the action of mere age, which must evidently be of some importance, has been more and more lost to view. And yet in $1853 \mathrm{Lycll}$ (69, p. 702$)$ wrote

As a general rule, however, species common to many distant provinces, or those now found to inhabit very distant parts of the globe, are to be regarded as the most ancient. Numerically speaking, they may not perhaps be largely represented, but their wide diffusion shows that they have had a long time to spread themselves, and have been able to survive many important revolutions in physical geography.

Again he says

Nor do I doubt that if very considerable periods of equal duration could be compared with one another, the ratc of change in the living... world might be nearly uniform.

And yet again

Every local revolution...tends to circumscribe the range of some species, while it enlarges that of others; and if we are led to infer that new species originate in one spot only, each must require time to diffuse itself over a wide area. It will follow. therefore, from the adoption of this hypothesis, that the recent origin of some species, and the high antiquity of others, are equally consistent with the general fact of their limited distribution; some being local, because they have not cxisted long enough to admit of their wide dissemination; others, because 
circumstances in the animate or the inanimate world have occurred to restrict the range which they may once have obtained.

Hooker (55 $a$, p. xxv), in the same year, 1853, quotes the first passage from Lyell, and goes on

If this be true, it follows that consistently with the theory of the antiquity of the alpine flora of New Zealand, we should find amongst the plants common to New Zealand and the Antarctic Islands some of the most cosmopolitan, and we do so in Montia fontana, Callitriche verna, Cardamine hirsuta, Epilobium tetragonum and many others.... On the other hand, it must be recollected that there are other causes besides antiquity and facility for migration, that determine the distribution of plants; these are their power... of invading and effecting a settlement in a country preoccupied with its own species, and their power of adaptability to various climates...though we may safely pronounce most species of ubiquitous plants to have outlived many geological changes, we may not reverse the position, and assume local species to be among the most recently created, for species, like individuals, die out in the course of time; whether following some inscrutable law whose operations we have not yet traced, or whether (as in some instances we know to be the case) they are destroyed by natural causes (geological or other) they must in either case become scarce and local while they are in process of disappearance.

It is thus clear that the subject of Age and Area is by no means new. Until comparatively recently I was not aware of the above very striking quotations, and it is interesting to find that my experience of actual distribution in many lands has led me, as it has led Guppy and many more, to much the same conclusions as those reached by two authorities so great as Lycll and Hooker. Had it not been for the appearance and rapid rise of the great theory of Darwin, with its inevitable diversion of effort into other and at the time much more profitable lines, it is evident that Hooker or some other worker of an earlier time would have discovered not only the principle which I have termed Age and Area, but also the many and remarkable conclusions to which it leads.

During the last twenty years, since finishing my monograph of the Indian Podostemaceae (116), I have deroted my spare time to the study of geographical distribution. My studies of that family had convinced me that the vital factors were not, to any great extent, responsible for the existing dispersal of the species, and in May, 1907, I published the first sketch of the 
theory that was growing up in my mind in respect to it. Almost simultaneously Copeland (18) presented evidence for the same view, practically enunciating the hypothesis itself, though not in definite arithmetical terms.

In various subsequent papers I published further suggestions in regard to Age and Area, and the other hypotheses that I had associated with it, but it was not until in $1912 \mathrm{I}$ actually worked over the complete flora of Ceylon with respect to local distribution that I discovered that the effects of mere age upon dispersal were so clear and unmistakable that they could be expressed in figures. My paper embodying these results was published in 1915, and has been followed by many others upon the same subject.

While the distribution of any single species is due, as has been said, to the complex interaction of many factors and barriers, it must be remembered that only in the case of a group of allied species will these be likely to act with some uniformity. Age, on the other hand, pulls all alike, so that if one deal with groups of allied species, and call the various factors $a, b, c, d$, e, etc., while some will probably pull different ways on different species, and so cancel one another, others will pull the same way upon all, so that the dispersal of one group of ten may be due to $(a+b+e+f) \times$ age $=10$, and of another (allied to these) $(a+b+e+g) \times$ age $=20$. The latter will evidently be of much greater age than the former, as it occupies twice the area, and the factors other than age are much the same. But if one take two groups of unallied types, e.g. one of Leguminosac and one of Gramineae, or one of trees and one of herbs, one may have in one case $(a+c+d+c) \times$ age $=10$ and in the other $(b+d+f+g) \times$ age $=20$, and a comparison as regards age alone will cvidently be impossible.

A very excellent illustration of the principle here involved is given by the tables of expectation of life published by the insurance companies. In no single case does "age" alone determine the period to which a man will live, yet by taking averages of men of the same race it is possible to say with perfect accuracy how long an average man of 45 will have to live, or a man of 46 , etc.

If one be dealing with one species only (or one life only), then the interaction of many factors, including age, will be so complex that one cannot say to which the distribution (or length of life) is actually due. It must always be remembered that the 
effects of age only show clearly when one deals with many species, and those allied (and therefore more or less similar, both in structure and reactions).

I must consider myself very fortunate in having finally discovered that the effects of age were sufficiently clear to be arithmetically expressed. It is consequently possible now to disentangle them to some extent from the effects of the other factors acting upon distribution, and this should tend to make the study of these other factors and their results an easier matter. It seems to me by no means impossible that they too may prove amenable to statistical treatment. Many biologists have a feeling of dislike to the introduetion into biology of the more exact methods of arithmetic; as Hooker wrote, many years ago, "all seem to dread the making botanical geography too exact a science." But we have become accustomed to their use in the study of genetics, and we may hope that their employment in geographical work may not ultimately prove too repugnant.

What has really surprised me in my work upon Age and Area more than anything else, and what seems at the same time to rouse some antagonism, is that the figures that have been given in many papers, by myself and others, show such clear and unmistakable results that it is evident that mere age of species is a much more important factor in geographical distribution than we had been inclined to suppose. By the use of my hypothesis that area occupied is largely dependent upon age, one can make so many predictions about the geographical distribution of plants, especially within comparatively small areas, and find them correct within such small limits, that it is evident that mere age is a very important factor indeed, and consequently that distribution, when one works with groups of species, and over enormous periods of time, is a much more mechanical phenomenon than we had been inclined to think.

Of course age in itself cannot effect anything; what is really meant is that the resultant effect of all the active factors, like dispersal methods, etc., is so uniform, when one considers long periods of time and takes an average of several allied species, that these species spread indefinitely at a fairly steady average rate. This rate, as I have pointed out in most of my papers, will probably not be the same for any two species, but for allied forms will not usually differ very much, so that by taking groups of ten allies, and comparing with other groups allied to the first, the rate of expansion of area will be a fair measure of age. 
Argument of Part I. In the next eight chapters I have endeavoured to set forth the hypothesis as thus far developed, and shall follow this in Chapter XI (Part II) with a general statement of the argument of the remainder of the book, in which the hypothesis, which now stands upon a good basis of facts, is pushed to some of the conclusions to which it appears to me to lead, and which are so wide-ranging that they cover much of the ground occupied by all the biological sciences.

In Chapter II the dispersal of plants is considered. Only by such dispersal, accepting the views of the present day about origin, could they have covered the large areas that so many now occupy. It is shown that while the possession of a good mechanism for the purpose is of great advantage to a plant, especially in reaching areas that are a little distance away, it is by no means necessary for world-wide distribution. The examples quoted about the actual dispersal of plants into new areas are practically always cases in which there was virgin soil available for their reception, and in actual life one very rarcly sees such distribution. Most places are occupied by societies of plants, into which a newcomer will find it very difficult to enter, and it may have to wait a very long time until the changes that are always going on allow it to get a foothold. Barriers to dispersal, even though quite small, may produce very large effects, and as a rule dispersal appears to be extremely slow.

The questions of Introduction and spread of foreign species and of Acclimatisation are then dealt with, and it is shown that the popular interpretation of the rapid spread of introductions - that they spread, and especially in islands, because they have come from continental areas or from the north, where the struggle for existence is keener, and has made them more cfficient-rests upon very insufficient evidence, and that the real explanation, in all but a very few doubtful cases, is that their spread is due to change of conditions. This has usually been effected by man, who has often altered, or even destroyed, the conditions under which many societies of plants formerly flourished, thus giving a fair field to those newcomers that were suited to the new circumstances. Acclimatisation is very bricfly considered, the general conclusion indicated being that as a rule it must be very slow and gradual, as in fact is the case with most of nature's work.

In Chapter $\mathrm{v}$ it is pointed out that only in rare cases will a seed be carried more than a few yards to survive and grow, and 
also that in view of the time available there is no need for rapid dispersal. The various causes are then considered that may help, or far more often hinder, dispersal, e.g. purely physical barriers like seas or mountains, barriers partly physical, partly dependent upon the constitution of the plant, like changes of soil or of climatic factors, or barriers (or aids to spread) dependent wholly upon the latter, like the fact that herbs may spread much more rapidly than trees, that parasites can only spread with their hosts, that a plant may or may not spread quickly according to the particular society of plants with which it meets, and so on. The general impression is that dispersal in nature, except in a few (probably very few) cases, must be an exceedingly slow process. Only in cases where man has interfered is there much evidence of rapid spread, and the popular impression that this is general cannot be justificd by any of the facts at our disposal as to plants in unchanged natural eonditions.

Passing on to the consideration of Age and Area itself, in Chapter vi, it is pointed out that when I began to investigate the flora of Ceylon, I soon noticed the extraordinary differences in area occupied that were to be found in species of the same genus, where there were no characters of difference that could, by any stretch of imagination, be regarded as fitting or unfitting them for the struggle for existence. Endemic or purely local species very rarely oceupied the whole island, and must evidently be adapted, if adapted at all, to local conditions within its area. This led to a careful study of areas, and it was found, for Ceylon, New Zealand, and elsewhere, that those species were the most widely distributed in a country which had the widest distribution outside, while the local or endemic species showed the smallest areas of distribution; in both cases working always with averages of ten allied species.

Dividing the species of a country into classes according to the amount of area occupied, it was found that the endemies were most numerous in the lowest class (smallest areas), the numbers decreasing steadily upwards, while the widely distributed species were arranged in the exact reverse direction. Such facts were much opposed to the supposition that endemics were adaptations to local conditions, and equally so to the other supposition that they were relies. The facts call for a mechanical explanation, and the most reasonable seems to be that area occupied on the average increases with age, independently of the origin of the species. Endemic species are usually young beginners. 
The next chapter gives a few illustrations of the suceessful manner in which Age and Area has been applied to the making of predictions about local distribution. For example, the floras of the outlying islands of New Zealand being in general derived from the same sourees as that of the main islands, must be composed of species that were among the earliest arrivals, in their own affinity groups, in New Zealand, and should therefore, by hypothesis, be very widespread there. This proved to be the case, in a very striking manner, the species of the islands ranging on the average nearly 300 miles farther in New Zealand than the species that did not reach the islands. Further, the endemic species that reached the islands ranged much farther in New Zealand than the widely distributed species of New Zealand that did not reach them. This result seems explicable only by aid of Age and Area. Other predictions that were equally suceessful are also instanced, and it will suffice to say that as Age and Area has been applied in this manner in over ninety eases without a failure, the hypothesis now stands upon a very firm basis.

A further chapter is then given to the consideration of the way in which it may be applied to the study of the invasions of plants that may have reached a country, New Zealand being taken as an example. By a consideration of an imaginary case in which a single widely distributed speeies enters New Zealand and gives rise to endemies in a easual way, it is shown that the endemies in a country will in general show numbers decreasing from the centre where the parent entered down to the two ends. On examining the facts it was found that all the genera of the New Zealand flora gave such curves. A study of the position of the maxima shows that they are concentrated in three chief regions-north, south, and central-and one infers that these must have been the centres of corresponding invasions. Careful study of the curves given by the single invasions goes to show that the northern was mueh older than the southern, and this is confirmed by the fact that the latter is mainly composed of the more mobile group of herbs, while the former is ehiefly trees.

Lastly, Chapter Ix is devoted to a detailed consideration of the many objections that have been brought up against $A$ ge and Area, and many or most of them seem to be satisfactorily met, very many of them depending simply on misunderstanding of the work upon which it is based. 


\section{CHAPTER II}

\section{THE DISPERSAL OF PLANTS INTO NEW AREAS}

A very large number of species are to be found at more or less frequent intervals over enormous areas of territory, often in regions separated by large stretches of water, or sometimes of land. Never, since the days of the hypothesis of special creation, has it been maintained that a species originally arose over the whole of the area upon which it now occurs. This would be a difficult proposition to uphold, as it is usually found that when a species occupies a large territory, it has different varieties in different parts. Various views, however, have at times held sway as to the probable extent of the land surface upon which a species began. Darwin $(22,111,109)$, for example, had at one time the idea that it might arise under Natural Selection from one or a few individuals varying in the desired direction, but Fleeming Jenkin brought up a criticism of this position so incisive that he was forced to abandon it, and postulate for a much more numerous original ancestry, of course occupying a much larger amount of ground. It is perhaps from this latter position taken up by him that the current view has arisen, according to which species that now occupy very small areas of country owe the smallness of that area to the supposed fact that they are really in process of dying out, for they could not have arisen by aid of the Darwinian mechanism of Natural Selection upon so small a space.

At the present time, however, when this mechanism of infinitesimal variation with natural selection (or survival of the fittest) is not commonly accepted as being the principal factor in the production of new species, it is probable that comparatively few people would be found to demand more than a relativcly limited area for the purpose. Not many, perhaps, have any exact idca of how much would be needed, but possibly the majority would require either a little more than just a few square yards, or the repeated origin of the same species upon the same area. A good many writers, both of former times and of the present, have adopted the view that it is not absolutely 
necessary that a species, genus, or tribe should arise upon one spot only, or even in one region only. They consider that the same thing may arise independently in different places, very rarely indeed the species, more often the genus, tribe, or family, either from the same species by the same road (as would probably be the case with the origin of a species in this way), or from different species, which all made the necessary changes to place them in the same genus or tribe (cf. 116, p. 446). This supposition would unquestionably get rid of some of the difficulties of explaining many cases of discontinuous distribution, where the same species, genus or tribe appears in widely separated regions.

Whatever view has been held as to origin, however, it seems to have been generally taken for granted that except in so far as they have been prevented by actual barriers, such as seas, ranges of mountains, sudden changes of climate from one district to the next, and the like, species have spread over the whole area to which they are suited, i.e. where they can grow and reproduce in spite of any adverse conditions to which they may be subject. In other words, it seems to have been assumed that the distribution about the world of the species now existing therein is largely a closed chapter, except in so far as man by his various activities may alter it. Why this idea of finality should have sprung up is not quite so easy to decide, unless it has been that people take for granted that in nature dispersal of plants is rapid ${ }^{1}$, and it is one of the objects of the present work to show that we are still dealing here with open questions.

It is clear, however, that the large areas now occupicd by many species must almost always, if not always, be due to spreading from others originally much smaller, and a careful study of the ways in which this dispersal may be effected must form a necessary preliminary to the study of geographical distribution in general. It is of course obvious that, as a rule, a plant once established will not move again, but its sceds, or detached portions of itself (or sometimes, as in the case of runners, connected portions), may in various ways be carried to a distance

1 People see a dandelion seattering seed over a large area, or notice the rapid spread of a new weed in the garden, and are apt to reason that this sort of thing is always going on with all specics, while at the same time they forget that most, if not almost all, seeds dropped upon groumd already fully oceupied by plants, fail to grow, even if they germinate. One may see the same clump of traveller's-joy, for example, oceupy the same place without spreading, for a whole lifetine. 
from the parent. This dispersal implies the concurrence of various circumstances, and when all of these are external to the plant it is spoken of as occasional or accidental, while when some are inherent in the nature of the plant itself, it is said to take place by aid of the regular "mechanisms." As instances of "irregular" dispersal, we have such cases as the carriage of heavy seeds by a hurricane, or their casual attachment to a $\log$ which is accidentally floated across the sea to a new country; whilst it is "regular" in the case of seeds so light that they will always be carried by wind to some little distance, or fleshy fruits which are eaten by birds and the seeds subsequently dropped. It may prove of more interest if an account be given of some actual researches carried out upon this subject, rather than a mere enumeration of the various mechanisms, cte. $(54,71)$.

My chicf pleasure in life being travel, I have always been interested in the movement of plants, and in 1893, with Mr I. H. Burkill, published (137) a study of the flora found in the bowllike tops of the pollard willows that line the banks of the Cam, especially from Cambridge to Ely. We examined about 4000 of these trees, and counting each occurrence of one species in one tree, whether represented by few or many individuals, as 1, and only as 1 , we obtained 3951 records. The tops of the trees being about six feet above the ground, it is clear that without some assistance seeds would be quite unable to reach them, though when once reached, a willow top presents a virgin area of soil, with no other species growing there. There were some 200 to $\mathbf{2 4 0}$ species in the neighbourhood which if planted in the willows would probably have been able to grow there, but of these we found that only so, or about a third, actually oecurred, showing that the presence of a barrier even so trifling as the height of a willow was sufficient to exclude very many. Most of the plants with well-marked "regular" mechanisms were among the so, though one missed Cormus (dogwood), Salix, the willow itself (possibly it would not grow in its own humus), Populus, the poplar (possibly for the same reason, it belonging to the same family), and a few Compositae and the orchids. The commonest plant in the tops was Galium Aparine, the goose-grass, found in 644 trees, or over 16 per cent. of the total records. The fruit of this plant has little hooks, so that it may easily cling to an animal or a bird for time enough to be carried to a willow. But it was also found to be largely used by birds in nest-making, and probably the bulk of the records are due to this, for ripe 
fruit would often be present upon the pieces carried to the trees for this purpose.' The next most common plant was Sambucus nigra, the elder, with 550 records; this has a fleshy fruit which is eaten by birds, and the seeds subsequently dropped. The third plant was Rosa canina, the dog-rose (410 records), also with a fleshy fruit; the fourth Urtica dioica, the nettle (306 records), with very light seeds that are easily carried by wind, but also largely used in nest-making. These mechanisms were repeated in the next two or three plants on the list, and then followed the ash, Fraxinus excelsior, with 100 records. This has a winged fruit, which when falling from a tree of some height during a fairly strong wind may be earried to some distance; and as there were many ash trees close to the river, this aceounts for the frequency of the oceurrence of this speeies in the willow-tops. Next after this came the dandelion, Taraxacum officinale (82 reeords), with a fruit which in a breeze is easily earried upwards by means of its parachute of fine hairs. By the time that we come down the list to plants with 40 records, or 1 per cent. of the total, 21 species have appeared there. All but one of these have well-marked "regular" mechanisms, but the remaining 59 include a considerable number whose arrival in the tree-tops must have been due to some "irregular" aid, for they have neither light, winged, burred, nor fleshy fruits or seeds. Nineteen of them showed only one reeord each, and their appearance must be due to some such accident as having been carried in a ball of earth attached to a bird's foot, driven by an unusually strong wind, or some other irregular transport.

Classifying the records according to mechanism, we find:

$\begin{array}{lcccc} & \text { Species } & \text { Records } & \begin{array}{c}\text { Per cent. } \\ \text { of records }\end{array} \\ \text { Fleshy fruit (animals) } & 19 & 1763 & 44 \cdot 6 \\ \text { Winged or feathered } & & & \\ \text { fruit or seed (wind) } & 33 & 995 & 25 \cdot 1 \\ \text { Burred fruit (animals) } & 3 & 651 & 16 \cdot 4 \\ \text { Light seed (wind) } & \ldots & 9 & 425 & 10 \cdot 7 \\ \text { Doubtful methods } & \ldots & 16 & 117 & 2 \cdot 9\end{array}$

Thus quite an appreciable number of species are sometimes transported, though in no great numbers. Of the 117 records, Anthriscus sylvestris, which is used in nest-making, accounts for 63.

Three important facts appear in this result: (1) that even a slight barrier may produce a large effect; (2) that the bulk of the individual plants (not speeies) travel by aid of the "regular" 
mechanisms, especially by help of birds; but also that (3) a large number of species, even if few plants, travel by aid of "irregular" or accidental methods. If one could follow up the entire history of distribution of plants about the globe, one would be quite likely to find that all species sometimes travel in this way, even though only very rarely. One would hardly expect to find the buttercup, Ranunculus bulbosus, or Lathyrus pratensis, in the willow-tops, yet both occur, though one does not find such common plants as clover or daisy $(44$, p. 277).

Two other important results also appeared: (4) that in only two instances did a plant oceur of which there was not a representative actually growing on the soil within 200 yards. Even in these cases it was quite possible that at the time of reaching the willows the distance to be traversed did not exceed that figure, for one of the two, Lactuca muralis, was recorded for the same tree in Babington's Flora of thirty-five years earlier. In any case, it was clear that as a rule transport was only over short distances; and (5), a result which appeared on comparison with similar work done elsewhere in Europe, that the proportions of species distributed by the various mechanisms were much the same $(10$, p. 120$)$, so that one might be able to predict to some extent the probable composition of such a flora.

Another type of distribution was studied in working out, with Prof. J. Stanley Gardiner, the flora of the Maldive Islands (138), a group of coral atolls about 400 miles south-west of Ceylon, far removed from other land. There is no reason to suppose that any of their flora survives from the far-distant period when there was probably a land bridge from India to Africa, so that they probably formed a virgin area for the arrival of species from elsewhere. Of their 160 species, 66 proved to be suited to carriage by sea currents, possessing easily floated seeds or fruits, impervious to salt water; 17 were bird-carried, with fleshy fruit, 4 were wind-carried, and there remained 73 , probably mostly due to unintentional carriage by man, but some doubtless brought upon floating logs or in other ways. Again a large percentage of the species had thus arrived "irregularly."

Another piece of work of this kind was done upon the flora of Ritigala (117), a solitary precipitous peak, rising to 2506 feet in the low-lying "dry" north country of Ceylon, about 40 miles from the main mountain mass to the sonth, which forms part of the "wet" zone. The dry zone receives practically no rain during the six months of the south-west monsoon, and has thus 
a long period of drought, but Ritigala is high enough and steep enough to condense the moisture of this wind, and its upper part therefore forms an outlier of the wet zone. Upon the summit is a wet-zone flora, which must in general have reached it by overstepping the whole $\mathbf{4 0}$ miles of separation, for the configuration of the country, and the course of the monsoons, render it very improbable that the intermediate country can ever have been "wet," i.e. have received rain in the south-west monsoon also, which alone would render life possible for these species. Of the 103 wet-zone plants at the summit, 24 had fruits suited to bird carriage, 49 had light fruits, seeds, or spores suited to wind, and 30 may be classed as doubtful, being entirely unsuited to any of these methods, and yet equally so to growth in the intermediate "dry" country. Here, therefore, was carriage by doubtful methods over a good 40 miles, most probably by the aid of birds in some way, as the species were largely mountain species.

Of the actual wind-carried species, 24 were ferns and lycopods with dust-like spores, 20 were orchids with very light seeds, and the other 5 were Compositae, Apocynaceae, and Asclepiadaceae, with parachute-like fruit or seed.

It is noteworthy that the peak of Ritigala, a mere small area projecting out of a sea of dry-zone plants, was probably not a virgin area, though suitable to wet-zone forms. It was probably covered with plants of "dry-zone" type, which have only gradually been ousted by "wct-zone" arrivals, and in the whole of the enormous period since it became suitable to the latter it has only received 103 of them, and also bears a great number of plants which are the same as those of the dry-zone areas below. The Maldive Islands, which were probably a virgin area, have received 160 species, in probably much less time, and Krakatau, which we shall next eonsider, received 137 in thirty years.

Krakatau, the classical instance of the distribution of plants to new ground, is an island in the strait between Java and Sumatra, about 25 miles from each, and about $11 \frac{1}{2}$ from the nearest island with vegetation. In 1883 it was absolutely sterilised by the famous eruption. In 1886 Dr Treub of Buitenzorg visited it to see to what extent it had been re-colonised (109); he found many blue-green Algae, 11 ferns (spores easily carried by wind), 9 flowering plants on the beach (carried by currents, or drifted over by wind), and 8 inland, two of these the same as on the beach. These eight were a Wedelia, two Conyzas, and a Senecio, all Compositae, with dandelion-like fruits, easily carried 
by wind, Phragmites and Pennisetum (grasses, ditto), Tournefortia and Scaevola (fleshy fruit, bird-carried). In 1897 (34) a further examination showed that there were 50 flowering plants, of which about 30 were due to sea carriage, and 16 to wind. In 1905 the number had increased to 137 , and the island was beginning to show thick forest growth. But again the effect of a barrier should be noted, for the flora of Java alone is over 5000 species.

Thus at first only the regular mechanisms produced any result; but sooner or later the irregular begin to show, for in the 137 are a few species as to whose method of reaching Krakatau it is impossible to do more than guess. On Ritigala, where there are 30 species of doubtful method of transport, the time allowed has been enormous, while on Krakatau it was less than thirty years. Yet in those thirty it had, thanks to virgin soil, and somewhat greater nearness to the sources of supply, received many more species than Ritigala.

Another case of this kind was the re-regetation of the Taal volcano (38), in the middle of a lake in the Philippine Islands. Here, again, the wind-carried plants arrived very early, and in larger numbers of species, but the bird-carried tended to be numerous in individuals. Both upon Krakatau and upon Taal the vegetation began before very long to settle down into associations of plants. While at first chicfly herbaceous plants, these were soon followed, as happens in damp regions when sufficient time is allowed, and no other agency, such as man, interferes, by shrub and forest.

Incidentally, a method of dispersal which has not been mentioned above must receive a word of notice. This is the explosive mechanism, as it is sometimes called, where, owing to tensions set up in the fruit by turgidity, as in Impatiens, or by drying, as in Claytonia, Montia, Hevea, Hura, etc., the seeds when ripe are jerked away from the plant. The distance is commonly quite small, but when, as in Hura or Hevea, the fruits are at the top of a tall tree may be slightly increased.

In many respects, the last regular mechanism which has to be mentioned, that of vegetative reproduction by portions of the plant itself, like runners, suckers, bulbils, etc., is the most efficient of all, as witness the profusion of daisies in most lawns, or the difficulty of eradicating Jerusalem artichokes once established; while anyone who has had the misfortune to have his garden infested with goatweed, enchanter's nightshade, celan- 
dine, or couch-grass, will need no information as to the efficiency of this method. Tithonia diversifolia (Compositae), which has no pappus, and is dispersed almost entirely by vegetative methods, has spread in Ceylon as widely and almost as rapidly as Lantana, which is bird-carried. Elodea in the waters of western Europe was a similar case, for only the female plant is known there. Vegetative reproduction cannot carry a plant very far at one operation, but it is probable that to travel far, unless into virgin soil, is really rather a handicap; and the young plant has the enormous advantage of connection with the parent, or in any case of a good supply of food with which to commence life.

Several other researches have been carried out in recent years upon the actual transport of seeds and fruits. Of these by far the most important are those of Guppy upon the stocking with plants of islands of the Pacific and Atlantic Oceans (44, 47). He discusses in detail the agencies that can effect distribution, pointing out that the currents only take a comparatively minor part in it. About 90 per cent. or more of the plants in the islands have fruit which is not buoyant, and could only be carried by some accidental concurrence of circumstances. After talking about the lists of sea-carried plants given by Schimper and Hemsley, and including in each case about 120 species, he says: "De Candolle was quite right in minimising the effect of currents on the distribution of plants," and again, "one can scarcely controvert Kerner's opinion that the dispersal of plants, as a whole, is not appreciably affected by this process." Leguminosae as a family are conspicuous among sea-borne plants.

He considers that as an agency in stocking far outlying islands birds take the first place, though there are many difficulties in explaining the distribution. Why, for example, should Fiji have about 200 genera not found in Hawaii or Tahiti, and yet many of them just as well suited for bird carriage as those that actually occur there? He considers, however, that the age of birddispersal is now practically over in the Pacific, and that just like the plants the birds have tended to become local species confined to islands or groups of islands. This phenomenon of endemism or local species is shown most markedly in the case of both plants and birds in the far outlying islands of the Pacific, while in islands where none of the plants are peculiar, endemic birds are few or wanting.

He goes on to point out that the development of local species is largely correlated with degree of isolation, not only as regards 
distance from the mainland, but as regards frequency of arrival of species from elsewhere. There are few local island species among the beach plants, which are continually arriving with the ocean currents, more among the mountain-top plants, where probably birds most commonly alight on arrival, and most among those of intermediate elevation.

He regards as the oldest, on the whole, those groups with actual genera confined to the island or group of islands, then those with genera all of whose species are endemic, followed by those having genera with some species endemic and some widely distributed, and as the youngest, on the whole, those having only genera with no species endemic. He regards the development of endemic species as due to what he ealls the principle of differentiation. They are most often allied to some common widely ranging and polymorphous species which he regards as the parent. To this very important conclusion he returns in other papers (45-6), and in his later book upon the Atlantic Ocean (47), where he comes to much the same general conclusions upon distribution as in the case of the Pacific.

In fact, as we shall see in more detail in the course of this book, Guppy arrived at, and published a year sooner, the samc general conclusions to which I also have been driven by a lifetime spent, like his, in travel and botanical investigation, chiefly in the tropies.

Interesting facts in regard to the distribution of the Compositae have been worked out by Small (103). The fruits of these plants are usually carried by aid of a parachute-like tuft of hairs, as may be well seen in the dandelion. The general evidence that he marshals goes to show that the fruits may frequently be dispersed to a distance of from four to twenty miles, and even at times over one hundred (cf. Ritigala and Krakatau above). His experimental observations show that so long as the relative humidity of the air remains at a figure that keeps the pappus open, a wind of two miles an hour (barcly pereeptible) is enough to keep the fruit floating in the air for an indefinite period, but if the moistness increases, the pappus closes, and the fruit soon falls to the ground. Thus the dispersal of these plants on land, where the air in general is drier, may at times be to great distances, but over the sea such conditions of dryness will comparatively rarely occur.

Important papers have also been published by Ridlcy on the actual facts of spreading observed by him (91-2). For example, 
he studied the Dipterocarpaceae in the Botanic Gardens at Singapore. These are tall trees with rather large fruit, upon which two or more of the persistent sepals grow out into large wings. Falling as they do from a considerable height, and revolving as they fall, these fruits may be carried to some distance before they drop, if there be a wind blowing. A Shorea, 100 feet high, was found to scatter its fruits freely up to 40 yards distance, but not beyond 100. As it fruits at thirty years old, a little calculation will show that in the most favourable circumstances conceivable, with the ground clear of other vegetation, it would take about 60,000 years to migrate 100 miles. Dipterocarpus grandifolius, another of this family, ranges from the Malay Peninsula to the Philippines, and Ridley estimates that at least $1 \frac{1}{2}$ million years would be needed to traverse this distance. He considers that light powder-like secd affords the most rapid transit, plumed fruit or seed, like the dandelion and other Compositae, next, and winged fruit or seed, like the ash or the Dipterocarps, the slowest (of the "regular" mechanisms for wind-dispersal). In another paper he gives interesting points about the dispersal of seed by mammals, calling especial attention to the small distances usually travelled in such cases.

What has been said so far might be read to mean that dispersal of plants was always a comparatively simple and rapid process, only interfered with to some extent by aetual barriers; and it is nccessary now to make clear that in nature this is far from being the ease. The desirability, under the Darwinian theory, of finding as many, and as effectual, "adaptations" as possible, has led to those for seed-dispersal receiving much greater credit than is their due. In all the cases (except Ritigala) that we have so far considered, the dispersal of the plants has becn into areas of ground that could be easily occupied, on account of the lack of competition; and the same is the case with the introductions described in the next chapter. But suppose that, instead of the 4000 willow-tops, one thought of 4000 areas of a square yard each (or of a single acre) upon a moor or in a forest, it is at once obvious, from ordinary observation, that in 100 years they would not receive 80 new spccies of plants, even though these might be growing within 200 yards. It is doubtful if they would even receive one or two. Nor would an area equal to that of the island of Krakatau, but upon a tropical savannah, 
receive 137 new species in less than 40 years. As Lyell stated in 1853 :

Every naturalist is familiar with the fact, that although in a particular country, such as Great Britain, there may be more than 3000 species of plants, 10,000 insects, and a great variety in each of the other classes; yet there will not be more than a hundred, perhaps not half that number, inhabiting any given locality. There may be no want of space in the supposed tract; it may be a large mountain, or an extensive moor, or a great river plain, containing room enough for individuals of every species in our island; yet the spot will be occupied by few to the exclusion of many, and these few are enabled, throughout long periods, to maintain their ground successfully against every intruder, notwithstanding the facilities which species enjoy, by virtue of their power of diffusion, of invading adjacent territories $(69, \mathrm{p}, 670)$.

This fixity of the vegetation in any given neighbourhood, though familiar enough to everyday observation, tended to be ignored during the period of the hunt for adaptations; but with the rise of the study of ecology it has once more come into prominence, and the tendency at present is perhaps to regard it as too permanent. A given area of ground is occupied by a society or association of plants, made up in a fairly definite way. This association may be open, leaving room for possible newcomers, but tends always to become closed, by taking in the maxinum number which can mutually adjust thenselves to the conditions there prevailing, and as altered to some extent by each new arrival. It is a matter of extraordinary difficulty for a neweomer to obtain a foothold in a closed association, which may thus form an almost complete barrier to passage. But with the changes brought about in the soil, etc., by the vegetation itself, and for other reasons, an association sooner or later passes its climax, and tends to be succeeded by others. As Clements says (16), "the most stable association is never in complete equilibrium"; and again, "local migration is primarily responsible for the population of new areas...most of the evidence available shows that effective invasion in quantity is always local." It is clear that to think of plants in gencral as travelling rapidly about the world by aid of their dispersal mechanisms is to take a completely incorrect view of the situation.

In fact, it is clear, and will be made clearer in the chapter upon barriers, that in nature dispersal will be an extremely slow process. The majority of plants have no special "mechanism" for 
the purpose, and depend on a small transport due to wind or animals, often only of a few inches. Ritigala, which was probably covered with a "dry-zone" flora, but which has apparently existed in its present place since the Tertiary period, has only received 103 "wet-zone" plants in all that time, though the conditions are favourable to them, while Krakatau, with virgin soil, has received 137 in less than thirty years. All the work, whether upon dispersal or upon plant-associations, that has been quoted, goes to show the enormous influence of barriers; but as the floras of most countries, even of most islands, do not show any such influences of the barriers that cut them off, the natural inference is that in general they received the bulk of their floras when the barriers were not there.

Looking at the dispersal mechanisms in a general way, one gathers a broad impression that they are really of much less importance to plants than one has been inclined to imagine. This is confirmed by the fact that one finds many genera with little or no mechanism for dispersal just as widely spread and cosmopolitan as others with the most perfect arrangements. For example, among the former we find Callitriche, Ceratophyllum, Carex, Cocculus, Desmodium, Euphorbia, Hippuris, Juncus, Lemna, Piper, Pistia, Polygonum, Salvia, Utricularia, etc. Altogether more than half the cosmopolitan genera have no good dispersal mechanism. (Cf. Lantana and Tithonia mentioned above, p. 17.)

Of genera occurring in both Old and New Worlds, the family with most (9ז) is Gramineae, whose fruits are to some degree suited to wind dispersal, but it is followed by Leguminosae (79) which are ill-suited to rapid spread, except to some extent by currents. These families are followed by Compositae, Orehidaceae, Rosaceae, Rubiaceae, Scrophulariaceae, Liliaceae, Umbelliferae, Cyperaceae, Cruciferae, Caryophyllaceae, Ericaceae, Euphorbiaceae, Ranunculaceae, Acanthaceae, Convolvulaceae, Coniferae, Labiatae, and Malvaceae, in the order named. The general impression is not that of the predominance of plants with good dispersal mechanisms.

The first ten largest families in the world (judged by number of genera)-the Compositac, Orchidaceac, Leguminosae, Rubiaceae, Gramineae, Asclepiadaceae, Euphorbiaceae, Umbelliferac, Cruciferae, and Acanthaceae-are not remarkable for the possession of extra good methods of dispersal, excepting the first two. Yet not only have they the largest number of genera in 
the world, but they have also the largest number in most large sections of it, e.g. the Tropics, or the islands of the world, taken together. This fact goes to show that dispersal has not altogether depended upon the possession of a good "adaptation" for the purpose, and also that when one takes large numbers and long periods, it is to a marked degree mechanical. Attention was first called to this striking fact by Hooker in 1888 (56, p. Ixiv), in these words "the conditions which have resulted in Monocotyledons retaining their numerical position of 1 to 4 or thereabouts of Dicotyledons, in the globe, and in all large areas thereof, are, in the present state of science, inscrutable."

If the methods of dispersal be compared throughout a family, it will be found that they are often attached only to a genus or group of genera, and thus are probably comparatively modern. Even in Compositae, which as a whole have the same mechanism, there are a good many widely dispersed forms with no pappus. "Of the Compositae common to Lord Auckland's group, Fuegia, and Kerguelen's Land, none have any pappus at all! Of the many species with pappus, none are common to two of these islands" (55 $a$, p. xxi, note). "Plyyllanthus shows by its distribution in the Pacific that dry-fruited Euphorbiaceae are as widcly distributed and as much at home as the fleshy-fruited ones" (44, p. 325). And ef. 7, p. 573.

\section{Summary}

It being generally agreed that plants dispersed over large areas began upon smaller, a study of the methods of dispersal must form an introduction to that of distribution in general, and a number of cases of such investigation, from the flora found in the pollard-willow trees near Cambridge to the new flora of the island of Krakatau, are given. The general results that seem to come out of all such work are (1) that barriers to spreading produce very important results; (2) that most individual plants travel (to anything more than the very smallest distance) by aid of the "regular" mechanisms for dispersal by wind, water, or animals (or vegetative reproduction); but (3) that a great many species are sometimes, even if very rarely, carried by various "irregular" methods-mud on birds' feet, hurricanes, floating logs, etc.; (4) that the distance covered is usually very small; but (5) that dealing with large numbers and long periods, the general result tends to be much the same in all cases under somewhat similar conditions. On the other hand, the fixity of 
the vegetative covering of any given area shows that the possession of a good dispersal meehanism is only rarely of much value. A general comparison of the flora of the world shows that more than half of the most cosmopolitan genera have little or no mechanism for dispersal, nor is such well marked, on the whole, in the largest and most widely distributed families. It also goes to show that in most eases where there are now wide separations by seas, etc., the floras are too large to have been able to arrive across such formidable barriers. 


\section{CHAPTER III}

\section{THE INTRODUC'TION AND SPREAD OF FOREIGN SPECIES}

$\mathrm{O}_{\mathrm{NE}}$ of the most commonly misunderstood or misinterpreted phenomena in connection with the distribution of plants is that exhibited by many species that have been introduced, whether intentionally or not, into countries to which they were not really native. Often they have spread rapidly, and are now among the most common plants. The easual traveller in Ceylon, for example, will notice everywhere by the roadside the sensitive plant (Mimosa), the Mexican sunflower (Tithonia), Lantana, Mikania. various Cassias, guavas, Turnera, Vinca rosea, etc., not one of which is really native. Higher in the hills he will see abundance of elover, dandelion, gorse, shepherd's purse, spurrey, ete., also introduced in recent times.

When Europeans first settled in tropieal and other countries to which they were newcomers, the places in which they located themselves were not determined by mere chance, but were places to and from which transport was most easily and cheaply obtainable $(114$, p. 36). They had not come to these countries for the benefit of the inhabitants, but to begin trade with Europe in those products that they only could supply. Accordingly the white men settled at the mouths of the great rivers like the Ganges, Yang-tze-kiang, Amazon, de la Plata, ete., where ports existed or could be easily made, and goods could be easily brought down from inland. Even more frequently they settled upon the islands, beginning with the smaller oncs. Here there was less risk of invasion by the natives in great force, and transport from the interior was usually easy, by reason of the comparatively small size of the country, though of course rivermouths were utilised, for purposes of port accommodation, and of transport from the interior, whenever possible.

In these places introduced plants were soon found spreading about, especially when the country, prior to occupation-as was very often the case, especially on the islands-was in its natural state of forest. No notice was taken of this spread until the rise of the theory of Natural Selection, when it was found that these introductions apparently gave good cridence in its support. This 
evidence was accepted without being always subjected to proper sifting, and it was for a long time believed that these introductions spread with this rapidity and success because they came from large continental areas (chiefly Europe and tropical America) where they had, so to speak, become highly efficient and "up-to-date" by competing in the struggle for existence amongst a large crowd of other species, and were in consequence exterminating the native productions because these had not had such advantages. In a comparatively short time the fact that introductions also occurred on continental areas was almost lost sight of, and the argument was applied almost entirely to islands. Darwin, for example, states $(23$, p. 340) that "in many islands the native productions are nearly equalled, or even outnumbered, by those which have become naturalised; and this is the first stage towards their extinction." Wallace (111, p. 527) makes very similar statements.

Now the fact of rapid spread in many cases is undeniable, and also that it has been largely, if not mainly, recorded from islands. But no proper analysis of the evidence has been made. One soon finds that introductions are just as common on continental areas, especially where these (as was nearly always the case upon islands) were untouched forest at the time of settlement. Thus 141 species have been recorded as spontaneous in the Transvaal, 368 in South Australia, 364 in Victoria; 800 introductions, of which 107 have become naturalised, occur near Montpellier, and 348 in the Tweed valley $(14,11,35,107,143)$. One also finds that the cases of rapid spread without alteration of the conditions are very few indeed; in most cases man has removed the forest, made great clearances, introduced grazing animals, or in other ways completely altered the circumstances, thus enabling those introductions to survive and prosper which were suited to the new conditions. And one further finds that when introductions have spread, it has been just as much, if at all, at the expense of species in the native flora that are of wide distribution as of species of the most strictly local kind. The great bulk of cases of spread of introductions are due, not to the fact of their having come from Europe or America, but to the fact of their suiting the new conditions created by clearance of the forest, or cultivation of the ground, to which there were few or no native species suitable, and to the fact that man has thus broken up the old associations of plants that covered the ground, and made it possible for new plants easily to gain a foothold. In Ceylon, for 
example, which has been much quoted in this connection, all but 11 of the 387 naturalised species (115) are either weeds about houses, due to cultivation, or wecds of open ground, which was all but unknown in the old days of forest. Seven of these 11 are only a clump or two of planted trees, and there are really only two cases of natural or nearly natural spread, and then only to a distance of a few hundred yards, downstream, in a very steep valley.

The only instances of rapid spread in Ceylon, on land already occupied by a growth of plants suited to the conditions, have been in the case of a few such weeds as Tithonia and Mikania, which have spread rapidly over the open ground already occupied by weeds previously introduced. One is inclined to think that this is due to the fact that such areas have not as yet elaborated the best plant societics suited to their conditions, and that room is still left for newcomers. On the other hand, there is no evidence for rapid spread in forest, where the adjustment of species to environment has probably been carried to great lengths.

In a few cases, new species have spread rapidly over ground already occupied by herbaceous plants, like Elodea in the waters of western Europe, or Spartina in the low coast lands on the south of England. Here, again, one may suppose that there has still been room for newcomers, especially in the case of the Spartina, which is largely found on land that was submerged not so very long ago.

The enormous majority of cases of rapid spread of introduced weeds are due to cutting of forest, or other serious alterations of conditions; in North America and Argentina often to cultivation of the soil (even if only once), leaving conditions different from what they were. In St Helena, which has been much used as an argument for natural selection, man introduced goats, which are most destructive to regetation, with the result that there is left only a flora practically "goat-proof." Even the largest trees are not safe, for the goats may destroy the smaller trees, and expose them to the action of the sun and wind. [Cf. also the effects of the cxclusion of rabbits from a heath (36, $191 \%$, p. 1).]

Cockayne has devoted much attention to New Zealand, an island in which over 550 introduetions have become more or less naturalised, and which has often been quoted as evidence for the great supcriority of introductions from the crowded flora 
of Europe. In actual fact, however, man, by felling the forest, introducing cattle, and in other ways, has completely altered the local conditions. Cockayne states $(\mathbf{1 9}$, p. 32) that introductions only give the characteristic stamp to the vegetation "where draining, cultivation, constant burning of forest, scrub, and tussock, and the grazing of a multitude of domestic animals have made absolutely new edaphic conditions, which approximate to those of Europe." And farther on in the same paper he says, "the indigenous vegetation is still virgin, and the introduced plants altogether absent, where grazing animals have no access, and where fires have never been."

Bolle regards the Canarian endemic flora as "everlasting" and "indestructible," and writing of the same flora Christ views the local conditions as all in favour of the native plants and against
intruders.

There are very few cases of rapid spread of introductions that cannot be accounted for by changed conditions, and in many of these it is probable, as in the cases of Elodea or Eichhornia (water-hyacinth) in the water, or cacti or Cynara (cardoon) on the land, that they have proved suitable to joining a plant society which as yet was incomplete (open) and allowed room for newcomers. The few cases remaining, that are quite incapable of explanation as yet, are so very limited in number that to base any argument upon them would be in a very high degree dangerous.

The spread of introductions is often so rapid and striking that one is tempted to lay too much stress upon it, and to think that the original rate of spread of most species was something of the same kind. But there is no evidence to support this view, and the natural rate of spread is often so slow that one may even think that nothing is happening at all, and that a species has reached its limit of distribution, whereas if things could be left quite untouched for several centuries, one might find an appreciable change at the end of that time.

\section{Summary}

An endeavour is made to show that in the great majority of cases the rapid spread of plants introduced into new countries is due to the changes of conditions that have been made by man, and not to the fact that these plants have usually come from more complex and "efficient" floras. Introductions are just as common upon continental areas as upon islands (to 
which they are sometimes supposed to be largely confined); and their spread is practically always due to some change of conditions that has to a greater or less extent interfered with the success of, or has even destroyed, the society of plants formerly growing upon the ground which they now occupy. 


\section{CHAP'TER IV}

\section{ACCLIMATISATION}

Acclimatisation may be deseribed as the accustoming of plants to new conditions and climates till they are not only capable of growing there, but also of reproducing themselves freely. Thus, though the cherry and apple will grow readily enough in the hills of Ceylon, they are not really acclimatised, for they do not produce fertile seed, and if left to themselves would inevitably die out. Lantana, on the other hand, is completely acelimatised, and seeds freely.

As practised by man, acclimatisation is chiefly modern, but in nature it has been going on for ages. Hers is much more gradual, but there is no nursing of a delicate plant till it can survive and reproduce; if in any way unsuitable to the altered conditions, it will die out. Man used to try to make enormous changes, as from Europe to the Tropies, but has slowly learnt that this is usually impracticable, and has even begun gradual acclimatisation, as for example in the way in which he has treated Liberian coffee in Java, taking the seed of successive generations a few score yards higher up each time, till he has persuaded the tree to do well at a much higher elevation than that to which it is naturally suited.

In the Ceylon Botanic Gardens we were very anxious to acclimatise the bcautiful Cyperus Papyrus; so long as we tried seed from Europe we failcd, but seed from Saharanpur in India succeeded at once. Sometimes the difficulty is with change of climate in regard to periodicity, as when one tries to acclimatise plants of the southern hemispherc in Europe. Sometimes the plant requires a mycorhiza (or fungus in association with the roots) for its successful growth, and it may not be possible to persuade this to grow, as with heather in Ceylon, which has never succeeded there. But it would lead too far to discuss all the many and complex phenoncmu of acelimulisation ns proetised by man, and we must return to that carried on by nature, which almost never attempts to make great changes at once, except when, for example, the Gulf Stream carries to Europe seeds which refuse to grow there cxcept in hothouses.

As a rule, nature's acclimatisation is simply to the slightly 
different conditions that may be experienced in a transit of a few score of yards or less, but small journeys like this, added up over many ccnturies, ultimately result in enormous differences of conditions, as when one finds Hydrocotyle asiatica growing in the low country of Ceylon, with a steady mean temperature of $80^{\circ}$, and in Stewart Island, New Zealand, with winter snow and frost.

Acclimatisation may also take place in nature without the plant changing its position, by the secular changes of climate which are usually going on. New Zealand had probably at one time a more or less tropical climate, and now has a temperate one, yet the tropical species are still to be found there, and quite probably may have originally arrived when the climate was warmer, and then become gradually acclimatised, themselves and their descendants, to climates steadily becoming colder. The rise of a mountain chain may gradually acclimatise plants to a colder climate, by carrying them upwards.

This gradual aeclimatisation that is carried on by nature has often been so successful, as illustrated by Hydrocotyle asiatica above, and by scores of other "tropical" species which are found far south in cold but still damp climates (to the northwards the change to dry is more sudden) that it makes it very difficult to say when a species has really reached its elimatic limit, beyond which no amount of acelimatisation would be of any use. People are apt to say that laboratory experiments show that such or such a temperature is the lowest that a plant will stand, forgetting nature's very gradual acclimatisation. Hydrocotyle from Stewart Island would almost certainly give reactions in the laboratory different from those of the same plant from the plains of Ceylon.

It is possible, again, that in nature's acclimatisation by gradual change of climate, plants may become slower in the performance of their functions, or in growth, so that the generations may be farther apart.

Yet another factor that has probably an important influence is the increasing number of speeies upon any given piece of country. As the species increase in number, they probably begin to form more or less complete or "closed" associations of plants, into which intrusion of a newcomer becomes increasingly difficult, so that probably both rate of travel and acclimatisation are rendered slower and more troublesome. 


\section{Summary}

Acclimatisation in the hands of man, who is impatient of results, has been largely a matter of trial and error, with numerous failures, but there is reason to suppose that this is not so much the case in the hands of nature, working as she does over vast periods of time, with very small steps. Species have thus been acclimatised to conditions wonderfully different from those in which they began. 


\section{CHAPTER V}

\section{CAUSES WHICH FAYOUR OR HINDER THE DISPERSAL OF SPECIES}

$\mathrm{I}_{\mathrm{T}}$ being generally eonsidered that a speeies eommences upon a eomparatively small area (or areas), it is elear that it has to do much travelling to eover the large territory whieh is now oecupied by so many forms. In general it will be dispersed by aid of one of the methods already described, whether regular or not, and will be aided, or far more often hindered, in its journeyings by various faetors whieh we have now to eonsider.

Whatever one's views may be as to the effieaey of transport to a distance, it is unquestionable that as a rule new plants of a given speeies grow up fairly near to pre-existing specimens of the same kind. For one thing, though it is often overlooked, it is mueh more difficult for a plant carried to a distanee to establish itself, under the different conditions of climate, soil, and especially of plant societies, ete., that it will then meet with, than if it were simply transported a few yards, just as it would be more diffieult for an emigrant from England to establish himself in a forcign country, rather than in a colony or the United States.

If near to a solitary tree of a given kind there exist, at distanees of ten, a hundred, and a thousand yards, spaces where its seeds if sown would stand a reasonable ehance of growing and flourishing, then it is clear that to put a seed on every square yard ${ }^{1}$ up to a distance of ten (supposing the impossible case of uniform distribution), the tree would have to disperse 314 seeds; up to 100 yards 31,400 ; and up to 1000 yards it would need no less than $3,140,000$ seeds, a number probably far beyond the capacity of most trees. In aetual faet, the seeds are notoriously carried in such vastly greater numbers to the smaller distances, that this figure would probably have to be multiplied by 100 , or even 1000 or more, to allow of the plant placing a seed on every square yard up to a radius of 1000 yards. But even this is not enough, for a seed plaeed in one part of a square yard, while the suitable spot for its growth is in another, will have no better ehanee of suceess than if a dozen yards away.

1 Area of cirele $=\pi r^{2}$, e.g. $3.14 \times 10 \times 10$. 
One must again multiply by say 150, to allow a seed for every three inches square, or probably by even more than this. Unless, therefore, a seed just happens to fall on the exact spot where it can grow, the chance that the plant, will ever travel more than a few yards from its parent is but a small one ${ }^{\mathrm{I}}$; and the majority of plants cannot in any case travel more than a few yards, except by irregular aid, for want of a suitable mechanism.

of course, in cases where a wall of uniform vegetation, like the edge of a pine forest, is advancing, the number of seed required per tree to reach to a considerable distance will be much reduced, or even where the plant, as is more often the case, is thinly scattered along a given front, but in any case, to reach a favourable spot at some distance away, a vast number of seed will be required. In the temperate zone, where secd may survive for a long time, the chance of such suceess is greater, but in the tropies, where they rarely remain viable for long, is but slight. Not only so, but the vegetation of the wetter tropics is usually forest, and so thick that a sced dropped near the top of the tree canopy will be unlikely to reach the soil if not very heavy, unless by mere chance.

There is not the least need, when one has regard to the vast periods of time that are available for the purpose, for rapid dispersal. Few people, perhaps, have fully grasped the fact that while some species occupy very large areas, the bulk of them do not, and the acerage area is but comparatively small. Upon 50 million square miles of land there are about 160,000 species of flowering plants, so that if each occupied its own area, and alone, the average would be about 300 square miles. But in fact, at a rough and fairly liberal estimate, there are say 30004000 in any given country, which would make the average about a million square miles, probably an overestimate. But taking it at a million for convenience, this area could be covered in a million years (a mere detail in geological time) by an annual plant which merely moved forward a yard a year, and which started on an open plain of the necessary size, with a uniform climate.

While the radius of the area occupicd increased 1, 2, 3, 4, 5, etc., the area $\left(\pi r^{2}\right)$ would incrcase $3,12,2 \pi, 48,75,108$, the differences being $9,15,21,27,33$, or an annual increase of 6 .

1 The rapid spread of weeds does not affect this argument, for they are spreading upon cultivated ground, and owe their rapid dispersal to changed or unnatural conditions, as do the introductions considered in Chapter $\mathrm{u}$.

w. A. 
The area would thus grow with increasing speed ${ }^{1}$, and though for a long time it would be very small, at the end of a million years the radius would be 1 million yards, or roughly 600 miles (London to the Shetlands, Dresden, and the Pyrenees), and the area over a million square miles.

Thus, in a period of time which is almost insignificant from a geological point of view, a species without competition or interference might cover an area which is probably larger than the average area of a species to-day. At the same rate of travel, in 12 million years it would cover an area of 50 million square miles, equal to the whole available land-surface of the globe, and in 24 million years might cover the entire surface of the earth, supposed land with uniform conditions. All these periods are probably small compared even to the Tertiary period of the earth's history, for Lord Rayleigh has estimated the time since the Eocene alone at 30 millions.

These figures are of course the merest rough approximations, and are given simply to show how little actual forward movement is required to do, in a comparatively short space of time, what has actually been done by even the most widely distributed species. No special mechanism for dispersal would be imperative in such a case. It is clearly obvious that in nature what actually happens must be delay of spread rather than acecleration.

Another important point that one must not allow to be forgotten, and which may perhaps be dealt with best in this place, is the simple arithmetical ratio in which an early species will gain upon one that appears at a later period, both in the area occupied, and in the ehanee of giving rise to new species. Let us suppose that both of these are purely mechanical proeesses, and that the species spread uniformly in every direction, as before, without let or hindrance. Then if two species $A$ and $B$ start at different periods, spreading at the same rate, $B$ will never catch up to $A$, but will always fall behind. The areas occupied will be (cf. above):

\begin{tabular}{rrrrrrrrr}
$A$ & 3 & 12 & 27 & 48 & 75 & 108 & 147 & 192 \\
$B$ & - & - & - & 3 & 12 & 27 & 48 & 75 \\
\hline Difference $\ldots$ & 45 & 63 & 81 & 99 & 117
\end{tabular}

1 The dispersal would of eourse tend to become less and less dense, but as for Age and Area purposes area is estimated by drawing a circle round the outermost localities, this matters little. 


\section{cH. v] HINDER THE DISPERSAL OF SPECIES}

The differences in area occupied will continually increase (by 18 every time) though in radius of area $B$ will always be only 3 behind $A$. And in the same way, if each give rise to new species in proportion to the area occupied (i.e. number of individuals), $A$ will continually gain upon $B$. In actual practice, of course, the result will not be so mechanical, but on the average the earlier formed species will gain upon the later, both in area and in number of progeny of new species, unless the later formed ones are superior to the parents. This gain is incidentally shown to be the case by looking over the geological record. The genera that are found in the earljest horizons are in general large genera of the present day. Twenty of them from one horizon, though one or two are now extinct, include over 2000 species now living, so that their average size is at present over eight times the average of twelve species per genus.

It is clear that in nature the usual case will be transport to a small distance only. But when this has been accomplished, the seed has still to become a plant capable of reproducing itself, and to do this it has to overcome many difficulties, the chicf perhaps being the fact that, as a rule, the ground is already all but completely occupied by plants more or less fully grown, so that even a vacant space left by the death of one of them will be full of roots, and overshadowed by the neighbouring plants. Not only so, but the plants that grow upon any given piece of ground in its natural state generally form what is called an association or society, into which a stranger, i.e. a plant of a species not usually occurring in that association, will find entry very difficult. We shall return to this subject below.

When a species is just commencing its life as such, and consists possibly of a very few individuals, there is no doubt that its chance of spreading, by seizing upon spots more or less vacant, will be much less than when it becomes more common, as indicated by the very few plants that make up many endemic species (below, p. 55). A species, unless it start upon an unoccupied piece of ground, will probably take a very long time to spread from the condition of half-a-dozen plants on a few square yards to reasonable frequency on a squnre mile. Once established with commonness more or less equal to that of its neighbours, it will probably spread with a rapidity much the same as that of other species of the same genus living in the same country and in the same type of vegetation, inasmuch as all will probably have much the same type of mechanism for 
dispersal, and will react to their surroundings in much the same way. But as yet we have no means of comparing the rate of spread of species that are separated in systematic relationship, and which may differ in many ways. Some may have powderlike seed, easily carried by wind, others fleshy fruits dispersed by birds; some may be herbs, with a generation every year or two, and a corresponding chance of frequent dispersal, others may be trees with as much as twenty to thirty years between generations; and so on.

If the dispersal of plants depended simply upon their "mechanism" to that end, it is evident that (working with groups of species, and long periods) it would be almost a purely mechanical process, the area occupied enlarging steadily with the increasing age of the species; and of conrse each species would probably progress at a different rate, those with good mechanisms, or in good environment, or flowering while still young, travelling more rapidly. After a certain period of time the areas occupied by a set of different plants, say a Dipterocarp tree (p. 19), a Leguminous tree, a Cruciferous herb, and a Composite herb, all starting simultaneously on area represented by 1 , might at a guess be, say, 2, 5, 10, and 100. But in actual life many other causes come in to facilitate or delay the spread of species, and it seems probable that delay, rather than acceleration, is the usual result. This is chiefly the case, for instance, with the actual physical features of the world, which we shall consider first.

Open seas, for example, and even comparatively narrow arms of the sea, like the English Channel, may offer practically insuperable barriers to migration, only to be occasionally passed by a few species, unless with the assistance of man. An important point to remember is that such seas, or arms of the sea, may be comparatively recent, or of very ancient standing in geological history, so that their total effect upon distribution may be relatively small, or of very great importance indeed. Once formed, however shallow or deep, a sea will offer much the same obstacle, and the degree to which it obstructs passage of species will to some extent depend upon the direction of any currents that may traverse it. Further, even when it has become wide enongh, in the process of formation; to stop some species completely, others, by virtue of good dispersal mechanisms, may be able to cross.

Mountains, again, are of great importance. Considered merely 


\section{cH. v] HINDER THE DISPERSAL OF SPECIES}

as elevations of the ground, they would probably make comparatively little difference to the existence or to the migrations of plants, unless very high or very steep, but their presence usually involves change of climate from one side to the other, and from bottom to top, so that they may produce great effects upon the composition of the vegetation, whether as seen in simply ascending them, or in crossing to the other side. The climate usually becomes cooler and damper in ascending, until the cloud belt is passed at high elevations; and if the range be transverse to a damp air-current, as so often happens owing to the fact that ranges are frequently parallel to the sea, much rain will be precipitated on the nearer side, and the farther side will have a much drier climate. This effect can be well seen in the mountains of Scandinavia, of Portugal, of New Zealand, in the Western Ghats of India, the northern Rocky Mountains, the Cascades, etc. If the change is very great, the flora may be almost totally different on the two sides of a range.

Mountains may also serve as agencies facilitating migration of species, inasmuch as they may enable the passage into or through a country, otherwise unsuitable in whole or in part, of the plants of cooler or moister climates, or of herbs of open ground. They are also favourable to rapid migration because the frequently occurring landslips may open appreciable areas of new soil not covered by vegetation, upon which plants may at once take hold, without having to wait to secure a spot temporarily free, or struggling to effect an entrance into a closed association of plants. Such plants will probably be mostly herbs or small shrubs, inasmuch as landslips will be more common at the higher elevations, which are above the tree line in many cases. Owing to the fact that changes of climate have often taken place in a north and south direction, mountain chains rumning east and west have been of especial importance.

As a general rule, a river hardly seems to be of sufficient width to offer a very formidable obstacle to migration, though it will doubtless delay it considerably. The only river that really seems large enough to be, possibly, an actual boundary to migration in some cases is the Amazon in the lnwer half of its course, from Manáos, where it is joined by the Rio Negro, to the sea, and where it may be several miles wide. Owing to the density and enormous size of the forests, however, we do not yet know enough of the local distribution of the plants of that region to be able to say whether or not any species really mect 
the river with a long frontage to it, and are not found at all on the other side.

Soil may be considered as a geographical factor in migration, inasmuch as it depends upon the geology of the country, or may be considered under the next heading, of ecological factors. Nothing has been a subject of greater controversy than the effects of its composition upon the vegetation which it carries. There is no doubt that one may observe quite different floras upon, say, a chalk soil and a siliceous soil in England, and quite another again upon a soil impregnated with salt. Exactly to determine, however, what part of this effect is due to the chemical composition of the soil, and what part to its physical constitution, is a very difficult problem. My own experience with tropical agriculture, extending over nearly twenty years, inclines me to lay more stress upon the physical constitution, for crops will succeed almost equally well upon soils of very different chemical composition, if only they be, for example, of such physical consistency as to retain water well. Chalk soils in the natural condition are dry, and little retentive of water, sandy soils even more so, while clays may retain water very well indeed.

It is comparatively rare for any plant to be confined in its growth to one kind of soil only. Festuca ovina is so abundant and successful upon the chalk downs that one is tempted to think it a chalk plant till one finds it almost as common upon a bilberry moor in Derbyshire, or a grass moor in Scotland, with peaty soil. Both chalk and peat demand in the plants that grow upon them some eapacity of resistance to insulficieney of water, and it may be the physical rather than the chemical constitution that matters most.

There is no doubt that if in the same climatic and other general conditions there exist two belts of different soils, these will be covered with floras that will be differently constituted in detail, but it is comparatively rarely that a species will not occur on both, though it may be common on the one and very rare on the other. The only chemical constituents present in the soil that really seem to have a determining effect in allowing some species and excluding others are calcium carbonate (chalk or limestone) and sodium chloride (salt). A good case is mentioned by Drude (33) of a line of chalk-loving shrubs found running through a forest on siliceous soil in France; on investigation it was found that they occupied the track of an old Roman road, for which chalk had been used. 
As a general rule, a change of soil does not cover a breadth of country sufficiently wide to form an absolute barrier to the passage of some species, or a special assistance to that of others. If it is broad one way, it may be narrow in the direction perpendicular to that. There can be no doubt, however, and this is all that matters to our present discussion, that it may readily hinder or delay the passage of some species, and assist that of others; and that it may distort as well as delay some species in their distribution, by compelling them to go round.

We come now to those hindrances interposed by change of conditions (to which plants react in different manners) either from one place to another, or from one time to another, which in a general way may be classed as ecological. The change may be very sudden, as from forest to dry grassland (seen very strikingly at the edge of the patanas of Ceylon; cf. 81), or from a wet to a dry climate, as on the two sides of many mountain chains; and in this case one comparatively seldom finds the same individual species growing on both sides of the barrier thus formed. But if the change be more gradual, as from warm to cold in ascending a mountain, one often finds this to occur. To what extent the barrier is effective, therefore, will depend largely upon its sharpness of definition, as well as its width and depth, and upon whether a geuus on reaching it is able to form new species capable of living upon the other side. This is a phenomenon which is very often seen, and it is in fact by no means certain that an ccological barrier will interrupt completely the progress of a genus, though it may stop a species. When a genus is found confined to wet or dry, high or low, it is most probably, as we shall sce, because it is still comparatively young in that country, and has not yet had time to spread widely; quite possibly it has not yet even reached the actual boundary. Widely distributed genera, if they have many species in the country, more usually have species on both sides of the boundary. In the first hundred genera of the Ceylon flora, for example, the genera which have species in both wet and dry zones (which have a very different climate, cf. p. 14) are 32 with 141 species, or an average of $4 \cdot 4$ per genus, while those confined to one zone are 68 with 135 species, or an average of 2 only. [The average for the whole flora is $2 \cdot 7$.] Of genera in the entire flora that have over 10 species, seven only, with 21 , $20,13,12,12,12$, and 11 (average 14), are confined to one zone; eight, the largest with 27 species, have one or more species 
oecurring in both zones (average 16), and 21 genera with 484 speeies (largest $43,42,40,38$, average 23 ) have separate species in each zone.

There are many ecologieal changes whieh may be summed up as climatic, and which, if they occur over a suffieient depth and width of country, may offer very formidable checks or barriers to dispersal. Such, for instance, are change of rainfall, of distribution of rainfall, of temperature, of dampness of air, of light, of wind, etc. The combined effeets of these form what may be termed the climate of a place. In the existing conditions of the world the elimate is determined in broad outline chiefly by latitude, position with regard to the sea, to prevailing winds, and to mountain ehains which are at no very great distanee. The lower the latitude, the warmer the climate; the nearer the sea, and the more wind blows from it, the damper; the nearer the lee side of a range erossing the prevailing wind, the drier.

Further, during at any rate the later periods of the world's history, great ranges of mountains have sprung up in different directions, especially from east to west in the Old World, from north to south in the New. These ranges are so lofty that apart from the changes of climate due to them, they have acted as very formidable barriers. And when to this is added the enormous difference of climate on the two sides, it is clear that they must have completely altered the distribution of speeies, and in general rendered it more diffienlt for the greater number, though on the other hand, species, chichly herbaceous, which ean live at high levels in the mountains, have been enabled to travel through and into regions otherwise impassable (cf. p. 37). It is in this way, probably, that many herbaceous and shrubby types of regetation, including such genera as Caltha, Ligusticum, and Veronica, characteristic of the north temperate regions, but now also found in New Zealand, South America, etc., have been enabled to reach those countries; and that the eomparatively young Compositae have spread so widely over the world.

The effeets of the mountain ranges on the two chief continents may be seen by comparing the climates of North Ameriea and of Europe, both in the zone of prevailing westerly winds from the ocean. The west coast of the former is very wet, in latitudes equal to those of northern Europe, and was originally eovered with forest; but as one comes to the east of the Caseades and Rocky Mountains, which lie across the path of the westerly winds, one reaches the land of prairie, whieh is especially dry 


\section{cH. v] HINDER THE DISPERSAL OF SPECIES}

in the near neighbourhood of the mountains. In north-central Europe, on the other hand, the climate slowly becomes drier with fair regularity in passing from England to the Urals, and then becomes suddenly much drier. In the Scandinavian peninsula, the mountains lie more across the wind, and Sweden is much drier than Norway.

Farther south, there is a great belt of more or less dry and desert country, almost round the world in the northern, much less marked in the same latitudes of the southern, hemisphere, and between these two drier regions, which oppose all but impassable barriers, lies the wet zone of the equatorial tropics, where the climate is usually damp, and often very rainy through a great part of the year, though there are alternations of dricr and wetter periods.

If a country be flat, or nearly so, as, for instance, North Europe from England to the Urals, the rainfall gradually falls off as one goes inland from the sea, but only in averages over a number of years. If, for example, at a series of stations, working inland from the sea, the rainfall average $50,45,40,35$ inches, it is quite possible, if not even probable, that in some years the fall at the station farthest inland may be 50 , or in others that the fall at the station nearest the sea may be only 35. Unless, therefore, plants are suited to a great range in the amount of rainfall, they cannot hope to succeed in most stations, and it also becomes doubtful when and where the rainfall reaehes an absolute maximum or minimum which causes it to be an ecological barricr. It is also highly unlikely that this point will be the same for any two species. That there is such a barrier secms not improbable when we consider the difference in flora between the steppes of Russia and the British Islands, but where it exists for any single species we are unable to state.

If, however, as very often happens, a mountain chain stand athwart the prevailing or most frequent winds, there may be a sudden change in the rainfall. The damp air from the sea, striking the mountains, is forced upwards and cooled, parting with much of its moisture; then as it descends upon the other side, it becomes warmed, and thereby much drier. In Ceylon, for cxample, the south-west monsoon blows for about six months over a vast expanse of ocean, and reaches the island a saturated wind. Meeting the mountains, it deposits an cnormous rainfall (over 100 inches at the foot of Adam's Pcak), and upon the eastern side (they reach 8000 feet) becomes a dry scorching wind, deposit- 
ing less than 10 inches of rain at Batticaloa on the east coast. The change at the summit-level is so sudden that one may sometimes find a wet climate at one end, and a dry and sunny one at the other end, of the short summit tumnel on the railway. The position is largely reversed during the other monsoon, so that very many species can grow on both sides, though usually with different periodicity, Para rubber, for example, ripening its seeds on one side of the mountains in February, on the other in August.

In South India the chain of the Western Ghats causes a heavy fall of rain in the south-west monsoon on the western side, while the north-east monsoon is comparatively dry, so that there is a great difference in the climate of the two sides, and many species are confined to one or the other. This contrast in climate and vegetation between lee and weather'sides is also well shown in the trade belts in the tropical Pacific islands, large and small, and is very marked in the Andes, in the section from $10^{\circ}$ to $30^{\circ}$ south of the equator. The wind striking them is usually the easterly trade wind, and their western side is almost completely dry. Farther south the eastern side is comparatively dry, because of the westerly winds from the Pacific Ocean. Chains that run north and south are of greater importance in this connection than chains that run east and west, regarded simply as mountain ehains causing differences in rainfall, for the question is less complicated with change of temperature following latitude. But from the general historieal point of view of geographical distribution, the east and west ehains, by forming barriers to the plants spreading south or north with the advancing or retreating cold of a glacial period, have been, in all probability, of enormously greater importance than the chains that run north and south. An immense number of species, and even genera, have probably perished against the ehain of mountains that runs east and west with few gaps from Spain to eastern Asia.

The effect of the drier climate on one side of a chain of mountains will gencrally be to encourage a more herbaceous type of vegetation. So long as there is a reasonable amount of rainfall, not too much concentrated into one period of the year, the usual type of covering of the soil, in comtries that have not been disturbed by ice periods, or by man, is forest. But below a certain amount of rain, forest does not seem readily to survive, nor to occupy new ground, even if it survive upon ground that was 
forest in days of greater moisture. The general tendency, therefore, of the change of climate brought about by a chain of mountains transverse to the prevailing damp wind, is to encourage the growth upon the lee side of herbaceous and shrubby plants which can stand greater extremes of drought, and to make it very difficult, if not impossible, for the forest species, whether trees or undergrowth-herbs and shrubs, to travel into the drier country. A complete barrier may thus be offered to the passage of some species, while others, that would have been quite unable to pass the level forest, may be enabled to pass easily by the development of a mountain chain at a later period, like the development of the Andes in Cretaceous times.

Distribution of rainfall and moisture of the air is of eren greater importance to a plant than total rainfall. The largest rainfall in the world is at Waiáleále, in the mountains of the Hawaiian Islands; it is also well distributed throughout the year, so that the place is always wet, with no dry season at all. As the result, it has a flora of a very moisture-loving kind. Cherrapunji, in Assam, which has almost as great a rainfall, but badly distributed through the year (April 29 inches, May 50 inches, June 110 inches, July 120 inches, August 78 inches, September 57 inches, October 13 inches, and the other five months only 14 inches amongst them), does not show this, but has a vegetation which almost suggests a dry climate.

Kandy in Ceylon has a very steady mean temperature just over $75^{\circ} \mathrm{F}$., and a rainfall well distributed through the year (the twelve months have approximately $5,2,3 ; 7,6,9 ; 7,6,6 ; 11$, 10, and 9 inches, total about 82 ), and though there is a "dry" season" in February and March, the flora is distinctly forest of the ordinary rain-forest type. In the dry zone of northern and eastern Ceylon lies Anurádhapura, with a total rainfall of 55 inches, distributed mainly in the north-east monsoon from October to April $(3,1,2 ; 7,3,1 ; 1,2,3 ; 8,10,9)$. In a hot climate like Ceylon, a fall of less than 4 inches in a month is practically negligible, so that there is really a long drought from January to September, broken only by the April rains, and the flora is of the dry-forest type, with comparatively few specics in common with Kandy, only about 90 miles away. Calcutta, on the edge of the tropies, with a hot sun, and a rainfall of 66 inches, is equally a "dry" climate (rain $0 \cdot 4,1,1 \cdot 3 ; 2 \cdot 3,5 \cdot 6$, $11 \cdot 8 ; 13,13 \cdot 9,10 ; 5 \cdot 4,0 \cdot 6,0 \cdot 3)$. Going to the other and damper hemisphere, at Rio de Janeiro, also on the edge of the tropics, 
one finds a place with only 40 inches of rainfall $(5,4,5 ; 4,4,2$; $2,2,2 ; 3,4,5)$ which shows as much of the character of rainforest and a wet climate as does Kandy with 82 inches. Evidently the distribution of the rainfall, and of the humidity of the air, which largely goes with it, is of much greater importance than the actual total. Rio, with 40 inches, is better suited to plants needing a moist climate than Cherrapuńji with 470 ; its sun is not so hot as that of tropical Asia, and its season of less rainfall coincides with the weaker sun of June-September.

Change of distribution of rainfall, if at all sudden, usually coincides with the presence of a mountain chain. The presence of the mountains may alter the periodicity of the rain, as in Ceylon (above), when the only plants that can cross the boundary will be those that can alter their periodicity; or it may completely alter the rainfall, as in the case of the Andes, where the flora is very markedly different on the two sides. Gradual change, on the other hand, will usually accompany gradual change of rainfall. Change of dampness of air, again, if permanent between one place and another, will involve differences in the plants in their reactions to moisture, and some will be more droughtresistant than others.

Change of temperature is usually of a more permanent, or regularly recurring nature, especially in the tropics. At Colombo in Ceylon, for example, the maximum is usually about $88^{\circ} \mathrm{F}$., the ninimum about $75^{\circ}$. all the year round, except for a small increase from February to May. At Rio, on the edge of the tropies, there is more range, from say $98^{\circ}$ absolute maximum in summer to $52^{\circ}$ absolute minimum in winter, and at Nuwara Eliva (elevation 6000 feet) in Ceylon the absolute maxima and minima are about $81^{\circ}$ and $28^{\circ}$, with much greater daily ranges in dry than in wet weather. The farther one goes from the equator, or the higher in the mountains, the greater the rangc on the whole, whether annual or diurnal, and the range is also greater the farther one goes inland from the sea. The extreme variation of all is reached by going both north and inland, to the centre of northern Siberia, where it may touch $80^{\circ}$ in summer, and $-60^{\circ}$ in winter.

Morc rapid change of temperature is experienced in ascending a mountain, the mean falling abont $3-4^{\circ} \mathrm{F}$. for cvery 1000 feet of ascent. Correlated with this is the rapid change of the composition of the flora, as compared with the change experienced in going north or south at the same level and under the same 
conditions. The plants in the mountain garden in Ceylon are very different from those in the gardens in the "low" country, not from any special wish to keep the collections distinct, but from the great permanent difference of $20^{\circ}(\mathrm{F}$.) in the mean temperature, though the highest and lowest of both stations may easily be reached in the same day at the same place in Europe or North America.

Every function in every plant has a temperature (the minimum) below which it will not go on, a temperature (optimum) at which it will best go on, and a third (maximum) above which it ceases. As these differ for every species, one kind of climate will suit one, and not another, though there is no doubt that species may become acclimatised (cf. Chapter Iv). If the extremes of temperature come at a season when the functions concerned are not being performed, they may be easily withstood, as for instance the great cold of winter in North Siberia, which does not kill the conifers there. Extreme cold, when unseasonable, does at times kill out species, but the loss is usually recoverable, especially as it is only necessary for the plant to regain a foothold in societies of plants of which it has already been a member.

Light, again, changes too gradually from place to place for it to be supposed that it has any appreciable effect in opposing a barrier to any species. Species from one part of the equatorial tropics do just as well in another part with much less intense light, or vice versa. It is in general only in descending into deep water that there is any great change in light over a large area, and even there some plants are found below the limits of darkness.

Wind is chiefly of importance in an indirect manner, according to whether it is wet or dry, and according to its direction in reference to that of the mountains, but if very strong, it may alter or prevent the growth of some species. On the west coast of Britain one may often see trees blown into a one-sided type of growth, and a little more wind would prevent their growth altogether. A cyclone may uproot so many trees that it may render passage through a country possible for herbs which can quickly seizc upon the vacant spots before the growth of the forest once more suppresses them.

Though climatic differences are thus of such enormous importance one must be careful not to say of any species that it has certainly reached its climatic limit, when one has regard to the very slow and gradual acclimatisation that is practised by 
nature. If one carried seeds of Hydrocotyle asiatica (p. 30) from Ceylon to the south of New Zealand, and planted them there, they would probably refuse to grow, yet nature has gradually acclimatised the species to both regions. Many species range 4000-8000 feet vertically in the Himalaya; seeds from the higher levels produce plants much more at home in Europe than seeds from the lower levels, and might spread much more rapidly in cooler climates than the latter. Travel may be much slower in a vertical direction, where conditions change comparatively rapidly, than in a horizontal.

Finally, we must go on to consider what are probably the most important positive causes favouring or hindering species in their dispersal; barriers are obviously negative. These causes may also be classed in general as ecological, depending on some peculiarity inherent in the plant itself, often described as being an "adaptation" to something or other. We have already considered in Chapter II one of the most important of these - the method of dispersal of the plant-and must now go on to deal briefly with the others. In my published papers I have perhaps not allowed enough for ecological barriers, but I am not sure that they are sufficiently permanent to do more than delay spread, rarely to eompletely stop it.

Take, for example, the wide differences seen between trees, shrubs, and herbs. The flora of the wetter tropical and southern regions of the globe, and of large portions of the north, prior to the great clearances made by man in recent times, consisted mainly of trees. These had, it is true, more or less of herbaceous undergrowth, but there was comparatively little open country covered with herbs suited to a life exposing them to the sun and the wind. Even in much of Europe, Asia, and North America, that is now covered with herbaceous or shrubby vegetation, there appears to have been forest over a great part of the country during Tertiary times.

It used to be generally supposed that the Angiosperms commenced as herbs and that trees were a later development, but this view is now usually reversed, and the herbaceous form is looked upon as the younger. The change of view dates largely from a paper by Sinnott and Bailey (99) in which they marshal the evidence from palaeobotany, anatomy, phylogeny, and geographical distribution, etc., showing that it all points in the same direction, to the conclusion that herbs on the whole are the younger form of vegetation. 


\section{CH. v] HINDER THE DISPERSAL OF SPECIES}

Now this conclusion, taken just as it stands, is open to exactly the same objections to which, as we shall presently see, Age and Area is subject. One must not say that all trees are older than all herbs, or that such or such a tree is older (i.e. as a species) than such or such a herb. One must work with averages of species, and keep to the same eircle of affinity. One may with reasonable safety say that ten allied herbs, belonging say to the family Leguminosae, are on the whole probably younger (i.e. as independent species) than ten allied trees belonging to the same family, but one cannot say with any approach to certainty, if even of probability, that ten herbaceous species of Piperaceae are younger than ten woody Proteaceae.

But, in general, there is little doubt that the bulk of the chiefly herbaceous families, like Compositae or Cruciferae, has developed in comparatively recent times, while the bulk of the chiefly woody families, like Euphorbiaceae or Rubiaceae, is probably very old. It must be clearly understood, however, that this is not saying that the families Compositae and Cruciferae are younger than the Euphorbiaceae or Rubiaceae, but that the great development of the herbaceous type has probably taken place since the glacial period, the gradual desiccation of climate, and other causes, have rendered vast spaces of country, which were formerly largely covered with forest, available for the growth of herbs of open ground.

So long as a region is covered with forest, no herbaceous regetation can succed that cannot live in the shade, or (in the case of deciduous forest) vegetate before the leaves of the trees have grown so much as to make the shade too deep. There is little evidence to show that herbaceous regetation can aetually invade and replace forest without assistanee from desiccation of the climate, or from man or animals, but a good deal to show that the reverse may happen, and that forest may overwhelm and replace herbaceous vegetation.

Another point that must not be forgotten is that "trees" as a whole have not descended from a single tree ancestor. The group is extremely polyphyletic, i.e. its members havc arisen independently from many different and often unrelated ancestors. Within the same genus one often finds trees or shrubs, and herbs, e.g. in Solanum, Hypericum, Euphorbia, Senccio, Phyllanthus, Ficus, Urtica, etc. It is evident that for nature to form a tree from a herb or shrub, or vice versa, is not a specially difficult or unusual feat. 
But we must go on to consider the advantages or disadvantages in the matter of spreading about the world that arise from herbaceous or woody nature. It is clear that a herb will in general go through its generations more rapidly than a shrub, and still more quickly than a tree. A herb produeing seed in its first year may get three or more generations, and as many chances of dispersal, whilst a shrub, starting at the same time, is getting one, and may get from ten to thirty for the single opportunity offered to a tree. It is thus evident in the first place that the chance of rapid dispersal to a distance is much greater for the herb, and in the second that the chance of forming a new species, by whatever method it may be evolved, is also much greater in a given time.

It must, however, be clearly understood that dispersal is chiefly conditioned by the barriers which have already been discussed. Though the Compositae, for example, developed into a herbaceous type, and though they developed a firstrate mechanism for dispersal, they would not be so widespread and abundant to-day were it not that the north temperate regions of the world were largely cleared of forest by the ice in the glacial period, that large areas beeame more open on aceount of desiccation of climate, and that they were enabled to spread widely by the development, often in comparatively recent periods, of the great mountain ehains which form an almost eontinuous track leading over a very great proportion of the world, upon which they were able to move above the limit of the forest, and often aided by the formation of landslips (p. 3r). One can clearly see that had the world remained comparatively flat, and covered by forest, to the present time, the Compositae to-day might be little more widespread and abundant than say the Dipsacaceae.

One may thus point to the development of herbaceous habit, with the capability of living in open ground exposed to the sun, as an ecological feature which has made possible the comparatively rapid and extensive spread of certain families, the spread being accompanied by a correspondingly rapid development of new forms, whether species or genera. But that rapid and wide spread was only rendered possible by the incoming of certain physical conditions to which these plants proved suitcd. It is quite possible, if not probable, that these families, and even the herbaceous type suited to open ground, are really very ancient, but were eonfined to small localities, and never able to spread widely, till the new eonditions rendered it possible. There is 
reason to believe that given sufficient time, and no interference by man, forest would once more replace the open herbaceous vegetation of the damper parts of the globe.

Other types of habit may have entirely different effects upon spread. Water plants can obviously only spread so long and so far as there is water available (leaving out of account in this place all negative factors like barriers of temperature, etc., already considered above), parasites can only spread with their hosts, saprophytes only with the presence of the necessary products of decay in which they live, epiphytes with the presence of sufficient moisture, etc. Halophytes can spread wherever the ground is sufficiently salt, mangroves where it is muddy and covered by a quiet sea at high water. Climbers as a rule can only go where there are plants sufficiently tall upon which to climb. Xerophytes or plants of dry climates, once formed, will be able to advance into dry country until the drought becomes too great for them to survive, and so on.

So long as a plant remains of average (mesophytic) type, suited to an average damp climate and good water supply, it may have an enormous territory possible of occupation if only no barriers interfere, while a plant that becomes very specialised in these respects may be limited in its capacity for spreading to little more than the small area upon which it commenced. As Thiselton Dyer says (94, p. 311), "The Nemesis of a high degree of protected specialisation is the loss of adaptability."

General evidence seems to indicate that it is not improbable that in the Tertiary period the world as a whole was better suited to mesophytic vegetation than at present, and hence it is not unlikely that the earlier species not only gained in the mechanical way described on p. 34, but also found fewer barriers to their spread. Later formed species, on the other hand, as they could not survive if not exactly suited to the conditions in which they were evolved, would be increasingly likely to find themselves with climatic or other ecological barriers to further spread at no great distance away. A progressive specialisation of climate and other factors seems to have been going on in the world since the Tertiary period, the comparatively damp and uniform elimates of the latter being replaced by every variety from very damp to very dry. Hence the more recent species tend to become more and more specialised to match the climates. To quote Guppy, "when one finds Salsola Kali upon the Devonshire coast, upon a Chile beach, and upon the uplands 
of Tibet, one can hardly doubt that here a very ancient type of plant finds its still more ancient conditions of existence." On the other hand, many species of very local range seem to be suited to very local conditions, and more or less incapable of further spread without further modification. Some Utricularias in South Brazil, for example, are specialised to grow in Bromeliad pitchers, and can only go where those exist. Copeland (18) mentions the case of Stenochlaena areolaris, which is epiphytic on Pandanus utilissimus only, and confined therefore to places where that grows. It seems not impossible that some Mesembryanthemums in South Africa are specialised to suit the exact climate in which they grow, and are thus rigidly localised.

It is thus highly probable that at times very local species may in reality be much older than from the area occupied one would be inclined to think. This, however, does not affect the soundness of the hypothesis of Age and Area to be advanced below, but merely goes to show that ecological barriers may often be very effectual.

An ecological factor which is of the greatest importance to a commencing species is the type of vegetation into which it is born. In the natural state of the vegetation of a country, the ground in any place is covered with an assortment of plants which is found to be fairly constant in its composition so long as the general conditions are much the same. This assortment is termed a plant society or association, and upon the chalk downs, for example, or the moors of Yorkshire, one finds much the same society, made up of much the same proportions of its various nembers, in places far removed from one another. Consequently, if a new species is evolved at a given place, and cannot enter the society that exists there, it will die out again by the simple action of natural selection. The instant that it is produced, it will have to undergo a strenuous struggle for existence, but if it pass successfully through that, it may succeed, and may spread with the society which it has entered, and ultimately also enter other societies.

As the number of plants, and their variety, in any society, increases, the entrance of a newcomer probably becomes increasingly difficult. The society is said to be in progress from an "open" condition to a "closed" one. But as Clements has said, a society is never in a state of stable equilibrium, and though one may regard it as perfectly closed, it may yet be able to admit new members. The most conspicuous plant upon the 
chalk downs south of Cambridge is Festuca ovina. Suppose, however, that this plant in its dispersal had not yet reached the downs. They would, none the less, be covered by a society of plants which might be very numerous, and which we might think closed. Yet when the fescue appeared, there can be little doubt that it would soon secure a foothold.

An association of plants ultimately passes its zenith, and becomes gradually superseded by another, the process being known as succession (16). "The pine...gave place at length to the oak, and the oak...yielded in its turn to the beech, the periods when these three forest trees predominated in succession tallying pretty nearly with the ages of stone, bronze, and iron in Denmark" (68, p. 372).

The more closed an association is, probably so much the more difficult will a newcomer find it to obtain any foothold, and by so much will its dispersal be retarded. One will expect that most newcomers will find it quite impossible to gain a footing at all, but that every now and then (as in the case of Elodea, the famous "American water-weed" of the last generation, which spread so rapidly through the waters of Western Europe, though only the female plant was introduced) one will do so, and will spread, more especially to those places which the association concerned already reaches.

In many instances, of course, a plant in its travels will come across a type of regetation into which it cannot spread at all, and which may thus, if broad and wide enough, form a complete barrier. If an ordinary herb, aceustomed to a good water supply, and to life in the open sunshine, comes across a stretch of country which is cither a forest or a desert, it will be held up in this manner, and whether it can cross will depend upon its mechanism for dispersal, upon the width of the barrier, and upon other factors. Forest trees arriving at a desert will undoubtedly be stopped, but when they meet a herbaceous association, in a country where the rainfall is sufficient, will probably spread at the expense of the herbs, and cover previously open ground with trees. One may see this going on at the edge of a pine wood, or on any small clearing made by a peasant in a tropical forest. There is litlle evidence for the occurrence of the reverse process, without the aid of desiccation of the climate or something of the kind.

Changes of conditions will make great differences to the rate, or even to the possibility, of spread, often by the effects they 
produce upon the composition of the plant societies that occupy the ground. Farrow's work upon the changes in the plant societies upon Cavenham heath (36) made by the exclusion of rabbits may be quoted as an example. A new disease may arrive in a district, and a plant that was previously very common may fall an easy prey to it; the more common it is the more likely is it to suffer badly.

From a general distribution point of view, of course, geological changes, with the changes that they cause in climates, in barriers of sea or mountain, and the like, are by far the most important in this connection. They have been so fully discussed in geological books that there is no need to enlarge upon them in this place.

In this connection we must briefly mention the action of man, which in recent times has become by far the greatest help or hindrance to dispersal, though in the consideration of Age and Area we have endeavoured to deal with the vegetation as much as possible as it was before his interference. By clearing of forest, opcning of roads, making fires, cultivating the ground, introducing grazing animals, carrying seeds, voluntarily or involuntarily, about the world, and in many other ways, man has made, and is making, the most enormous differences in the vegetation of the globe, sometimes favouring the spread of a species, sometimes retarding it, sometimes destroying a species in whole or in part.

Other features, again, must be considered, which would hardly come under any of these heads, and yet which may make a great difference in the actual spreading of species. Suppose a country, comparatively empty of species, united to another by a broad belt of land, which is gradually sinking. Then the first species to arrive across it may reach almost the whole country at once, while later ones may only reach the centre, and require to take an immense period to spread about.

\section{SumMary}

As a rule, a new plant of a given species springs up not far from its parent, so that transport is at most a few yards. Even if a species only travelled a yard a year, it might in a million years (a mere detail in geological time) travel from London to the Shetlands, Dresden, and the Pyrenees, or on an open plain might cover a million square miles. The whole surface of the globe might be covered in less time than it is now supposed has 
elapsed since the Eocene period-a portion only of the time during which the flowering plants have existed. It is clear that delay, and not acceleration, of spread has been the rule.

The various barriers that species may meet with are then con sidered, first those purely physical, such as seas or mountains, then those due to change of climatic factors from place to place, which are partly physical, partly depend upon the constitution of the plant, and lastly barriers (or at times aids to dispersal) depending upon the type of vegetation into which a plant may try to intrude, such as forest or open grassland, or various associations of plants, some of which may suit it and some not. A herb, for example, may spread ten times as rapidly as a tree. The effects of specialisation in structure and function are also pointed out; the more specialised a plant becomes, the more limited its possible range.

The general impression which I have tried to convey in this and preceding chapters is, that until man began to interfere upon the large scale with cultivation, war, and clearing, the dispersal of plants from one place to another must have been a matter of the most extreme slowness. 


\section{CHAPTER VI}

\section{AGE AND AREA}

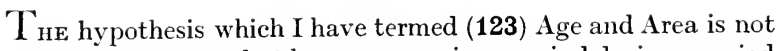
a sudden discovery, but has grown up in my mind during a period of about twenty years of work, in the study more especially of the flora of Ceylon and its neighbouring countries. It will perhaps prove of interest, therefore, to sketch this gradual development, enlarging for the purpose a short account recently published (135).

Going out to Ceylon in 1896, and remaining there till 1911, I had constant occasion to refer to the volumes of Trimen's Flora (37). There I gradually found, somewhat to my surprise, that the many species which are confined to that country (endemic to the island) were usually confined also to small areas within it. Now at that time I held the view, then very usual, that these endemics were specially adapted to the local conditions, and it seemed very remarkable that they should be so rare in those very conditions. If they were specially adapted to Ceylon, therefore, it could hardly be to the general conditions of the island (whatever those might be), but must be to strictly local conditions within its area. Now this was the explanation that was usually applied to the very numerous species that were endemic in such regions as West Australia or South Africa, and it was therefore clear that there were no differences between the endemics of an island and those of the mainland, and that any explanation that fitted the one would fit the other.

Still more remarkable, therefore, did the facts appear, when I gradually began to study in greater detail the local distribution of the cndemics, and found that they were not, as a rule, confined each to one spot or small region characterised by some special local peculiarity in conditions. Had this been the case, they might have been supposed to have been evolved to suit such spots, which in actual fact might be found without any local species upon them.

Coleus elongatus, for example, was confined to the summit of Ritigala Peak (p. 14), a minute area, and was found nowhere else in the world; but $C$. inflatus, another endemic species, was common all over the high mountain regions of the island. $C$. 
malabaricus also occurred there, but was found in the plains too, and in the mountains of South India, while $C$. barbatus, the remaining Ceylon species of this genus, covered the range of C. malabaricus, and also occurred almost throughout tropical Asia and Africa. It seemed hard to believe, when one could not see in plants like these four Colei any characters whatsoever that one could point to as advantageous or as disadvantageous, that there should exist internal characters so distinct and different as would enable $C$. barbatus to cover so enormous an area, and $C$. malabaricus a smaller but still large one, while keeping $C$. inflatus confined to the Ceylon mountains, and $C$. elongatus to a few square yards on the peak of Ritigala. No differences in efficiency of the dispersal "mechanism" could account for the differences in area covered by these allied species of the same genus.

This question of areas occupied roused my interest, and a little study soon showed that species, endemic or not, occupied every conceivable area, from a few square yards to a large part of the surface of the globe (the "area" being determined by the outlying stations, even if the plant be absent from the area, or part of the area, between them). On the older view that distribution was chiefly determined by degree of adaptation to conditions, it had come to be more or less unconsciously supposed that species were divided into a comparatively few "successful" species covering large areas, and a great number of "unsuccessful" covering small. This view proved to be a very inadequate explanation of the very striking facts of distribution that have just been outlined above. We shall return to this subject again under Endemism.

Of the 809 species of flowering plants endemic to Ceylon, less than 200 were confined to what one might, by a stretch of the imagination, regard as single spots, and about half of these occurred upon the tops of single mountains or small groups of mountains (121). On the summit of Nillowe-kánda, for example, which is a mere precipitous rock, there are found, and therc only, Acrotrema lyratum, Stemonoporus reticulatus, and Ochna rufescens; on Ritigala (p. 14) three species, on Hinidún-kanda (another somewhat isolated mountain) three, on Adam's Peak ten, one of which extends into a valley 2000 feet below; and so on. Evidently the investigation of areas occupied bid fair to furnish interesting information, and I devoted much attention to it. A careful study of the remaining three-quarters of the 
endemics showed that they were found upon areas of various sizes up to the full extent of the dry or the wet zone of Ceylon, or more rarely of both, but that the numbers grew smaller as one went up the scale toward the larger areas. Trimen in his Flora had rendered yeoman service to the student of areas, by attaching to every species a note to the effect that it was Very Common (VC), Common (C), Rather Common (RC), Rather Rare (RR), Rare (R), or Very Rare (VR). A study of the localities in which species had been found showed that as a rule, though with a good many exceptions, a VR species occurred in
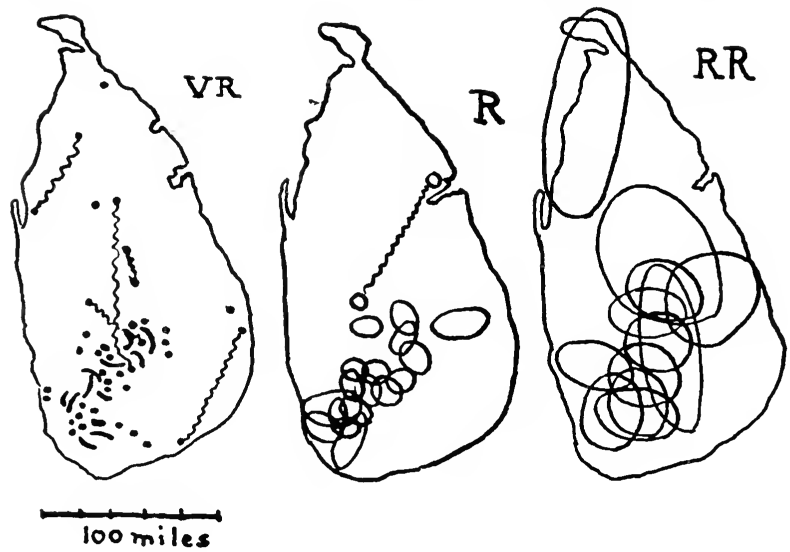

one place only, or two close together, $\mathrm{R}$ in an area about 10-30 miles across, $\mathrm{RR}$ in one $30-60$ miles across, and $\mathrm{RC}$ and $\mathrm{C}$ in areas larger yet, while $\mathrm{VC}$ referred rather to unusual commonness on areas represented by $\mathrm{C}$. .

The three diagrams here reproduced give the ranges of a number of the earlier endemic species in Trimen's Flora of Ceylon, belonging to the classes VR, R, and RR. The VR species are. it will be seen, usually well localised, though a few ( 5 in the diagram) have been recorded from two widely separated localities, joined by a wavy line. The $R$ and the RR species, however, cover arcas that overlap one another in every possible way, and look something like the rings in a shirt of chain mail. Nowhere do the areas occupied by two endemic species coincide, except 
(approximately) in the case of a few VR species, which occur together on the same mountain-top. The VR species that occur in the large forests have each their own loeation. Now a little consideration will soon show that from the point of view of evolution to suit local conditions this is a very remarkable state of affairs. It is of course obvious that if a species newly crolved upon a small area does not suit the conditions that obtain upon that area at the time in which it was evolved, it will be promptly killed out; but while this is so there is no actual need to imaginc that it was evolved specially "adapted" to those conditions.

If two species $A$ and $B$ grow in overlapping areas, both must be growing in the coincident portion; and what keeps $A$ from growing into the rest of $B$ 's territory, and $B$ into $A$ 's? It has usually been insisted that it was because $A$ was adapted to its own territory, and $B$ to its own. But when one considers that the conditions are never the same from one spot to the next, nor from one year to the next, this would mean a most wonderful adaptation if the species were not to grow into each other's territory, especially when one remembers the many more widely distributed species that occur in both. In reality the case is more complex, for there are at least a dozen overlapping at any one point, while in Ceylon the soil is essentially the same throughout the greater part of the island, the flora was practically all forest before the arrival of man, and the rainfall varies very much from year to year in quantity and distribution. It was evident that the old ideas of particular adaptation were untenable, and this riew was enormously strengthened by subsequent discovery of the way in which species were grouped in a country.

This conclusion was confirmed by later work on the Podostemaceae (124), a family of water-plants of smooth rocks in rushing tropical and subtropical mountain streams only. Here there is nothing to which the many genera and species can be adapted, for the conditions are the same for all, and could not be equalled for uniformity in a laboratory of the temperate zone. They grow only upon a smooth rigid substratum, from which they take no food; all grow in water, and have no climatic differences, no difference in circumambient medium, in light, or in any other factor. And yet there have evolved many genera and species, with very striking and bizarre differences between them. Evidently it is not necessary to have local conditions to which to be adapted in order to ensure that evolution 
shall go on. Cordyceps, with 60 species on insects, is a similar case (73).

Another popular theory about localised species like these Ceylon endemics is still strongly held, though the one just considered (local adaptation) has suffered somewhat of an eclipse with the gradual decay of the hypothesis of natural selection. Like the first, though completely at variance with it, this second explanation is also founded upon natural selection, but somewhat less obviously. It is to the effect that species on very small areas are really in process of dying out. It is evident that they eould not have arisen by aid of natural seleetion upon areas so small, and therefore they are assumed to be moribund. This hypothesis is supposed to be supported by the facts of fossil botany, which unquestionably proves that many species have cxisted in the past and no longer occur in the world to-day. There is, however, nothing to show that the two cases are parallcl, except in a few instances where there is good cvidence that the present existing species once covered a much larger area. It was simply assumed that such a species as Coleus clongatus had once occupied more ground.

Like the previous theory, however, this explanation breaks down when applied to the very striking facts of the distribution of endemics in Ceylon. How can species be dying out in a ehainmail pattern, like the $R$ and $R R$ speeies given in the diagrams above? And why were there so many more with the smallest areas (VR) than with areas not quite so small ( $R$ and $R R)$ ? Had one arrived in Ceylon just in time to see the disappearanee of a considerable flora? Was the dying-out becoming less and less, and if so, why? This graduation of the areas of endemic speeies from many small to few large was a most difficult point indeed to explain upon this supposition of dying-out, just as it had been for the theory of local adaptation.

Again, why did so many of the "very rare" endemics choose mountain-tops as a last resort? There were many widely distributed species, with very restricted areas in Ceylon, but these did not choose such places, and why did they not? The "dyingout" explanation supposes endemics to have aseended mountains as the last refuge from the invading flora of the plains, but in such a small and uniform country as the wet zone of Ceylon it is hardly possible to suppose that there was, for example, a separate Eugenia at crery few miles; whilst some of the mountains with endemic Eugenias did not even rise directly from the 
plains, but from a high plateau. And why did the endemics climb right to the summits of the hills? One would have expected to find them at varying heights, pursued, so to speak, by the widely distributed species before whose onslaught they were dying-out, instead of finding, as is not infrequently the case, a great gap in elevation between the two. It suggests an unnecessary degree of alarm about the coming competition, and further suggests that they are not so incapable of adaptation to new conditions of life that they need fear it. If they can undergo the great adaptive changes necessary to reach a summit of 5000 feet or more, they must have a very fair capacity for modification, and should be able to hold their own against the intruders. Queries like these might be put by the dozen $(131$, p. 351, and p. 88 , below), and the explanation now under consideration could give no answer. Clearly the theory of dying-out was as untenable as that of local adaptation, so far as the Ceylon endemics were concerned. There is no doubt that a considerable number of species here and there, especially within the range of the glacial periods, may be looked upon as dying-out, or sometimes as locally adapted, but these are comparatively few and far between, and the mass of local endemics, partieularly in the tropies, cannot be looked upon as coming within these categories.

Just before leaving Ceylon I published a Catalogue of the flora (115), which rendered the task of enumerating the species with their distribution a much simpler affair, and on reaehing
Rio I began this work. Dividing the species into three groups-those endemic to Ceylon, those found in Ceylon and Peninsular India (cut off by a line from Calcutta to the north of Bombay), and those with wider distribution abroad than this-I found that the endemics were (VC 19), C 90, RC 139, RR 136, R 192, VR 233, increasing fairly steadily from top to bottom of the list.

Examining the distribution in Ceylon of the species (which I termed "wides" for short) that occurred outside the island to a greater distance than merely into the peninsula of southern India, it was found that the areas they occupied in the island went in the reverse order, being ( VC 221), C $462, \mathrm{RC} 313, \mathrm{RR}$ 209, R 159, VR 144.

If now, leaving out of account the somewhat uncertain $\mathrm{VC}$ class (its greater uncertainty is largely due, as already explained, to the fact that it is not based on actual area occupied), we number the other classes 1 to 5 (i.e. by degree of rarity, not of 
frequency), then the number 1 attached to a species will mean that it has the maximum, the number 5 the minimum, dispersal in Ceylon. And we can find the acerage distribution of a group, whether Ceylon endemics or widely distributed, by multiplying the number under cach head from 1 to 5 by the number of that head, adding up all the marks thus obtained, and dividing by the total number of species. Thus we obtain:

\begin{tabular}{|c|c|c|c|c|}
\hline \multirow[b]{2}{*}{ Class } & \multicolumn{2}{|c|}{ Endcmic species } & \multicolumn{2}{|c|}{$\begin{array}{l}\text { Widely dis- } \\
\text { tributed species }\end{array}$} \\
\hline & $\begin{array}{l}\text { No. of } \\
\text { species }\end{array}$ & Marks & $\begin{array}{l}\text { No. of } \\
\text { species }\end{array}$ & Marks \\
\hline 1. $\mathrm{C}$ & $90 \times 1$ & 90 & $462 \times 1$ & 462 \\
\hline 2. $\mathrm{RC}$ & $139 \times 2$ & 278 & $313 \times 2$ & 626 \\
\hline 3. $\mathrm{RR}$ & $136 \times 3$ & 408 & $209 \times 3$ & $62 \pi$ \\
\hline 4. $\mathrm{R}$ & $192 \times 4$ & 768 & $159 \times 4$ & 636 \\
\hline 5. VR & $233 \times 5$ & 1165 & $144 \times 5$ & 720 \\
\hline Tota & 790 & $2 \tau 09$ & $128 \pi$ & $30 \pi 1$ \\
\hline y repres & nted by & $3 \cdot 4$ & & $2 \cdot 3$ \\
\hline
\end{tabular}

Average rarity represented by $3 \cdot 4 \quad 2 \cdot 3$

Now the actual number of species under each of these heads in the whole flora is (VC 285), C 670, RC 555, RR 429, R 415, $V R$ 455. If we take the average rarity of the last five classes, we find it to be just over $2 \cdot 7$. The average rarity of an endemic we have seen to be $\mathbf{3 \cdot 4}$, and of a wide $\mathbf{2 \cdot 3}$, while the remaining species, which are endemic to Ceylon and South India, show a rarity of $\mathbf{2 \cdot 7}$, the same as the whole flora. The difference of $\mathbf{1} \cdot \mathbf{1}$ in average rarity between wides and endemics represents over a quarter of that between the most and the least widely distributed species ( 1 and 5 , difference 4 ). In other words, the most widely distributed species in Ceylon, on the average, are those that show a distribution abroad to a greater distance than merely to Peninsular India; then follow those that reach the peninsula, and the least widely distributed are those that are found in Ceylon only. Taking the estimates of actual area given above for the different classes, the differences actually found indicate that an endemic has an average area about 40 miles in diameter, a "wide" one of 80 miles, or four times as large.

A cursory examination of other floras soon showed that their species behaved in the same way, occupying areas of all sizes, overlapping in the same manner, and with their endemics occupying areas from many small up to few large, and the wides the reverse. At the same time, the figures for the Ceylon flora indicated clearly that this graduation of areas, wides largest, 
Ceylon-Peninsular-India next, Ceylon endemics least, showed not only for the grand total, but also for every family of 14 or more species. It was clear that any one group of allied species behaved like any other group, and it was therefore obvious that nothing but a mechanical explanation would serve. Natural selection could not act on all plants alike with even pressure. The only possible mechanical explanation seemed to me to be age, which would almost necessarily act alike upon all. If one supposed the "wides" to be (on the average) the oldest, and to have been the first arrivals in Ceylon, they were thus allowed sufficient time to spread to the largest extent. On the way, they would give rise, perhaps somewhere south of the middle of the peninsula, to the species now found in Ceylon and Peninsular India; these would be next oldest, and would spread in Ceylon to the second degree of distribution. The Ceylon endemics would arise in Ceylon, and on the whole probably later still, from one, or more likely both, of these groups, and being the youngest, would have spread the least. It seemed to me that I was at last provided with a simple and feasible explanation of the distribution of species, though it involved a great break with the older ideas, inasmuch as it indicated that the Ceylon species were confined to Ceylon simply because they had been too young to have had time to spread abroad.

It is clear, of course, that age in itself can effect nothing, but it allows time for the various factors that are active in distribution to produce their effects. The mechanical regularity of the figures given above demands a mechanical explanation, and the only possible one seems to be that age is mainly responsible for the distribution, or in other words, that the various factors that are operative produce an average or resultant effect-so much dispersal in so much time. Dispersal therefore becomes a measure of age, except in so far as barriers, physical or ecological, interfere. Distribution is very slow, and probably the vast majority of species have not yet reached the limits that they might reach, if sufficient time were allowed.

The greatest change from the older vicw of matters, however, consists in the fact that since one can no longer accept either the view of local adaptation or that of rclic nature, for the great majority of local species, and as these show definite numerical relationships to those of wider distribution that occur beside them, one must regard the two classes as related. But as area goes with age, the endemics must be the younger, and must 
therefore be looked upon as in general descended from the wides, and as young species just commeneing their careers.

I called this hypothesis, that on the average the area occupied by species in a country depended upon their age within that country, by the convenient jingle of "Age and Area" (123, p. 337, footnote), and from the very first I was careful to point out that this result was only true when averages of about 15 allied species were taken. People, however, have nearly always insisted upon applying the rule to individual cases, and then complaining that it does not fit the facts. In regard to the facts that have just been discussed, for example, they say "there are many VC endenics, and a lot of VR wides, so it must be wrong." A simple illustration will perhaps make my position more clear.

Suppose that five wides are approaching Ceylon (then attached to the mainland), spreading at a uniform speed, and let the distance from the forcmost of $A$ to the foremost of $B$ be represented by 2 , that from $B$ to $C$ by 2 also, and so on. Then $A$ will reach Ceylon first, and when $B$ reaches the island $A$ will occupy there a space represented by 2 . When $C$ arrives $A$ will occupy 4 , and $B 2$. Ultimately they will occupy spaces represented by 10,8 , 6,4 , and 2. Now let each give rise in South India to another species $\alpha, \beta, \gamma, \delta, \epsilon$, each always at a distance behind its parent represented by 2 . Then $\alpha$ will arrive in Ceylon simultaneously with $B, \beta$ with $C$, and so on, and these Ceylon-Peninsular-Indian species will ultimately occupy areas represented by $8,6,4,2$, and 0 . And if, lastly, each species, when it has reached a distribution in Ceylon represcnted by 2. gives rise to a Ceylon endemic, then if we subtract 2 from the figures of distribution of all the preceding spccies, we shall get the distribution of the endemics. This will be, for the endemics derived from the wides, $8,6,4,2,-$, and for those derived from the Ceylon-PeninsularIndian species $6,4,2,-,-$.

Now the most widely distributed endemic, derived from $A$, the first wide to arrive, will have a range of 8 , while three out of five of the wides, and three out of four of the Ceylon-Peninsular-Indian species will have ranges of 6,4 , or 2 , considerably less. If one attempt to apply the rule to individual cases, it is at once liable to break down. But if we add up the dispersal of all the wides, and divide by the total of species, we get $(10+8+6+4+2=) 30 \div 5=6$ as the arcrage range of a wide, $20 \div 4=5$ as the average range of a Ceylon-PeninsularIndian species, and $32 \div 7=4.5$ as the average range of an 
endemic, figures which obviously agree with the rule. If onc take the figures in groups, one may safely say that the wides will range the most, the endemics the least.

In the same way, one must work, not only with groups of species, but with groups of allied species, which will have more or less the same dispersal-mechanisms and the same reactions to their surroundings. If $A, B, C$ be three species with wide separation in relationship, and great differences between them in regard to habit, dispersal-method, or other things, their rates of dispersal may be entirely different, and $A$ may travel ten times as fast as $C$. But with a group of ten allied species one will be fairly safe.

Changes of condition, again, might evidently completely alter the relative rates of dispersal of species, or might even stop) some of them altogether. And we must also take account of the presence and action of barriers, already discussed, remembering that some forms may cross a barrier when it has become quite impassable to others.

Age shows clearly in the distribution figures because it always pulls the same way, whereas other causes of dispersal will either tend to cancel one another by pulling different ways, or more commonly to exert a practically uniform pull upon a group of allied species, so that when two groups of allies are compared, one will be able to see the relative effects of age upon either. In any single species its effects are liable to be completely hidden by those of some of the other causes, just as the effect of gravity, which is admittedly universal, is hidden in the case of an aeroplane, a balloon, or a moving bullet.

The most recent expression of the rule of Age and Area so far published (133) is as follows:

The area occupied ${ }^{1}$ at any given time, in any given country, by any group of allied species at least ten in number, depends the ages of the species of that group in that country, but may be enormously modified by the presence of barriers such as seas, rivers, mountains, changes of climate from one region to the next, or other ecological boundarics, and the like, also by the action of man, and by other causes.

Extensions, which will be considered below, have since been given to Age and Area, which appears to be a general law covering all or nearly all the plants now existing upon the globe, and

${ }^{1}$ Determined by the most outlying stations. 
to have determined their distribution thereon, in broad outline. When stated thus, it would appear to be almost axiomatic, but for a very long time the simple effeets of age upon dispersal have been lost sight of, under the widely held view that distribution was rapid, and that local species were either local adaptations or were dying out.

The Ceylon figures gave strong evidence in favour of Age and Area, but confirmation of the most satisfactory kind was soon obtained by working out the distribution of the flora of New Zealand (127), employing north and south diameters of areas occupied (i.e. in the direction in which the islands run), and obtaining these by actual measurement. This flora followed the law with great exactness, as a quotation of actual figures will show.

$\begin{array}{lccc} & \text { Range } & & \\ \text { in N.Z. } & & \\ & \text { (miles) } & \text { Endemies } & \text { Wides } \\ \text { 1. } & 881-1080 & 112 & 201 \\ \text { 2. } & 641-880 & 120 & 77 \\ \text { 3. } & 401-640 & 184 & 53 \\ \text { 4. } & 161-400 & 190 & 38 \\ \text { 5. } & 1-160 & 296 & 30^{1}\end{array}$

Further work was then earried out upon various other similar phenomena, the conclusions already made being confirmed by the Orehids of Jamaica, Callitris (a Conifer) in Australia, and the flora of the Hawaiian Islands. A study of the ferns there and in New Zealand also gave the same result, showing that the law was probably quite general.

Breakwell (13) studied the grasses of Australia, and found that while the speeies of very wide distribution showed an average rarity there of 3 , those confined to Australia and New Zealand or Asia showed $4 \cdot 1$, and those confined to Australia only an average rarity of $4 \cdot 6$, the figures agreeing exactly with those already given. He also found that the genera showed the same thing, and that it showed in Panicum alone, while several of the larger genera showed a very close agreement.

Taylor (105-6) has studied the endemics of New York and of the Bahama islands, obtaining results that harmonise quite well with the general theory of Age and Area. In the latter ease, it was noticed that the difference usually seen between the distribution of the endemies and the wides was not nearly so large as usual. This may be due to one or more causes; it may

1 Largely undoubted introductions of recent years. 
be that the peculiar conditions of the Bahamas, with their sterile soil and considerable droughts, suit the endemics-which must have been developed in them, and have had, as just explained, a strenuous struggle to become established, and which, therefore, should be unusually well suited to the local conditions. Although the parent species were able to survive there, the endemics were probably better suited, and would therefore be able to overtake the former to some extent.

\section{Summary}

Studying the flora of Ccylon, it was very soon noticed that there were enormous differences between the areas occupied by species of the same genus, some of which were endemic to the island, some not, and this led on to a study of areas occupied in general, when it was soon found that the endemic species occupied, on the average, the smallest areas in the island, those found also in Peninsular India (but not beyond) areas rather larger, and those that ranged beyond the peninsula the largest areas of all (again on the average). The two current theories about endemic species-that they were local adaptations, suited to special local conditions, and that they were relics-proved to be incapable of explaining the facts when it was found, as was ultimately done, that the areas occupied, both by endemics and by widely distributed species, were arranged in a graduated series, the first from many small to few large, the second in the opposite direction. It was not possible to suppose that local adaptation should exist in this graduated manner, nor that there should be many relics at the final stage of dying out, and successively fewer at all the stages leading up to that. Some mechanical explanation was necessary, and the only simple and reasonable one was that the area occupied increased with age. The actual quotation of the Age and Area hypothesis, as so far developed, is given on p. 63 . 


\section{CHAPTER VII}

\section{AGE AND AREA (contd.). CONFIRMATION BY PREDICTION}

Confirmation of the general idea advanced in the hypothesis can be easily obtained by applying it to predict what will be found in certain places or under certain circumstances. Many successful predietions of this kind have been made for the area comprised by New Zealand and its surrounding islands (the Kermadecs, 420 miles north; Chathams, 375 miles east; and Aucklands, 190 miles south). It will be well to instance a few of these.

To begin with simple cases (129); from the fact that to the east of these outlying islands the soundings are in general

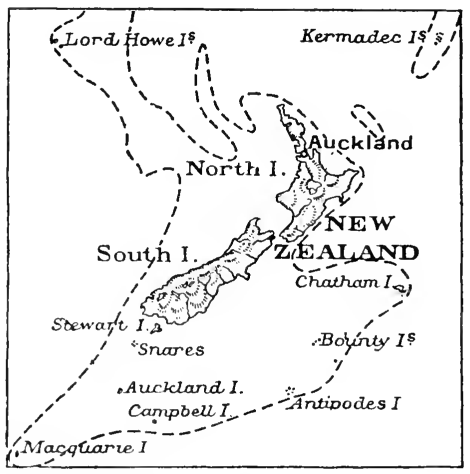

New Zealand and outlying islands. The dotted line is the 1000-fathom limit. of enormous depth, while the water between them and New Zealand is comparatively shallow, one may infer that their floras have in general the same sources of origin as that of New Zealand. This is indicated also by the very few species in them, other than their own local endemic species, which do not occur in New Zealand. If they had received their flora by casual transport over sea, one would expect that it would be a miscellaneous assortment, and that it would not show any numerical relations to the flora of the larger island. But as such relationships are shown very clearly one may, I think, take it for granted that the connection was by land, at least so far as the bulk of the flora of these islands is concerned. Now in this case it is clear that on the hypothesis of Age and Area, this flora should in general be very old in New Zealand, or it could not have 
reached the islands before they were cut off. In the case of the Chathams, more particularly, where except New Zealand there is no other source for the flora than casual arrivals by sea, by currents which also run close to New Zealand, this should be the case. The Kermadees must have lain fairly near to any incoming northern current of plants, the Aucklands probably to any southern invasion, and both these islands therefore may contain plants that were too late, or only just in time, to reach New Zealand at all, but this does not apply to the Chathams.

One will therefore expect, upon the hypothesis of Age and Area, that while on the average all the floras of these islands will be old, and therefore widespread, in New Zealand, those plants that reach the Chathams will be the oldest, and most widespread. Actual examination soon shows that those plants that reach all three groups, and which are therefore, by hypothesis, about the oldest of all in New Zealand in their own eircles of affinity, show the maximum possible range in New Zealand, ranging it from end to end. Three of the five are Compositae, including Lagenophora Forsteri, which is endemic to New Zealand and the islands, and the others are Samolus repens and Deyeuxia Forsteri. In my papers upon New Zealand I have divided the plants into ten classes by range, instead of the six of the Ceylon flora. The average rarity of a plant in New Zealand, including all the flora, is represented by $5 \cdot 6$, and the rarity of these five species is represented by 1. Those plants that reaeh two groups of islands, which must also, by hypothesis, be very old forms, have a rarity represented by an average of $1 \cdot 5$. Of these plants there are 16 species in class 1,4 in elass 2 , and a solitary species in class 8 , about whose identification there is some doubt, and whose inelusion brings the average from $1 \cdot 2$, at which it would otherwise stand, to $\mathbf{1 \cdot 5}$.

There are a great many species that reach only one group of islands, and these show on the average less range in New Zealand, but it is very noticeable, that just as was predicted above, those of the Chathams show a much greater average range than those of the Kermadecs or Aucklands. The average rarity for a species reaching the Chathams is represented by $1 \cdot 7$, and it would be $\mathbf{1 . 5}$ were it not that, though there is otherwise no species below class 4 , there is one eonspicuous exception in elass 9, which brings up the average figure. This exception is the Tainui of the Maoris (Pomaderris apetala), which they assert sprang from the rollers or skids of their invading canoe the Tainui, and which is 
only found in a short range on the north-west coast of New Zealand. It is fairly clear, from the marked way in which it forms an exception to the rule as regards distribution of these island species, that this legend is probably the truth, and that this species therefore may be regarded as an introduction, and omitted from the indigenous flora. Even including it, however, the average figure for the Chatham plants is $1 \cdot 7$. The species that reach the Kermadecs show an average rarity in New Zealand represented by $3 \cdot 6$, and as each $0 \cdot 1$ represents 12 miles in range, this means that they range New Zealand on the average 228 miles less than the Chatham species. Their range, however, is still much greater than the average for the species of New Zealand as a whole, which is represented by $5 \cdot 6$, or 240 miles less than the Kermadec species. The number of species in the different classes ranges down to class 7 , and in class 9 there is again a species which may be looked upon as an exception - Ipomoea palmata, which is possibly carried by sea currents, and may have reached both Kermadecs and New Zealand in this way, as they are washed, where it occurs, by the same current.

Lastly, the species that reach the Aucklands (only) show an average rarity in New Zealand represented by $\mathbf{3 \cdot 5}$, or practically the same as the range of the Kermadee species, with the lowest species in class 4 . The prediction as to range in New Zealand of the various species reaching the islands is thus fully verified, and this suceess lends great support to the hypothesis of Age and Area. There is no conceivable reason why ranging to one or more of these little groups of islands, and to any one of them ${ }^{1}$, though they differ widely in climate and geology, should make a species more widespread in New Zealand than the average, unless it be the mere fact that to have been able to reach the islands at all it must have been above the average age in New Zealand, and thus have had more time in which to spread.

This is confirmed by the fact that there are in New Zealand many species, both widely distributed (reaching Australia, etc.) and endemic, which do not reach the islands at all. These by hypothesis should be younger, each of course, as already explained, in its own circle of affinity, than the species which reach the islands, and should therefore be less widespread in New Zealand. There are 213 such "wides," and they show an average

${ }^{1}$ Kermadecs in latitude $29^{\circ} \cdot 15$, volcanic; Chathams in $44^{\circ} \cdot 20$, schists, volcanic and tertiary; Aucklands in $50^{\circ} \cdot 35$, igneous, mostly volcanic. 
rarity in New Zealand represented by the figure $4 \cdot 3$, i.e. $0 \cdot 7$ greater than the largest figure for any that reach the islands (Kermadecs, $3 \cdot 6$ ), or a range of 84 miles less. This difference between the two groups comes out in a very striking way if we place the figures in columns by classes:

$\begin{array}{cc} & \text { Range in } \\ \text { N.Z. } \\ \text { Class } & \text { (miles) } \\ 1 & 1001-1080 \\ 2 & 881-1000 \\ 3 & 761-880 \\ 4 & 641-760 \\ 5 & 521-640 \\ 6 & 401-520 \\ 7 & 281-400 \\ 8 & 161-280 \\ 9 & 41-160 \\ 10 & 1-10\end{array}$

\begin{tabular}{cc}
$\begin{array}{c}\text { Reaching } \\
\text { islands }\end{array}$ & $\begin{array}{c}\text { Not reaching } \\
\text { islands }\end{array}$ \\
$45 \times 1=45$ & 35 \\
$19 \times 2=38$ & 39 \\
$3 \times 3=9$ & 26 \\
$3 \times 4=12$ & 28 \\
$1 \times 5=5$ & 19 \\
$1 \times 6=6$ & 17 \\
$3 \times 7=21$ & 12 \\
$1 \times 8=8$ & 14 \\
$2 \times 9=18$ & 7 \\
$\dot{0} \times 10=$. & 16 \\
\hline 78 with 162 marks & 213 with 919
\end{tabular}

Average rarity $2 \cdot 0$ (= range of 940 miles); $4 \cdot 3(66+$ miles).

Difference $2 \cdot 3$, representing $2 \div 6$ miles of range. If one subtract from class 10 in the second column about a dozen that are probably introductions, one gets 201 with 799 marks, an average of $3 \cdot 9$, rcpresenting 228 miles less range than the first column.

There are also 98 species that are endemic to New Zealand and one or more of these island groups, but not found elsewhere in the world. These have an average rarity in New Zealand represented by $\mathbf{2 \cdot 9}$, or in other words, they are a good deal more widely ranging in New Zealand than those species which reach Australia, etc. (enumerated above in the second column), but do not reach these little islands. The difference of 1.4 in average range represents 168 miles. Now here, still more than in the previous case (p.68), there is no conceivable reason why ranging to these little groups of islands (and to any one of them, though they differ completely in climate and geology) should make these endemic species more widespread in New Zealand than many others whose distribution touches Australia, etc., unless it be simply that being older, they have had time to reach the islands, and to range more widely in New Zealand itself.

Another interesting point shows in the table given above, which also indicates the greater age of these species, whether wide or endemic, that reach the outlying islands. The wides that reach them show 45 in class 1 , whose range covers Stewart Island, a separate island near to the south coast of New Zcaland, 
and only 19 in the next class, which does not in all eases include Stewart. In other words, most of these species were so old that they were also in time to reach Stewart before it was cut off. The endemics that reach the jslands also show 41 in class 1 and 21 in elass 2, but the wides that do not reach these islands (last column in table above) show 35 in class 1 and 39 in class '2, indicating that they were on the whole a good deal younger, so that many of them were not in time to reach Stewart. The endemics that do not reach the islands show 52 and 60 in these classes respectively, in the same way.

That these outlying islands of New Zealand are not a special ease may be seen by comparing with the flora of Great Britain those of some of its outlying islands. If we take the Orkneys (north Scotland), Colonsay (south-west Scotland), Clare (west Ireland) and the Seillies (south-west Fngland), islands widely separated, and differing very much in climate and geology, and if we take in these, at random $(37,108)$, the families Ranunculaceae, Caryophyllaceae, Leguminosae, Orehidaceae, and Gramineae, we find that while (going by the London Catalogue, 8 th cd.) the average distribution of a species in Great Britain is to 47 of the vice-counties out of 112 , the 175 species of these families that occur on the islands mentioned range on an average to 71 (or 50 per cent. more), whilst those that reach three or four of the islands show an average range of 99 . The facts are exactly parallel to those for the islands off New Zealand, though of course not so striking, as the islands are very much eloser to their mainland.

Before going further we must onec more consider the reservations which are laid down in the statement of the hypothesis in the preceding chapter, and whose misunderstanding scems the chief stumbling-block in the way of an acceptance of Age and Area. It is easy to pick out of the list of "wides" reaching the islands a few that have less range in New Zcaland than other wides that occur there and do not reach the islands. The hypothesis is often treated in this manner, and then rejeeted for nonagreement with aetuality. It must not be forgotten that if it could be applied in such minute detail we should have at our command a theory that would explain more faets in distribution and phylogeny than any other that has ever been suggested. Too much is expected of an hypothesis which claims no more than to be a useful guide, and the reservation, that it must not be applied to a group of less than ten allied species, is ignored. 
It may be applied to less if it be simply desired to gain an argument from greater or less probability to add to other arguments in favour of some point, but when it is to form a main argument it must be applied to at least ten allied species at once. By this means the exceptional species, of which there are many, will be lost in the crowd, and also a group of species will be obtained which react to their surroundings in much the same way, have more or less the same rapidity of dispersal, and so on. On averages there can be no question about the wider dispersal in New Zealand of the Chatham plants, though individuals can be found with little dispersal there. The herbaceous Compositae may be enormously younger in the islands than the woody Leguminosae, for example, and also younger in New Zealand, yet by virtue of their better dispersal mechanism, and the fact that they are herbs, may be much more widely distributed in the latter, and may even have started much later from New Zealand than the Leguminosae (which could hardly cross a strait) and yet have reached the islands. Both groups, however, obey Age and Area, though they cannot be compared with one another as to relative age.

If there were, again, $a^{*}$ great change of conditions between New Zealand and the Chathams, or any serious barriers like mountains, this would completely alter the list of plants that might arrive. One must remember all these provisos in dealing with the distribution of plants, but none the less one finds that by keeping to the Age and Area rule as enunciated, and dealing always with groups of allied species, results may be obtained that are fairly reliable.

To return to predictions, another upon the following lines (132) was equally successful. A family will rarely arrive in a country as a group of genera simultaneously; some will arrive sooner than others. On the average, therefore, in any circle of affinity, the families with several genera will be older in that country than those with one or two, as it is all but impossible that their first genus should only arrive at the same time as the solitary one of another family. This being so, we shall therefore expect the larger families of New Zealand to he hetter represented upon the outlying islands than the smaller, as being older. On Stewart Island, at the south end of New Zealand, we do in fact find this to be the case, as the following table shows: 
Family represented in New Zealand by

$\begin{array}{cc}\text { (genera) } & \text { (families) } \\ 1 & 36 \\ 2 & 15 \\ 3 & 15 \\ 4-5 & 10 \\ 6-10 & 9 \\ \text { over } 10 & 6 \\ & \frac{6}{91}\end{array}$

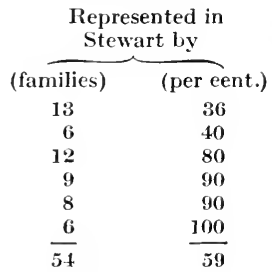

Not represented
there (families)

23

9

3

1

1

$\dot{1}$

We may even take the genera, and consider those represented by most species in a country to be the oldest in the country. Testing this on the flora of Stewart Island, we get:

\begin{tabular}{|c|c|c|c|c|}
\hline \multirow{2}{*}{$\begin{array}{c}\text { Genus } \\
\text { represented in } \\
\text { New Zealand by } \\
\text { (species) }\end{array}$} & \multirow{2}{*}{$\begin{array}{l}\text { In New } \\
\text { Zealand } \\
\text { (genera) }\end{array}$} & \multicolumn{2}{|c|}{$\begin{array}{l}\text { Represented in } \\
\text { stewart by }\end{array}$} & \multirow{2}{*}{$\begin{array}{c}\text { Not represented } \\
\text { there } \\
\text { (genera) }\end{array}$} \\
\hline & & (genera) & (per cent.) & \\
\hline 1 & 155 & 32 & 20 & 123 \\
\hline 2 & 54 & 22 & 40 & 32 \\
\hline 3 & 29 & 20 & 68 & 9 \\
\hline $4-5$ & 29 & 23 & 79 & 6 \\
\hline $6-10$ & 36 & 32 & 88 & 4 \\
\hline $11-20$ & 16 & 15 & 93 & 1 \\
\hline \multirow[t]{2}{*}{ over 20} & 10 & 10 & 100 & $\therefore$ \\
\hline & 329 & $\overline{154}$ & $\overline{46}$ & $\overline{175}$ \\
\hline
\end{tabular}

Thus, just as with the families, the proportion of genera represented in Stewart shows a steady increase with the increasing number of species in the genus from 20 per cent. of those with one up to 100 per cent. of those with more than 20 speeies.

If we test the same question on the farther outlying islands of New Zealand, the Kermadecs, Chathams, and Aueklands, we find that the average size of a family that reaches all three groups is 47 species, of a family reaching only two is 14 , reaching one 5 , and of a family reaching none is only 2. A similar result follows a test of the gencra. This fact also shows in the flora of the islands off the British coast mentioned above.

Or again, as the wides are, according to hypothesis, the oldest forms, one will expect to find them the best represented in the floras of the outlying islands of New Zealand. In New Zealand itself the wides form about 18 per cent. of the flora in number of species, but when we pass over into Stewart Island, the plants reaching which must, by hypothesis, be older on the average than the plants of New Zealand proper, we find that the wides form 36 per cent. of the flora. In the plants that reach Stewart, 
and also one of the three outlying groups so often mentioned, the wides form 41 per cent., when two groups are reached they form 64 per cent., and of those plants that reach Stewart and all three, i.e. Kermadecs, Chathams, and Aucklands, they form 80 per cent. The result agrecs exactly with the prediction, confirming the hypothesis in a very striking manner.

Or we may predict that the far outlying islands will have a large proportion of forms in common with onc another and with Stewart, all being old in New Zealand, and that the proportion will be much larger than that in common with New Zealand. In actual fact, one finds 81 per cent. of the Stewart families, 67 per cent. of the genera, and even 40 per cent. of the species, on the other islands, while of the plants that occur in New Zealand, but not on Stewart, only 32, 17, and 15 per cent. respectively occur, an enormons difference. The prediction is completely borne out by the facts, and it will suffice to quote one or two instances. The Kermadecs have 30 per cent. of the genera that occur upon the Aucklands, 1200 miles away, in a totally different climate, and only 19 per cent. of those of New Zealand. Of 52 species occurring outside the Kermadecs, as well as in those islands, 30 occur in the Chathams, and even 5 in the Aucklands; and so on.

One may in the same way predict a great similarity between the floras of the islands off the British coast, above mentioned. On examination, one finds, in the five families before considered, that their $\% 0$ genera have in the British Islands an average of $4 \cdot 7$ species, against $3 \cdot 4$ for the whole flora. Whilst about 37 per cent. of the whole 175 species of these families are confined to one island, 24 per cent. are found on two, 19 per cent. on three, and 19 per cent. on all four, widely separated, and widely different in climate, etc., though they be. The average occurrence of each species is upon $\mathbf{2} \cdot \mathbf{2}$ island groups of the four.

Or we may predict that the genera which are common to the islands and New Zealand, taking at least two groups of the three, will be very old genera, and consequently in general will be large genera in large families. This is so obvious when one comes to make a list, and finds it composed of Ranunculus, Cardamine, Lepidium, Stellaria, Colobanthus, Geranium, ete., that it hardly needs any further elaboration. The 32 genera upon the islands in the first half of the New Zealand flora show an average size of 144 species, against an average for the world of only 12. Only five of them, Corynocarpus, Coriaria, Panax, Samolus, and Calystegia, are below the average in size. 
Or, lastly, one may take the endemics of New Zealand and the outlying islands, and make predictions about them. We have just seen that on the whole, each in its own circle, the larger families and genera of a country will be the older in that country. Now endemic species, by hypothesis, occupying small areas, will be on the whole younger than the wides, as already pointed out, and one will therefore expect the older families, which have had the longest time in the country, to produce the most endemics. That is to say, that the endemics should belong to the largest families in the country, working in averages. The same rule should of course apply to the genera. If now we test this on New Zealand and its surrounding islands, we find that in New Zealand and its outlying islands there are 22 families above the average size, with 1100 species, of which 890 are endemic to New Zealand or the islands, or 80 per cent.; there are 69 families below the average, with 292 species, of which only 110 are endemic, or 37 per cent., an enormous difference. In Stewart Island, all the 19 local endemics belong to the 15 largest families of New Zealand, and 10 of them to the three largest families in Stewart, and the same thing holds for the local endemics of the other outlying islands.

In the same way, one finds that the (local) endemics of the Kermadecs, Lord Howe Island, and Norfolk Island, all islands which must have lain more or less in the track of the invasions of New Zealand by plants from the north, belong ehiefly to those families and genera of their floras which have also reached New Zealand, i.e. to the oldest families and genera eontained in them.

On the supposition, which follows from Age and Area, that the wides have given rise to the endemics (p. 61), one will expect most endemics to occur in those regions where there are most wides, and not, as on the theory of dying out of endemics would rather be the case, in those regions where there are fewest wides. In fact, this is at once seen to be the case, whether in New Zealand, its outlying islands, or in Ceylon or elsewhere.

Age and Area is thus seen to be a hypothesis by whose use one may discover great numbers of new facts, and as so far all the predictions made by its aid have proved to be correct, on verification, the result is to afford great support to the hypothesis itself. Over 90 such predictions as those mentioned above have now been made and verified, and one may, one is inclined to think, regard the hypothesis, in the absence of any rival 
explanation, as sound. The question now is to bring it into accord with other views, theories, and facts, which often conflict with it, or apparently so.

\section{Summary}

This chapter is devoted to a few instances of the very successful way in which Age and Area can be used to make predictions about distribution. For example, it was predicted-and verified-that the outlying islands of New Zealand would have a flora which was very old in New Zealand, and therefore very widespread there. In fact it was found that on the average its species ranged nearly 300 miles more in New Zealand than did those that did not reach the islands. Further, those endemic forms that reached the islands were found to be more widespread in New Zealand than the species of its flora that reached Australia, etc., but did not reach the islands-a result only explicable by aid of Age and Area. Parallel results were obtained by a study of the floras of various islands off the British coast, from the Orkneys to the Scillies.

The reservations already laid down, that Age and Area must only be applied to groups of at least ten species, and to groups of allied species, are then once more insisted upon.

The successful prediction that as, on the whole, the larger families and genera in a country will be the older, therefore the flora of the outlying islands will be chiefly composed of these, is then described. Other predictions indicate that the farther out one goes the greater will be the proportion of wides, that the outlying islands will have much in common, especially of large genera in large families, that the endemies, both of New Zealand and the outlying islands, will belong mainly to large families and genera, and that most endemies will occur where there are most wides. All these predictions proved successful, and as this method has now been used over ninety times with no failures, it is evident that Age and Area has strong foundations on which to rest. 


\section{CHAPTER VIII}

\section{AGE AND AREA (contd.). INVASIONS}

The acceptance of the hypothesis of Age and Area involves various changes in our way of looking at many problems of geographical distribution, and of other branches of Botany, and we must go on to further illustrate its (published) implications and possibilities. The facts upon which it is based, as illustrated by the preceding two chapters, are so clear and so definite that they cannot go without an explanation; either one must accept Age and Area, or one must find some other explanation for them -a thing that no one has yet attempted.

If the distribution of plants about the world has been very largely the result of their age, it is clear that it should be comparatively easy to make predictions about it, as has already been shown. The very first prediction I employed (127) was the following, which will serve as a text for this chapter:

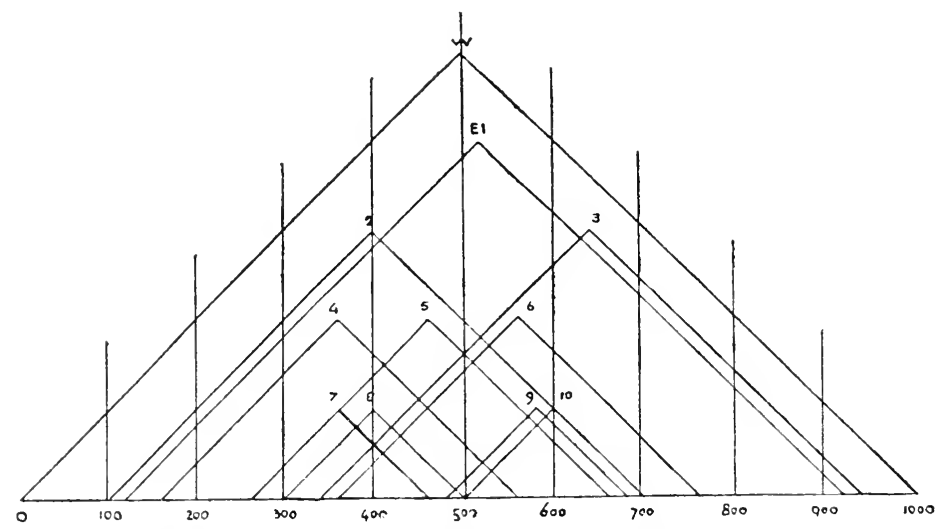

Let $W$ be a species arriving at the centre of New Zealand from abroad, and following the rule exactly in its dispersal (there is reason to suppose that it would not do so unless the direction were east and west, not north and south as in New Zealand; but this does not affect the prediction). Such exactness probably never 
occurs in real life, but by taking groups of ten allied species one may cancel out many of the effects of chance differences. This dispersal is indicated by drawing a right-angled triangle, which expands regularly till after a certain time it reaches both ends of New Zealand. As it does so, and covers more country, $W$ is supposed to give rise casually to new species (shown at every increase of 200 miles of range, their locations of origin obtained by drawing numbers at random). These new species, $E 1$ to 10 , spread like the parent, as is shown by the similar triangles, so that when $W$ reaches 0 and $1000, E 1$ reaches 120 and 920 .

If now we divide New Zealand into ten zones by drawing a vertical line at every 100 miles, and count in every zone the number of endemics found there (derived directly or indirectly from $W$ ), we find the number small at each end, and with a maximum (or at times two or more) near the middle. In the present case, for instance, the numbers in each of the zones from left to right are: $0,3,5,8,9,8,7,3,2,2$.

If we obliterate the left-hand half of the diagram, we get the result of entrance of $W$ at one end of New Zealand, and find the maximum near that end; it always tends to be near the point of entry. If the entrance be not at a point, but at a zone, e.g. from 300 to 700 miles, at the level of $E 2$ and 3 , then, if one omit $E 1,2$, and 3, one finds that the remainder give the figures: $0,1,3,5,6,5,4,1,0,0$, a similar but shorter curve.

Occasionally, with a casual development of new endemic species, it so happens that the curve may show two, or even more, maxima with a slight drop between them, but to have one maximum only is the general rule.

One might therefore predict that one would find the endemic species of any genus in New Zealand to form such a curve, and this proved to be the case for every genus in the flora. A few examples are here given:

\begin{tabular}{|c|c|c|c|c|c|c|c|c|c|c|}
\hline & \multicolumn{10}{|c|}{ Zone in miles } \\
\hline & $\begin{array}{c}0 \\
\text { to } \\
100\end{array}$ & $\begin{array}{l}100 \\
\text { to } \\
200\end{array}$ & $\begin{array}{l}200 \\
\text { to } \\
300\end{array}$ & $\begin{array}{c}300 \\
\text { to } \\
400\end{array}$ & $\begin{array}{c}400 \\
\text { to } \\
500\end{array}$ & $\begin{array}{l}500 \\
\text { to } \\
600\end{array}$ & $\begin{array}{c}600 \\
\text { to } \\
700\end{array}$ & $\begin{array}{c}700 \\
\text { to } \\
800\end{array}$ & $\begin{array}{c}800 \\
\text { to } \\
900\end{array}$ & $\begin{array}{c}900 \\
\text { to } \\
1000\end{array}$ \\
\hline Ranunculus & - & 2 & 3 & 5 & 7 & 11 & 12 & 18 & 18 & 10 \\
\hline Drimys & 2 & 2 & 2 & 2 & 2 & 3 & 3 & 2 & 1 & 1 \\
\hline Pillosporum & 11 & 11 & 11 & 11 & 8 & 7 & $\theta$ & (3) & 5 & 5 \\
\hline Colobanthus & . & . & . & . & . & 2 & 3 & 3 & 4 & 2 \\
\hline Coprosma & 12 & 12 & 15 & 16 & 17 & 18 & 18 & 16 & 15 & 12 \\
\hline Metrosideros & 8 & 8 & 8 & 8 & 5 & 6 & 6 & 2 & 1 & 1 \\
\hline Ligusticum & . & 1 & 1 & 1 & 2 & 7 & 8 & 9 & 7 & 6 \\
\hline Veronica & 6 & 6 & 10 & 14 & 15 & 39 & 41 & 43 & 38 & 26 \\
\hline Utricularia & 3 & 3 & 3 & 1 & 1 & $\mathbf{I}$ & 1 & 1 & • & . \\
\hline Pimelea & 4 & 4 & 5 & 5 & 7 & 8 & 8 & 6 & 5 & 4 \\
\hline
\end{tabular}


These curves show many things. The first point that appears from their study is that the maxima are not casually scattered all over New Zealand, but occur in masses at particular regions, e.g. chiefly at the far north, at a little south of the middle of the

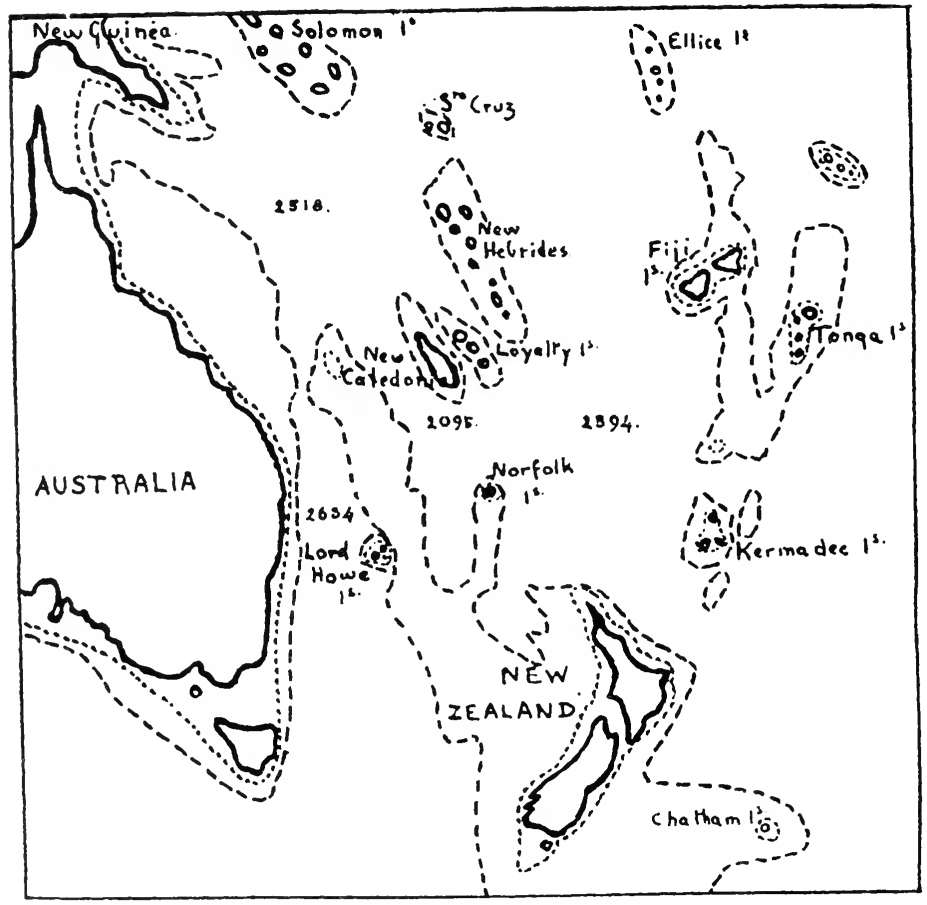

Soundings in the New Zealand area. Numbers inserted here and there give the depth in fathoms at those points. (From the Annals of Botany.) ... - 100 fathoms. -- - - 1000 fathoms.

South Island, and at the north end of the same island. These last two groups are so close to one another that they are somewhat confused together. Of the examples given above, Pittosporum and Metrosideros have northern, Ranunculus and Veronica southern, and Drimys and Coprosma central maxima. 
These are bare and unvarnished facts, and though found by aid of the hypothesis of Age and Area do not depend upon it in any way, but may be examined upon their own merits. It is clear from them that the previous distributional history of these groups of genera must have been quite different, and it would seem to point to the conclusion that the present flora of New Zealand has been the result of at least three distinct invasions of plants from elsewhere, which probably had their centres at the points, north, south, and central, where the masses of maxima occur.

This is confirmed by examination of the actual genera, for the northern group is composed of fanilies characteristic of Indo-

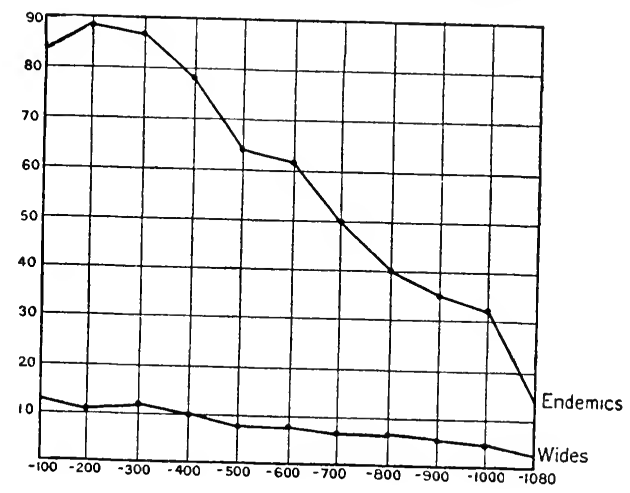

Malaya, probably indicating an invasion thenee, the southern group belongs to Ranunculaceae, Umbelliferae, and other families prominent in the northern hemisphere (the only exceptions being Stylidiaceae and Centrolepidaceae, both southern families), and the central group to Stackhousiaceae, Campanulaceae, Violaceae, etc., which may perhaps have come from Australia.

If now one add together all the species of the genera of the northern invasion that occur at each zone of 100 miles from north to south in New Zealand (ineluding Stewart Island), one nbtains the curves shown above, from which one may perhaps infer that the invasion was at about 0-300 miles from North Cape. The two curves fall off very steadily towards the south, 
but that for endemies much more rapidly than that for wides, the maximum in each case being at about the same spot, and

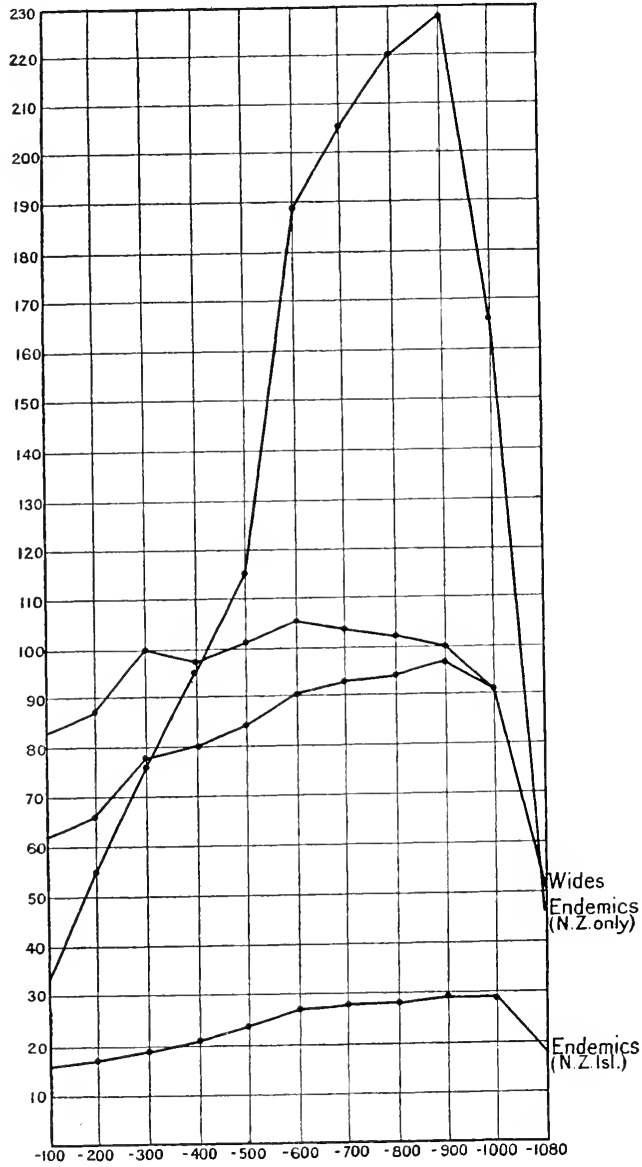


the minimum at the same. The more rapid fall of the endemic curve is to be attributed (on the hypothesis of Age and Area) to the fact that they are in general younger, and so have not had time to spread so far.

Treating the southern invasion in the same way, one obtains the curves on p. 80, showing both endemics and wides falling off towards the north. The latter are shown with a double curve; the upper shows the grand total of wides, but many begin at the north and do not occur in the far south, showing that they probably really belong to the northern invasion. Subtracting these gives the lower curve, and the diminishing distance between these two curves shows the way in which these species diminish southwards. The endemies, being more numerous, are split into two curves, one endemic to New Zealand only, one endemic to New Zealand and the outlying islands (Kermadees, Chathams, Aucklands).

These curves provide a very formidable argument against the supposition that endemies are dying out, for if so, why does their number show its maximum with that of the wides, and fall off to a minimum at the same point with the latter?

They also illustrate various other points. For example, from the much steeper curves of the southern invasion, one may probably infer that it was much younger than the northern, both wides and endemies having had less time to spread widely in New Zealand. This is confirmed by the fact that both northern curves, and that for southern wides, show no break of any kind between 500 and 600 , where Cook's Strait lies, while that for southern endemies shows a marked drop there, indicating that when this group (the youngest of all, by hypothesis) came along, the strait was at any rate beginning to be formed. The same feature shows in a much more marked way at Foveaux Strait, between the last two figures in the curves; even the northern "wides" show a drop here, and the southern endemies an enormous one.

The greater age of the northern invasion may also be inferred from the fact that in it the number of the endemics at any zone is always at least twiee as great as that of the wides, while in the southern invasion the curve for endemies goes below that for wides at both ends, or adding the endemics of islands, below that for wides at the northern end.

The greater youth of the southern invasion is also emphasised by the fact that it is composed to the extent of 83 per cent. of 
herbs, while the northern has $\mathbf{\$ 4}$ per cent. of trees and shrubs, and, as we have pointed out above, the latter will be likely to spread with vastly greater slowness. The average areas occupied by the species of the two invasions are much the same.

I am informed by the well-known palaeobotanist, Mrs Clement Reid, that geology gives evidence that invasions follow directions which offer stability of climatic conditions to their members; polewards when climates are warming, equatorwards when cooling. One feels inclined to infer, therefore, that at the time of the northern invasion New Zealand was warm in the south, whilst the Antarctic land was habitable to the northern types of plants that largely compose the southern invasion, and which perhaps reached Antarctica by way of the Andes, as most of them occur in that chain. Then as the south cooled, the southern invasion perhaps cntered New Zealand, working northwards. It is very noticeable in the curves for this invasion that they fall off much more gradually to the north than to the south.

Yet other probabilities may be deduced from the figures and curves given. The curve in the southern invasion for endemics that reach the outlying islands is flatter even than the curve for wides, showing that they are probably older than the average for wides, as we have shown above (p. 69). But if we split the curve for wides in the same way, into two, that for the wides that reach these islands proves to be even flatter than that for the endemics which do so, as we should expect by hypothesis.

From the diagram given at the commencement of this chapter. one may deduce that the average range of endemic species that occur in the outer zones of $N$ W Zealand will be greater than that of those that occur in the centre, for obriously those of short range will be mainly concentrated towards the middle. Examination of the actual figures for the southern invasion shows that this is very strikingly the case, the average range of all the endemics occurring in the northern half of the South Island being abont a third of that of those occurring to the south. Not only so, but they belong in much greater proportion to the smaller genera of New Zealand, i.e. by hypothesis (p. 71 ) the younger. The long-ranging endemies of the outer zones belong mainly to large genera (of the New Zealand flora).

It is clear that Age and Area can be used with considerable directness in the study of the invasions by which a country has received its present population of plants. 


\section{Summary}

The application of the hypothesis to a study of the way in which a country has been peopled by invasions of plants is illustrated by the case of New Zealand. If a species enter the country and give rise casually to new (endemic) speeies, then, if the country be divided into equal zones, it will generally occur that the endemic species occupy the zones in numbers increasing from the outer margins to some point near the centre at which the parent entered. Applying this prediction to New Zealand it was found that all the genera in the flora showed figures of this type. Further, it was noticed that the points at which the maxima occurred were not scattered casully all over the country, but tended to mass together in three places-northern, southern, and central. The most reasonable explanation of this is that these points represent the centres of corresponding invasions. Curves are given showing the way in which both wides and endemics fall off, from the centres of the invasions, the latter much the more rapidly. As the curves of the southern invasion are much more steep than those of the northern, one may perhaps infer that the latter was much the older (perhaps even a geological period older), and this is confirmed by the fact that it consists mainly of trees, while the southern is composed chiefly of herbs, and also by other considerations. It is clear that Age and Area can be applied with effect in the study of the peopling of a country with plants. 


\section{CHAPTER IX}

\section{OBJECTIONS TO THE HYPOTHESIS}

VerY many objections and critieisms have already been published, and many more are doubtless to follow. A consideration of them, however, shows that in general they are based upon a few general principles, and that a proper understanding of Age and Area, and of the provisos with which it is hedged round, will go far to remove the most of them.

The first few, (1) that the numerical results are accidental, (2) that the figures are not reliable, and will be vitiated by further work, and (3) that the figures can be accounted for by changes in climate and eonfiguration of the countries concerned, require no discussion at the stage which Age and Area has now reached. Far too many facts have been accumulated from too many places, to leave room for them to be seriously advanced.

Another, (4) that the hypothesis is an assumption, has really little bearing upon the matter. Natural Selection, and many other fruitful hypotheses, are also assumptions, and Age and Area has already led to new discovery.

Some writers show a confusion of thought between (5) endemism and endemie species. The former, if it oecur in a country, is a sign of age, for time must be allowed for it to appear; but the cndemic species are in general the youngest in the country, in their own groups of affinity.

Some say (6) that the wide dispersal of the wides is due to their wide dispersal outside the country, but give no reason for this. It utterly fails, however, to explain the graduated distribution of the wides, those that occur farthest away showing (on the average) the maximum local dispersal (cf. the CeylonPeninsular-Indian species with the wides of greater range, or the speeies that reach the outlying islands of New Zealand with those that do not). To explain sueh cases the most improbable supplementary hypotheses have to be adduced (126, p. 16).

A number of objections arise from the attempt to apply Age and Area to individual cases; such are ( 7 ) that there are many exceptions-species whose area does not at all represent their age, and the like, (8) that species may die out or be killed out in part of their area, (9) that one cannot properly eompare a single 
species to its nearest relative, (10) that a species may owe its wide range to being part of a wide-ranging association of plants, (11) that a species that occurs in a greater number of associations must have taken longer to spread than one that only occurs in one, (12) that climate produces great effects upon the distribution of a species, (13) that altitude does the same, (14) that latitude also does the same, (15) that of two species with equal latitudinal range the one with the greater altitudinal range will be the older, and so on.

It has, I hope, been made clear above that the distribution of any one species depends upon very many factors-method of dispersal, acclimatisation, suitability to the society of plants in which it may find itself, local adaptation, barriers of all kinds, whether physical, climatic or ecologieal, individual habit of the species itself, and so on, as well as upon mere age. With so many factors active, it is clear that probably in no single case does age alone determine the area upon which a species occurs. In exactly the same way, when a baby is born, it is very rarely possible to say of what complaint that baby will ultimately die, yet if one take a large number of babies, living in the same country, one can say that just so many will be accidentally killed, so many will die of tuberculosis, and so on. In India one can say that just about so many deaths from snake-bite will occur in a year; and there are many other similar cases of reasoning upon large numbers, where in the large figure and the long run the result is certain, yet cannot be predicted for the individual. And the same is the case for Age and Area, and such objections as just quoted have really no bearing upon its validity or otherwise.

When one takes groups of ten allies, and compares them with other related groups of ten allies, for instance, ten Mimosas with ten Ingas-nearly related genera in the same family, living under much the same conditions-the effects of age will show clearly, because all the other factors in dispersal will either be pulling the same way upon all, or will cancel one another out by pulling in different directions. Ten herbaceous Compositae may occupy an area $X$, and ten woody Dipterocarpaceae may occupy the same arca $X$, but the two are not comparable. In the former case, the herbaceous habit implies many more generations in a given time, and therefore many more opportunities of dispersal; the parachute mechanism of the seed-dispersal enables it to travel better; the fact that herbs of this kind grow in the open 
also enables dispersal to be more rapid, and so on. The two cases are quite incomparable. But if the ten Compositae be compared with ten other nearly allied Compositae, then the effects of the "other" factors will be much the same, and age, which is always pulling alike upon all species, will show its cffects clearly. The greater the number of allied forms taken, and the greater the length of time considered, the more clearly will the cffects of age show.

Other objections come under the head of comparison of unallied forms. For example, it has been objected (16) that herbs must be older than trees, because they occupy greater areas, but that all probability is against this, (1i) that Age and Area shows that new species must have been formed morc rapidly among trees (because there are more of them among the endemie forms), and that this also is against probability, (18) that local endemies are usually unrelated to the wides that grow beside them, and are often very unlike them, and so on. What has just been said about comparing groups of allied forms only really covers most of these, and a reference to such works as Hooker's Flora of Nez Zealand, or other systematic works, will show that a great deal too much has been made of the supposed differences between the endemics and the wides that accompany them. In the great majority of eases the two are allied, and if they were unrelated, it would be a very remarkable thing that they should show the numerical relationships that we have seen to exist. There are a considerable number of endemic forms, especially within the range of the last glacial period, for example in temperate North America, which are not related to the wides beside them, but when groups of tens are taken, these are quite lost in the erowd, or in some cases ean not find a erowd to which they can be attached. There are, however, at most about 400 such cases in North America ${ }^{1}$, and the endemics of most of the world, especially the countries south of the Tropie of Cancer, are to be counted by tens of thousands. Only very rarely, again, will one find a group of ten allied herbs, with a group of ten allied trees closely related to it. In such a case, which will very

1 Sinnott (95) instanees as endemics of this class Carya, Plancra, Maclura, Garrya, Sassafras, Xanthorhiza, Baptisia, Nemopanthus, Ceanothus, Dirca, IDionaca, Hudsonia, Rhexia, Ptelea, Dccodon, Iloustonia, Symphoricarmus, etc., pointing out that many oeeur as fossils in the Old World, and that they inelude most of the woody endemics of north temperate Ameriea. In dealing with such, one must, as already pointed out, inelude the "fossil" area, and in any ease they are lost in the crowd when not considered singly. 
seldom occur, comparisons on the basis of age will be impossible. But a group of mixed trees and herbs may be compared with another allied group of the same general composition.

These considerations also dispose to a large extent of the objection (19) that age is only one factor of many, and (20) that enough is not allowed for the action of other factors. Age is, as has been pointed out above, only one factor, but it is a factor whose action can be shown in figures which no one as yet has been able-has even indeed attempted-to explain upon any other supposition. If one were dealing with individual species, one would have to allow for each individual factor, and could never, or very rarely, be in a position to say how much was due to this, and how much to that. No one has yet bcen able to reduce to figures the effects of any of these factors, and their action is still accepted upon a priori considerations. The effect of my work is to disentangle from among them the effect of age, and to show that it is very considerable indeed; and this should of itself make much easier the study of the effects of the many other factors that take part in the dispersal of a species about the globe.

The next group of objections is to the general effect (21) that endemic forms, whether species or genera, are local adaptations, suited expressly to the spots in which they occur. In one sense this objection is a truism, for if a species or genus were not suited to the spot where it occurred, it would die out there, so that if it were endemic to a very small locality, it might casily disappear from the earth. But the general explanatory idea which lies behind this objection is very hardly pressed when it comes to explaining such a series of species, arranged in "wheels within wheels," as those of Ramunculus in New Zealand (p. 156), or Doona in Ceylon (p. 153), and breaks down altogether when it is once realised that endemic species and genera, as will be more fully shown below, represent only a special case of species and genera in general. It is not possible to explain upon any theory of adaptability the varying areas occupied, and occupied in a way that can be reducẹd to statistics which agree for each family and area. Onc cannot suggest conditions that will overlap like the rings in a shirt of chain mail, as do the genera and species (p. 56). Nor will this view explain the increase of cudemism as one goes southwards, or outwards from the continental areas. Nor will it enable us to do any prediction about geographical distribution whatever, though Age and Area has 
already been successfully used in this way nearly a hundred times. Nor, again, can it explain such cases as Castelnavia, with seven species in an area where there are no differences in conditions (126, p. 15). Above all, it will not explain the mechanical way in which every group of species behaves like every other, as has been pointed out above.

The next group of objections takes the general position that endemies are mostly the relics of pre-existing floras; the first is (22) that endemies are usually relicts in the sense of species that are dying out; that they are old species driven into quiet nooks or odd corners; the most recent statement to this effect is that Very many endemies owe their limited distribution to the eircumstance that they are remnants of comparatively unsuccessful types which have been exterminated elsewhere, and which even in these isolated floras are waging a losing fight against more vigorous and adaptable newconer's.

This is undoubtedly true of a great number here and there especially in the north temperate zone (particularly North America and China), where the influence of the last glacial period was severely felt, and so far as the first part of the sentence (to "clsewhere") is concerned. We know from geological evidence that in the Canaries and Madeira there are many generic survivals of the Tertiary flora now extinet in Europe itself, but we have no proof that they are dying out there without change of conditions. Age and Area has always insisted upon the reservation "so long as conditions remain reasonably constant," though erities and opponents frequently ignore this. Guppy has recently $(50)$ shown that the endemics of the Canaries which may be looked upon as Tertiary relics oceupy more space in the Canaries than do the more recent Mediterranean type of endemies, while they also extend to the Azores or Madeira, which the latter do not. As these Tertiary relics are mainly woody, the conditions are naturally against them so soon as man has settled in the country (cf. p. 27).

When a species is really dying out, the fact is usually due to some change of conditions; and, as we have shown above, dispersal is usually so slow and to such small distances that the species may easily be eut off by the changing conditions, and then gradually exterminated, through no fault of its own. Cupressus macrocarpa is probably the most generally suitable Conifer for average sub-tropical climates, and is planted in millions all over the warmer parts of the world; yet it is dying 
out in its only natural habitat, the Monterey peninsula of California, probably on account of the secular drying of the Californian climate.

The comparative rarity of seriously broken areas of distribution among endemic forms, especially south of the influence of the last glacial period, is much against any very large amount of dying out. One would not expect a moribund species to retain its area intact-though it is true that with the Cycads, often supposed moribund, this is largely the case.

It is very hard to suppose that a genus would choose certain spots upon the globe where its species should die out in large numbers, yct the facts of distribution require that this should be so under this explanation. Why should the Senecios retire to die, in large numbers, to Mexico, California, Bolivia, Peru, South Africa, Australia, etc.? The larger the genus the greater the number of local species, and the greater the number of places in which they occur.

As this is the principal argument brought forward by opponents of Age and Area, it will be well to bring up other points. If all or most endemics are to be regarded as relics, then they must evidently be, on the whole, older than the "wides," and the reply to another objection (23) that greater distribution may be due to youth, rather than age, may be given at the same time.

The great difficulty is to explain why, in most countries remote from the influence of the last glacial period, the "dying-out" is purely mechanical. Every family and genus behaves in the same way, whether it has or has not wides, and whatever its habit of growith, its origin (local or foreign), or its distribution generally. The general type of distribution-in "wheels within wheels"-is shown below (Chapter xv) in several maps, and not even the most determined upholder of a general dying-out can interpret these maps into a support for his position. There is no doubt that a large number of species and genera in the north temperate zone may be interpreted as dying out (cf. footnote, p. 86), but they are insignificant in number beside the endemics of more southern regions. North-temperate America has perhaps 400 , but Ceylon alone has 800 endemies, and Brazil perhaps 12,000. The latter country has 240 endemic Eugenias alone.

A still greater difficulty for the supporters of general dyingout is to explain why there should be many more endemics at the point of death (VR in Ccylon, for example) than there are a little further removed from it $(\mathbf{R})$, and more of these than of 
those still further away (RR, RC, and C, in diminishing numbers as one goes up the scale). This is a general rule for all endemies of the tropics and the south, and is impossible to explain on any theory of dying out.

Yet another difficulty, considered below in Chapter $\mathrm{xv}$, is to explain why the endemics should belong in larger proportion to the large and "successful" families and genera than to the small and broken ones which we have been accustomed to consider moribund.

Or again, why should those genera, like Gunnera, in which there are no wides at all, behave exactly like those in which there are such? And why do not the moribund species congregate in special regions, so to speak, reserved for derelicts, instead of choosing each its own special location? Why should many Eugenias in Ceylon choose each its own mountain upon which to die?

To these one may add the following notes and queries, which if not successfully answered, are very fatal to the view that endemics are chiefly relicts:

(a) How, on the view that endemics are relicts, is it possible to predict what has already been successfully predicted by the aid of Age and Area?

(b) How are the faets of the regular graduation of speeies, of narrowly loealised endemics up, and of wides down, to be explained at all?

(c) Why is there no difference in behaviour between endemic genera and species?

(d) Why does a genus behave in just the same way in New Zealand (for example), whether endemic with small area, endemic with large, endemic in New Zealand, endemic in New Zealand and islands, endemic in New Zealand and Australia, or endemic in New Zealand and the rest of the world?

(e) Why are the endemics of the same order of rarity whether there are or are not wides in the same genera?

$(f)$ Why should the islands round New Zealand have more endemics the more wides they have $(129$, p. 332)?

(g) Why are the endemics of New Zealand least numerous at the ends of the islands and not in the middle, and the wides the same (128, p. 201)?

(h) Why do the endemics that reach the ends of New Zealand range on the average so much farther than those in the middle $(127$, p. 448$)$ ? 
(k) Why are the endemics still less numerous in proportion on the islands surrounding New Zealand than on New Zealand itself, and the wides more numerous? (N.Z. Wides/Endemics 301/902, Kermadecs 45/25, Chathams 69/76, Aucklands 27/72.)

(l) Why do the endemies of both northern and southern invasions of New Zealand taper down in number with the wides, but much more rapidly, so that in the case of the southern forms they are actually less numerous than the wides in some zones?

( $m$ ) Why, if endemies are being driven in by the wides, do their areas almost invariably overlap and why are there practically no broken areas among them?

(n) Why do the Ceylon-Peninsular-Indian species show a range on the average intermediate between the Ceylon endemics and the wides?

(o) Why are the species endemic to New Zealand and the islands so common in New Zealand, more so than the average of the wides in that country $(\mathbf{1 2 9}, \mathrm{p} . \mathbf{3 3 1})$, and why are the wides that also reach the islands yet more common again?

$(p)$ Why do endemics on the average occupy so much larger an area in New Zealand than in Ceylon, even proportionately to the size of the country (127, p. 454)?

$(q)$ Why do fern endemics, which must on the average be older, show greater distribution areas than angiosperm endemies $(\mathbf{1 3 0}$, p. 340)?

$(r)$ If the wides are the younger, there is no reason why they should be specially closely related to the endemies, and why should they show the same arithmetical relationships thronghout?

$(s)$ Why do endemies and wides, in the majority of eases, belong to the same genera?

(t) Why are the cndemics so often on mountain-tops and why do separate species of endemics occur for different mountains near together (121, p. 132)?

(u) Why do the endemics belong principally to widely spread and successful genera, and this even more on very isolated islands like the Chathams? The Chatham endemics belong to Geranium, Aciphylla, Pseudopanax, Corokia, Coprosma, Olearia, Cotula, Senccio. Sonchus, Cyathodes, Myrsine, Gentiana, Ieronica, Carex, Poa, Festuca. The Auckland endemies belong to Kanunculus, Stellaria, Colobanthus, Geum, Azorella, Ligusticum, Coprosma, Olearia, Celmisia, Cotula, Abrotanella, Gentiana, Veronica, Plantago, Urtica, Bulbinella, Hierochloe, Deschampsia, Poa.

(v) Why does the maximum of the wides, in Ceylon, New 
Zealand, etc., coincide with that of the endemics, and both decrease together from that point, the endemies much the more rapidly?

Other formidable arguments against this view are given below, in Chapters Xv, Xri of Part II.

The hypothesis of youth (within a country) and area can only bc accepted if one be prepared to accept with it the numerous absurdities to which it leads. In particular, it involves a most remarkable amount of rising and falling in the scale of area of distribution, for which we have no warrant. The distribution of the plants of the outlying islands of New Zealand (p. 66) seems to provide a very strong case against it, for how can youth ensure that a species shall reach more of these little islands?

"The families Tristichaceae and Podostemaceae also afford an excellent test case for the question of age or youth, for owing to their peculiar morphology one can say with reasonable approach to certainty which are the older forms. He would be a bold man who would say that such forms as Lawia in the one family, or Castelnavia in the other, with their violently dorsiventral structure, shown in the lichen-like regetative body and the extraordinarily modified flowers, were older than such forms as Tristicha or Podostemon, which are almost radially symmetrical, and come near to the ordinary type of submerged water plant. Yet the latter are widespread and almost universal, covering the whole range of distribution of families, while the violently dorsiventral forms are all endemie to comparatively small areas, Lawia, for example, occurring from Ceylon to Bombay, Castelnavia in the Araguaya and one other river in Brazil. It is impossible to talk of local adaptation in these plants, as I have elsewhere pointed out (124); there is nothing to be adapted to. The non-dorsiventral forms are just as common as the dorsiventral, whether in slowly or in swiftly moving water" (quotation from 128).

Mrs Arber (4, p. 306) has brought up a parallel case in the genus Callitriche.

Some, while admitting that in general endemics are not relicts, say (24) that the endemics of mountains, at any rate, are usually such, especially as the wides, not infrequently, do not ascend as high as they do. This latter fact is a strong argument against the explanation often given of mountain endemics, that they have retreated upwards to escape the competition of the wides in the plains below, for it would be very remarkable if they 
should at once, so to speak, retreat as far as possible beyond pursuit.

There is no doubt that the species of mountain chains often show much less affinity to the species of the lowlands, than do the species of islands to those of their mainland. In some cases there can be no doubt that such species of mountains are relics of a flora that once occupied the lowlands, as in the case of the many aretic species that oecur upon the mountains of the north temperate zone. In other cases the difference may be simply due to the fact that, as explained on p. 37, a mountain chain may act as a road for migration to the plants of another country, which would not otherwise be able to enter the country under consideration, by reason of unfarourable eonditions. In the mountains of Ceylon, India, Java, and most tropieal eountries, one finds two types of vegetation at least. There are the more northern types, such (in Ceylon) as Thalictrum or Heracleum, which may be relies of a former more northern type of vegetation in the plains, though they are more probably invaders by way of the mountains; and there are the more numerous forms like the Eugenias, the Impatiens, or the Memecylons, which are related to those growing at lower elevations.

While it is elear that many mountain endemics are relicts, and probably many more are local adaptations, the former especially within the range of the last glaeial period, the evidenee for relict nature in the tropies and the southern sub-tropies is not sufficiently clear to make it safe to regard any of them as such without some direet evidence in favour of sueh a eonclusion.

Others, again, maintain (25) that very many endemies are waging a losing fight against more vigorous and adaptable newcomers. This is no doubt the ease with many woody endemies in North America, etc.-genera which once were widely spread, and are now left as representatives of a former woody flora in a land of herbaceous vegetation. But to say that this latter is more adaptable seems rather stretching a point. Were its members turned into a forest they would die out there much sooner than the woody endemics seem likely to do as things are. The dying-out is owing to change of conditions, which has been earefully guarded against in the statement of the rule of Age and Area given above.

Lastly, it is maintained that in general (26) endemies are relicts in the more literal sense that they are remains of floras that have disappeared elsewhere, in whole or in part, but are 
not necessarily dying out. This is a perfectly sound position, but is not really an objection to Age and Area, when this is properly understood. If a genus has 5 species in one region, and an outlying species 6 in another, and one ean produce geological evidence of former connection, whether by living or by extinet species, then there is no doubt that 6 is a relie in the sense of this objection. One must simply take the whole area covered by 1-6 as the area of the genus in consideration of any matter by Age and Area. This type of relie, however, is really rather uneommon.

A more frequent type is that so often found in temperate North America, where the mountain chains, running north and south, did not offer such a barrier to the ice and cold of the glacial period as in the Old World. Sinnott (p. 86, footnote) instanees Carya and others, pointing out at the same time that many occur as fossils in the Old World, and that they include most of the woody endemics of north temperate America. Such endemies, showing wide taxonomic separation from the rest of their surrounding forms, are, however, comparatively rare, and as already pointed out, in dealing with them from an Age and Area point of view, one must include the "fossil" area.

In the tropies, or in the southern hemisphere, on the other hand, and even in the north among the herbs, which Sinnott has shown to be in all probability very much younger than the trees and woody plants, and which are probably mostly forms that have spread there since the glacial period, the endemics are usually closely related to the forms around them, whether other endemics or "wides." It would be absurd to apply the "relic" explanation to such a case as Doona in Ceylon (p. 153) or Ranunculus in New Zealand, and yet on this supposition Ranunculus in that country, or at any rate I'eronica, must be considered as a relic, though the vegetation of north temperate type represented by Ranunculus, Veronica, and many other genera is a very marked feature in the total vegetation of New Zealand.

Another very serious reply to this objection is contained in the faet that the endemics of a country remote from the effects of the glacial period usually belong to the large and what have usually been considered the "suceessful" genera, as has been pointed out elsewhere (Chapter xv of Part II).

The next objection $(27)$ is based upon the supposed rapid spread of introduetions, and is urged to show that dispersal 
within a country, when a species first arrives, is rapid, not slow. But we have already seen that the evidence of introductions (p. 24) forms a very broken reed upon which to lean. It only shows that the spread may be rapid when the conditions have been changed, and cannot be twisted into meaning that spread is always rapid even in such circumstances. Even in Ceylon or New Zealand, only a small proportion of the introductions have spread rapidly, although the conditions have often been changed. Nowhere is there any indication of a whole flora, or great part of it, spreading in this rapid way, whereas in the case of an island like Great Britain, near to a continent, the local flora is simply a somewhat reduced edition of that of the continent, and the flora of such an island as Ireland, a little farther out again, is a reduced copy of that of Great Britain. One may even go further, and find upon littlc islands off the coast of Ireland a still further reduction of the Irish flora.

A careful consideration of what has been said in Chapters II and $\mathrm{v}$ will lead to the conclusion that in general the dispersal of plants into new areas must be exceedingly slow, so slow that as a general rule one will notice little or no progress in a lifetime of observation. One cannot regard this objection as sound.

An objection often brought up is (28) that in many places characterised by the presence of endemic forms there are many genera composed of endemic species only. This very striking fact has been termed "swamping" by Dr Simnott, who proposes a hypothesis to the effect that "the longer a successfully invading species remains in an isolated area...the less eommon it tends to become until it is actually 'swamped' out of existcnce-quite the reverse of the 'age and area' idea." He suggests that "some may simply be exterminated outright, and some by continual crossing with new forms may ultimately lose their specific identity." Cf. also Guppy (44, Chs. xxI-XxiII), who gives full accounts of it.

On the whole, the older and more isolated the region, the greater is the proportion of such genera. Ceylon has 89 of 1027 (apart from actually endemic genera); New Zealand has 127 of 329 , the Hawaiian Islands have 101 out of 256 genera.

There is no doubt that the fact that genera are common in these floras with endemics only, and no wides, is a feature which requires explanation; but as the genera with endemics only behave exactly like those which also contain wides, or like the endemic genera, the fact that it cannot at the moment be satis- 
factorily explained ${ }^{1}$ does not in the least militate against the hypothesis of Age and Area. Age and Area may seem to disagree with other views as to this or that, but it is based upon very clear and definite figures, which must either be controverted or explained in some other way-they are far too striking to go without any explanation. It is somewhat difficult to controvert figures which simply represent bald facts, and if Age and Area be not accepted, it is consequently necessary to have some other hypothesis, which must be mechanical, owing to the fact that the figures show such mechanical regularity.

The objection is based largely on the undoubted fact that the proportion of "swamped" genera is larger in the more outlying of the big islands. But that mere isolation is not sufficient as an explanation would seem to show in the fact that in the very isolated islands round New Zealand the proportion is not so high as in New Zealand itself. In New Zealand 127 genera out of 329 show it, in the Kermadecs only 8 out of 62 , in the Chathams the same, and in the Aucklands 12 out of 64 . In none of the islands is the proportion anything like so high as in New Zealand, and it is highest in the Aucklands, which were perhaps nearest to an incoming stream of plants (131). On the other hand, the number of genera which are swamped in New Zealand is 13 in the Kermadees, 33 in the Chathams (the most isolated), and 26 in the Aucklands, facts tending to show that the swamped genera were in existence fairly early opposite to the Chathams, and therefore were rather old in comparison to some of the rest, though even in the Chathams the unswamped genera (29) are almost as numerous.

Another test that we may apply is to find the proportion of "swamped"genera in the northern and southern invasions of plants into New Zealand (p. 79). The northern shows 45 out of 75 or 60 per cent., while the southern shows 36 out of 108 or 33 per cent. We have seen that probability is in favour of the greater age in New Zealand of the northern invasion, so that to some extent this speaks in favour of the objection in a general and purely local sense. But as only one herb (Elatostema) is "swamped" in the northern invasion, and all the shrubs but one (Veronica) in the southern, it is, it seems to me, equally possible that swamping may go with woody habit, and further tests are necessary.

1 Small (103, pp. 189, 224) has suggested two explanations, both quite probable; but as the phenomenon (as shown above) does not affect the probability that Age and Area is a correct hypothesis upon which to work, the question may be left out of consideration in this place. 
Of the "swamped" genera, only about half are herbs, while of the unswamped, herbs are 83 per cent. Of the unswamped genera with no endemics, 85 per cent. are herbs, while of those with endemics 80 per cent. are herbs. From these figures it would seem that the evidence is just as good for the connection of swamping and woody nature as of swamping and age.

The Coniferae are probably older than the flowering plants, and as they have no wides at all in New Zealand, this speaks in favour of age, but they are also all woody plants. The Ferns, on the other hand, which are probably older again, show very little "swamping," only 5 genera out of 31 exhibiting this phenomenon. Of these it may be noted that three are the only tree-ferns in New Zealand. The remaining two, and all the unswamped genera, are herbaccous. It is evident that the question of swamping must be disentangled from the question of the relatively greater age of woody vegetation, but inasmuch as woody vegetation in general is probably older than herbaccous, it seems probable that swamping goes to some extent with age.

Actual measurements show that the average range in $\mathrm{New}$ Zealand of one species of a swamped genus is 509 miles, which within a very close approximation is the same range as that of the whole flora of New Zealand, and considerably more than the average range of the total of the species endemic to New Zealand, or New Zealand and its ontlying islands, which is only 446. On the whole, therefore, one may probably say that these "swamped" genera are older than the unswamped.

Further confirmation of this view may be obtaincd from the fact that $\mathbf{4 5}$ of the swamped genera reach the outlying islands round New Zealand, while only 27 of the unswamped do so, though the latter are much more numerous.

There is a possibility that with mere passage of time species may undergo change, and it may be that "swamping" is something of this nature.

An important fact must be noticed in considering this objection, that the genera without "wides" behave just like those that include such. They have (cf. the map of Gunnera in New Zealand, p. 158) similar local distribution; their centres of greatest density are the same; their proportion of species belonging to the different classes (i.e. the classes in order of area) is the same when several genera are taken. If the endemic species of the genera that possess wides are dying out before the competition 
of the latter, then the same thing is going on in the genera that possess none, i.e. they are dying out without competition, and at the same rate, a remarkable fact. If endemics are local species developed in response to local conditions, then it is very remarkable that in the genera where they have not been able to kill out the wides, the latter shouid occupy the largest range (cf. map of Ranunculus, p. 156, or almost any other genus of Ceylon or New Zealand that possesses wides).

What the explanation of "swamping" may be is not as yet clear, though it seems probable that it goes to some extent with the mere age of a genus, especially if of woody habit. But its existence does not in any way prejudice the validity of Age and Area as an explanation of distribution, for the presence or absence of wides makes no difference to the behaviour of genera.

Another objection is (29) that much detailed work is being done in splitting up large and wide-ranging Linnean species into micro-speeies, and that this will destroy the value of my work, as I have dealt only with Limnean species. This, translated into terms of the figures which have been given in Chapters vi-viII, means that species are being removed from the column of "wides" into that of endemies, and perhaps usually to near the bottom of this. The result will not be to undermine my work, but rather to strengthen it. As one of our leading eeologists says in a letter to me, and underlines, "this will be strongly in favour of your Age and Area hypothesis."

It is also objected (30) that speeies with wide distribution are usually found in an early stage of the plant suceession. This is practieally the same as the old axiom of the systematists "simplieity of type goes with increase of area." Later species in a country that is undergoing change of elimate will tend to be adapted to more strictly local conditions, and their spread will therefore be hindered by ecological boundaries. But it is to some extent a single-species objection.

The general objection, never perhaps expressed in so many words, but running through a number of those actually given, (31) that Age and Area does not agree with ecologieal results, is largely answered in what has been said above. Age and Area works over much longer periods than does local ecology, and must not be applied to single speeies, and it must not be forgotten that it is not a mere unsupported hypothesis, with no 
facts to back it. It rests upon a large number of very clear and definite figures, which are so consonant with one another that they must be explained; they cannot be passed by as unimportant, any more than can those upon which Mendel's Law is based. Further than this, Age and Area has been used as the basis for numerous predictions, all of which have proved to be correct. Unless, therefore, some other hypothesis can be found to explain the facts, and make the predictions, and that a mechanical hypothesis, on account of the mechanical regularity of the figures, Age and Area must be regarded as holding the field for the present.

Ecological factors work at right angles to the age factor, to a considerable extent, and on groups of allied species, taken over a long time, their influence will then rarely be visible, as regards total areas. The objections of the ecologists should, it seems to me, largely disappear when they fully realise the meaning of the careful provisos with which Age and Area is hedged about. Not only are there those already considered (groups of ten species, and allied species), but it is also pointed out that conditions must remain reasonably constant. A serious change of conditions is bound to make a great change in the dispersal rate of the plants subject to it. If it only comes after the plant has already spread into the neighbourhood affected by it, it will probably make little difference, unless it reach the margin of the arca to which the plant has reached. Merely to cxterminatc a plant in a portion of its range does not affect the total as marked by the outlying stations.

Further than this, it is expressly stated that great modifications may be introduced by barriers, including ecological changes, changes of climate, and the like. All these provisos, taken together, seem to me to make sufficient allowance for any possible ecological influences, and the fact remains, as just stated, that the figures, which are incontrovertible, go to show the great, and indeed overwhelming, effect of mere age, when working with a group of allied species over a long period.

As has already been pointed out several times, age in itself effects nothing, but the average result of the opcration of ecological and other factors is so uniform, when one works with long periods, that the average rate of dispersal is also very uniform. Barriers may of course completcly stop it, but usually, perhaps, only when they are physical, or due to such a cause as 
a very marked alteration of ciimate. Ordinary ecological barriers, which most often, perhaps, are not very broad, will usually only be able to check it. The check may be long-lasting, but often the succession (pp. 51, 20) which usually occurs in plant societies may give opportunity for passage. Further, by working with groups of ten one allows for chance differences, and by working with groups of allies one obtains groups upon which all the various factors will probably operate in a more or less uniform way, so that their rate of (total) dispersal will be more or less uniform.

Finally, one writer does not like big changes; (32) "if the camel can go through the eye of the needle, the gnat can follow." In other words, presumably, if age can produce such effects, the various later conclusions to which we shall presently proceed will present little difficulty. But if large changes were not sometimes made in our way of looking at things, progress would be remarkably slow. Even if the new point of view is not permanently adopted, it will do no harm to spend a little time there.

In conclusion, it may be noted that many of these objections will perhaps cease to be urged in view of the interesting facts to be brought up in the next few chapters, facts which will quite possibly educc an entirely fresh set of objections. 


\section{PART II}

\section{THE A PPLICATION OH AGE AND AREA TO THE FLORA OF THE WORLD, AND I'TS IMPLICATIONS}

\section{CHAPTER X}

\section{THE POSITION OF THE AGE AND AREA THEORY By H. B. Guppy, M.B., F.R.S.}

$W_{E}$ would sometimes infer that there is only one way of regarding the central problem of Plant-Distribution. If this were so, distribution would stand alone among the great studies of plantlife, and it would be particularly unattractive and uninteresting. Generally speaking, the more numerous the standpoints, the more complete will be our grasp of the problem. The surveyor who has the most accurate conceptions of the extent and outlines of a great mountain range will be the man who has viewed it from the greatest variety of stations, and so it will be with the student of distribution.

The fewer limitations we impose upon ourselves at the start, the better progress shall we make. Some are inevitable, but they should be light easy burdens that do not gall. Thus when we find ourselves constrained to associate our point of view with the story of Evolution, we are at onee confronted with the query as to the kind of evolution implied. What is the genetic sequence in the scheme of the ordinal, tribal, generic, specific, and varietal types? It is possible to hold views in this connection that are as far asunder as the poles. In the case where we begin with the larger groups we have evolution on a plane, or differentiation pure and simple. The basic principle here involved, the change from the Simple to the Complex, from the General to the Particular, from the Homogeneous to the Heterogeneous, is at the back of the development of life on the earth. It is symbolised in all natural systems of classification and in the daily practice of the systematist, and was a part of the faith of the old philosophers. 
On the other hand, to lay down, as the Darwinian evolutionist does, that the order of development begins with the variety, varieties diverging into species, species into genera, and genera into families, is to reverse the method followed in nature, since it implies that the simpler, least mutable, and least adaptive characters that distinguish the great families are the last developed. This could never have been. Nature has ever worked from the simple to the complex, from the general to the particular. Had she followed the lines laid down by the Darwinian school of evolutionists, there would be no systematic botany. All would be confusion. There would be no distribution in the sense in which the term is generally understood, and the plant world would be a world of oddities and monstrosities. This is the view expressed by the writer in his volume of West Indian Observations published in 1917, p. 320 (47).

It is this incompatibility between theory and practice that has given Dr Willis his opportunity. Under the glamour of Darwin's great theory Distributionists lost tonch with old basic principles, and it is as an endeavour to establish the old connections, or as an effort to return to the pre-Darwinian position, which we have largely abandoned or forgotten, that the Age and Area hypothesis will find its place. The vain attempts to bring together ends that could never meet, and the failures to reconcile views that were hopelessly apart, have all prepared the way for a reconsideration of the central problem of Plant-Distribution.

Until we are in agreement about essentials we cannot utilise the evolutionary standpoint for a general view of the subject. The possible standpoints need much further exploration, and several of the oldest have been forgotten. At any time a distributionist is liable to be held up by a query that in some quaint old-time fashion will raise an issue that has been floating in men's minds through the centuries. Distribution bristles with the points made by the old philosophers, and many of our new notions can there be matched. We cannot turn up any of the old abandoned fields of research without unearthing some of these old notions as fresh and as sound as in the days of their entombment. But the query may belong more to our own time. Thus one might be asked for the real significance of the fact that we could found the Institutes of Botany on much the same principles whether we based them on the flora of China or of Peru. One of the implications of a recent paper by Dr Willis (135), in which insular and continental floras are compared, is con- 
cerned with precisely the same point. The question may be unanswerable; but there are those who might see in a primeval jumble of family types the background of the whole story of Distribution. They might regard it as the most signifieant indication of the great antiquity of the higher plants, and they would see in this world-wide mixture of family types the impress of the lost Mesozoic ages on the history of the flowering plants, ages of unceasing revolutionary changes in the relations of land and sea. They would see in this world-spread mixture the materials on which the great laws of development have operated in the later ages. Such would be their standpoint. But the problem may prove to be one for the biometrician; and we may perhaps be able to learn from him in the ease of other world-spread mixtures of organisms of different types the significance of the development of uniform mixtures of types in Time.

There is another way of approaching the central problem of Distribution, and that is best typified in the ease of the goldminer who, guided at first by a faint show of colour in his pan, follows the clue through until he finds the reef. This is pretty much what Dr Willis has been doing for years in the working out of his Age and Area theory. With a history of small beginnings in Ceylon long ago, it is still in the making, and we can watch its development. It is assimilating as it grows numbers of jdeas that have been floating in the minds of biologists for generations, and linking together others that have always been diffieult to place. Its tendeney to unify and eo-ordinate as it develops are two of its striking features. The writer's attitude towards it may be thus stated. Recognising that we had here a courageous and persistent effort to utilise the statistieal method in getting behind the distribution of living plants, the question whether it was wrong in this or wrong in that did not seem to be of primary importance. For years the writer had been approaching the subject of Distribution from the opposite direction, that is, from the $a$ prior $i$ side. Like many a general theory that had not been linked up with the other side the one that he advocated (a theory of differentiation of generalised types) stood still for lack of verification; and there were echoes in his memory of the despairing counsels of those in this and other lands who regarded Distribution as beyond the pale of human endeavour. So that when he realised the possibilities of far greater extension that lay behind the Age and Area hypothesis, the question for him was not whether Dr Willis was right or whether he was wrong, but 
where he was heading for. Here was a daring attempt to get a grip at things from the inductive side, and the question wasWhich among the general theories will prove to be its goal?

But the prospeets of the new theory at the outset were not promising. Botanists had been inclined to regard the statistical treatment of distribution as illusory, and the believers in what Watson termed "Species-arithmetic" and Humboldt named "Arithmeticae botanices" were few. Yet Hooker, with the seer's outlook, took the true meaning of things three-quarters of a century ago when he wrote:

All seem to dread the making Botanical Geography too exact a seience; they find it far easier to speculate than to employ the induetive process. The first step to traeing the progress of the creation of vegetation is to know the proportion in which the groups appear in different localities, a relation which must be expressed in numbers to be at all tangible (57, Vol. I. p. 438).

A generation later, when Hemsley at his suggestion took up the preliminary statistieal treatment of floras in the introduction to his great work on the botany of Central Ameriea (51), Hooker characterised the subject as "that most instruetive braneh of phytogeography." The lode was rich in promise, but he passed it by. How was this?

It is clear from his lecture on Insular Floras (142), and from different letters written in the sixties, that the Natural Selection theory offered to him "the most hopeful future" for an advance on the problems of plant-distribution from the inductive side. In that lecture he also shadowed out a general notion of "Centrifugal Variation operating through eountless ages." It appears almost as a suggestion, but the idea had been evidently floating half-formed in his mind ever since he wrote his essay on the Tasmanian flora in the late fifties. It was the nueleus of a theory of Divergence or Differentiation that aequired more definite outlines as time went on, since it reappears in the intensely interesting account of a talk with Darwin which is given in a letter to Huxley in 1888 (57, ir. p. 306).

We can perhaps understand the long intervals of time now. For the confirmation that such a theory would have derived from a line of researeh instituted on Darwin's lines was denied to him. The two proved to be incompatible. For no inductive process based on Darwin's lines eould have found its goal in a theory of centrifugal variation. "I well remember," Hooker describes in his letter to Huxley in 1888 , "the worry which that 
tendency to divergence caused him (Darwin). I believe I first pointed the defect out to him, at least I insisted from the first on his entertaining a crude idea which held that variation was a centrifugal force, whether it resulted in species or not." Huxley was in the same case. For he held views of the general differentiation of types, and his road that would lead to the discovery of the causes of erolution started from the Darwinian position. That road was barred to him.

The secret of the success of Dr Willis is that he works with limited objectives and is always free to shape his course according to his results. A distant objective with a specified general theory of distribution as his goal might easily have brought him to the ground. As it is, he has struck a wonderful trail that seems to increase in promise as he advances. But the logical outcome of establishing his theory successively for the species, the genus, the tribe, and the family. is a general theory of differentiation. In other words, it will bring him to the preDarwinian position. Once there, he will enjoy greater freedom in his choice of routes and methods, and new and unexpected fields of research will be opened up all around hin. This note may be concluded with a brief reference to a few of the more remarkable features of a theory that is still in the making.

Though the linking up of old ideas that have been without a resting place for generations is mainly incidental, it is none the less significant. I gather from Dr Willis that his "alliterative series," as he terms it, which began with "Age and Area." is increasing in its numbers as his work proceeds. "Thus we have Antiquity and Amplitude, Rank and Range, Size and Space, and several others, some of them overlapping, but cach with its own rariant, and some again capable of considerable extension and amplification. Thus Rank and Range implies Simplicity of Type and Increase of Area, a very old principle long recognised in the theory and practice of pre-Darwinian systematists. Simplicity of Type goes with Variability, another old principle. If, therefore, the simplest organisms of a group are the widest distributed and the most variable (ideas old enough and true enough) it is anong them that we ought to look for examples of genera that have arisen independently in different parts of thcir areas, as in the case of Senecio, the most primitive form of the Compositae. Incidental as such results may be, Dr Willis may well claim that his materials are working for him. Whilst he is following a definite plan, much is happening that was 
neither premeditated nor foreseen. Just as a river wearing its way into a mountain mass unites in a single system widely separated streams by capturing one water-head after another, so the Age and Area theory in its advance is bringing about the coalescence of principles that we have been wont to consider as things apart.

This may be the luck of the trail. But at all events we have to distinguish between the direct and indireet results, and one scarcely knows which will prove to be the most important outcome of this investigation. It is difficult to speak of work still on the stocks, but we will expect to find in the results of the tabulation of the genera of the flowering plants a survey of the distribution of some 12,000 genera over the great regions of the globe. Endemism will figure more as a world-affair than as a peculiarity of localities, and some unexpected results are to be looked for in a treatment of endemism in the mass. Then there will be the story of the monotypic genera that appropriate almost two-fifths of the total of the genera of the flowering plants; and their part in the forming of the curve of all the genera grouped by the number of their species will prove to be a triumph for the mutationists. A closing word may be said of the great labour involved in the preparation of the tabulated results, of the weeks of counting to establish a single point, and of the wearisome recovering of the ground to make some doubtful point assured. Since it was the purpose of the writer to place rather than describe the Age and Area theory more cannot be said here. 


\section{CHAP'TER XI \\ THE FURTHER EXTENSION OF THE APPLICATION OF AGE AND AREA}

$I_{\mathrm{N}}$ most of the work so far published, and in the first part of this book, Age and Area is used only within narrow limits, as applying to the flora of a single given country. But this is a purely arbitrary limitation, and was adopted in order to render less eomplex its application to the problems of distribution; and in this seeond part of the book Age and Area will be applied to genera as well as to species, and to the flora of the world as a whole.

Like Age and Area itself, its twin principle, to which I give the name Size and Space, has also been used as yet in a limited way, e.g. on p. 71, where it is pointed out that genera that are represented in a country by several speeies are likely to be (on the average) older in that eountry than genera that are only represented there by one. The exact graduation of commonness with number of species which is there shown indicated that this prineiple was also eapable of extension, and it is expanded in Chapter xis into the more general proposition that within any circle of affinity, the larger genera will be the older, and when taken in groups of ten allied genera will be older in rough proportion to their numbers of speeies.

This supposition is very strikingly eonfirmed by an examination of the British flora, which shows that the distribution in Britain of the most widely distributed speeies of eaeh genus (on the average of the whole number) varies with the number of speeies that the genus possesses in Britain. The same is the ease with the second, third, fourth, and so on to tenth, most widely distributed species in eaeh genus. Extension of the principle to the whole world is then illustrated by aid of the Helobieae, by referenee to Prof. Small's work on the Compositae (in the next chapter), and also to many other eases given below. The general result, therefore, is to show that Age, Size, and Space (or Area) go together.

In the next chapter Prof. Small shows how Age and Arca can be applied with effect to the distribution of a single family, by dealing with the Compositae. The average generic arca is deter- 
mined for each group of the Compositae, and it is shown that on the whole it increases with the inereasing age of the group as dedueed from phyletic, morphological, and geological considerations. This agreement forms a strong argument both for the general correctness of Age and Area, and for that of the previously dedueed genetic relationships of the different groups of Compositae.

In the second part of the ehapter Prof. Small takes up the applieation of Size and Spaee, showing that it holds very well indeed as a general rule in this family, so that here, as in other cases, "both the average generie area and the average number of species per genus are elosely related to absolute age." Age, Size, and Space go together.

Mrs Reid then takes up the application of Age and Area to the fossil botany of comparatively recent times, espeeially the Pliocene and Pleistoeene. She shows how great have been the migrations to and fro, north and south, of the floras of the north temperate zone, and discusses the applicability of this proved migration to the flora of New Zealand, leaving the question finally open for settlement by geologieal evidence. Discussing then the flora that at one time occupied the complete circle of the north temperate zone, and whieh is now confined to North America or to China, or to both, and often a good deal broken in distribution, she shows that the existing dispersal nay probably be attributed mainly to the effects of the Glacial period.

It is then pointed out that it is this unquestionable faet that a good many existing strictly loealised or endemic speeics are survivors of races that once flourished widely, that offers the greatest stumbling block to the acceptance of Age and Area, but that there is no insuperable difficulty in the aeceptance both of this fact and of Age and Area, for the latter is reasoning from the mass, the former from the individual, and while perhaps 1 per cent. of the grand total of endemie species are relies, the rest are not, and in reasoning about the mass the former are quite lost. There is good evidence to the effect that many or most of these survivals are due to the effeet of the Glacial period, and on the whole, therefore, the verdict is in favour of Age and Area.

Endemism and Distribution of Species are then considered in Chapter $x v$, and it is shown that the phenomena presented by endemic species in their distribution are simply a miniature of those presented by speeies in general, and that the distribution 
of both can be graphically represented by "hollow curves"," like those in the fig. on p. 155 (and cf. clearer figure on p. 174), with very many species occurring upon very small areas, the numbers rapidly diminishing towards the areas of moderate size and then more slowly to those of large size.

In view of these and many other facts brought up, and of which a summary is given upon p. 159, it is no longer possible, except in comparatively rare cases, to regard endemic species either as relics or as special local adaptations; though of course if not adapted to the local conditions as they existed at the time of their birth, they would be promptly killed out by natural selection. The explanation offered by Age and Area, that species of very small area of dispersal are in general young beginners, and that area occupied increases with age, seems the only possible one for the great majority of species. Not only so, but age proves to be by far the most important factor in the dispersal.

In Chapter xvi Endemism and Distribution of Genera are dealt with, and it is shown that the phenomena presented are exactly parallel to those exhibited by species, and that the distribution of endemic genera is similarly a miniature of that presented by genera as a whole. The areas occupied by the genera of a given family are arranged like those occupied by the species of a given genus. There are very many upon comparatively small areas, and many on the areas just a little larger, whilst there are but few upon areas that are really large. As one would expect from a consideration of the hypothesis of Size and Space, one finds that the sizes of the genera themselves (in number of their species) go mainly with the area occupied, so long as one keeps to the allied forms of a single family. The bulk of the genera of very small area are monotypic, or have but one species each, while the bulk of those of very large area have very many species (average 59), those with intermediate size of area having intermediate numbers of species. Plotting of the genera, whether by size or by area, thus gives hollow curves. While the latter represents their geographical distribution, the former obviously represents their evolution.

The same hollow curve type of distribution shows itsclf if one

1 The "hollow curve" arises when numbers are plotted as a graphic curve which are large for the first two or three cases (e.g. in the fig. on p. 174 the first three are 40,15, and 8 , or much more than half the total of 100), and then taper away gradually in a tail (e.g. the remaining 37 are divided among the groups of families from the 4 th to the 29 th). There is a large drop from the first to the second, and from the sccond to the third or fourth. 
sort into sizes the genera eonfined to any section of the world, whether it be an individual island, or a larger area of territory like Africa or South Ameriea, or whether it be the entire world itself. Always there are many monotypes with a rapid drop through the ditypes and tritypes, and a longer or shorter tail of larger genera.

The supposition that endemic genera are usually relics, as well as the other that they are usually local adaptations, must be ruled out of consideration in view of the facts brought up, and the only supposition that at present seems at all feasible is that provided by Age and Area, that in general they are young beginners. This is also shown by the faet that the proportions upon islands in the different families are not unlike the proportionate sizes of these families in the world.

Passing on to Monotypie Genera in Chapter xvir, it is shown that these, which are usually much localised, display the same phenomena. They are very numerous, over 38 per eent. of the genera of the world containing only one speeies each, while there are about 13 per eent. of ditypes, these two therefore eontaining more than half the genera in the world. The proportion of monotypes falls off with inereasing size of area, and the proportions of genera of other sizes bear a definite relation to that of monotypes, showing that to explain these in general as relics or as speeial adaptations would be absurd. They must usually be young beginners.

Not only do these numbers, when plotted, exhibit a beautiful hollow eurve for the distribution into sizes of the genera of the world, but the same thing is shown by every individual family.

Other arithmetical relationships between the monotypes and other genera, depending upon the size of the area considered, are also pointed out.

Chapter xvil deals with the Hollow Curve of Distribution and shows, by summing up what has already been said, how universal this type of eurve is, not only in the distribution of species and genera (endemic or not) by area-Geographical Distribution or Distribution in Space-but in the distribution of genera into groups aceording to their number of species-Evolution or Distribution in Time. It is clearly evident throughout, and usually in a very marked and unmistakable way, and goes to show that Evolution and Geographical Distribution have gone on "meehanically." The former appears to have been organised at the start upon a definite plan, and its further unfolding, and 
the distribution of species about the globe, have been chiefly determined by age, when one is dealing with the mass of species, the various other causes that may be operative-climatic, ccological, geographical, geological, etc.-simply causing deviations to one side or the other, but not permanently diverting the dominant plan. Age and Area obviously, therefore, becomes a corollary of the larger law.

But if this be so universal a rule in plants, it is obvious that it must probably show in animals also, and Chapter xix shows that this is actually the ease, and that it is exhibited as clearly in the animal kingdom as in the vegetable.

The question of Origin of Species is then touched upon (Chapter $\mathrm{xx}$ ), and it is shown that probability is much in favour of mutation as against infinitesimal variation, and that the effect of the recent work upon distribution and evolution deseribed in this book is to make extremely probable the contention that I have frequently put forward, and which is now aceepted by Prof. de Vries, that mutations may at times occur of the necessary "size" to give rise at once to Limnean species. If one such mutation survived in fifty years, the whole existing population of flowering plants could be evolved in eight million years, which is perhaps less than 25 per cent. of the time that has actually been available for, and occupied in, their evolution. If evolution be a predetermined result, then it is clear that advantage as guiding it is ruled out of acceptance, and it is difficult to see, upon this ground alone (though there is strong evidence upon other grounds), how anything but direet mutation giving Linnean species can be effective.

In the following chapter (xxI) Prof. de Vries deals with the relations of Age and Area to the Mutation theory, first pointing out the essential diffe"ence between this and the theory of infinitesimal variation. In the latter there is no change in the genes, or material bearers of characters, but merely a fluctuation or oscillation of the emphasis of the characters about a mean value, so that in one member of a group of plants of common descent a character may be large, in another small, and so on. In the theory of Mutation, the changes have involved the genes, the alterations in these resulting in permanent and usually hereditary differences in the organism.

Prof. de Vries then points out that while Darwin recognised that both mutation and fluctuation might result in new speeies, the material of facts at hand was insufficient for any kind of 
definite proof, and he decided in favour of the latter. The theory of natural selection of infinitesimal variations has, however, met with great and increasing difficulties in explaining the general occurrence of useless characters, or the manner in which natural selection can take hold of the first beginnings of a change. It is now generally recognised that the bulk of the morphological characters by which the systematic arrangement of plants into related groups is carried out have no physiological value to the plant at all.

At this point Age and Area comes in, showing that the dispersal of species is largely independent of their distinctive morphological characters, for even in the youngest of them (those most limited in area) no relation can be pointed out between these things, and yet the conditions under which these very confined species are living must approximate at any rate to those under which they began. One must therefore conclude that specific characters have erolved without any relation to their possible significance in the struggle for existence. Area occupied depends mainly upon age, and not upon morphological characters (of course there are many exceptions); species spread where they find suitable conditions, and the adaptation is not on their side, but in the long run they choose the best environment. Prof. de Vries regards this as being the great proof whieh the mutation theory still wanted for its complete aeceptance.

Finally, a bricf chapter (xxis), which does not lend itself to a summary in advance, is given to show the general bearings of the subject-matter of the book upon the study of distribution. Age and Area, and Size and Space, are both so valid, and ean be so successfully used to make predictions about geographical distribution, and these predictions are so near to accuracy, that it is clear that in general distribution has been mainly governed, positively by age, negatively by barriers (of course including ecological barriers). This being so, it seems probable that a very promising line of work for the present may be the study of invasions of plants, of course taken in connection with ecological investigation into the formation (or disappearance) of barriers. Age, and geographical proximity, again, will have to be taken into more serious account in dealing with taxonomic questions, and there are other directions in which the changes in our methods of viewing problems of distribution that seem necessary may produce considerable effects. 


\section{CHAPTER XII}

\section{SIZE AND SPACE}

$W_{E}$ have already pointed out, on p. 71 , that on the average the larger families and genera in a country will probably be the older there, inasmuch as it is highly improbable that the single species of a genus represented only by one would always arrive as soon as the first species of a genus represented by many. The tendeney will be for the latter to arrive first, and if, as Age and Area indicates, there is but little killing out of species once established, one will expect that the first arrivals will have spread the most. It is obvious, of course, that one must work with averages of considerable numbers to obtain reliable results, but it seems to me that this extension, for which I propose the name Size and Space, may be given to the original idea of Age and Area. Under this supposition one will say that on the whole, keeping to the same circle of affinity, the larger families and genera will be the older, and will therefore occupy the most space. This, however, involves a break with the long current idea, that the larger families and genera are the successful ones, the smaller the (comparative) failures.

This principle obviously follows, once the central principle of Age and Area is recognised, and it is further realised that destruetion of species by natural selection takes place when they are newly born and occupy minute areas of ground, and not when they are once established on a reasonable area. Destruction then, so far as we can see, will rarely happen, exeept in the case of some great change of conditions, such as the secular drying of climate, which (among other things) is apparently responsible for the fact that Cupressus macrocarpa, etc., are now apparently dying out (or rather not expanding) in California.

One may get very good evidence in farour of this view by applying it to such a flora as that of Britain, for which there are good statistics of distribution available. If we take the distribution of the plants by the number of Watson's "vice-eounties" that they reach (37) we get the table on p. 114.

The diminution of the numbers in every line from left to right of course means nothing, for the species are taken in order from first to fifth most widely dispersed. But all the columns also 
Table showing (in the horizontal lines) the average number of vicecounties in Britain reached by the most widely distributed species in each genus of different sizes, and by the second, third, fourth, and fifth, most widely distributed species in each genus.

Average number of vice-counties reached by the

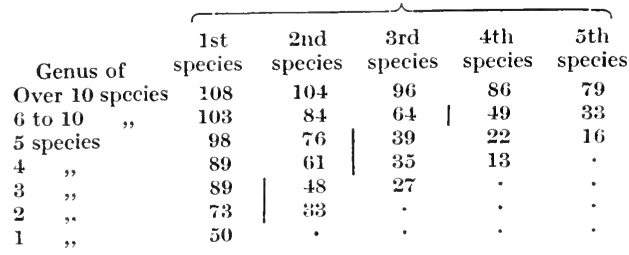

show a steady diminution from top to bottom, whether the first, second, third, fourth, or fifth species be taken; and examination of the remaining figures shows that the rule holds equally well for the sixth, seventh, eighth, ninth, and tenth most widely distributed species. The most widely dispersed species of a large genus (i.e. a genus with many species in Britain) is (on the average) more widely dispersed than that of a genus with 6-10 species, this than that of a genus with five, and so on right down the scale, and the same thing shows with the second, third, fourth, and fifth to tenth most widely distributed species. Nothing but a mechanical explanation can explain such mechanical regularity. If the vital, climatic, or ecological factors had many differences, other than purely local, in their action, one would expect some breaks in the regularity, but there are none. The genera occupy areas in Britain in proportion to their numbers of species there, and age has been the overwhehming factor in their distribution.

As the species of those genera with one species each arerage 50 vice-counties, and those with two 73 and 33 , one may imagine that on the average one species in the latter genera arrived before the solitary one of the former. In the same way (as indicated by the rertical lines in the table) two species in the genera with four or five, three in those with 6-10, and at least five in the larger genera, probably did so.

Such results as this, which could be easily multiplied, go to show that in a given country the area occupied by a genus increases (on the average of considerable numbers) with the 
number of species representing that genus in that country, or, in other words, that the principle of Size and Space is valid. Very little consideration, however, is required to show that in general a genus of many species occupies a larger area than an allied genus of few species. It is not perhaps always realised how close the agreement really is, when one considers a number of allied genera (as with Age and Area) between the size of a genus (as marked by the number of its speeies) and space oecupied. Everyone knows that Senecio or Astragalus, with 1500 or more species, oceupies an enormous area, whilst monotypic genera like Fatsia (Japan), or Welwitschia (south-west Africa), or, again, like Ionopsidium (Portugal) or Kitaibelia (Lower Danube) oceupy small ones, and genera with intermediate numbers of speeies often occupy areas between these extremes. But, on the other hand, people point ${ }^{1}$ to sueh a genus as Mippuris, with one nearly eosmopolitan species, or Veronica, with about 80 speeies in New Zealand, and maintain that there is no comnection between size and space. Now there is no doubt that these exceptions to the rule are very numerous and very important, so that it would be in the highest degree dangerous to draw a rule with limits as narrow as those for Age and Area (ten allied species); but we are, nevertheless, of the opinion that such a rule may be drawn, in sueh a form, say, as "Within any cirele of plants of near affinity, living under similar ecologieal conditions, the areas oceupicd, taking the genera in groups of ten, will vary with the number of speeies in the genus, being large when that is large." It is to be noted that proportionate areas are not elaimed; one would probably have to deal with the genera by hundreds rather than tens for this.

The number of speeies in a genus seems to bear a distinet general relation to the variety of eonditions that exists in its range: for example, water plants in general have much fewer speeies than land plants that cover the same area. It is clear, however, that this is not a complete explanation, for Veronica in the comparatively uniform conditions of New Zealand, or Eugenia or Strobilanthes in those of Ceylon, is represented by muny spresies, while some species are able to stand a varicty of conditions, such, for example, as Cissampelos Pareira or Senccio vulgaris. On the whole, however, greater variety of conditions

1 "There is no neeessary relation between the area a genus eovers, and the number of species it eontains, though speaking generally, monotypes have a restricted area" $(51, \mathrm{p} . \mathrm{xxx})$. 
means greater variety of forms, and as to obtain that greater variety of conditions means in general larger areas, size of a genus and space occupied go largely together.

A good proof for the general correctness of Size and Space is that, as we shall see in more detail below, the further out we go among the islands, the larger on the average do the genera become (in the number of species they contain in the world). Whilst the world average for a genus is 12-13 species, the nonendemic genera found in India contain on the average about 50 species in the world, in New Zealand about 75 , and in the Hawaiian Islands about 100.

Prof. Small (see below, Chapter xirI) has worked out the hypothesis of Size and Space with reference to the Compositae, and his results form a remarkable verification of its correctness in broad outline, and consequently a further proof that however much the distribution of an individual form may be subject to the many and various factors already mentioned, on the average of large numbers the results go very largely in accordance with the laws of probability, so that the distribution, under the steady pull of age, is, on the large scale, much more mechanical than we had previously been inclined to suppose.

If one take again such a group as the order Helobieae ( 7 families) which are chiefly water or marsh plants, and closely related, one finds:

4 eosmopolitan genera, with 12 genera oceupying large areas in the tropics, with $\quad \ldots \quad \ldots$... $\quad \ldots \quad \ldots$

2 genera, temperate and subtropieal regions 26 genera of small area 138 species; average 34

showing very clearly how size goes with space. And yet it is quite possible here as usual to pick out genera that go in the reverse direction; e.g. Zannichellia with one species is cosmopolitan, while Philotria with five is confined to North America.

On the whole, thercfore, the principle we have laid down may be seen to be justified by the facts when large numbers are dealt with. But this is a recognised necessity of all statistical work, as, for instance, in working out results under Mendel's Law.

Now, taking this principle together with Age and Area, it is clear that Age and Size, or Antiquity and Amplitude, if an alliterative title be preferred, go together, and on the whole the larger a genus, the older will it be, within its own circle of affinity. No one would suggest that a herbaceous genus of 100 species was 
of the same age as a tree genus with 100 , but both will follow this principle as far as possible. It goes to show that on the whole, as the area occupied increases, a genus tends to break up into more and more species: only at times does the original specics of the genus cover the whole of its range when it has reached a very large area, and then most often when the conditions are very uniform, as in the case of Zannichellia for example. In the case of the Podostemaceae, where the conditions are perhaps even more uniform, and yet a great many species have arisen, it is due, as I shall hope to show in a later publication, to the fact that the plants are always under the influence of plagiotropism, to the greatest extent possible.

If we take the 28 largest genera in the world (51), we find that about 16 are cosmopolitan in their distribution, 5 are cosmotropical, 4 tropical America, and Quercus Old World, leaving only Erica and Mesembryanthemum, whose large number of species is correlated in both cases with the fact that they grow in South Africa, where the extreme conditions seem to tend to produce large numbers of species, though, as we shall hope to show in later publications, there are other factors in the matter.

Nearly half the species in the world $(69,000$ of 162,000$)$ belong to 1171 genera that occur in both worlds (average 59 species per genus), while only 66,750 belong to 9671 genera that are confined to a single continent (average 7 ), and the 2026 genera of the northern palaeotemperate and the palaeotropical regions. etc. (i.e. widely distributed in the Old World) have about $\mathbf{2 6 . 2 5 0}$ species (numbers from my Dictionary), and form, as one would expect upon the hypothesis of Size and Space, an intermediate between the other two groups (average 13).

Of the 28 large genera named above, the British Isles contain 10, Ceylon 17, New Zealand 11, the Hawaiian Islands 14 and the Galápagos 15. Solamum (1225 species), Euphorbia (750), and Cyperus (400) occur on all five, and four others on four, of these groups, the only ones that occur on none being Myrcia and Mammillaria. Of the $\mathbf{2 4 4}$ genera that contain over 100 species, no fewer than 166 occur in both Old and New Worlds, 28 in tropical America, and 19 in the Old World tropics, leaving only 31 for the remaining smaller divisions of the world, like tropical Asia, which has only 7 .

In the same way, the smaller families usually occupy smaller areas than the larger, and the question arises whether they should be considered of equal rank to the latter. Guppy has 
suggested a grouping of families into classes based upon these principles, for which he has suggested the title Rank and Range, and it is clear that in all future systematic work, the question of area must occupy some attention.

Excellent examples of the application of the principle of Size and Space may be found below, e.g. on pp. 132, 164, 165, $171-2,174,178,187-8,190$, and 197 .

\section{SUMmary}

If species spread in a country mainly in accordance with their age, then it is clear that on the average some of those in the genera represented by most species will have arrived before the first of those in the genera represented by few. This principle may be extended, and under the name Size and Space may be thus expressed; on the whole, keeping to the same circle of affinity, a group of large genera will occupy more space than a group of small. The space occupied will vary more or less with the number of species.

Illustrations of the operation of this principle have already been given in Chapter vil, and further examples are drawn from the Helobieae, and from the flora of Britain, while a good instance is also given by Prof. Small in the next chapter. Many other instances can be found, too, in later chapters. 


\section{CHAPTER XIII \\ AGE AND AREA, AND SIZE AND SPACE, IN THE COMPOSITAE

\author{
By James Small, D.Sc., F.L.S.
}

Age and Area. In a previous contribution to the study of the geographical distribution of the Compositae (103) many of the conclusions were based upon the Age and Area hypothesis as far as the phenomena could be determined roughly by simple inspection of a series of maps which included all the genera. It was mentioned $(\mathbf{1 0 3}$, p. 190) that although this hypothesis was still restricted to "age within a given country, its proved extension to absolute age and total area seems to be only a question of time and application." This extension of the original hypothesis, which was suggested in 1916 by the writer (103, p. 208), has now been adopted by Dr J. C. Willis, and the present contribution consists of a critical analysis of the statisties for Age and Area in the Compositae in the light both of that extension and of previous phyletic conclusions. These previous suggestions were summarised as "the basis of future discussions" (103, p. 313) in a family tree which is reproduced upon p. 125. The statistical data are given in Table I, and were obtained by the following methods. (Table I. pp. 120-124.)

In order to avoid the unbalanced effects of the inclusion of new genera which have been discovered or resuseitated frequently as the result of special studies of only one or a few tribes, the data have been prepared only for the genera included by Bentham in the Genera Plantarum. The area covered by cach genus has been determined approximately in millions of square miles. For this purpose Mikania and Eupatorium have again (cf. 103, pp. 133 and 204) been taken as one genus, and so have Aster and Erigeron as two genera which are "so very closely allied that the transitional species are comparatively numerous and the grenera in these cases are distinguished only by the socalled indefinable characters of the taxonomist" (103, p. 30\%). All genera occupying less than 1,000,000 square miles have been included in Class 1; while 59 other classes have been taken for the other genera, the total area of the land surface of the world being approximately 60 million square miles. This method is, 


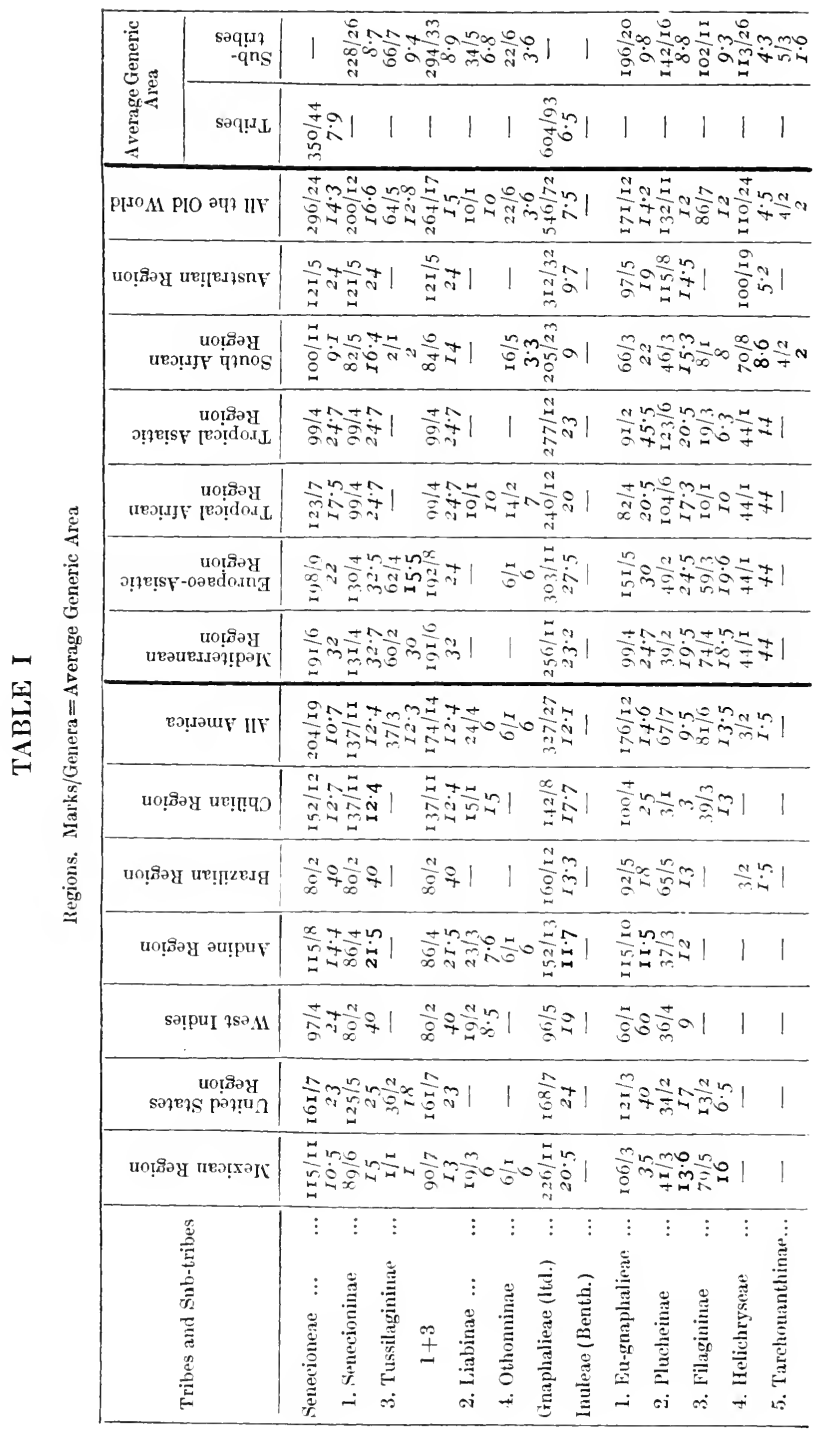




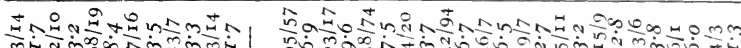

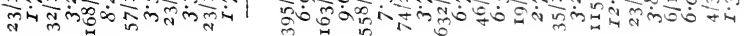

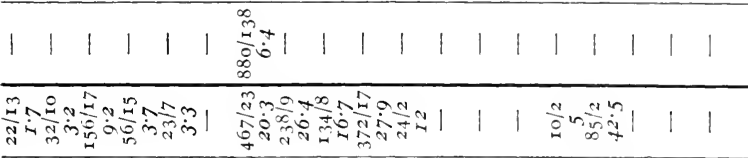

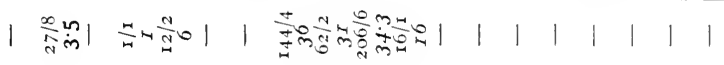

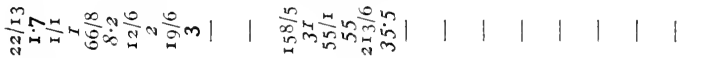

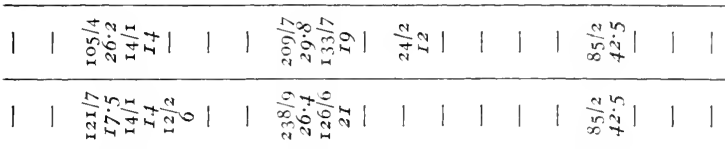

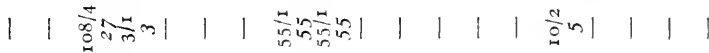

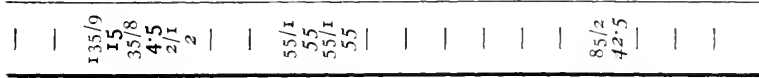

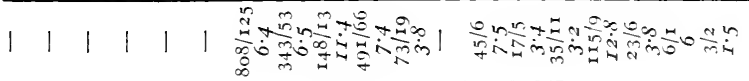

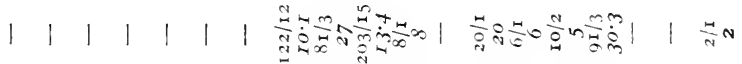

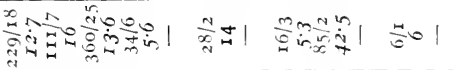

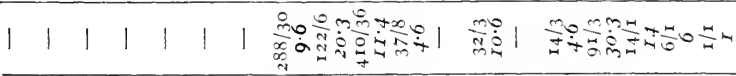

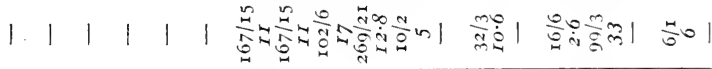

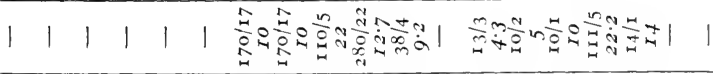

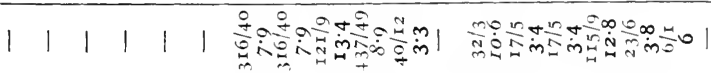

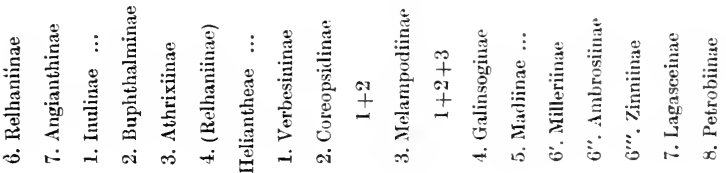




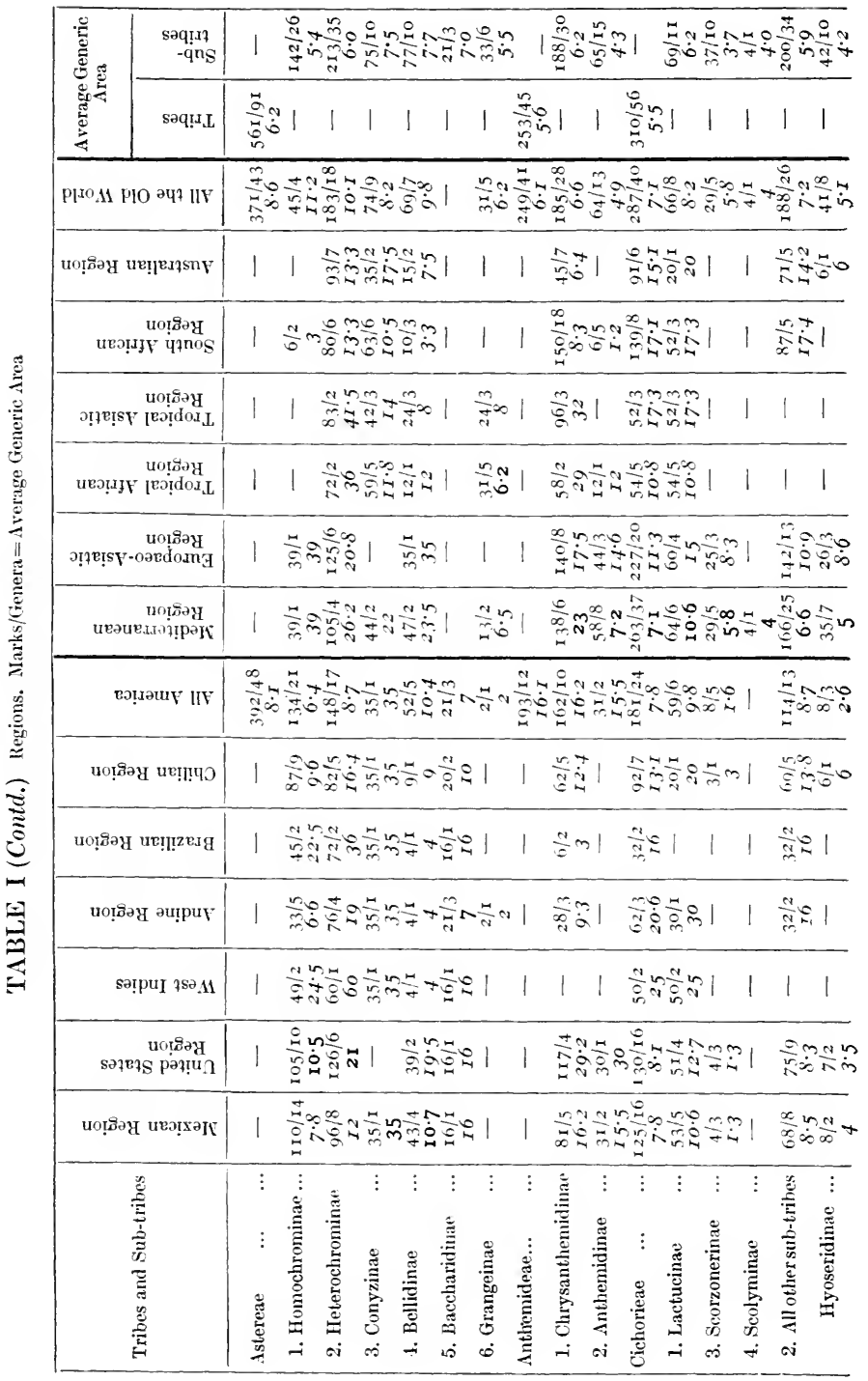




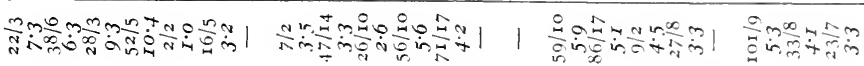

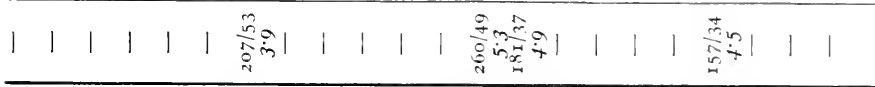

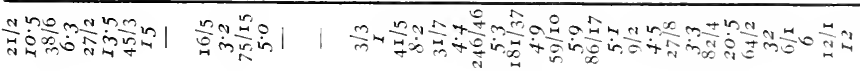

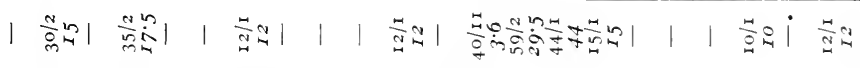

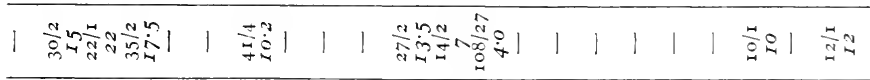

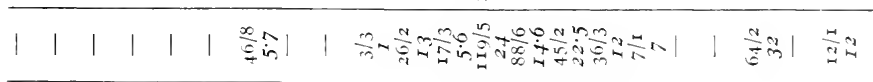

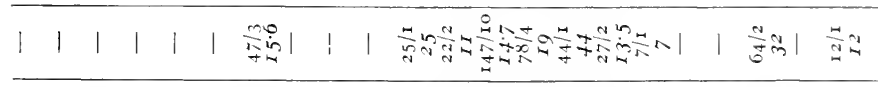

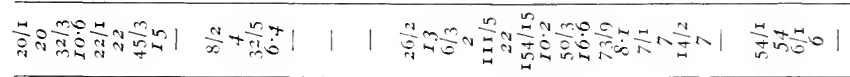

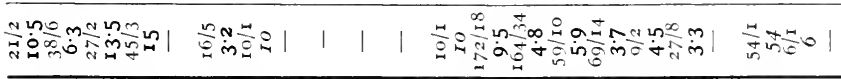

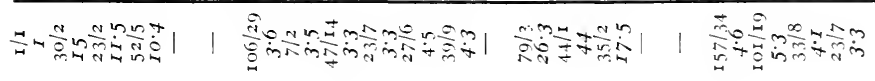

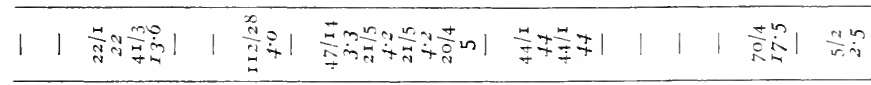

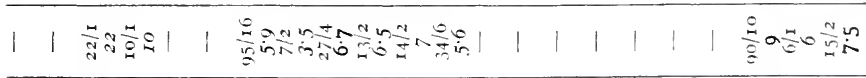

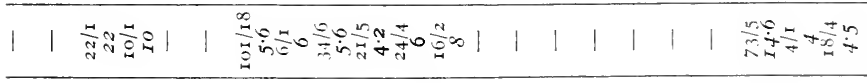

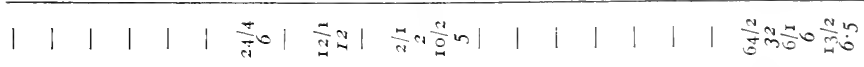

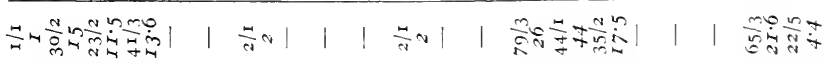

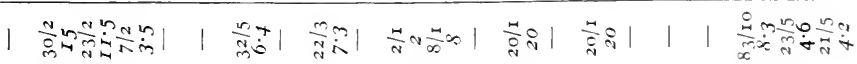

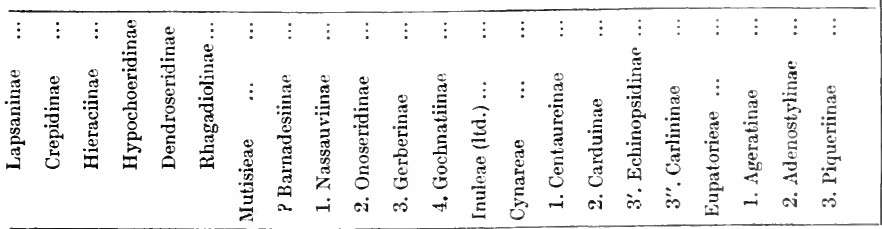




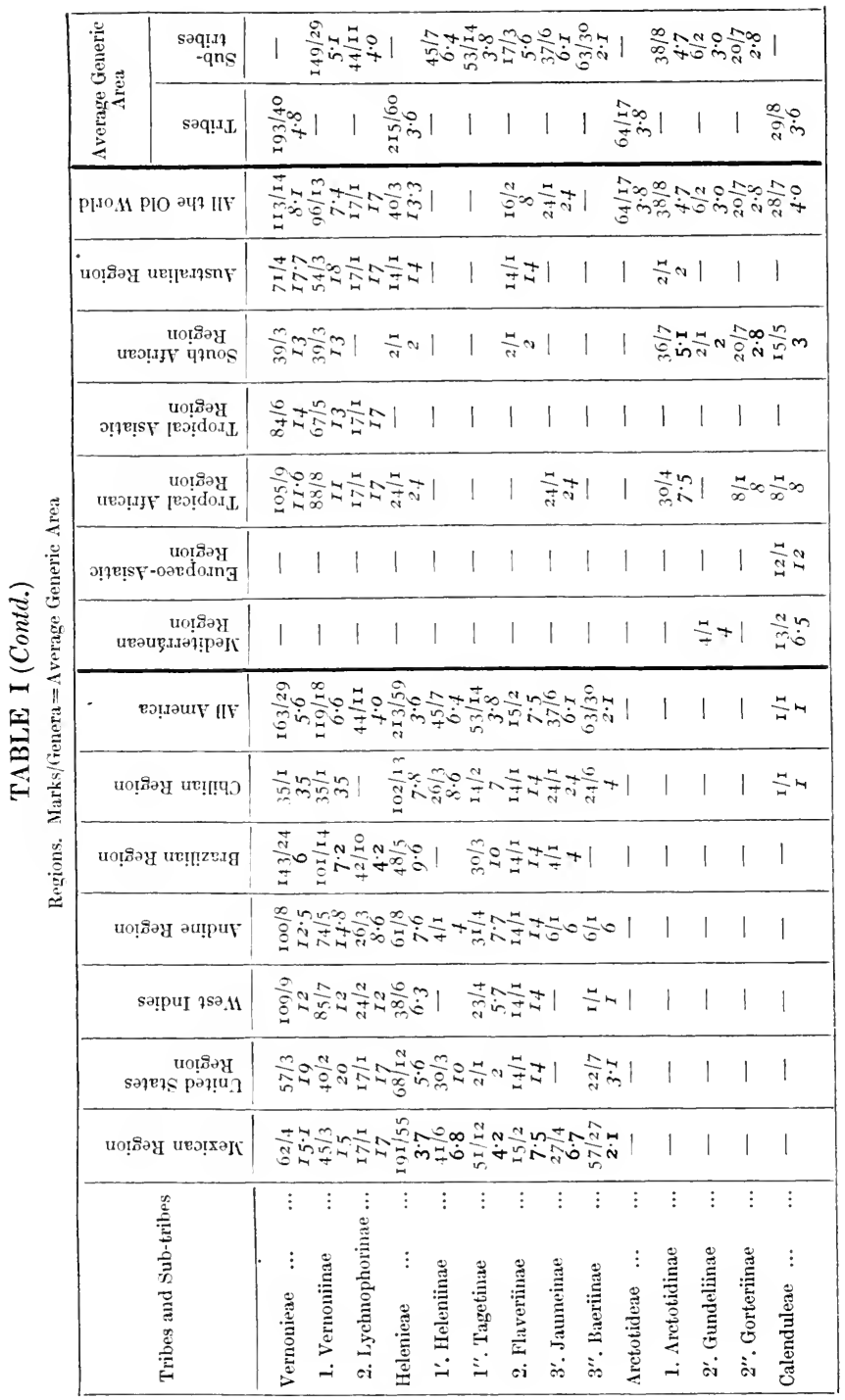




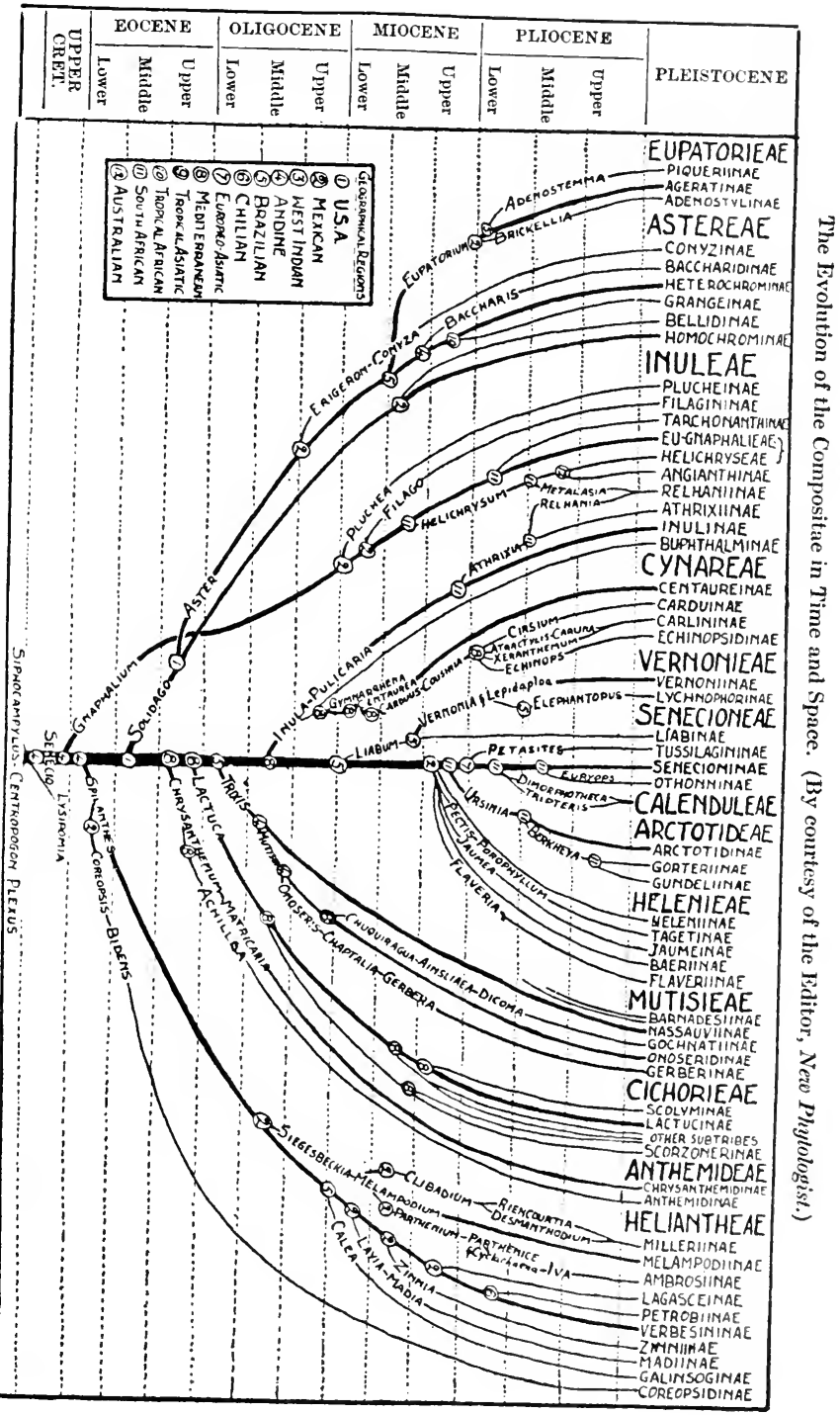


of course, only one of rough approximation, but the inequalities more or less cancel out when the genera are taken in groups of ten or more as specified for the Age and Area hypothesis.

The average generic area has been determined by adding up the marks (= square miles in millions) for all the genera in each group and dividing by the number of genera. This "average generic area" has been determined for each tribe and sub-tribe in the Compositae, firstly, for the whole world (using my own notes); then for the Old World, all America and, in the subtribes, for each of the twelve great regions into which Bentham divided the world in relation to the Compositae (7), using the data given by that authority. The use of two sources for the data has introduced some slight discrepancies in the figures, but the value of the check also introduced by this method makes these slight differences of no real consequence. All these data are presented in 'Table I, and on the whole, taken in conjunction with the relative ages and sources of these groups as previously determined (fig. on p. 125), they form a striking corroboration, both for the Age and Area hypothesis and for the previous phyletic conclusions.

In accordance with the indications of a diphyletic origin of the Inuleae (103, p. 301), that tribe has been given in Table I as two, the Gnaphalieae (limited) which includes the first five sub-tribes (with the Gnaphaliinae divided into Eu-gnaphalieae and Helichryseae) together with half the Relhaniinae; and the Inuleae (limited) which includes the last three sub-tribes together with the other half of the Relhaniinae (cf. fig. on p. 120). The Inuleae as a eomplete tribe may, therefore, be omitted.

Taking the tribes in order of origin, as given on p. 125, we find (Table I, col. 16) that the average generic areas range from $7 \cdot 9$ (Senecioneae) through $6 \cdot 5,6 \cdot 4,6 \cdot 2,5 \cdot 6,5 \cdot 5,3 \cdot 9,5 \cdot 3,4 \cdot 9,4 \cdot 5$, $4 \cdot 8,3 \cdot 6$ and $3 \cdot 8$ to $3 \cdot 6$ (Calenduleae). In this list there are three figures not in series-3.8 for the Arctotideae follows $3 \cdot 6$ for the Helenieae, and 4.8 for the Vernonieae follows 4.5 for the Eupatorieae, but these two pairs of tribes are approximately of the same age (p. 125), and the relative positions could be reversed without any argument. The third figure not in scries is $\mathbf{3 . 9}$ for the Mutisieae, a tribe in which much geographical splitting of the genera largely increases the number of genera in proportion to the area occupied, thus decreasing the average generic area for the tribe.

The gradual increase of average generic area with geological 
age is shown even more strikingly when the mean is taken for the tribes arising in each sub-division of the geological periods; the Mutisieae are then the only exception in the scries (Table II, col. 4). When the mean is taken for each period an unbroken series, running $7 \cdot 2,5 \cdot 9,4 \cdot 6,4 \cdot 3,3 \cdot 6$, is obtained (Table II, col. 5 ).

\section{TABLE II}

\begin{tabular}{|c|c|c|c|c|}
\hline Time & Tribes & $\begin{array}{l}\text { Average } \\
\text { Generic } \\
\text { Area }\end{array}$ & $\begin{array}{c}\text { Average } \\
\text { for } \\
\text { Divisions }\end{array}$ & $\begin{array}{l}\text { Arerage } \\
\text { for } \\
\text { Periods }\end{array}$ \\
\hline $\begin{array}{c}\text { Pliocene } \\
\text { Upper } \\
\text { Middle } \\
\text { Lower } \\
\text { Miocene } \\
\text { Upper } \\
\text { Middle } \\
\text { Lower } \\
\text { Oligocene } \\
\text { Upper } \\
\text { Hiddle } \\
\text { Lower } \\
\text { Eocene } \\
\text { Upper } \\
\text { Middle } \\
\text { Lower } \\
\text { Cretaceous } \\
\text { Upper }\end{array}$ & 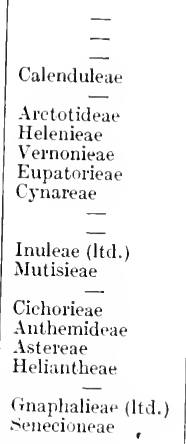 & 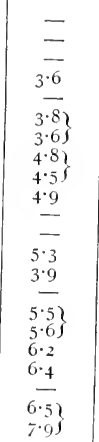 & $\begin{array}{l}\bar{Z} \\
\bar{Z} \cdot 6 \\
- \\
3 \cdot 7 \\
4 \cdot 65 \\
4 \cdot 9 \\
- \\
5 \cdot 3 \\
3 \cdot 9 \\
- \\
5 \cdot 55 \\
6 \cdot 2 \\
6 \cdot 4 \\
- \\
7 \cdot 2\end{array}$ & $7 \cdot 2$ \\
\hline
\end{tabular}

Arranging the sub-tribes within eaeh tribe in the order of origin as given on p. 125, we find that even there the series follow the average generic area scries more or less. The series (Table I, col. 17) for the following six tribes are unbroken in each case:

Anthemideae: $6 \cdot 2,4 \cdot 3$.

Inuleae (limited): $8 \cdot 4,3 \cdot 5,3 \cdot 3,1 \cdot \%$.

Cynareae: $5 \cdot 9,5 \cdot 1,4 \cdot 5,3 \cdot 3$.

Eupatorieae: $5 \cdot 3,4 \cdot 1,3 \cdot 3$.

Vernonieae: $5 \cdot 1,4 \cdot 0$.

Arctolideac: $4 \cdot 7,3 \cdot 0,28$.

The Calenduleae has no sub-tribes, so that only half of the fourteen tribes require special consideration.

As we are in many cases dealing with fewer than ten genera, and since a number of the sub-tribes are more than slightly 
artificial, while several contain genera which are exceptionally widespread because of special dispersal mechanisms, we cannot expect a complete correspondence. On the other hand, a family tree is available (p. 125) which was worked out in the first place from the morphological characters of the styles and stamens (103, fig. 7 ) and subsequently modified only slightly as a result of the consideration of the most extensive data. It is, therefore, interesting to examine the deviations from the numerical sequence in average generic area for the other seven tribes.

Senecioneae. The Tussilagininae have been shown to be a somewhat mixed group of genera, separated from the Senecioninae in a rather artificial way (103, pp. 39 and 298), and these two sub-tribes are, in faet, fused by Hoffman in the Pflanzenfamilien. The proper statistical procedure is, therefore, to take them as one group for comparison with the other groups within the tribe; then we obtain another unbroken sequence- $8 \cdot 9,6 \cdot 8$, $3 \cdot 6$ (Table I, col. 1\%).

Gnaphalieae (limited). With the Eu-gnaphalieae and Helichryseae as two distinct groups the series for the Gnaphalieae reads $9 \cdot 8,8 \cdot 8,9 \cdot 3,4 \cdot 3,1 \cdot 6,1 \cdot 7,3 \cdot 2$. There are in this case two marked exceptions to the sequence. The first is the Filagininae $(9 \cdot 3)$ with only cleven genera including Micropus as a widely spread weedy type, and Filago also of the weedy type and a distribution suggesting either early dispersal by man or-a polyphyletic origin. If this genus were broken up into three, as was done by many of the earlier synantherologists, the average generic area for the sub-tribe would be $\tau \cdot 8$, and the sequence would be umbroken except for the last sub-tribe. The second exception is the Angianthinae (3·2), ehiefly an Australian group with only ten genera, the distribution of which in Australia may be somewhat less on the whole than has been estimated. Such a reduction in this sub-tribe would bring the average for the Gnaphalieae to about $6 \cdot 3$, but a similarly careful revision in detail of the other sub-tribes might result in raising the average one or more decimals, so that such changes may be considered negligible when the broad outlines of the history of the family are being considered.

Heliantheae. The series for this tribe appears rather irregular, running thus: $6 \cdot 9,9 \cdot 6,3 \cdot 7,6 \cdot 5,2 \cdot 7,3 \cdot 2,12 \cdot 8,3 \cdot 8,6 \cdot 0,1 \cdot 3$; but most of the sub-tribes contain less than ten genera. It is, therefore, advisable to group them; the first three groups are of early origin (see p. 125), while those numbered $6^{\prime}, 6^{\prime \prime}, 6^{\prime \prime \prime}$ in Table I 
are so marked because they are presumed to have arisen about the same time. Taking these six sub-tribes as two groups we get the series $6 \cdot 7,6 \cdot 5,2 \cdot 7,6 \cdot 6,6 \cdot 0,1 \cdot 3$. In this series there is only one prominent break, $2 \cdot 7$ for Madiinae with only seven genera. Considering the sub-tribes showing exceptional figures for average generic area, there is the Coreopsidinae $(9 \cdot 6)$ with 17 genera of which Bidens is a very widely spread wecdy type with a very special dispersal mechanism, especially when the early migrations of man are regarded as a means of dispersal. The Melampodiinae shows a low average, but it has an average generic area very similar to several of the other young subtribes. The other exceptional figure is $\mathbf{1 2 . 8}$ for the Ambrosinae; in which there are only nine genera, of which both Ambrosia and Xanthium are widely spread weeds, the latter like Bidens with a special dispersal mechanism.

Astereae. The series for this tribe is very uniform, running $\mathbf{5 \cdot 4}$, $6 \cdot 0,7 \cdot 5,7 \cdot 7,7 \cdot 0,5 \cdot 5$. Such a sequence, with the most primitive sub-tribe showing the lowest average generic area, might well seem to show that the present thesis cannot be maintained, but only two of the six groups have more than ten genera. Further, the division into sub-tribes is introduced by Bentham (7, p. 402) thus:

The vast tribe of Asteroideae is neither so well marked as a whole..., nor yet is it well divisible into distinct groups. Nearly the whole of the 90 genera, comprising above 1400 species, pass into each other through exceptional or intermcdiate forms.... The Asteroideae not being divisible into distinet sub-tribes, we may for geographical purposes consider a number of types with the various divergences from them.

Bentham also gives the key to this anomalous distribution as follows: "Aster, taken in its most extended sense, ranges over the whole area of the tribe; but isolation has been ancient enough to admit of its having established special forms in different eountries, which are now admitted as genera by most botanists" (7, p. 402); and in the Solidago type (7, p. 410):

We have here about 320 species in 24 genera, all nearly allied to each other and only distinguished technically from Aster and its immediate allies by the homochromous florets, the ray florets, when present, being yellow, like the disk-a character in gencral of so little value that it eannot, in Senecio for instance, be admitted as of more than specific importance.

Translating these quotations from Bentham, who makes several other statements of a like nature (cf. op. cit., pp. 405 
and 412), into modern terms (46), one would say that the Astereae was predominantly a case in which a primitively world-ranging type has been differentiated $i n$ situ with practically no spreading of markedly new types from definite centres of origin. Some such explanation is almost necessary for the frequeney of intermediate species and the grading of the Aster, Erigeron and Conyza types into each other.

Guppy's theory of "Rank and Range," which, although similar to "Age and Area," is slightly different, is therefore exemplified in this tribe of the Compositae; whereas the other tribes are examples rather of "Age and Area." A detailed examination of many of the sub-tribes in other tribes shows that within the sub-tribe there are seldom groups of genera which show markedly different average generic areas. The Eugnaphalieae and Helichryseae are exeeptions. This leads to the conclusion that, in spite of the large numbers of genera and species in the Astereae, this group is really of the same "rank" (with regard to differentiation and Age and Area statisties) as the normal sub-tribes of most of the other tribes.

Cichorieae. The ten sub-tribes into which this tribe is divided are admittedly artificial. Bentham (op. cit., p. 475) writes: "It is very difficult to arrange these genera into sub-tribes; and those we have adopted are in a great degree artificial, and have little or no connection with geographieal distribution; we must, therefore, now eonsider the prineipal genera separately."

The Lactucinae have been indieated (103, pp. 271 and 282, and p. 125) as the primitive group, while the Scorzonerinae have been indieated as a fairly definite and advaneed group (103, p. 282). Scolymus is quite a distinet genus and the only one in the Seolyminae. Grouping the other seren sub-tribes together as one, we have the series $-6 \cdot 2,5 \cdot 9,3 \cdot \tau, 4 \cdot 0$. The last figure is of little importance sinee it represents only one genus, while the other figures are in the usual sequence. Of the seven sub-tribes which are grouped only one, Hyoseridinae $(42 / 10=4 \cdot 2)$, has as many as ten genera; while the other two sub-tribes which are taken singly show the figures $69 / 11=6 \cdot 2$ (Lactueinae) and $3 \pi / 10=3 \cdot 7$ (Seorzonerinae). The inclusion of the American genera in Seorzonerinae is distinetly artifieial, and if only the Old-World genera are taken the average is $5 \cdot \mathbf{8}$. Then the series for the Ciehorieae reads $6 \cdot 2,5 \cdot 9,5 \cdot 8,4 \cdot 0$, and it is in complete sequence and in perfeet accord with the origins given on p. 125 . With appropriate statistical treatment, therefore, this tribe 
shows the action of the Age and Area law, and it is interesting to note that it is a clear ease of an origin in and dispersal from a definite centre (see 103, Pl. 2, fig. 31), contrasting markedly with the Astereae.

Mutisieae. As stated above (p. 126) the low average generic area for this tribe is to be explained, at least in part, by the rather artificial splitting into geographical genera. This occurs chiefly in the Gerberinae and Gochnatiinae, and an allowance for this "error" would bring into greater prominence a feature which is marked in the series as given. The origin of the Barnadesiinae is still obscure, therefore the $\mathbf{3 \cdot 5}$ for that sub-tribe may be neglected for a moment. The series for the other sub-tribes reads $3 \cdot 3,2 \cdot 6,5 \cdot 6,4 \cdot 2$. A diphyletic origin for the Mutisieae, as far as the Barnadesiinae is eoncerned, has already been suggested (103, p. 211), but the data for Age and Area suggest very strongly that the origin of the rest of the Mutisieae has also been diphyletic, giving a triphyletic origin for the tribe as a whole. Some difficulty was experienced in tracing the interrelationships of these sub-tribes (ef. 103, pp. 211 and 305), and it is quite probable that the purely American sub-tribes, Nassauviinae and Onoseridinae, are relatively recent, while the other two subtribes are a more ancient group evolved along similar lines. Then we have two groups and two series, $3 \cdot 3,2 \cdot 6$, and $5 \cdot 6,4 \cdot 2$, with the Barnadesinae $(3 \cdot 5)$ intermediate from probably a third origin. The struetural affinities combined with the Age and Area data allow of no other explanation of the origins of this unique tribe.

Helenieae. This, the last of the tribes showing exeeptional figures, gives the series $6 \cdot 4,3 \cdot 8,5 \cdot 6,6 \cdot 1,2 \cdot 1$; but three of the five sub-tribes have less than ten genera so that further grouping is required. This can be done by taking as one group the first two sub-tribes, marked $1^{\prime}$ and $1^{\prime \prime}$ ('Table I, col. 1) on aceount of suggested simultaneous origin, and as another group the last two sub-tribes $3^{\prime}$ and $3^{\prime \prime}$ for the same reason. The series then becomes $4 \cdot 6,5 \cdot 6,2 \cdot 7$. The middle figure is not in sequence, but it refers to the Flaveriinae with only three genera $(17 / 3=5 \cdot 6)$, and does not, therefore, vitiate the general argument which applies quite well to the first and last groups, both with more than ten genera.

With the one exception of the Astereae, which has been explained (p. 129), the statistical data for Age and Area in Com- 
positae can, therefore, be said to demonstrate in some considerable detail the action of the Age and Area law as far as relative age is concerned in a group, the evolutionary history of which in time ean be confirmed by many other lines of evidence.

Size and Space. Dr Willis has also forwarded another prediction to the effect that, "on the whole the area occupied by a genus (taking a great many, say ten allies at least) varies in the same sense as the number of species it eontains." This also has been worked out for Compositae, using the number of species recorded for each genus by Bentham in the Genera Plantarum, in order to avoid the inequalities of modern species-splitting and specialisation in particular genera. The results which are given in Table III, when analysed properly, form a remarkable verification of this prediction. The average number of species per genus does follow on the whole the same series as the average generic area.

TABLE III

Species/Genera

\begin{tabular}{|c|c|c|c|c|c|}
\hline \multicolumn{2}{|l|}{ Tribes and Sub-tribes } & Tribes & \multicolumn{2}{|l|}{ Sub-tribes } & $\begin{array}{c}\text { Average } \\
\text { Generic } \\
\text { Areas }\end{array}$ \\
\hline Senecioneae ... & $\ldots$ & I $266 / 44=28 \cdot 7$ & - & & $7 \cdot 9$ \\
\hline 1. Senecioninae & $\ldots$ & - & $1053 / 26=40 \cdot 5\}$ & 32.6 & $8 \cdot 7$ \\
\hline 3. Tussilagininae & $\ldots$ & - & $24 / 7=3.4\}$ & $32 \cdot 0$ & $9 \cdot 4$ \\
\hline $1+3 \quad \ldots$ & $\ldots$ & - & $1077 / 33=32.6$ & & $8 \cdot 9$ \\
\hline 2. Liabinae ... & $\ldots$ & - & $50 / 5=10 \cdot 0\}$ & & $6 \cdot 8$ \\
\hline 4. Othonninae & $\ldots$ & - & $139 / 6=23 \cdot 1\}$ & 171 & $3 \cdot 6$ \\
\hline Gnaphalieae (ltd.) & $\ldots$ & $975 / 100=9.7$ & - & & $6 \cdot 5$ \\
\hline Inuleae (Benth.) & $\ldots$ & - & - & & $6 \cdot I$ \\
\hline 1. Eu-gnaphalieae & $\ldots$ & - & $214 / 20=2 \pi \cdot 4$ & & $9 \cdot 8$ \\
\hline 2. Plucheinae & $\ldots$ & - & $\left.157 / 16=9^{.8}\right\}$ & & $8 \cdot 8$ \\
\hline 3. Filagininae & $\ldots$ & - & $46 / 1 I=4.2\}$ & $7 \cdot 5$ & $9 \cdot 3$ \\
\hline 4. Helichryseae & $\ldots$ & 一 & $393 / 26=15 \cdot I$ & & $4 \cdot 3$ \\
\hline 5. Tarchonanthinae. & & - & $10 / 3=3.3$ & $10 \cdot 9$ & $I \cdot 6$ \\
\hline 6. Relhanininae & $\ldots$ & - & $\left.9 \mathrm{I} / \mathrm{I}_{4}=6 \cdot 5\right\}$ & & $x \cdot 7$ \\
\hline 7. Angianthinae & $\ldots$ & - & $64 / 10=6.45$ & & $3 \cdot 2$ \\
\hline 1. Inulinae $\ldots$ & $\ldots$ & - & $\mathrm{I} 3 \mathrm{I} / \mathrm{I} 9=6.9$ & & $8 \cdot 4$ \\
\hline 2. Buphthalminae & $\ldots$ & - & $45 / 16=2.8$ & & $3 \cdot 5$ \\
\hline 3. Athrixiinae & $\ldots$ & - & $39 / 7=5 \cdot 5$ & & $3 \cdot 3$ \\
\hline 4. Relhaniinae & $\ldots$ & - & $9 \mathrm{I} / \mathrm{I} 4=6.5$ & & $x \cdot 7$ \\
\hline Heliantheae ... & $\ldots$ & $\operatorname{IIOI} / x_{3} 8=7 \cdot 9$ & $9 \times 1 \times 4$ & & $6 \cdot 4$ \\
\hline 1. Verbesininae & $\ldots$ & - & $604 / 57=10 \cdot 6$ & & $6 \cdot 9$ \\
\hline 2. Coreopsidinae & $\ldots$ & 一 & $153 / 17=9.0$ & & $9 \cdot 6$ \\
\hline $1+2 \quad \ldots$ & $\ldots$ & - & - & & $7 \cdot 5$ \\
\hline 3. Melampodiinae & $\ldots$ & - & $95 / 20=4 \cdot 7$ & & 3.7 \\
\hline $1+2+3 \ldots$ & $\ldots$ & - & $852 / 94=9^{\cdot} \mathbf{I}$ & & $6 \cdot 7$ \\
\hline 4. Galinsoginae & $\ldots$ & - & $8 I / 7=I I \cdot 5$ & & $6 \cdot 5$ \\
\hline 5. Madiinae ... & $\ldots$ & 一 & $52 / 7=7.4$ & & $2 \cdot 7$ \\
\hline $6^{\prime}$. Milleriinae & $\ldots$ & - & $40 / I x=3.6$ & & $3 \cdot 2)$ \\
\hline 6". Ambrosiinae & $\ldots$ & - & $40 / 8=4.4\}$ & $4^{\circ} \mathrm{O}$ & $x 2.8\} 6.6$ \\
\hline $6^{\prime \prime \prime}$. Zinniinae & $\ldots$ & & $25 / 6=4 \cdot 1)$ & & $3 \cdot 8 !$ \\
\hline
\end{tabular}


TABLE III (Contd.)

Species/Genera

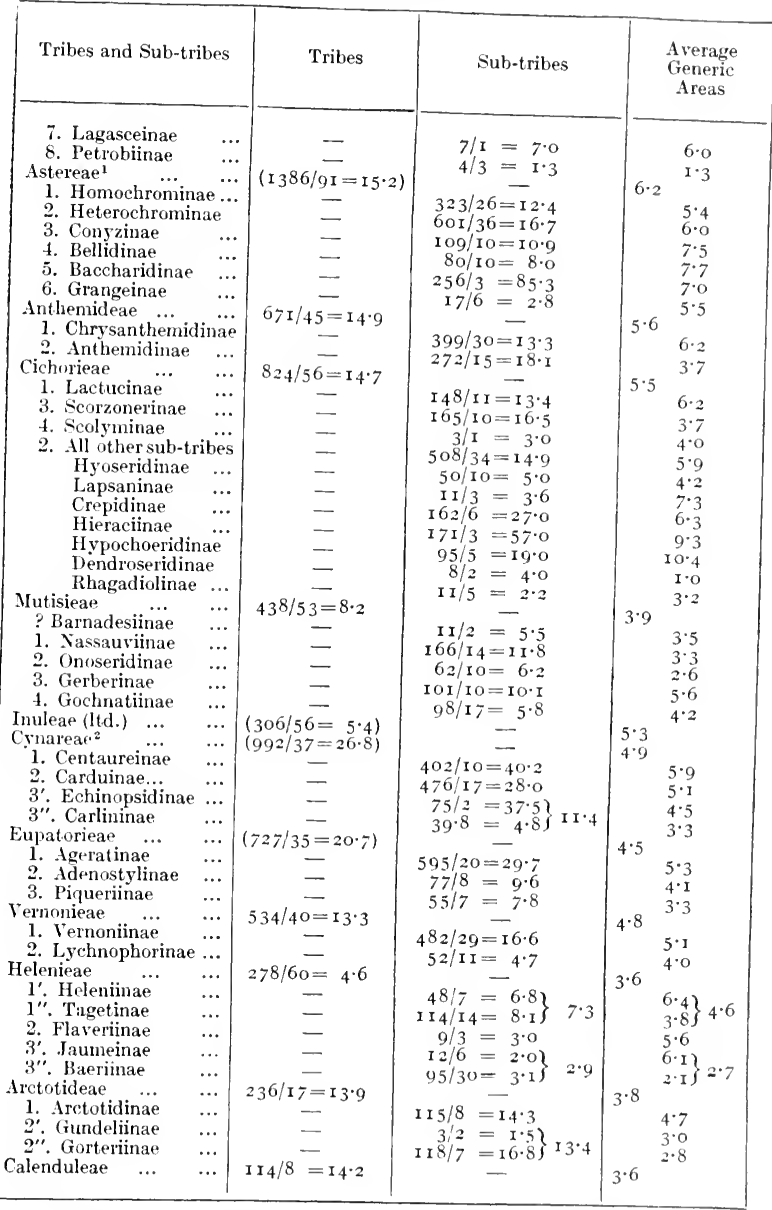

${ }^{1}$ Astereae +Eupatorieae $=$ I6.7.

${ }^{2}$ Cynareae +-Inuleae (ltd.) $=$ I 3.9. 


\section{AGE AND AREA, AND SIZE AND SPACE, [PT. II}

In this case it is clear that the larger the groups of allies taken the more reliable the results, therefore the Astereae has been grouped with its derivative tribe (Eupatorieae) and the Inuleae (limited) has been grouped with the derived Cynareae. In this way the number of larger groups has been reduced from fourteen to twelve, and these give the following series of averages for number of species per genus ${ }^{1}$ :

$$
28 \cdot 7,9 \cdot 7|| 7 \cdot 9,16 \cdot 7,14 \cdot 9,14 \cdot 7|| 8 \cdot 2,13 \cdot 9|| 13 \cdot 3,4 \cdot 613 \cdot 9 \| 14 \cdot 2 .
$$

The last two numbers are not quite in series, but they represent groups with only seventeen and eight genera respectively. All the four numbers out of sequence are practically in series with each other. The low figures for the Gnaphalieae $(9 \cdot \tau)$ and Heliantheae $(7.9)$ may be traced to the fact that many of the genera are plants of the plains, where the average number of species per genus is lower, according to Harshberger (ef. 103, p. 187), than it is along the mountain ranges with their highly diversified topography. The low figure $(8 \cdot 2)$ for the Mutisieae furnishes a curious piece of evidence in favour of the prediction, for it may be noted that the average generic area is also lower than it should be in the series; and the geographical splitting of genera already mentioned would reduce not only the area but also the number of species per genus. The low figure $(4 \cdot 6)$ for the Helenieae also oecurs in conjunction with a low figure for average generic area. Thus, of the twelve groups taken only two do not fall into the same series as that for average generic area.

The inerease of average number of species per genus with age shows even more strikingly when the mean is taken of the figures for each geological period. The figures for the groups arising in the five periods concerned are separated by vertical lines in the series as given above; and the means for the Upper Cretaceous, Eocene, Oligocene, Miocene and Pliocene read thus: 19.2, 12.8, $11 \cdot 0,10 \cdot 6,14 \cdot 2$. Only the last figure is out of sequenee, and it represents a single small tribe, the Calenduleae, with eight genera and $11+$ species, which are scarcely sufficient for reliable data.

When we take the subordinate gromps the same correspondence between the two series shows very well on the whole. For the present purpose as much grouping of the sub-tribes as seems reasonable has been made in order to get groups with more than ten genera. Taking the tribes seriatim we get the following data:

Senecioneae. The Tussilagininae are sunk as before giving $\mathbf{3 2 \cdot 6}$; the Liabinae and Othonninae are grouped to get more than ten

1 Numbers in italics are in series or nearly so. 
genera giving $189 / 11=17 \cdot 1$; and the series is complete. An interesting point is the large figure $(\mathbf{4 0 \cdot 5})$ for the basal sub-tribe of the family, which is exceeded only in the Baceharidinae $(85 \cdot 3)$ and the Hieraeinae $(57 \cdot 0)$, both with only three genera.

Gnaphalieae (limited). The Plueheinae and Filagininae are grouped as similar in age and in area, giving $203 / 27=7 \cdot 5$; the Heliehryseae is grouped with its derivatives Relhaniinae and Angianthinae giving $\mathbf{5} 48 / 50=\mathbf{1 0} \cdot 9$. The series for the tribe then reads $21 \cdot 4,7 \cdot 5,10 \cdot 9,3 \cdot 3$. The larger figure for the Helichrysum group may be explained as an effeet of the diversified topography in South Afriea; the other figures are in series.

Inuleae (limited). 'Two out of the four figures are in series, but the numbers of genera are low in all eases.

Heliantheae. The first three sub-tribes and those marked $6^{\prime}$, $6^{\prime \prime}, 6^{\prime \prime \prime}$ are again counted as two groups; and the series reads thus: $9 \cdot 1,11 \cdot 5,7 \cdot 4,4 \cdot 0,7 \cdot 0,1 \cdot 3$. The exeeptions are $11 \cdot 5$ for the Galinsoginae with only seven genera and $\tau_{0} 0$ for the Lagaseeinae with only one genus.

1stereae. The series $(\mathbf{1 2} \cdot 4, \mathbf{1 6} \cdot 7, \mathbf{1 0} \cdot 9,8 \cdot 0,85 \cdot 3,2 \cdot 8)$ in this tribe again shows the series following age as previously suggested, with two exeeptions. These are $\mathbf{8 5 \cdot 3}$ for the Baceharidinae with only three genera, and $\mathbf{1 2} \cdot \mathbf{4}$ for the Homochrominae as compared with $16 \cdot \tau$ for the Heterochrominae. The latter figures, when eompared with $5 \cdot 4$ and 6.0 for average generie area, are seen to follow the sequenee for area.

Anthemideae. In this tribe the figures are not in the proper scries.

Cichorieae. The series in this ease runs practically in the opposite direetion to the average generie area series, but the numbers of genera are low in three of the four groups. These two exeeptional tribes, it should be noted, show the proper sequence as tribes, so that it would seem that, not only the admittedly artifieial subdivision in both tribes (see below), but also the small number of genera in most of the subordinate groups has an effect on the correspondenee of the series in these cases.

Mutisicae. Adopting the triphyletic origin of this tribe, which is suggested above, we have three sets of figures which correspond to the three series for area and show the same sequenee within the sets.

Cynareae. Grouping $3^{\prime}$ with $3^{\prime \prime}$ as being of the same age, we get the series $40 \cdot 2,28 \cdot 0,11 \cdot 4$, which corresponds completely with the series for area. 
Eupatorieae. The series here $(29 \cdot 7,9 \cdot 6,7 \cdot 8)$ also corresponds completely with the series for area.

Vernonieae. The series here $(\mathbf{1 6} \cdot \mathbf{6}, \mathbf{4 \cdot 7})$ also corresponds completely with the series for area.

Helenieae. Grouping $1^{\prime}$ with $1^{\prime \prime}$, and $3^{\prime}$ with $3^{\prime \prime}$ as being of the same age we get the series $7 \cdot 3,3 \cdot 0,2 \cdot 9$, which agrees completely with the order of origin as given previously (p. 125).

Arctotideae. Grouping $2^{\prime}$ with $2^{\prime \prime}$ as being of the same age we get the series $14 \cdot 3,13 \cdot 4$, which also corresponds completely with the series for area.

The prediction that the series for the average number of speeies per genus will follow those for the average generic area may, therefore, be said to be verified for the tribes on the whole, ten out of twelve showing a similarity; and also for the subtribes on the whole, with the exception of three tribes out of fourteen. Further, the divergenees amount to two out of four sub-tribes in the Inuleae (limited); while the subdivision of the other two tribes (Anthemideae and Cichorieae) is admitted by Bentham to be artificial. For the Anthemideae he reeords (7), p. 451): "In the Genera Plantarum we have, for convenience" sake, elassed the genera somewhat artificially," and (op. cit., p. 450) "It is not easy, either, to group them into well-marked sub-tribes." On the artifieial subdivision of the Cichorieae he has already been quoted (p. 130).

The conelusion is, therefore, quite justified that in the Compositae on the whole both the average generic area and the average number of speeies per genus are elosely related to absolute age. 


\title{
CHAPTER XIV
}

\section{AGE AND AREA FROM A \\ PALAEOBOTANICAL STANDPOINT}

\author{
By Mrs E. M. Reid, B.Sc., F.L.S.
}

\begin{abstract}
Axy student of ancient floras must feel that in its power to meet the facts of geology and palaeobotany lies the supreme test of Dr Willis' theory of Age and Area. The time has not come when such a test can be applied with any degree of fullness, for the history of Tertiary floras, which are those chiefly coneerned, is still but imperfectly known; and more especially is this true of their migrations. Nevertheless, even if we cannot make a full comparison, it may be of use to make a beginning, by comparing such conelusions as have been reached by the two studies; not only for the sake of testing a new theory, but because, if it holds, palaeobotany has much to learn from it of the past history of plant-life and must therefore reeonsider its conclusions in the light of new knowledge.
\end{abstract}

In what follows I do not propose to go much beyond the range of my own studies, but these have been largely coneerned with the questions of whieh Age and Area treats, the migration of floras, the age of speeies, and the extermination of species. The material of study has been the Pleistocene floras of Britain, and some late Tertiary floras of West Europe, ehiefly the following Plioeene floras: Cromerian (East Anglia), Teglian (Holland), Castle Eden (Durham), Reuverian (Duteh-Prussian border), Pont-de-Gail (Cantal). These have been investigated by an examination of seeds and fruits.

Plant Migration. If there is one fact which has emerged more clearly than another from the study of Pleistoeene and late Tertiary floras in West Europe, it is that at different geological times, different floras have occupied the same locality. By "different floras" is meant different assemblages of plants which have lived in the past, as they do in the present, in regional, or in ecological assoeiation, more especially in climatic assoeiation.

Thus, by the quantitative study of pollen-grains in the successive horizons of the peat-bogs of Scandinavia, it has become possible for Scandinavian workers to trace successive assemblages 
of plants at different periods, not only so as to gain a knowledge of the species occupying the country at successive times in the Pleistocene, but so as to gain also some knowledge of the proportion in which those species flourished (60).

Or, again, we may take in our own country the succession seen in our eastern counties. In the Cromerian (83) at the close of the Pliocene period, we find a temperate flora almost identical with that now inhabiting East Anglia. At a later period we find a flora composed of plants now inhabiting colder regions-subarctic, alpine, or cold temperate $(\mathbf{1 5}, \mathbf{7 2}, \mathbf{8 2})$. Yet again, in the present day, after a further interval, when the climate has once more become temperate, we find the old temperate flora of the Cromerian back in its former locality, shorn only of a few of its elcments.

The instances of such successions could be multiplied, but the above are sufficient to show that we have definite evidence of a continual swaying to and fro of plant-life.

Evidence of this kind can scarcely be interpreted otherwise than as indicating the movement of plant assemblages, under the influence of climatic change; in other words, migration.

But if migration has occurred, how has it been brought about? The answer is suggested by Dr Willis' theory of Age and Area, though the idea of plant movement embodied in it would seem to need some modification. Dr Willis suggests, as a result of his work, that newly arrived, or newly formed, species tend to spread outwards in all directions from their point of arrival, or point of origin. like rings formed by casting a stone into a pool. In such a tendeney we see a motive force; but migration is a dirceted movement, and the combined evidence of geology and palaeobotany indicates that the directing force is change of climate. Each species flourishes best under definite climatie conditions, within limits appropriate to itself. Change of climate, acting ecologically, works as a weeding process, so that movement, instead of being general all round, becomes a movement in one definite direction-migration.

From various considerations of geology, palaeontology, fossil and recent botany, the conclusion has been reached that if change of climate has been from cold to heat, in a flat country migration has been polewards, in a mountain country upwards. If the change has been from heat to cold, then in a flat country migration has been equatorwards, in a mountain country downwards. 
In the paper on the "Sources and Distribution of the New Zealand Flora," pp.354-362, the conclusion is drawn that there were two main plant-invasions by which New Zcaland was populated, a northern and a southern. In a subsequent paper (134) this conclusion is amplified. The northern invasion is split into three, a principal one from the north, and two subsidiary ones, called the Kermadec and western invasions respectively.

It will at once be seen that we have here postulated three invasions (northern, western, and Kermadec), which in their general direction are poleward, and one invasion (southern) which is equatorward. Bearing in mind the conclusions we have reached as to the relationship between direction of migration and change of climate, it would appear that the three poleward invasions must have occurred whilst the climate of all the regions involved, or possibly only that of New Zealand, was becoming warmer; the southern invasion, equatorward, must have occurred whilst the climate of the regions involved was becoming colder.

It will be sufficient for our argument if we consider only the two main divisions, the northern and southern.

Dr Willis brings forward strong evidence (132, and cf. p. 81) to show that of the two, the northern was much the older. We have: therefore, to consider one very old migration polewards whilst the climate was warming, and one newer, equatorwards, whilst the climate was eooling.

For the migration of floras (plants in ecological association), as opposed to the casual transport of individuals, Dr Willis rightly insists that land connection, complete or all but complete with the source of dispersal, at the time of dispersal, is necessary. It is inconceivable that associated assemblages could travel in one definite stream except by land. A sca-passage must have sifted out species with inferior powers of dispersal across water in a way that is not found to have oceurred.

We have now traced the conditions necessary for these two main invasions as postulated. For the northern, a very ancient land connection between New Zealand and Indo-Malaya, with a climate incrcasing in temperature, certainly in New Zealand, and probably over the whole of these regions. For the southern, a very much later land comnection sonthwards, at least as far as the Campbells and Aucklands, with the climate of these regions becoming coldcr. It will readily be seen that for the western and Kermadec invasions, conditions very similar to 
those needed for the northern invasion must have occurred, possibly at intermediate periods.

Such are the problems which present themselves for solution when we attempt to apply the results of the comparative study of Pliocene and Pleistocene floras to the postulated migrations of the New Zealand flora. Whether the geology of New Zealand and Indo-Malaya will bear out the possibility of these changes of sea-level associated with the corresponding changes of climate, it is for students of those regions to say. The answer is outside the range of my knowledge.

Extermination. The study of West European Pliocene floras led to the recognition of an extinct Tertiary flora in West Europe. This flora, which I have named the Chinese-North-American Association of Plants, is now represented by two living plant associations; the one the forest-belt flora of the East Asian mountains, the other the allied flora of parts of North America. There is much evidence from recent and fossil botany, and geology, to show that all three are migrant floras, branches of a common polar or circumpolar flora, which migrated southward in later Tertiary time under the influence of a cooling elimate in the Northern Hemisphere. The travel southward of each branch must have extended over many hundreds, more probably thousands, of miles. In the end there resulted the complete extermination of the European branch, and the isolation of the other two, in regions of the Old and New World respeetively, separated by many thousand miles of sea and land.

In the history of this flora we see exemplified two kinds of extermination, both of which are concerned with the questions raised by the study of Age and Area. In the first plaee we have regional extcrmination; no trace being left, in the region where such extermination occurs, of the life that has been. In the second place we have specific extermination; the species being killed, but an allied one taking its place.

Regional Extermination. Regional extermination, as illustrated by the history of the Chinese-North-American flora, may be of different degrees.

(1) It may be confined to one region only. We have numerous instances of this in our flora. Take, for example, the genera Magnolia, Liriodendron, Menispermum, and Nyssa. These have been exterminated in Europe, but have survived in East Asia and North America; though they are now represented by different 
species in the two regions. Survivals of this kind in Japan and North America, which are many, led to the recognition by Asa Gray of the fact that the floras of Japan and Atlantic North America are allied.

(2) It may have occurred in two out of the three regions. Thus Phellodendron, Actinidia, and Zelkowa have been exterminated in Europe and probably in North America, but survive in the East of Asia. Dulichium, Karwinskia, Proserpinaca have been destroyed in Europe and probably in East Asia, but survive in North America. When such regional distribution has occurred, there is nothing to indicate in the present how wide the distribution may have been in the past, or to say whether genera are survivals or not.

(3) Extermination may have extended to all three regions. In that case the past is completely wiped out, and in the present there is no sign of the life that has been. We have numerous instances of such extermination in the case of species-extinct species of Dulichium, Euryale, Liriodendron, and so on, far too numerous to name here; but we have also in all probability instances of genera exterminated in the many undetermined fossil forms which would appear to belong to living families, but cannot be placed in living genera. These forms are mostly unnamed so cannot be referred to, but by consulting the works cnumerated they will be recognised.

It is this fact, that endemic species can frequently be proved to be survivors from a wide-ranging past, which offered to me the greatest stumbling-block to the acceptance of the theory of Age and Area. So formidable did the difficulty appear that I felt it must vitiate the reasoning which pointed to endemics as the newest elements in plant-life; and yet it was hard to see where the flaw could lic; and the theory offered so simple and reasonable an explanation of much that one met with in palaeobotany.

A student of Tertiary floras must stand by the fact that in many instances endemics are survivors from races that once flourished widely, though they do so no more. Take the genus Sequoia. It once inhabited Europe, Eastern Asia, the Aretic regions, and large areas of North America; now it is confined to the Pacific coast of California. Euryale, again, was once represented by many species scattered at different times (some at the same time) throughout Europe; now it survives as a single species only in parts of China and Assam. Or again, with individual 
species; Liriodendron tulipifera, Nyssa sylvatica, Pilea pumila, Dulichium spathaceum were once all inhabitants of Western Europe; now they are confined to the North American continent. The list could be continued to great length but this is enough to show that genera and species formerly widespread have contracted their range and become endemic. Are we then to throw over the conclusions of Age and Area which show that immensely the greater proportion of endemics represent new life: and take the position that the two lines of research are mutually contradictory? It is not necessary if we make due allowance for the differences of method and subject-matter in the two studies, and their consequent limitations.

Throughout his work Dr Willis has insisted that his conclusions are based upon mass-investigation, averages. Consequently he warns us that, as with all average calculations, though the conclusions will be true for the mass they quite possibly may not be true for the individual. Now the whole of palaeobotanical research is based upon the study of the individual; consequently we must be prepared to find that our results may not conform to the conclusions of mass-investigation, though we ought to be able to explain the causes of divergence. The palaeobotanist states that some endemics are relicts. Dr Willis replies that if it is so, they are of no account in comparison with the vastly greater number of endemies which are not. Not having counted up the total of endemies in the living flora of the world, as he has done, I am prepared to accept his estimate that relict endemies form only about 1 per cent. of the total. Even if the pereentage were higher, it would not vitiate Dr. Willis' reasoning. And here we come to the explanation of our difference. Whereas Age and Area fixes its attention upon, and argues from, the 99 per cent., palaeobotany has its attention fixed upon, and seeks to argue from, the 1 per cent. In the nature of things the 99 per cent. are outside the scope of its investigations, for if they represent the newest forms of life, then they cannot occur fossil. Consequently, though palaeobotany is right to hold to its 1 per cent., it must yield place in the argument to the superior force of numbers.

Specific Extermination; Extinction and Survival of Species; Killing out and Dying out. Specific extermination, the replacement of old forms by new, is continually met with in Tertiary botany; one of the most striking instances is seen in 
the monotypic genus Stratiotes. Miss Chandler's work on the subject is not yet published, but we may state that a succession of species has been found at different geological horizons which carries the history, with but few interruptions, from the top of the Eocene to the present time. A whole series of extinct forms lies behind the living species. The same is true of other genera though the succession may be less completely known. To name but a few, Dulichium, Sparganium, Potamogeton, Najas, Sambucus, Vitis, Magnolia, Rubus, Cotoneaster and Phellodendron are all known to have a long fossil record of species that are now extinct. Given time, the fate of all speeies is extinction, though exceptionally they survive for long periods. The oldest living species I have myself come across are Vitis lanata and Polygonum Convolvulus in the oldest Pliocene (Pont-de-Gail), or possibly Calla palustris in the Borey Oligocene.

If now we turn to $A$ ge and Area and inquire what evidence it has to offer, we find that it points to survival as the probability, unless extermination be due to "killing out."

It is possible that we have here a real diserepancy between the two studies, for the evidence of universal extinction of speeies furnished by the pages of palaeobotany is incontrovertible; but we should bear that proviso "unless killed out" in mind. For further evidence on the subject we may turn to the history of the Chinese-North-American flora.

We have seen that all branches of the flora have suffered extermination, either complcte extermination, or partial. By a comparison of its old constituents, as seen in the Pliocene deposits of West Europe, with its present constituents, as seen in the Far East and in North America at the present day, we may gain some idea how the flora has ehanged.

In the first place we discover that not all species have been exterminated, in spite of the great lapse of time, and the immense distances travelled to their present homes. Even if we consider the older deposits, the Reuverian belonging low down in the Lower Pliocene, and the Pont-de-Gail at the base of the Pliocene, we find some species of those remote times still living. As instances we may cite Dulichium spathac'um, Brascnia peltata, Zelkowa keaki, Magnolia kobus, Liriodendron tulipifera, Stewartia pscudo-camellia, and Nyssa sylvatica from the large Reuverian flora, and Vitis lanata and Polygonum Convolvulus, as already stated, from the Pont-de-Gail flora.

But though some species have remained unchanged, it is far 
more common for change to have occurred, and we find that the greater the lapse of time, the greater proportionately has been the change. That is to say, more species found in the older deposits are extinct, than in the newer. This may very clearly be seen by comparing the percentages of species and varieties, which there is reason to think are extinct, in the successive Pliocene floras. There is an element of uncertainty in such a comparison for this reason. It has not always been possible, for lack of living material, to discover whether a seed belongs to a living species or not. The following figures will, I believe, have at least some approximation to the truth. The deposits read downwards in order of age; they are those from which the main evidence of the facts discussed in this paper were derived.

Percentages of extinct species belonging to the Chinese-NorthAmerican Association of Plants in the West European Pliocene at successize periods.

\begin{tabular}{lcc}
\multicolumn{1}{c}{ Deposit } & Age of deposit & $\begin{array}{c}\text { Percentage of } \\
\text { extinct species } \\
\text { (approximate) }\end{array}$ \\
Cromerian & Top of Pliocene & 0 \\
Teglian & Upper Pliocene & $\mathbf{3 5}$ \\
Castle Eden & Middle Pliocene & 44 \\
Reuverian & Lower Pliocene & $\mathbf{7 0}$ \\
Pont-de-Gail & Base of Pliocene & $\mathbf{9 0}$
\end{tabular}

The figures show clearly a progressive extermination of older forms as compared with newer. In some way age has acted as an exterminating agent. How? Is it, to use the language of Age and Area, by dying out, or by killing out?

I take it that, by the use of these terms, Dr Willis intends to distinguish between extinction of species due to exhaustion of vitality, and extinction of species due to external agencies. That is, between internal and external causes. It cannot always be possible to distinguish between these two, for frequently, as we know, external causes are assisted in their work of destruction by pre-disposing conditions in the individual, or it may be in the race. Such relationships are seen in that of disease to susceptibility to disease, of change of climate to a weakened constitution. It is the external cause which seems the cause of death, though the internal cause may have an equal share in it.

Viewing the fact of the immense amount of extermination that has oceurred in this flora, I was at first inclined to think that such destruction of species, one might almost call it uni- 
versal destruction, must be the effect of dying out. It scemed that some all-embracing, inevitable, cause-" dying out"-must be at work, which in time would kill everything; "killing out" must be more localised and more discriminating. If due to climate, it might act in one region, if due to disease, upon one species, but not in regions far apart, or upon so many species.

Yet, with further consideration, the problem appeared differently. It had to be taken into account that the mere fact of age means so many more chances of destruction. Therefore these older forms must have suffered far more vicissitudes, and have been subjected to far more numerous attacks from exterminating agencies than the newer. The lapse of time since the deposition of the Eocene basalt of Antrim has been the subject of investigation by Lord Rayleigh, F.R.S. Basing his calculation on the amount of helium as compared with radium (and hence of uranium) present in haematite iron of that age, he reached the conclusion that the interval is one of 30 million years.

We must acknowledge that the vicissitudes of 30 million years are quite beyond the powers of our mind to grasp, and it seems possible that they may have furnished ample cause, through disease or other adverse conditions, to bring about all the destruction to which palaeobotany bears witness.

There is very strong evidence to show that the whole European branch of the Chinese-North-American flora was killed out, by being subjected to cold which it could not withstand, with no possibility of escape; and that it perished. trapped between the cold of the north behind, and an impassable trans-continental barrier of mountains and seas in front.

What of the other two branehes, the living ones? Has there becn extermination of species there? And if so, how has it occurred? We have already gained some knowledge on this subject, by comparing some of their species with those of the European Pliocene-which it must be remembered are nearer in time to the ancestral forms, even if they be not actually the ancestral forms-and we find that of the few species so compared somewhere about 90 per cent. have changed.

'To discover something more of the changes which have taken place, we may compare the living members of this flora with what are, without any doubt, the ancestors of some of them. The description of these is to be found in Prof. Nathorst's account of the Post-Miocene flora of Mogi in Japan (78-9). This is the largest of several Post-Miocene floras (mostly very frag- 
mentary) examined by him. With regard to the age of the flora, Dr Kryshtofovich, who has also worked much upon Japanese fossil plants, believes that it should be assigned to the base of the Pliocene (63). In that case it is contemporary with the flora of Pont-de-Gail.

Nathorst remarks of the Mogi flora that the outstanding fact regarding it is its closeness to the living flora of the forest-belt of the Japanese mountains; and we have only to consult his lists to see how true the statement is. But though the living flora be close to that of Mogi, it has changed. If we cxamine Nathorst's list we shall see that about 44 species may be considered as belonging to what I have termed the Chinese-NorthAmerican Association; and that of these. 39 are now represented by different species or varieties. That is, about $\$ 9$ per cent. have changed. The figure approximates closely to the 90 per cent. of changed species found, when we compared the Pont-de-Gail specics with living Chinese-North-American species. I do not wish to press the similarity of the figures. Whether it be due to chance, or really represents the degree of extinetion of older forms since the beginning of the Pliocene, I do not know. The number of species in the Pont-de-Gail flora, belonging to the Chinese-North-American plant association was small; also Prof. Nathorst's referenees to living speeies suggest that the Japanese Plioeene forms may be nearer to living forms than those of Pontde-Gail would appear to be. Anyhow, his work, like mine, bears evidence that old forms have very largely given place to new. We may say at once that the work gives no eridenee as to how the new forms arose, though the endemic Japanese spccies whieh are related to these old Mogi speeies would seem to have arisen in Japan; but though we cannot trace the history of the new, we can find out a little more about the extinction of the older forms.

If a list be made from all the five European Pliocene floras (those already named), of all the Chinese-North-American species which are still living-26 in all-it will be seen that by far the greater number are now foumd living in East Asia. Twenty species, out of the 26 , about $\mathbf{7 7}$ per cent., are there found; 5 species, or 19 per cent., in North America; whilst one species (Brasenia), or 4 per cent., oceurs in both continents. Again, consider the living genera represented-55 in all-33 of these, or 60 per cent., are found living on both continents; 17 , or 31 per cent., in East Asia only; 5, or 9 per cent., in America only. Therefore, whether we consider genera or species, there would 
appear to have been greater destruction in America than in East Asia. Such a conclusion is not wholly unexpected, and may help to suggest in part the fate of some of the older species.

In travelling to and fro in latitude in America, the plants would find themselves mostly in a country of great plains; not so in East Asia, where successions of north and south mountain chains existed in those old times, as in the present. It is known that many of the climatic changes which occurred during the Pleistocene were fairly rapid. When such rapid changes happen in a flat country, it may result that a migrating flora may be overtaken in its travel by the change of climate, and in that case many of its components will be exterminated, whereas in a mountain country, by change of altitude, they may escape.

Such facts may in part account for the lesser survival of Pliocene species in America than in East Asia. If so, it would seem that in part extinction in America too was due to killing out.

Age and Area. Let us now turn to the main theme of the subject and inquire whether the Chinese-North-American flora has any evidence to offer as to present distribution in connection with age. Taking it as a whole, we see an ancient flora associated, either fossil or living, with the widest possible range in longitude. Is there any evidence that it shows wide distribution in latitude associated with age? Such distribution would appear to me, certainly in the case of a flora with a dispersal originating in polar regions, to be a far more crucial test of age than dispersal in longitude, for with a circumpolar flora as a source of dispersal, with a cooling climate, spread would be equatorwards through all possible regions. The distance of travel would therefore be measured, not by span in direction of longitude, but by travel in latitude. In the case of the Chinese-North-American flora there is some evidence that travel in latitude is an accompaniment of age. It is too small to be estimated quantitatively, but is seen in the presence, especially among the older Pliocene floras (Reuverian and Pont-de-Gail), of such genera as Hakea, Symplocos, Styrax, Polanisia, and Trichosanthes, which have a present distribution into the southern hemisphere. The evidence as to the source and direction of migration of the Chinese-NorthAmerican flora to which they seem to belong indicates that these genera too are migrants from the north, and that their present distribution in latitude is partly due to age. 


\section{CHAPTER XV}

\section{ENDEMISM AND DISTRIBUTION: SPECIES}

$\mathrm{T}$ uE term endemic has long been used to connote a species, genus, or other group confined to a small area, such especially as a single island, a group of islands, a mountain chain, or a comparatively small country like South Africa or West Australia, largely bounded by the sea or by a marked alteration of climate. In recent years species of larger areas have been spoken of as endemic, but the term is used in an arbitrary way, for one speaks of species as endemic to Australia, though not to Brazil, which really has far more of them (533 endemic genera, perhaps 12,000 endemic species).

There is almost never any real and demonstrable difference between species and genera of small and of large area, other than in the territory occupied, but since the rise of natural selection it has been generally assumed that such a difference really occurs. On that theory one will expect to find many species "going under" in the struggle for cxistence, and the fact that so many are actually localised to small areas of territory, particularly in somewhat isolated regions of the globe, provides the necessary material for this explanation to rest upon. Botanists have long been accustomed to look upon endemic forms as the oldest, and very often as in some way expressly suited to the very local conditions in which they occur. This latter must of course be true for any species, anywhere, or it would be exterminated in a short time; but the study of detail which has resulted in the putting forward of the hypothesis of Age and Area gives reason to believe that in general the supposition of greater age of endemics is incorrect.

As endemics usually occur in somewhat isolated places or countries, the question at once arises whether endemism is correlated with isolation as such, for if so, the fact will have an important bearing on the question of evolution generally. There is also some ground, however, for supposing that the soil in isolated regions may be less completely taken up by its associations of plants, so that a newcomer would have a better chance of survival; and this may be the explanation.

From about $48^{\circ} \mathrm{N}$., to the southwards, all important islands. 
and mountain chains (if over 4500 feet), besides all more or less isolated pieces of country, like Italy, possess endemics. They are also frequent in such localities, even in large areas of country with large populations of plants, as are isolated in the sense that they do not lend themselves to free interchange of plants with their surroundings. Such are stations in large forests, or patches of grassland in forest country, patches of country with salt soil, and the like. The numbers and proportions increase to the southwards (and the isolation becomes less marked), till one finds the maxima in such places as West Australia, South Africa, Juan Fernandez, the Mascarene Islands and New Caledonia. Beyond about $40^{\circ}$ to $48^{\circ} \mathrm{S}$. they fall off again. "The greatest concentration of species in small areas occurs in... West Australia and South Africa" (52, p. 36). "The fertile portions of New South Wales, Victoria, South Australia, and West Australia do not probably...exceed in area Spain, Italy, Greece, and European Turkey, and contain perhaps half as many more flowering plants" (55 $b$, p. xxxi).

Endemism, though it is most commonly associated with islands in people's minds, is by no means a phenomenon confined to them. It is very strongly marked in comparatively isolated mountains, such as Kilimandjaro (and cf. 117 and 122), and in mountain chains, and in these cases the flora presents, as a general rule, less relation to that of the plains than does the flora of an island to that of the nearest mainland ${ }^{1}$. This may be largely due to the fact that, as explained upon p. 37 , mountains may act as highways of migration for the plants of other countries and climates.

Endemism is also strongly marked upon continental areas, and while the maximum proportion is in West Australia and South Africa-regions where conditions are rather extreme-all the southern land masses, more especially, show a great proportion of their species confined to themselves.

Whilst the largest numbers and proportions of endemics are chiefly in the more southern countries, there are also large numbers and proportions in several of the northern, e.g. in Mongolia, California, the region about the Mediterranean Sea, etc. There are a few endemies on the west coast of Europe, the Alps contain about 200, and Italy about the same; and the

1 "A great deal too much has been made of the assumed extreme differentiation exhibited by insular floras as compared to the continental flora" (52, p. 387). 
Iberian peninsula contains about 800 , or roughly the same as Ceylon, which, however, has only one-ninth of the area. The really large numbers are south of the tropic of Cancer. The Hawaiian Islands have 600, Ceylon 800, New Zealand over 1000, Australia about 7500, Mexico and Central America about 8000, and Brazil perhaps 12,000 . They are especially common in mountainous country, and it is worth noting that most islands are also mountainous.

No country or island has all its species endemic, though in several or most places where there is a very large proportion of endemic species, like Hawaii or New Zealand, it is very common to find genera with all their species endemic (cf. reply to objection 28, p. 95). St Helena, with a very small flora, seems to have perhaps the highest proportion of endemic spceies, but of countries with any large number, West Australia, with 85 per cent. of its species endemic, takes the first place. The Hawaiian Islands, with 82 per cent., are close behind. New Zealand (37) has 72 per cent., the Galápagos 46 per cent., the Bahamas 14 per cent., thus illustrating the fact that on the whole the further ont. and more isolated an island is, the greater is its proportion of endemic species. Fiji and Tahiti have much smaller proportions than the Hawaiian Islands, but Fiji, with 50 per cent., is much nearer to the mainland than Tahiti with 35 per cent., so that this alone is not sufficient explanation. Nearly half the ferns and lycopods in the Hawaiian Islands are peculiar to the group, in Fiji and Tahiti only about 8-9 per cent.

A study of the areas occupied by endemic species soon shows that they may be of any size from a few square yards upwards, and that there is no difference to be seen between them and species that are not usually considered endemic, and which may have areas of larger and larger size, up to one of a large portion of the globe. It was these extraordinary differences in area occupied, between species closcly resembling one another, and differing only in characters which conld not, by any stretch of imagination, be looked upon as fitting or unfitting them in any way for the struggle for existence, that first caused me to begin studying areas, and searching for some more potent agent in distribution than adaptation, a search which ultimately led me to Age and Area.

This new point of view, that the mere area occupied by a species has some more definite immediate interest than simply as an cxpression of some unknown character in the protoplasm, or 
some unsuspected property in apparently meaningless external characters, receives great support when the actual areas upon which species occur in any country are mapped out by drawing lines round their outermost locations. We shall begin with very localised endemics.

Mr H. N. Ridley (90, p. 555) found two plants of Didymocarpus Perdita Ridl. "on a bank in the centre of Singapore, surrounded by extensive cultivation. It has never been seen again." Dr Thwaites (37) found in the forest at Hakgala in Ceylon a few plants of Christisonia albida Thw. (C. P. 3929). This differed from its nearest relative, $C$. bicolor Gardn., in having the scales of the scape ovate and glabrous, instead of oblong-obtuse and pubescent; the bractlets below the flower instead of near the base of the peduncle; calyx glabrous instead of pubescent, with linear instead of triangular segments; and the corolla larger. Taken together with the fact that the whole plant was white, instead of the brownish colour usual in the Orobanchaceae, these differences were so large that the species was regarded as a Linnean species, and accepted as such in the Flora of British India, iv, p. 323. The plant has never been seen again, though the area of forest at Hakgala which could be reached by the invalid Dr Thwaites is very limited, and there is a botanic garden beside it, in which many botanists have worked, searching the forest thoroughly. Probably in both the cases just mentioned, the taking of a few specimens was sufficient to exterminate the species; and in the latter case, it is probable that the white colour alone would have been such a disadrantage as to ensure its extermination by nature in any event.

The next stage may be seen in such a casc as that of Coleus elongatus Trim., endemic only to the summit of Ritigala in Ceylon (p. 14). It occurs as about a dozen or two of plants upon open rocky places at the very summit, and differs so much from other Cole $i$ that it is a very distinct Linnean species, even if not subgenerically separate. Its nearest relative is $C$. barbatus. which also occurs on the summit, as well as in tropical Asia and Africa. The distinctive characters may be tabulated as on the following page.

It is all but impossible to imagine that any of these characters, and especially the two most important, the peculiar inflorescence and calyx, have any serious effect upon the capacity of the species to survive or progress, or that any of them can be seriously disadvantageous. It is worth while in this connection 


\section{C. barbatus}

(Bot. Mag. T. 2318)

Stem cylindrical, tending to quadrangular in inflorescence

Stem pubescent with long hair

Leaves oblong-oval, 1-2 inches

Leaves closely pubescent

Lcaves rather thick

Petioles rather short

Inflorescence of condensed cymes, each about 5-flowered, forming false whorls of 10 flowers at each node

Flowers large

Bracts large

Calyx with long hairs

Calyx of one large ovate upper tooth and four small lower

Corolla rich purple or white

Grows on rocky places

\section{C. elongatus}

(Fig. in Trimen's Ceylon Flora, T. 74)

Stem quadrangular

Stem pubescent with short hair

Leaves ovate-triangular, 1-2 inches

Leaves finely pubescent

Leaves rather thin

Rather longer and slenderer

Inflorescence of one-sided cymes, looking like racemes, about $1 \frac{1}{2}$ inches long, one at each side of cach node

Flowers small

Bracts small

Calyx with short liairs

Calyx of five almost exactly cqual tecth

Corolla pale purple

Trails over rocks

to look at the distribution of the other Ceylon Colei, already described on p. 54. There is no such difference in the method of dispersal as will account for the great differences in area occupied, nor is there any difference in the other characters of the plants that one can point to, as advantageous or disadvantageous.

A somewhat larger area than that of Coleus elongatus is that occupied by Campamula Vidalii, which is found (47, p. 42\%) on rocks near the sea on Flores and two other islands of the Azores. A still more interesting case is Cenchrus insularis, which is found only on one islet of the Alacran reef (75), about thirty miles off the coast of Yucatan, while Cakile alacranensis and Tribulus alacranensis are found on all the four islets of the reef, the largest being less than half a mile long, and very narrow. There seems some reason to imagine that the evolution of these species has been fairly rapid, as they were not noticed by the Admiralty expedition that visited the islands fifty-seven years previously. And scores of similar cases of distribution might be cited.

We may go on to deal with genera containing several species in the same neighbourhood, all or most of them endemic, giving a few actual instances. Doona, for example, a Ceylon endemic genus of Dipterocarpaceæ, has 11 species, whose local distribution (fig. on p. 153) is typical of that of many local genera, or genera with many spccies (mostly endemic) in one locality. The whole range of the genus (about 4000 square miles in south- 
west Ceylon) is occupied by one of its species, D. zeylanica, while the others occupy smaller and smaller arcas within this, down to a comparatively few square miles. This is perhaps the most common type of distribution with genera of small area, which upon the theory of Age and Area are to be regarded as young beginners. Another instance is Haastia in New Zealand (fig. on p. 154).

Distribution of the same type, but more extended, is shown by the (chiefly endemic) species of Ranunculus in New Zealand (fig. on p. 156), and by very many other genera in that country. In this map the widely distributed species, i.e. those occurring outside of New Zealand, are shown by dotted lines, and it

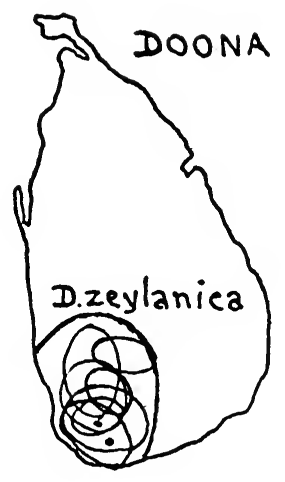

will be noticed that three of them range all over New Zealand (including the little Stewart Island to the south), and also to the Chathams, 375 miles to the eastward, while the fourth only ranges from the far south up to the middle of North Island. The endemics all have ranges within that of the first three wides, among which probably, upon the general implications of Age and Area, one must prineipally look for their parent or parents. The endemic with the greatest range covers slightly more ground than the wide of least range, and the others occupy smaller and smaller areas, becoming steadily more numerous in going south, till a maximum is reached a little south of the middle of South Island, as indicated in the following figures (ef. p. $\tau \tau$ ), which 
154 ENDEMISM AND DISTRIBUTION: SPECIES [PT. II

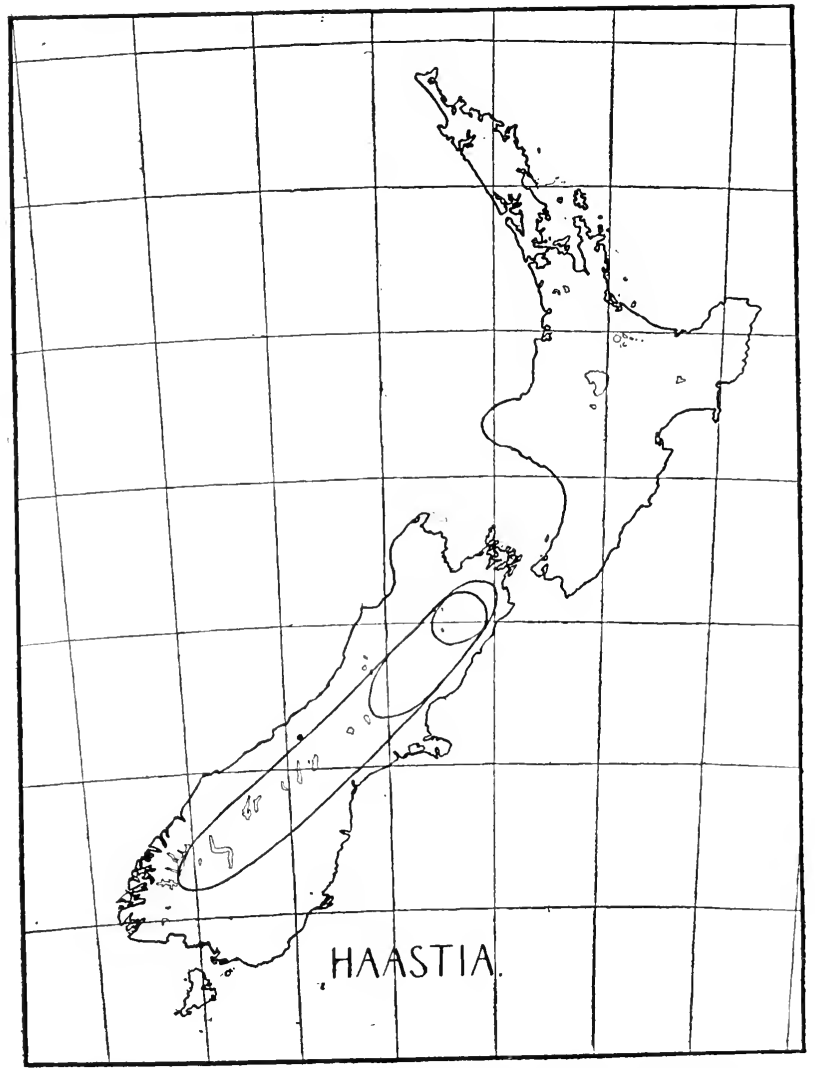

Diagram showing the areas oecupied by the species of IIaastia in New Zealand.

(By courtesy of the Editor, Annals of Botany.) 
show the numbers that oecur in each zone of 100 miles from north to south in the two large islands:

$\begin{array}{lrrrrrrrrrr}\text { Wides } & 3 & 3 & 3 & 4 & 4 & 4 & 4 & 4 & 4 & 4 \\ \text { Endemies } & - & 2 & 3 & 5 & 7 & 11 & 12 & 18 & 18 & 10\end{array}$

If instead of taking the distribution in this way by zoning, one take the actual longitudinal range of the different species, one finds that of the 28 endemic Ranunculi, 10 have a range not exceeding 60 miles longitudinally in New Zealand, while of ranges $120,180,240$, etc., there are only $1,3,1,2,4,1,1,1,2$, $0,1,0,1$. The great bulk are obviously crowded towards the short ranges. If one make five groups, occupying ranges from 0-200, 200-400, 400-600, 600-800, 800-1000 miles, one finds that they contain $14,7,5,1$ and 1 species respectirely. If, now, one plot these figures in a curve (fig. on p. 162, eurve 7 ), one obtains a curve which is concave upwards, or what we may term a hollow curve. This type of curve we shall presently see to be almost universal in distribution-and it proves of late to be equally so in evolution itself. At first, perhaps, its presence will not be readily noticed, but when one finds the figures for any example of distribution or evolution showing a great accumulation at one end, and the first two or three descending very rapidly, while the remainder tend to taper away gradually, one will generally find this type of curve shown, on actually plotting the figures. It shows very strikingly in many of the examples described below, e.g. the distribution of the IIawaiian endemie species of Cyrtandra described on p. 160, (same fig. curve 6).

Or one may take such a genus as Epilobium in New Zealand (37, p. 171). E. purpuratum is confined to the Alps of Otago, 4000-6000 feet, E. brevipes to the northern half of South Island, $E$. crassum to the greater part of the length of South Island; $E$. melanocaulon ranges the whole length of South and the southern half of North Island, E. microphyllum ranges yet farther north, $E$. glabellum farther again, while $E$. rotundifolium ranges the whole length of both islands, and reaches Stewart and the Chathams. E. nummularifolium reaches all this, and also Auckland and Macquarie Islands to the south, while E. pallidiflorum ranges this and reaches Australia and 'Tasmania. 'This, or something like it, is the eommon type of distribution in New Zealand. If we take a genus-and there are many-that has no wides in New Zealand at all (ef. p. 95), we find the same thing shown, as, for example, in Gunnera (fig. on p. 158). Here there is one 


\section{ENDEMISM AND DISTRIBUTION: SPECIES [PT. II}

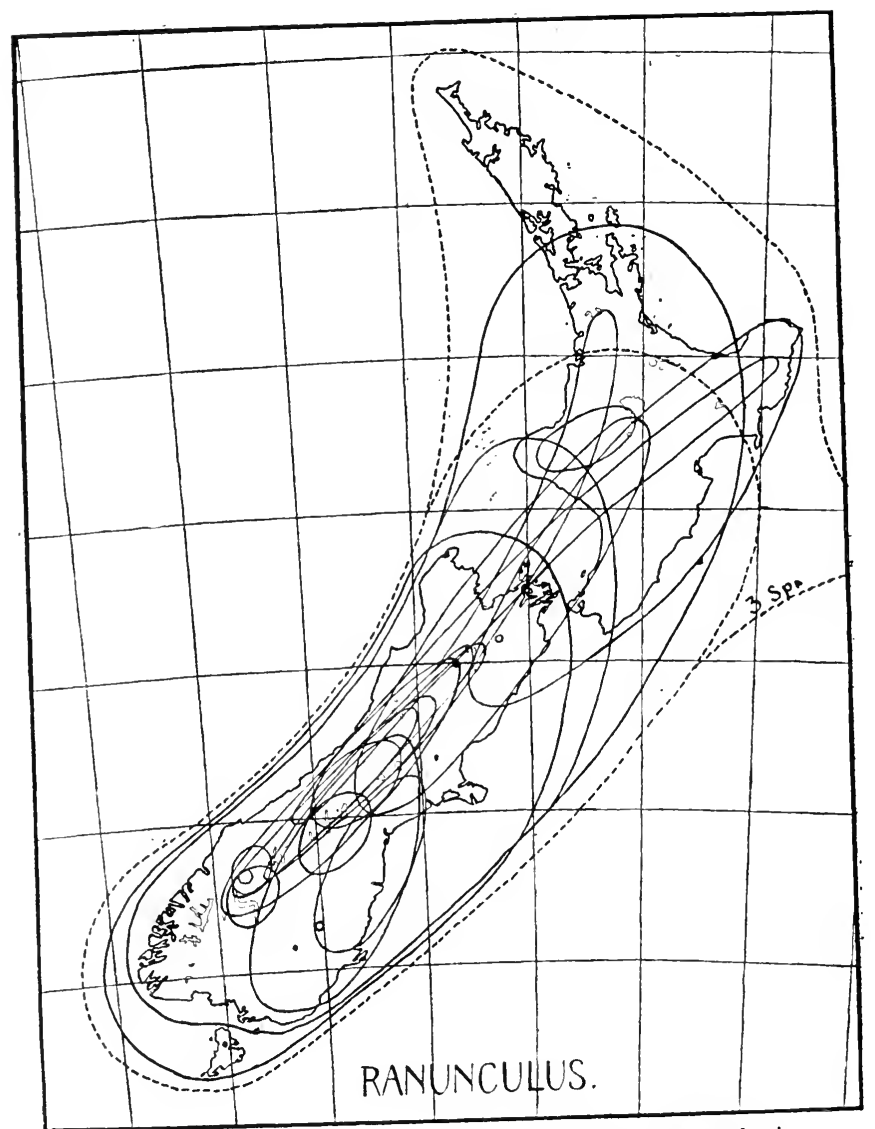

Diagram showing the areas occupied by spccies of Ranunculus in New Zealand. Wides dotted; extension East includes Chathams. (By courtesy of the Editor, Annals of Botany.) 
endemic species that covers all New Zealand, and reaches the Chathams, and the other endemics occupy smaller and smaller areas within this. The figures by zones show:

$$
\begin{array}{llllllllll}
2 & 2 & 3 & 5 & 5 & 5 & 6 & 6 & 6 & 5
\end{array}
$$

a result exactly similar to that for Ranunculus. The presence of wides does not seem in any way necessary, nor to eause the species of a genus to behave in any way differently.

If we go to Ceylon, and take a few species of the pan-tropical genus Eugenia, of which Ceylon has 29 species endemic to the island and 14 found elsewhere ( 6 only in southern India), we find that $E$. cyclophylla occurs only on Adam's Peak, E. lucida on several peaks close together, E. sclerophylla on a number of peaks and in the plains between, $E$. assimilis throughout the mountains and in the moist plains, E. hemispherica in all this and also in South India, and E. operculata in these regions, and also in Burma, Malaya, and China. And many other genera show the same type of dispersal, which, in fact, a little study soon shows to be the usual type. If one go to the state of Rio de Janeiro in South Brazil, which has an area about equal to Ceylon, one finds 52 Eugenias endenic to the state (which is very mountainous), and 6 going beyond it, 3 only into Minas, the next state, the other three as far as the states of Alagoas (1000 miles north along the coastal plain), Rio Grande do Sul (the same south) and Goyaz (600 miles inland, across the mountains). And one may find Eugenia behaving in the same manner in many other places. In Brazil it has many endemic speeies in Minas, the next state to Rio, but on the other and drier side of the mountains that fringe the coast.

This general type of distribution shows very clearly in the case of very many genera, whether they be endemic genera with all their species in a confined area, like Doona in Ceylon, or whether they be genera of wide distribution that have developed many endemic species within a certain small area, like Ranunculus in New Zealand. In such cases they do not scem as yet to have encountered any barriers of a very serious kind. But one may also find a great number of genera, or sections of genera, in which the same thing is displayed over a very much larger area than what would entitle the contained species to be considered endemic. In Callitris, for example, $C$. glauca occupies the whole range of the genus over Australia and Tasmania (130); two others range from New South Wales to Tasmania and to West 
158 ENDEMISM AND DISTRIBUTION: SPECIES [PT. II

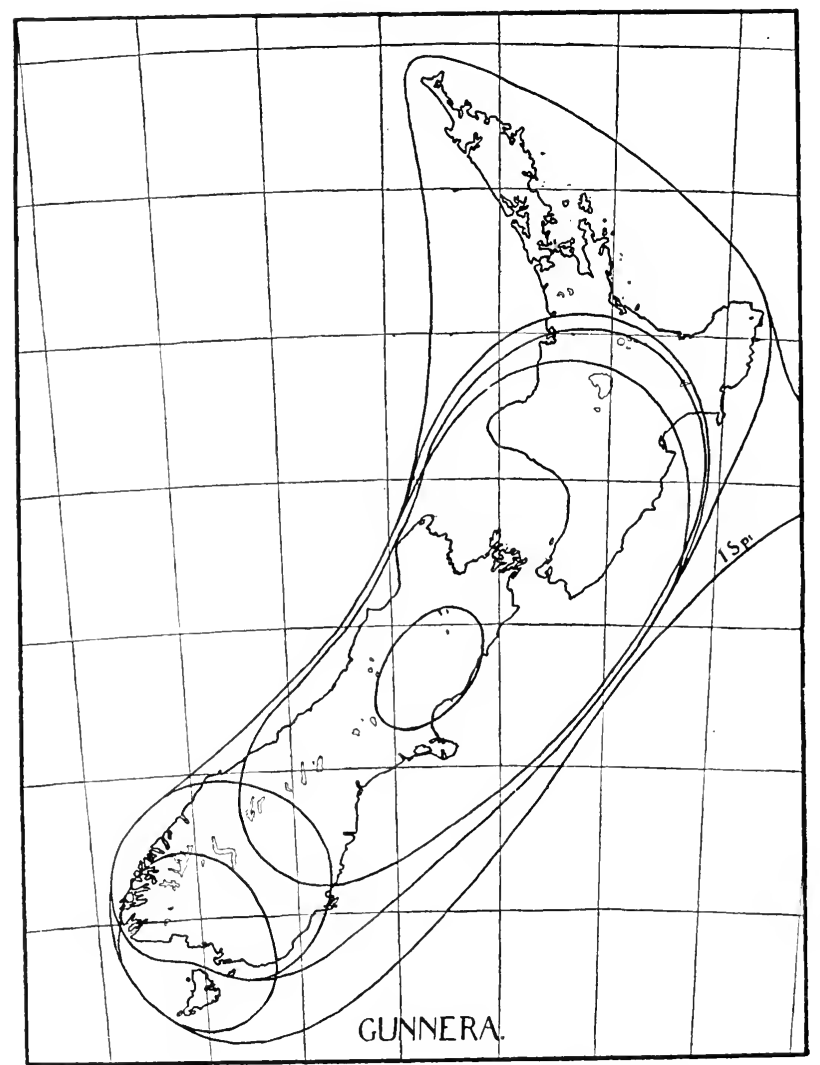

Diagram showing the areas oecupied by the species of Gunnera in New Zealand.

(By courtesy of the Editor, Annals of Botany.) 
Australia, while the remaining 15 species of the genus cover smaller ranges. In Dillenia, D. indica covers practically the range of the genus throughout Indo-Malaya, while there are many other species covering smaller and smaller ranges within this. In Gymnema, G. sylvestre covers almost the whole range of the genus from West Africa to Australia, whilst in Cissampelos, C. Pareira is found from tropical America through Africa and Asia to the Philippines, almost covering the whole range of this cosmotropical genus. In Najas, finally, N. marina is cosmopolitan, while five other species occupy very large areas, nine occupy areas of moderate size, and seventeen areas of small size.

Another very frequent case in endemic genera of small area, or in genera with a number of endemic species within a small area, is to have one species occupying a "circle" of some size, and another a (usually) smaller circle touching, or near to, the first, thus giving the impression that the plants occupying it have possibly sprung from some unusually isolated members of the first species, in the case of an endemic genus which has no species covering the range of both. In Ceylon, for example, in the endemic genus Hortonia, which has three species, $H$. angustifolia occurs in the moist plains, and to 2000 feet in the mountains, while $H$. floribunda occurs only in the mountains above 4000 feet, and H. ovalifolia is confined to Adam's Peak. Or in the Ceylon endemic genus Schumacheria, $S$. castaneaefolia is common to a height of 1000 feet, $S$. alnifolia above that level, and $S$. angustifolia occupies a tiny circle within the area of the first named, but a long way from $S$. alnifolia.

This type of distribution, in smaller circles, usually overlapping one another to a greater or less extent, while there is no single one covering the whole range, is also very common. To take an example at random from the Indian flora, Christisonia (37, Iv, p. 323) has three species in Ceylon, one frequent in the hills, two confined each to one spot (cf. p. 151), three in the Dekkan or the Konkan, three in both Ceylon and South India, and one in Sikkim and the Khasias. None has individually a very large range, yet the genus covers much ground, and there is some overlapping of species. One may sec the same type of distribution upon a fairly large scale by taking such a genus as Cyrtandra, whose species are distributed as follows $(25, \mathrm{r}, \mathrm{i})$ : 
Java, Sumatra, Singapore to Tenasserim . • • • • . $\quad 55$

Sumatra, Penang, Borneo, Celebes, Amboina, Papua $\quad 56$

Java, Borneo, Philippines . . . . . . . . 5

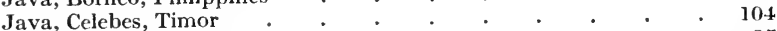

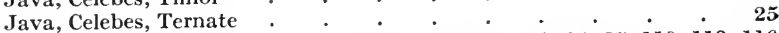

Java, Sumatra $\quad \cdot \quad 2,6,17,24,77,79,84,87,110,113,116$

Sumatra $4,8,14,18,57,58,73,74,75,78,82,85,86,88,90,91,114,163-5$

Sumatra and Penang or Malacea . . . . . . 1, 76

Java . . 19, 20, 21, 23, 71, 72, 107, 108, 109, 118

Java, Singapore, and Celebes, or Ternate - • • $\quad 83,106,115$

Borneo $3,7,9,10,11,12,13,16,22,64,66-70,80-1,99-102,112,117,160$

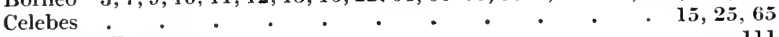

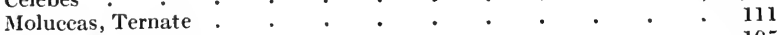

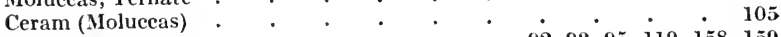

Philippines . . . . $\quad . \quad$. $\quad .92,93,95,119,158,159$

China . . . . . . . 94

New Guinea $\quad . \quad+\quad . \quad+\quad . \quad+\quad 89,97,98,103$

Carolines . . . . . . . . . 996

New Hebrides . . . . . . . . . 125, 157

Fiji Islands : . $\quad 51-4,59,124,128-9,132-3,139-40,151-6,161-2$

Samoas . . . $\quad 127,130-1,134-5,141,149-50,150,166-7$

Societies, Low Archipelago . . . . . . . 137

Societies . . . . . $\quad$. $120-22,126,136,138,146-8$

Sandwich Islands . . . . . . . $2 \tau-50,60-3,123,142-5$

The whole range of the genus is from Tenasserim to the Sandwich Islands, yet no single species reaches half this distance. Most have very small ranges, e.g. most of those upon Java or Sumatra, which are usually confined to portions of these islands, but there are a fair number, e.g. those in lines $3,4,5$ and 6 , which have rather large, and two at the top with very large, ranges (cf. fig. on p. 162, curve 1).

One may eren follow them into more minute detail, for example, in the Pacific Archipelagoes. In the Sandwich Islands, 1 species occupies four islands, 2 occur on three, 2 on two, whilst there are 24 on single islands, viz. 11 on Oahu, 4 each upon Kauai and Maui, 3 upon Molokai, and 2 upon Hawaii. The same thing may be seen upon the Samoan and other islands; this "hollow curve" type of distribution is general, as we shall see below (cf. fig. on p. 162, curve 6).

One may follow this type of distribution into the small varieties of Linnean species, to which specific rank is often given by local botanists. For example, dipping into Linton's British Hieracia, and taking the section Nigrescentia, one finds $\$$ species occupying six to ten counties, and 9 in onc to five, but no single one covering all the range. These two cases, (1) that there is one or a few widely ranging species with larger and larger numbers 
of more and more localised species scattered about within or close to their range, and (2) that there are many species of local range, usually more or less overlapping one another, and themselves overlapped in many places by fewer species of rather wider range, and in the total occupying considerable areas, which are as continuous as intrusions of the sea and other barriers will allow, seem to cover the case of the bulk of existing genera. The latter case also makes, though not so strikingly, a hollow curve, for there are more species of small areas.

It is clear that the types of distribution shown by endemic species, whether of endemic genera or not, are the same types that one may see in the dispersal of genera, species, and varieties of wider range; there is no place at which one can draw a line, and say that here is the distinction between endemic and nonendemic species.

But the resemblances between endemic and non-endemic species may be carried much further. In the case of the former, as we have seen above, their usual grouping in a country shows a few in the class containing those of widest local dispersal, and larger and larger numbers as one goes down the scale to the more localised classes. And this grouping shows, not only for the grand total, but for the individual families and larger genera. The actual figures for New Zealand show that the curve so produced is a hollow one (fig. on p. 162, curve 5). The peak in the middle of the curve is accounted for, perhaps, by the opening of Cook's Strait having checked the dispersal of some of the species $(\mathbf{1 2 7}$, p. 455). If, dipping at random into the New Zealand flora, one take the lBoraginaceae, and divide the endemics into five classes, one finds $2 / 1$ (two in class 1 ) $, \mathbf{1} / \mathbf{2}, \mathbf{2} / \mathbf{3}$, $5 / 4,13 / 5$; or if one take Olearia, one finds $2 / 1,5 / 2,4 / 3,6 / 4,14 / 5$. Always the same type of curve is formed, with an accumulation of species at one end.

But this same phenomenon shows in the case of all other species, whether endemic or not. In Doona in Ceylon, for example, one finds one species of large area, three of smaller, and scren of areas smaller yet. With the largest endemic genus in the Hawaiian Islands, Cyanea, one finds (cf. Cyrtandra above) one species on four islands, six on two, and 21 on a single island. Pelea, the next largest genus, shows $1 / 8$ (one species on all jslands), 3/4, 3/3, 2/2, 11/1, again a hollow curve, running out very much at one end. If one add up all the species of the 


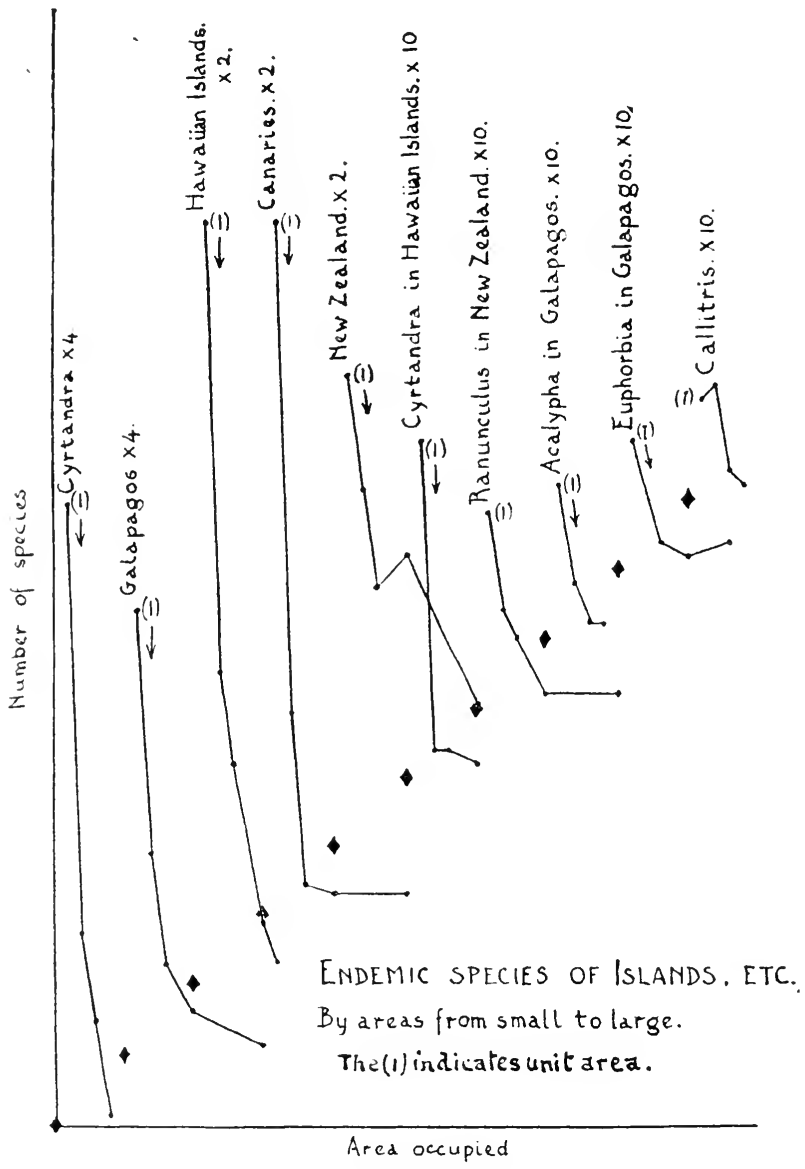

Endemie speeies by area from small to large 
endemic genera of the Sandwich Islands, and compare them with the endemic species in the non-endemic genera, one gets:

Table showing the numbers and proportions of species of endemic and of non-endemic genera that occur on all the Hawaiian Islands, or on four to six islands, etc. Thus on all islands there occur $3 \cdot 1$ per cent. of the species of endemic, $9 \cdot 5$ per cent. of the endemic species of non-endemic genera.

\begin{tabular}{|c|c|c|c|c|}
\hline \multirow[b]{2}{*}{ Occurring on } & \multicolumn{2}{|c|}{$\begin{array}{c}\text { Species of } \\
\text { endemic genera }\end{array}$} & \multicolumn{2}{|c|}{$\begin{array}{l}\text { Endemic species of } \\
\text { non-endemic gencra }\end{array}$} \\
\hline & species & $\%$ & species & $\%$ \\
\hline Afl islands & 7 & $3 \cdot 1$ & 34 & $9 \cdot 5$ \\
\hline $4-6 \quad$, & 23 & $10 \cdot 2$ & 51 & $1+3$ \\
\hline 3 & 25 & $11 \cdot 1$ & 55 & $15 \cdot 4$ \\
\hline , & 41 & $18 \cdot 2$ & 72 & $20 \cdot 2$ \\
\hline 1 island & 129 & $57 \cdot 2$ & 144 & $40 \cdot 4$ \\
\hline & 225 & $99 \cdot 8$ & 356 & $99 \cdot 8$ \\
\hline
\end{tabular}

Average dispersal 1.8 islands

Thus the species of the endemic genera are dispersed on the average some $\mathbf{2 5}$ per cent. less than those of the non-endemic genera. This proves on examination to be a general rule, and is a powerful argument against local adaptation. It shows with equal clearness in New Zealand and in Ceylon (123, p. 324).

If one go on to Ranunculus in New Zealand, which has "wides" as well as endemics, while Olearia (above) has not, one finds $1 / 1$, $1 / 2,5 / 3,7 / 4$, and $14 / 5$, taking only five classes instead of ten. If one take at random in Vol. Iv of Hooker's Indian Flora a few genera, one finds in Exacum one species with large, six with intermediate, and nine with small areas. In Christisonia, where there is no single widely ranging species, there are 4 with moderate areas, and 6 with small. In Ebermaiera 1 has a very large, 6 an intermediate, and 21 a small area. Or, finally, take Cyrtandra (above); there are, roughly, 2 with very large areas, about 20 with fairly large, and about 145 with small, these latter again showing gradations down to the smallest, as we have just scen (p. 160).

It is clear that the distribution of endemies is only a special case of a wide general phenomenon-that there are, in any family or genus of reasonable size, a few species of wide dispersal, and others of less and less dispersal in incrcasing numbers, the increase being more rapid as one descends the scale, so that the curve produced is hollow. When, as in very many genera, there 
is one species covering the whole range of dispersal, the classification can be carried into greater detail, but even in such cases as Cyrtandra, where there is not such a species, the phenomenon can be quite clearly seen. It is evidently perfectly general, and we shall sec many further examples of it in the next chapter, and go on to consider its general bearings in later chapters.

When one goes on to examine into the genera and families to which endemic species chiefly belong, one discovers that in most countries the bulk of the endemic species do not belong to the endemic genera. Even in a region of such marked endemism as the Hawaiian Islands (37), for example, where there are several very large endemic genera, only 225 out of 581 endemic species belong to the endemic gencra, or 38 per cent. In New Zealand less than 5 per cent. do so, and in Brazil perhaps 10 per cent.

The numerous endemic speeies that do not belong to endemic genera are found on examination to belong, not, as one might perhaps expect, to small and broken genera, which we have been accustomed to consider moribund, but in greater proportion to the larger and more important genera. The average number of species in a genus, taking the whole world, is about $12 \cdot \%$, and in the Hawaiian Islands, taking the first hundred genera in the flora (37), we find that of the 47 that contain endemics, but are themselves widely dispersed, 36 are above the average size in the world, and have 102 local endemics, while 11 are below, and have 22 endemies. Of these 11 belong to Lipochaeta, which only occurs outside these islands as a single species in the Galápagos. The average size of the whole 47 genera (in the world) is 97 speeies, or eight times the average. Of these genera 8 are cosmopolitan in their dispersal, 11 are tropical and subtropical, 8 are tropieal, these three categories including $5 \tau$ per cent. of the total (cf. Chapter xir, Size and Space). A further 9, bringing the total to 76 per eent., occur in both Old and New Worlds.

If we turn to New Zealand, and take the first 100 genera (37), of those with endemics 43 are above the average in the world, and only 14 below, while the average world-size of one of these 57 is 73 species, or six times the world-average. The same thing shows wherever I have tested it. For example, if one take the first 100 genera in Vol. Iv of the Indian Flora (37), most of them as it happens being Asclepiads, which are unusually small genera, one finds 52 non-endemic genera, of which 38 are above, and 14 below, the average world-size. The remaining 48 are largely endemic genera, for India, like all large areas, has a greater pro- 
portion of its genera endemic than have the outlying islands, etc. The average size of all 52 is 52 species, or still much larger than that for the world, though less than for New Zealand.

The further out one goes from the centres of greatest massing of genera and species, in other words, the larger on the average (in size in the world) do the non-endemic genera become. The genera above mentioned in the Hawaiian Islands, New Zealand, and India, that are below the average world size, are in all 39 with 89 endemics, while those above are 117 with 688 . This fits in with what was said above (p. 115) about Size and Space, that on the whole the larger the genera, the larger the area they occupy.

This faet, that the endemic species, in all regions of the world, belong in greater proportion, not to the small and loeal genera, but to the large and widespread, is one of the most striking features that spring to attention when one begins to study endemism. In New Zealand, for example (37), the genera that have most endenic species are Ranunculus ${ }^{1}$ (with 32), Epilobium (24), Coprosma ${ }^{1}(40)$, Olearia $^{1}(35)$, Celmisia $^{1}(42)$, Senecio $^{1}(29)$, Myosotis (21), Veronica ${ }^{1}$ (81), Carex $^{1}(36)$ and Poa $^{1}(21)$, a fairly well-known list of genera. These ten contain no less than 36 per cent. of the endemies of New Zealand. Or in Ceylon, the largest numbers of endemics are in Eugenia (29), Memecylon (21), Hedyotis (16), Symplocos (17) and Strobilanthes (25), again not altogether unknown genera, the five containing 13 per eent. of the endemies of the island. And if one study the endemic or local species of the world, one finds these same genera appearing in many other places with large numbers of local species; Eugenia, for instanee, has about 240 in Brazil (52 in the little state of Rio). If one adopt the explanation of dying out, these great genera must have become world-wide very early, and have left all these endemics as stragglers, dying out before the advancing host of those species which had proved the best adapted to the conditions.

The view to which all this leads is simply, as has already been mentioned (p. 61), that in the vast majority of eases endemic species are young species comparatively recently evolved, and still in the earlier stages of their distribution about the globe, while they show no points of distinetion from species of larger

1 These genera also occur with endemic representatives on the outlying islands (Kermadecs, Chathams, Aucklands), where they have 27 out of the grand total of 73 endemics of these islands, or 37 per cent. 
area, being distributed upon exactly similar principles, and like them showing many of small area, with numbers diminishing at first rapidly, and then more slowly, towards the few that occupy large areas, the effect of the figures, when plotted graphically, being to form a hollow curve (fig. on p. 162).

One may almost regard the question of endemism as the central point of taxonomic distribution, upon which all the rest depends. Controversy has largely centred around it, and there are at least three rival explanations in the field at the present time. These are (1) that endemics are very specialised species (and genera) suited only to the areas upon which they are found; (2) that they are old species (and genera) which have been driven into quict nooks, or left in odd corners, by the competition of better adapted species; and (3) the explanation just given, that in general they are young beginners, descended from the "wides."

The first and second explanations were based upon incomplete knowledge of the distribution of endemics, and can no longer be regarded as general. One has only to think over what has bcen pointed out above (and ef. p. 55). The facts (1) that the cndemics are distributed in "wheels within wheels" (cf. maps given above), (2) that the numbers in any genus in a country increase from the edge up to a maximum at some point or region, (3) that this is the same place at which many other genera have also their maxima, (4) that there may be more than one place in a single country (p. 78 ) where these maxima aggregate together, (5) that the distribution of the endemies by areas forms hollow curves, increasing most rapidly to the smallest areas of all, (6) that these hollow eurves show for country by country, for family by family, even for genus by genus, (7) that there is no difference in type of distribution between the species of endemic genera, those of widely distributed genera with all species endemic, and those of widely distributed genera with some species endemic and some not, (8) that the species of endemic genera show less dispersal in a country than the endemic species of non-endemic genera, (9) that the endemic species mainly belong, not to the endemic genera, or to small and broken genera, but to the large, widely distributed, and "snccessful", genera of the world, (10) that endemic species are distributed, and behave, just like other species, (11) that endemics increase in numbers and proportion towards the south; to say nothing of other facts already brought up, or of the difficulties in explaining in any single case what characters are disadvantageous (as 
required for dying out), or advantageous (as required for local adaptation), these facts, we repeat, are very much against any explanation that is based, as are the two first named, upon natural selection. Further, upon these suppositions it is impossible to make any of the predictions that have already been so successfully made.

There remains the third hypothesis, that in general endemics are species so young that they have not yet had time to spread to any great extent, or in other words that they are in general the most recent appearances of species in the genera to which they belong. Only in some such way can one explain the appearance of such maps as those given above for Doona or Ranunculus, or the "hollow curves" of distribution. No valid evidence has yet been brought up to show that this is not the correct view to take of the existence of the majority of endemics. There can be little doubt, however, that quite an appreciable number of existing species must be looked upon either as relics, or as local adaptations. The relics may or may not be dying out (cf. replies to objections, pp. 88 to 94). The local adaptations must, of course, be looked upon as simply a special case, i.e. as species which appeared at first (as all species, to survive at all, must do) as eminently suited to the local conditions that obtained at their birthplace, but which have not been able to spread far, by reason of ecological boundaries caused by changes of conditions at a very short distance.

There are many points in favour of this third hypothesis. It explains as well as the other two all the phenomena that they were able to account for, and also very many to which they were quite inapplicable, as, for example, the eleren given on p. 166. It also enables us to make predictions about distribution, which an examination of the facts shows to be justified, and it has already been successfully employed in this way nearly a hundred times. Under these circumstances, Age and Area may perhaps be regarded as at any rate possessing a greater basis of probability than either of the two hypotheses based upon natural selection.

\section{Summary}

It is shown that no real difference can be pointed out between endemic and non-endemic species (or genera). The former are frequent upon mountains, upon islands, and in isolated pieces of country, or in regions in which dispersal is very slow, or 
hindered by surrounding barriers. Instances are given of the space occupied by endemics, beginning with very minute areas, and going on to larger; the latter show no break as one goes on to areas larger again, up to any size possible for a species. No difference can be seen between endemic and non-endemics.

It is shown that endemics are distributed in "wheels within wheels" (cf. maps); and that other features obtain in their distribution, of which a brief list is given on p. 166. None of these, or but few, can be explained on the supposition that endemics are local adaptations, or are relics, and the only possible explanation, for the vast majority, seem to be that provided by Age and Area and Size and Space, that, in general, they are young beginners, descended from the "wides."

The most important general feature in the distribution of endemics is probably that it is always of the "hollow curve" type (fig. on p. 162) with most species on the small areas, and numbers rapidly decreasing upwards to the large. This same type of distribution proves to be the rule for all genera, however large they may be, and however large an area they may occupy. Endemics simply present a miniature of the general distribution in the world. 


\section{CHAPTER XVI}

\section{ENDEMISM AND DISTRIBUTION: GENERA}

$W_{\mathrm{E}}$ have seen that endemic species are especially common upon islands, upon mountain chains, and in more or less isolated localities (small or large), and that in all such regions they increase, on the whole, in passing from north to south, up to a certain limit. We have also seen that it is probable that the great bulk of them must be regarded as young beginners. But if this be so, there is no logical reason why the same should not be true of endemic genera, which occur in similar places, and there is every probability in its favour. Of course, just as in the case of species, there are doubtless many exceptions here and there, but we are speaking of the genera in the bulk.

When the number and proportion of endemic species is large, there are generally to be found a fair number of endemic genera also, but there seems no necessary relation between number of species and number of genera; or perhaps rather, this relation may be much interfered with by other causes. The Hawaiian Islands have more endemic genera than Ceylon or New Zealand, though they have many fewer endemic species; on the other hand, they are more isolated. This matter still requires more careful investigation.

The number of genera confined to islands or mountain chains seems to increase with at least three factors - with the size of the island or mountain chain, with the isolation of the same, and with increased southern latitude, up to $45-50^{\circ} \mathrm{S}$. The effects of all these factors may be seen in the list below, by comparing, for example, Ceylon and Java, Ceylon and the Hawaiian Islands, and Ceylon and New Caledonia (which is much smaller).

The greatest proportion of endemic genera to area is to be found in some of the southern and comparatively isolated locations, e.g. in the islands of Juan Fernandez, the Mascarenes, or New Caledonia, in south-west South Africa, in parts of West Australia, etc. But the actual numbers of endemic genera increase with increasing area, as the rough figures ${ }^{1}$ on p. 170 show.

As in the case of species, no country has all its genera endemic, and most are very far indeed from this condition. Contrary to

1 Taken, without criticism, from my Dictionary, and not revised in detail. 


\begin{tabular}{|c|c|c|c|}
\hline Islands & $\begin{array}{l}\text { Endemic } \\
\text { genera } \\
\text { about }\end{array}$ & Continental & $\begin{array}{l}\text { Endemic } \\
\text { genera } \\
\text { about }\end{array}$ \\
\hline British Islands & 0 & Meditcranean region & 280 \\
\hline Macaronesia & 20 & India & 320 \\
\hline Ceylon & 23 & Australia & 470 \\
\hline Jajan & 69 & Colombia & 87 \\
\hline Fiji & 56 & Peru & 75 \\
\hline Hawaiian Islands & 45 & Chile & 140 \\
\hline Borneo & 71 & Brazil & 533. \\
\hline Java & 62 & Argentina & 47 \\
\hline New Guinea & 146 & South Amcrica & 1731 \\
\hline New Caledonia & 134 & South Africa & 523 \\
\hline New Zealand & 32 & Africa & 1733 \\
\hline Madagascar & 266 & & \\
\hline Mascarenes & 64 & & \\
\hline Juan Fernandez & 10 & & \\
\hline
\end{tabular}

what is often supposed, the proportions of endemic genera upon islands are usually small: they range from nothing for the British Islands to about 12-20 per cent. upon such islands as Juan Fernandez, the Mascarenes, and New Caledonia, being as usual larger in the more southern islands. On larger areas of ground the proportions are greater; Brazil has about 21 per cent. of its genera cndemic, and so has Chile, Australia about 30 per cent., South Africa about 35 per cent. Africa as a whole has about 46 per cent., and the proportions increase with increasing area till one finds 100 per cent. endemic in the world.

Whilst in general it is truc that increasing size of area, greater isolation, and greater nearness to the southern limit of about $40-48^{\circ} \mathrm{S}$. are aceompanicd by increasing number and proportion of local genera, these are probably not the only factors in the question. If the country from which the invasion of plants has come be inhabited by great numbers of them, or if the communication between them be broad, the proportion of local genera will be more likely to be large.

There is no definite and demonstrable difference between endemic genera and others, and we shall endeavour to show, just as in the case of species, that the phenomena exhibited by them are simply a miniature of those exhibited by genera as a whole.

One may, to a very large extent. repeat the preccing chapter, but with genus substituted for species, and family for genus, and find it to agree with the facts about endemic genera, which behave like the species. Just as in their case, the areas occupied by genera, whether so local that they are classed as endemic, or whether of larger size, are nicely graduated from small to large. 
Inasmuch as a genus consists on the average of over twelve species, which never all occupy the same area, it is obvious that the average area occupied by a genus must be larger than that occupied by a species, but that does not affect the argument.

Some endemic genera occupy very small areas, e.g. IIomalopetalum in three parishes in Jamaica, Itatiaia on one mountain in southern Brazil, Sphagneticola in a suburb of Rio de Janeiro, Leichhardtia on the Daintree River, Carpolyza in the immediate suburbs of Cape Town, Traunia and Spondiopsis upon Kilimandjaro, Cladopus in one or two streams in Java, Alsinidendron upon Oahu Island, Neobracea upon several of the Bahama islands, Podadenia in the neighbourhood of Ratnapura in Ceylon, and so on. Or if one take a single country, New Zealand, for example, and take a few of its endemic genera, one finds Siphonidium and Townsonia upon very small areas, Pachycladus upon one slightly larger. Colensoa reaches about 80 miles along New Zealand, Tetrachondra about 100, Anagosperma about 140, Notospartium about 240, Ixerba about 300, Hoheria 700, Tupeia 1000, and Carpodetus the whole length of 1080 miles from North Cape to the south of Stewart Island. Of the eighteen genera endemic to New Zealand which have one species each (37), six are confined to areas not over 140 miles in length, or 33 per cent. of the genera upon areas not exceeding 13 per cent. of the whole, so that the tendency even here is to give a hollow eurve (cf. preceding chapter).

In Ceylon, the Hawaiian Islands, and elsewhere one finds the same type of distribution, and if one go on to larger and larger areas one finds larger and larger areas for genera in the same graduated way, until one comes to such a world-ranging genus as Senecio, or Astragalus. Though of course there are many exceptions, on the whole the size of the genera number of their contained species) becomes steadily larger with the inereasing area, as we have already pointed out in Chapter xil; of course allied groups only being compared.

If instead of taking individual genera, or the endemic genera of a single country, one take all the genera of a small family, one finds the same graduation of areas. Take, for example, the Polemoniaceae (from the Pflanzenreich). Of its twelve genera, three, with one species each, oceupy (roughly) California and Utah, Mexico and Guatemala, and the Pacific United States. One with five species is found in California, Utah, Nevada, and Arizona, one with six in the Andes from Colombia to Chilc. 
There are two with nine species, one in the Andes from Mexico to Chile, including Venezuela, and the other with eight species in Pacific North America and one in Atlantic. So far the areas occupied are closely correlated with the number of species, but in the bigger genera there is more variation. Loeselia with twelve species runs from California and Texas to Colombia and Venezuela. Gilia with 109 and Navarretia with 41 both occupy North America, the Andes, and Argentina, while Phlox with 48 covers North America and part of Siberia. Finally, Polemonium, which has only 29 species $^{1}$, covers North and South America, and north temperate Europe and Asia. Except for this last genus, which covers the whole family range, the area is roughly proportional to the number of species (cf. Chapter xir) and the grouping is just like that of the endemic species or genera.

This type of distribution is very common indeed, showing in perhaps the greater number of the families. One genus, usually with many species, covers the whole or most of the family range, the smaller genera, with more restricted ranges, being the more numerous, and on the whole increasing in number the smaller they are, and the more restricted their range. In the Polemoniaceae, there are eight genera below, and four above, the average size for the family, one of the latter occupying the whole family range.

If one take the Cistaceae (37), one finds Halimium with 26 species covering the whole family range. while Helianthemum with 70 covers the Old World from Macaronesia to Beluchistan and Arctic Europe, and Lechea with 13 covers North and Central America and the West Indies. The rest, with 20, 12, 9 and 3 species, cover smaller ranges within these.

Or if one take the large and widespread Menispermaceae (fig. on p. 173), one finds (37) Cocculus and Cissampelos with a distribution practically covering that of the family, Stephania and Tinospora covering most of the Old World, and Hyperbaena most of the New World, range. Within these are many genera of smaller and smaller range till one comes down to the 12 in West Africa, 5 in Brazil, 5 in Madagascar, etc. There are 2 genera of maximum range, $t$ of rather less (including $\mathbf{M e n i -}$

1 This curious point, that the most widcly spread genus of all has fewer species than some of the others, is by no means unique, but occurs in a number of families, e.g. also in the Menispermaceae, Cistaceae, and Hydrophyllaceae. It requires careful investigation with the aid of palaeobotany, for it seems to me not impossible that the deficiency in species may be connected with the occurrence of the glacial period. 


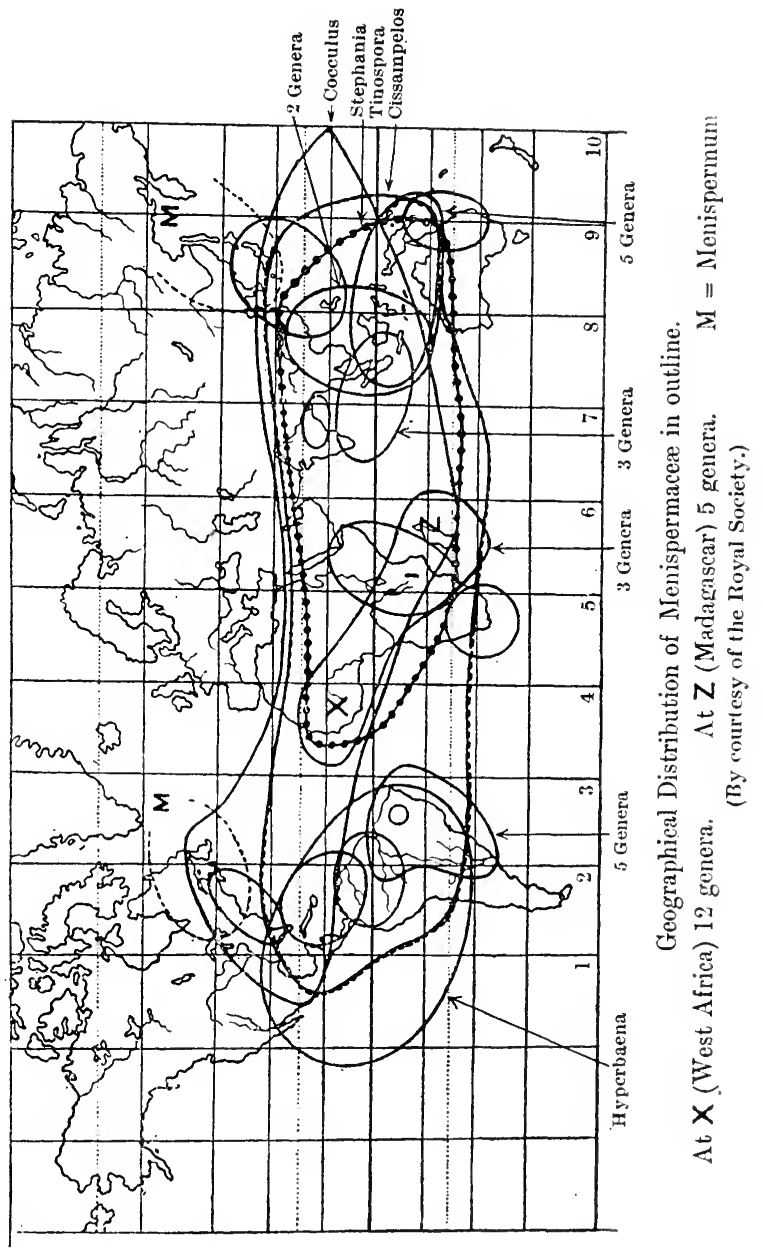


spermum in Atlantic North America and north-east Asia), about 19 in the next class, and 24 or more in the lowest class.

This type of distribution corresponds to that of the species of Doona, Gymnema, Cissampelos, etc., described in the preceding chapter (p. 157). But the Cyrtandra type (p. 159) can also be matched, e.g. by the family Monimiaceae (37), in which there are $\mathbf{2 2}$ genera with small areas (the largest being New Guinea and Celebes) and 49 species in all (average $2 \cdot 2$ species per genus), 5 genera with areas of moderate size (and 22 species, average $4 \cdot 4$ ), and 5 with areas of large size (and 196 species, average $39 \cdot 2$ ). These larger areas overlap one another to some extent in some cases, but there is no single genus covering, or nearly covering, the range of the family.

All these groups of genera, it will be seen, give indications, even when considered singly, that the areas they occupy go with their number of species, and if taken in groups, the applicability of Size and Space is clearly obvious.

So far, in dealing both with endemic (and other) species, and with endemic (and other) genera, we have been considering only the areas occupied by them, and we have seen that these are graduated from many very small areas through a good many of a size somewhat larger up to a tail of a very few that occupy the largest areas. Plotted graphically, as in fig. on p. 162, the numbers always form a hollow curve.

But now, if age be the chief determinant of spread $^{1}$, as would appear to be the case from all the figures that have been given, and from the success of the many predictions based upon it that have been made; and if Size and Space be equally valid, then it would seem that the sizes of the genera (i.e. their numbers of species) in any group of endemics should also be arranged in a hollow curve. If Age, Size, and Space (or Area) go together, then, as age is the only active ${ }^{1}$ factor of the three, it is clear that what-

1 As already pointed out, age of itself effects nothing, but the fact that dispersal goes so largely with age shows that the various factors that are operative produce an average or resultant effect, so that in twice the time, twice the dispersal will occur, unless barriers (plyysical or ecological) interfere. The essential difference between this view and the older one is that under Age and Area all species (with few exceptions) are looked upon as enlarging their area, instead of a few doing so, and many contracting theirs.

Many people take the popular view, which is based, it must be remembered, upon an assumed efficacy of natural selection for which as yet there is little proof, that species with small areas of distribution owe the fact that those areas are small to the competition of other more successful types. But there is little evidence for such a belief. It is simply a way of looking 
ever phenomena are shown by space should also be more or less paralleled by those shown by size. We are thus led on to the investigation of the sizes of genera, to see whether they may not show some definite relationships to one another, such as might be expressed by the aid of curves.

Very little investigation is required to show that this is indeed the case. If we take $16 / 1$ to mean 16 genera of one species each, $3 / 2$ to mean 3 genera of two species each, and so on, then examine the endemic flora of all the islands of the world, and pick out those genera that are actually endemic to the islands, one finds that all the islands show the same type of arrangement, as may be seen in the following list of examples:

\section{Table showing the numbers of Endemic Genera of different Sizes upon a number of Islands}

\begin{tabular}{|c|c|c|c|c|c|}
\hline \multicolumn{5}{|c|}{ Azores, Canaries, Madeira } & \multirow{2}{*}{$\begin{array}{l}16 / 1,3 / 2,1 / 4 \\
59 / 1,8 / 2,2 / 4,1 / 5\end{array}$} \\
\hline Borneo & . & . & . & . & \\
\hline Ceylon & . & . & . & & $19 / 1,2 / 2,1 / 3,1 / 5,1 / 11,1 / 5$ \\
\hline Cuba & & . & . & & $58 / 1,9 / 2,2 / 3,2 / 4,1 / 6$ \\
\hline \multicolumn{3}{|c|}{ Hawaiian Islands } & . & & $\begin{array}{l}14 / 1,6 / 2,7 / 3,4 / 4,3 / 5,2 / 6,2 / 7,1 / 9, \\
1 / 11,2 / 12,1 / 14,1 / 17,128\end{array}$ \\
\hline Japan & - & - & . & & $54 / 1,9 / 2,1 / 3,2 / 4,1 / 8$ \\
\hline Java & . & . & • & & $57 / 1,2 / 2$ \\
\hline Madagas & & & . & & $\begin{array}{c}191 / 1,37 / 2,10 / 3,7 / 1,9 / 5,2 / 6,2 / \tau, \\
1 / 8,5 / 10,1 / 12,1 / 18,1 / 20\end{array}$ \\
\hline New Cal & ledoni & & • & & $\begin{array}{l}73 / 1,2 \tau / 2,6 / 3,4 / 4,45,46,2 \tau, \\
\quad 1 / 9,3 / 10,2 / 12,1 / 15\end{array}$ \\
\hline \multirow{2}{*}{\multicolumn{4}{|c|}{$\begin{array}{l}\text { New Zealand (proper) } \\
\text { Socotra. }\end{array}$}} & & $22 / 1,2,3 / 3,24,1 / 5,1 / 9$ \\
\hline & & & & . & $1 \tau / 1,1 / 2,1 / 3$ \\
\hline
\end{tabular}

On such large islands as Madagascar, where there are many endemics, the same phenomenon is shown even by single families. Thus the Madagascar Compositae show $11 / 1,2 / 2,1 / 3,1 / 5$, and $1 / 10$, the Rubiaceae $14 / 1,3 / 2,1 / 4$.

Every island in the world that possesses any endemic genera

at the actual fact, which is all we have to go upon, that $A$ occupies a large and $B$ a small area. My way of looking at the same fact is to suppose that $A$ is older than $B$. This is really a much morc simple explanation, especially when we remember that the areas occupied by the different species in a genus, or the different genera in a family, usually increase fairly regularly from very small to large. If one have areas represented by $1,2,3,4,5,6$, $7,8,9,10,11,12,13,14,15,16,17,18,19,20$, it secms an innecessarily oblique way of looking at the facts to say that $1,2,3,4$, and 5 must be regarded as dying out, while 16 to 20 are to be looked upon as suceessful and expanding speeies, and no two authors can agree about whether the intermediate species 6 to 15 are one thing or the other. It is far more simple to regard all as still in process of expansion, but that some, by reason of greater age and perhaps other advantages, have grown larger than others. 
shows them arranged in this way, with many monotypes (or genera with one species only), a fair number of ditypes, and a tail of a few larger genera. When plotted graphically they consequently form the hollow curve that we have begun to meet so often in dealing with distribution (cf. fig. on p. 177). One must make allowance, in considering the figures above given, for the "lumping" that is practised in my Dictionary, especially at the fives and tens.

If one add up the grand total of 1582 endemic genera of all the islands of the world, one finds that they show 1037/1 (1037 of one species), or 65 per cent. of the total, and $233 / 2$, or 14.7 per cent., these two making up nearly four-fifths of the whole. There are $104 / 3$, or 6.5 per cent., $53 / 4,49 / 5$, and so on, the largest endemic genus of islands being Oncostemon with 60 species. If one take for comparison the endemic genera of Brazil, 533 in number, one finds $334 / 1$, or 62 per cent., $91 / 2$, or $15 \cdot 2$ per cent., $33 / 3$, or $6 \cdot 2$ per cent., and so on, the largest having 50 species. In both these cases the same type of result, showing a wellmarked hollow curve, is obtained, and one gets the same whatever region of the world one may try for endemic genera, e.g. any of the other countries of South America, or Sonth Africa (ef. the first two and th and 7 th curves in fig. on p. 17\%).

It is worthy of notice that in these two instanees, the islands and Brazil, the pereentages of genera of different sizes are much the same, the monotypes for example being 65 per cent. in the one, and 62 per ecnt. in the other. The islands, which actually cover about two million square miles, would probably be nearly equal to Brazil if the ineluded seas were taken. The average number of species per genus is also not unequal (islands $1582 / 3461$, average $2 \cdot 1$; Brazil 533/1291, average $2 \cdot 4$ ).

The endemics of mountains are also as a rule small genera, though there are a fair number of exceptions to this, but only in the large mountain chains. In the Andes, for example, there are Chaetanthera (30 specics), Cinchona (40), Cristaria (30), Nassauvia (50), Psammisia (35), Puya (25), and many more of smaller size.

One may go on to deal with still larger floras, and find that they are arranged in precisely the same way, so that the phenomena shown by the endemic genera are exactly paralleled by those shown by genera that occupy more area. If one take (as usual from my Dictionary, in which uncertain fours are counted as fives, etc.) the genera that are confined to single continents 


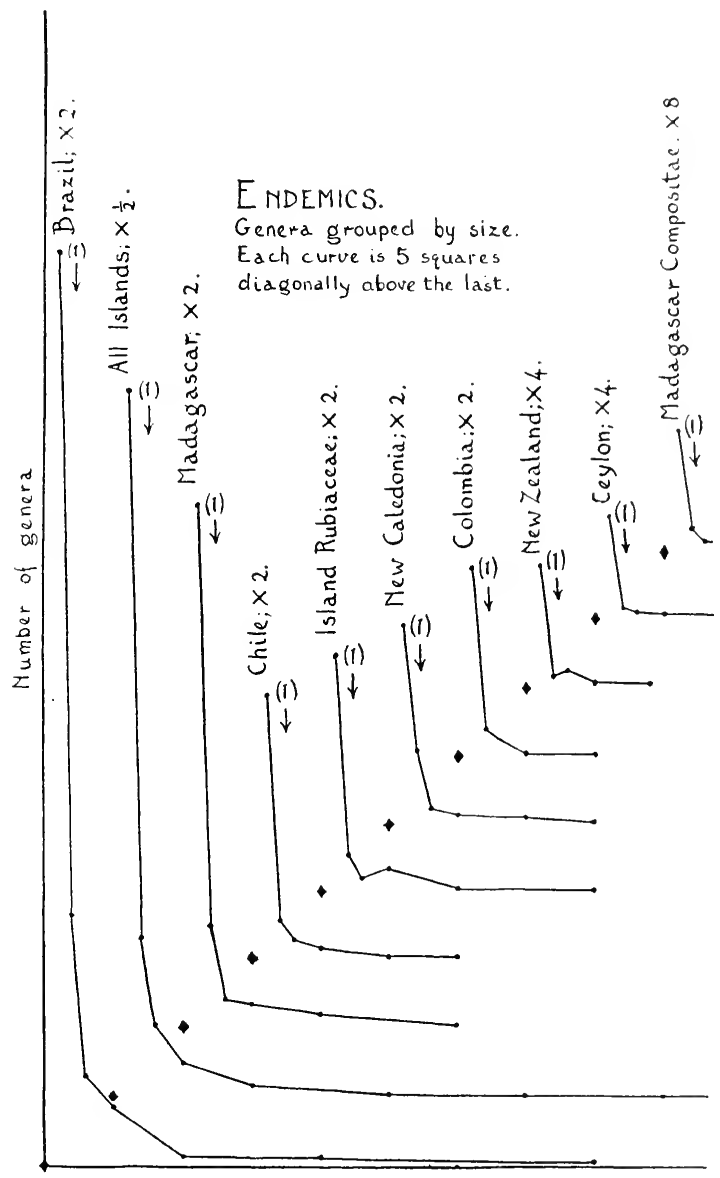

Number of specics.

Curves showing the numbers of genera of one, two, three, five, ten (and sometimes more) species, in various groups of endemic gencra. Always there is a great preponderance of ones and twos and a tail of few larger genera. The monotypes are at the left-hand end of the curves (1).

W. A. 
or continuous areas, one finds, for example, that in Africa there are $835 / 1,254 / 2,136 / 3,86 / 4,97 / 5,48 / 6$, and so on, the largest genus having 350 species. In tropical Asia one finds 445/1, 175/2, $90 / 3,68 / 4,77 / 5,56 / 6$, and so on, the largest genus having 600 species. In the north temperate region of the old World one finds $385 / 1,135 / 2,75 / 3,45 / 4,49 / 5,29 / 6$, and so on to 250 . From this one may go on to the world itself, and one finds (in the total of 12,571$) 4853 / 1,1632 / 2,921 / 3$, and so on to 1600 . All these groups of figures exhibit markedly hollow curves when plotted graphically.

The various figures that have just been given for islands, countries, continents, ete., show in a very distinet way that the larger genera are found upon the larger and more isolated areas, whether of islands or of countries on the mainland, as would be expected upon the principle of Size and Space (Chapter xir). Thus, while Java has no endemic genus of more than two species, nor Socotra of more than three, Borneo reaches five, New Calcdonia 15, Madagascar 20, and the very isolated Hawaiian Islands 28. The largest island endemic genus, Oncostemon with 60 species, is found in Madagascar and the Mascarenes, a large total area. Astronia, the next largest, with 30 species, occupies large parts of the Malay Archipelago and Polynesia. The largest genus confined to New Zealand proper has only 9 species, but that confined to New Zealand and surrounding islands (p. 66) has 20. In the same way, the possible size of a genus increases with the increasing size of the area, till we reach 600 species in a genus of Tropical Asia, and 1600 in the world.

All these groupings of genera, whether usually considered endemic, or not, whether confined to small areas, or found on larger (even up to the whole world), show the same type of arrangement, with the bulk of their number monotypic or ditypic, and a tail running out to the larger genera, the tail being longer the larger the size of the area dealt with. There is no difference betwcen the endemic genera and the rest.

It is also evident that the sizes of genera are grouped in the same way as the areas occupied by their species. Both go with age; the older the genus, the more space will it occupy, and the more species will it have. Of course one must only deal with groups of say ten genera, and must only compare allied forms, to get results that are at all reliable and comparable.

It is clear that the general types of relationship shown, whether between endemic genera only, between genera of larger area 
only, or between these two classes, are the same, and that they are the same whether we consider the areas oeeupied by the speeies of the genera, or the numbers of species in the genera themselves. The same type also appears in the population of a country by its flora, whether some of it is endemie or not. In all eases of distribution, whether it be distribution by areas occupied-geographical distribution or distribution in spaceor by numbers of species in the genera-evolution or distribution in time-the distribution seems to have been determined largely by time. If age alone were operative ${ }^{1}$, one would get much the same distribution as at present exists, when one allows for geological happenings, and the action of barriers. Among these latter, of eourse, eeological barriers are of great importance, but the general evidence goes to show that their aetion is prineipally negative, like that of physieal barriers.

Just as with speeies, endemie genera have been regarded as (1) locally adapted-a view which has largely died out, espeeially sinee it was realised how difficult it would be to find any thing to which such a list of genera as those given above for New Zealand (p. 171) could be adapted, and a view upon which it is impossible to explain sueh an arrangement of genera in order of size as we have just seen to be the rule; (2) as survivals; and (3) as in general new genera beginning life as sueh.

As islands have always been regarded as the typieal loeation in which to look for endemies-speeies, and still more generawe may do well to eonsider them.

Now if the endemie genera of islands be in reality survivals, one would expect that they would at least show a tendeney to belong to families that are small or of broken distribution, i.e. such families as we have been aceustomed to look upon as more or less moribund. And in any ease, one would not expeet the great bulk of them to belong to the large and "suceessful" families. If, on the other hand, Age and Area hold good, they should be found to oeeur upon islands (provided the eonnection was mainly by land) in proportions not dissimilar to the proportionate sizes of existing families.

In order to test this question thoroughly (135), I have added up from my Dictionary (1) all the endemie genera of all the islands in the world, (2) all the endemic genera of West Australia, South Africa, and Brazil, three areas very rieh in endemies, and with much variety of habitat, (3) all the genera confined to Australia.

1 I.e. if the average speed of dispersal of a speeies were constant. 
Africa, and South America, and (4) all the genera of the world. Arranging the families in groups of ten in the order of their size in the world (as judged by number of genera), and taking for each of the other three areas the number of genera in the same ten families, one gets the following table:

Table showing in each pair of columns the number, and the percentage, of genera that occur in the world, and that are confined to three sections of it (ending with those confined to the islands). The first horizontal line shows the figures for the ten largest families in the world for each of these, and the following lines those for the second, third, etc. tens of families in the world. The percentages are counted downwards; the 40 per cent. at the top of the first column means 40 per cent. of the genera of the world.

\begin{tabular}{|c|c|c|c|c|c|c|c|c|}
\hline \multirow{2}{*}{$\begin{array}{l}\text { Tens of } \\
\text { families } \\
\text { (world } \\
\text { order) }\end{array}$} & \multicolumn{2}{|c|}{ World } & \multicolumn{2}{|c|}{$\begin{array}{l}\text { Australia, } \\
\text { Africa, } \\
\text { S. Ameriea }\end{array}$} & \multicolumn{2}{|c|}{$\begin{array}{c}\text { W. Australia, } \\
\text { S. Africa, } \\
\text { Brazil }\end{array}$} & \multicolumn{2}{|c|}{ Islands } \\
\hline & Genera & $\%$ & Genera & $\%$ & Genera & $\%$ & Genera & $\%$ \\
\hline 1 & 5019 & $40 \cdot 1$ & $15 \% 9$ & $39 \cdot 1$ & 459 & $40 \cdot 5$ & 606 & $38 \cdot 3$ \\
\hline 2 & 1868 & $14 \cdot 9$ & 592 & $14 \cdot 6$ & 176 & 15.5 & 285 & $18 \cdot 0$ \\
\hline 3 & 1094 & $8 \cdot 7$ & 360 & $8 \cdot 9$ & 86 & $7 \cdot 6$ & 144 & $9 \cdot 1$ \\
\hline 4 & $8 \pi 4$ & $6 \cdot 9$ & 325 & $8 \cdot 0$ & 78 & $6 \cdot 8$ & 115 & $7 \cdot 2$ \\
\hline 5 & 695 & $5 \cdot 5$ & 271 & $6 \cdot 7$ & 75 & $6 \cdot 6$ & 83 & $5 \cdot 2$ \\
\hline 6 & 561 & $4 \cdot 4$ & 216 & $5 \cdot 3$ & 57 & $5 \cdot 0$ & 82 & $5 \cdot 1$ \\
\hline 7 & 456 & $3 \cdot 6$ & 83 & $2 \cdot 0$ & 19 & $1 \cdot 6$ & 55 & $3 \cdot 4$ \\
\hline 8 & 355 & $2 \cdot 8$ & 111 & $2 \cdot 7$ & 30 & $2 \cdot 6$ & 48 & $3 \cdot 0$ \\
\hline 9 & 296 & $2 \cdot 3$ & 99 & $2 \cdot 4$ & 24 & $2 \cdot 1$ & 29 & 1.8 \\
\hline 10 & 233 & $1 \cdot 8$ & 79 & $1 \cdot 9$ & 29 & $2 \cdot 5$ & 37 & $2 \cdot 3$ \\
\hline Total & 11,451 & $91 \cdot 4$ & $3 \% 15$ & $92 \cdot 1$ & 1033 & $91 \cdot 1$ & 1484 & $93 \cdot \tau$ \\
\hline 11 to 20 & 919 & $7 \cdot 3$ & $2 \tau 8$ & $6 \cdot 8$ & 90 & $7 \cdot 9$ & 86 & $5 \cdot 4$ \\
\hline 21 to $29 \cdot 1$ & $14 \pi$ & $1 \cdot 1$ & 38 & $0 \cdot 9$ & 10 & $0 \cdot 9$ & 12 & 0.75 \\
\hline Grand total & 12,517 & $99 \cdot 8$ & 4031 & $99 \cdot 8$ & 1133 & $99 \cdot 9$ & 1582 & $99 \cdot 85$ \\
\hline
\end{tabular}

The percentages agree with one another in the four columns in the most remarkably close manner, as a little inspection will soon show. The greatest difference in the whole table occurs in the second line, between $\mathbf{1 4 \cdot 6}$ per cent. for Australia, etc., and 18.0 per cent. for islands, a difference of 3.4 per cent. The second greatest is in the first line, between 38.3 for islands and 40.5 for West Australia, etc., a difference of $\mathbf{2} \cdot \mathbf{2}$ only.

If these percentages be plotted as curves, they give the remarkable figure shown.

The close coincidence of these (hollow) curves is very remark- 
have 195 endemic gencra in 43 families that also occur in the islands of Indo-Malaya, and only 19 in the 16 families that do not. They have $\mathbf{1 8 7}$ in 39 families that oecur on the African islands, and 27 in 20 families that do not.

Incidentally, the close correspondence of these curves shows that it is all but certain that the floras of the world, in the mass, must have been distributed by land eonnections, and at any rate those of the bulk of the islands, though some of the far outlying ones, with few endemic genera, probably were oeeanie.

Just as the endemic species belonged to the large and "successful" genera in greater proportion, so the endemic genera belong to the large and "suecessful" families, and only a very few indeed to endemic families. An analysis of the above table of 1582 endemic genera of islands shows that 1150 of them, or $\tau 2 \cdot 6$ per cent., are found in the 40 largest families in the world, which only contain $70 \cdot 6$ per cent. of the total genera in the world, i.e. these families eontain rather more than their proper proportion of endemics. The remainder occur in another 110 families, leaving 141 whieh are not represented upon islands by any endemic genera at all. The largest of these latter families is the Chenopodiaeeae with 86 genera, and the whole number only contain 890 genera, or 6 per family, against 77 per family for those which have island endemic genera. The proportion of endemic genera diminishes from top to bottom of the table (ef. 135, p. 509).

The further out, and more isolated, the island is, i.e. in general the more ancient the date of its peopling with plants, the more do the endemic genera tend to belong to the larger families. If one divide the 150 families that possess them upon islands into 75 larger and 75 smaller, one finds that in Madagasear 62 of the families with endemic genera belong to the larger, 18 to the smaller. In New Zealand the proportion is $\mathbf{1 6 / 4}$, and in the Hawaiian Islands 13/1.

If endemic genera were really largely relics, one would expeet that there would be a fair number of endemic families, but, as a matter of faet, these are few and small, and of the five that are found only upon islands (Chlaenaeeae, Balanopsidaeeae, Corynocarpaeeae, Lactoridaeeae, and Cercidiphyllaeeae), the largest is upon the largest island (Madagasear) that is also a good way out from the mainland.

Putting together all the facts about endemic genera that have been given above, and whieh show that in the mass they behave 


\section{cH. XVI] ENDEMISM AND DISTRIBUTION: GENERA 183}

like endemic species, and that both endemic species and genera behave like non-endemic, it is clear that nothing but a mechanical explanation will serve for the chief features of their distribution, when one is dealing with the mass. Age supplies such an explanation, but this is hardly possible to the supposition either that they are chiefly relics, or that they are chiefly local adaptations. It would thus seem to follow that endemics in the mass, whether species or genera, are chiefly young beginners, descended in general from the more widely distributed forms about them. The smaller the area occupied, on the average, the younger the species or genus.

Only in comparatively rare cases can we look on forms of small area as relies. The fact that in every family the monotypes are from two to three times as numerous as the ditypes is fatal to any idea of relic nature for the great bulk of them. Of course, just as in the case of species, we must make various provisos for the use of Age and Area, such as that the genera be only compared in groups of ten allies on either hand of the comparison, that they be only taken in tens in any case (to lose the relies in the crowd), and that conditions remain reasonably constant. Species and genera are endemic simply because they have not yet had time to spread abroad, or because they have been prevented by barriers, sometimes physical, sometimes ecological.

\section{Summary}

Endemie genera oceur in similar places to endemic species, and instances are given of the numbers that occur in various parts of the world, from which it appears that islands in general have the smallest proportions, while the proportion increases with inereasing area, up to 100 per cent. for the world. Examples are quoted of very small areas oceupied by many endemic genera, usually monotypic, and more detail is given of the distribution of genera in several families, showing that on the whole the area varies roughly with the number of species, and that both types of distribution seen in the preceding chapter-one species corering the whole generic range, or several species dividing it among them -can be matched in the families, and the genera pertaining to them.

It is then shown that endemic genera are distributcd in different countries in regular order, with many monotypes, fewer (but still many) ditypes, and numbers tapering away to the larger 
genera, which are usually found only in large islands or other large areas. If plotted as graphs the figures give the usual hollow curves, and it is clear that the sizes of the genera depend on factors similar to those that determine the sizes of areas occupied by species.

Still larger floras, e.g. those of single continents, or of the whole world, show the same type of arrangement of the genera, with many monotypes, fewer (but still many) ditypes, these two making about half the total, while the larger genera taper away steadily in number in a long tail.

It is clear that neither the supposition that endemies and small genera are relics, nor that they are special adaptations will avail to explain the phenomena presented by the great mass.

Endemic genera further prove to belong more to the large families, just as endemic species belong to the larger genera.

The case of islands, usually regarded as the typical home of endemic genera, is then considered in more detail, and it is shown that the proportions of endemic genera in (1) the islands of the world, in (2) West Australia, South Africa, and Brazil, and in (3) Australia, Africa, and South America, are much the same for all three, for each group of ten families in order of size, and this proportion is the same as occurs in the world for each of these groups. Confirmatory evidence is also given, the result of the whole being to show that in the mass endemic genera are simply, like cndemic species, young beginners, and probably the descendants of other genera still existing. 


\section{CHAP'TER XVII}

\section{THE MONOTYPIC GENERA, AND GENERA OF LARGER SIZE}

$P_{\text {Assing on now to deal with monotypie genera, or genera with }}$ one species only, one soon notices that they show the same phenomena that we have already seen in the endemic genera. This is what we should expect upon the hypothesis of Age and Area, as expanded by Size and Space, implying as they do that small genera, endemic or not, are on the whole younger than, and occupy less territory than, the larger genera in the same circles of affinity.

Few people, perhaps, have realised how numerous the monotypes are. No less than 4853 out of the 12,571 genera of flowering plants in my Dictionary (4th ed.) are monotypie, and are usually so restricted in area that most people would call them endemics. A number will doubtless prove to have more than one species when we finally know the flora of the world, but new ones are frequently discovered, or created by the splitting of other genera, and there is little likelihood that the pereentage will fall mueh below its present figure of $\mathbf{3 8} \cdot 6$ per cent. of the total. The ditypes, or genera of two speeies each, are also very numerous, and include 1632 genera, or 12.9 per cent. In other words, the monotypes and ditypes alone include more than half the gencra at present existing, or $\mathbf{5 1 . 5}$ per eent., while the tritypes include a further 921 , bringing the total to 58.9 per cent. The monotypes are approximately three times as numerous as the ditypes, and these almost twice as numerous as the tritypes. Beyond ten species the figure for number of genera goes below 500, and at twenty-five species below 200, tapering out in an enormously long tail to the final genera Senecio (1450 species) and Astragalus (1600).

We have already seen many instances of the hollow curve, and when the genera of the world are plotted by numbers containing $1,2,3$, etc., speeies, one gets a beautiful example of it. It is idle to suggest that further work will alter the form of this curve. The monotypes exceed the ditypes by 3221 , and the ditypes exceed the tritypes by 711 , and so on right through the list.

One may even go beyond the genera, and find that the families 
are arranged in the same way with regard to the numbers of genera contained in them. There are $54 / 1$ (5t of one genus), $45 / 2-3$ ( 45 of 2 or 3 genera), 40/4-6, 32/7-13, 28/14-23, 25/2t-38, 22/39-63, 20/61-100, 15/101-200, 13/201-1143. The numbers steadily decrease, while at the same time the number of species included increases, being $1,2,3,7,10,15,25,37,100,943$, again forming a hollow curve.

But if the whole flora of the world show such a remarkable grouping of its genera into sizes, then one will expect the same type of arrangement, in a hollow curve, to hold for the individual families, and in actual fact one finds that this type of grouping into sizes holds for the genera of any single family, with a few trifling variations among the very small families. For example:

The families

deanthaceae (266 gen.)

Aceraceae $(6)$

Aizoaeeae (20)

Alismaceae (15)

Amarantaceae ( $\% 2)$

Amaryllidaceae (94)

Commelinaccae (3s)

Compositae (1143)

Coniferae (45)

Saxifragaeeae $(96)$

Scrophulariaceae $(2+1)$

Simarubaeeae (39)

\section{Contain}

$1191,32 / 2,20 / 3,9 / 4,15 / 5$, and so on to 300

$1 / 1,1 / 3,14,1 / 5$, and $\tau$ and 115

$8 / 1,3 / 2,1 / 3,1 / 4,2 / 5$, and so on to 15

$51,3 / 2,33,1 / 4$, and so on to 33

$291,10 / 2, \tau / 3,2 / 4,2 / 5$, and so on to 100

$28 / 1,15 / 2,10 / 3,6 / 4,3 / 5$, and so on to 100

$15 / 1,4 / 2,3 / 3,2 / 4,2 / 5$, and so on to 110

$4+6 / 1,140 / 2,97 / 3,43 / 4,55 / 5$, and so on to 1450

$14 / 1,8 / 2,2 / 3,5 / 4,1 / 5$, and so on to 70

$51 / 1,12 / 2,2 / 3,5 / 4,1 / 5$, and so on to 225

$88 / 1,32 / 2,18 / 3,124,8,5$, and so on to 250

$171,62,23,24,35$. and so on to 30

The whole number of families form similar hollow eurves; the Coniferae are one of the most aberrant families of the entire list. As a general rule, the genera with one and two speeies make up about half the total (cf. fig. on p. 187).

This type of grouping even holds for families of lower type than the flowering plants; for example, the Jungermanniaceae acrogynae show $21 / 1,6 / 2,9 / 3,4 / 4,6 / 5$ and so on, the Rhodomelaceae $34 / 1,16 / 2,5 / 3,5 / 4,6 / 5$ and so on, the Hymenomycetineae $23 / 1,10 / 2,3 / 3,8 / 4,3 / 5$, and so on. The numbers are more irregular, but the hollow curve is clearly shown.

It is clear that this type of distribution of the genera by the number of their contained species is a perfectly general phenomenon. There are no execptions, when allowance is made for the lumping in my Dictionary. If endemic genera, or monotypes, were really mainly relics or special adaptations, such distribution as this would be inconceivable, obtaining as it does in every locality, and agreeing with the distribution of genera about the 


\section{CH. XVII] AND GENERA OF LARGER SIZE}

world, and with their distribution into families, as well as with the distribution of species - endemie or not-by area oeeupied. All show the same hollow curves.

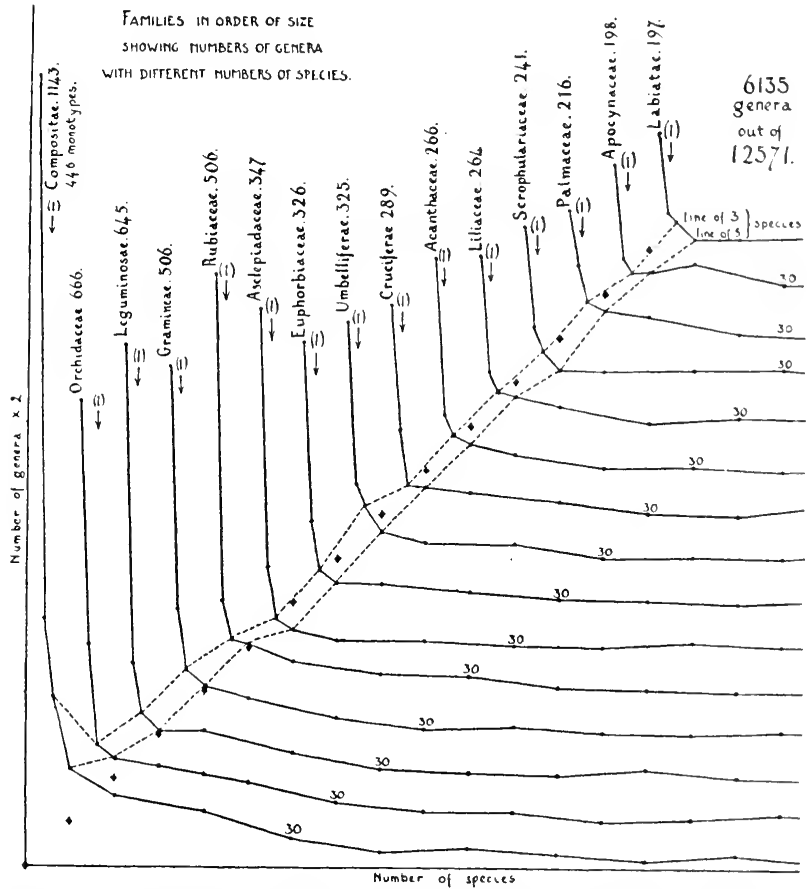

Hollow curves exhibited by the grouping into sizes of the gencra in the first 15 largest families of flowering plants. Each curve is diagonally above the preceding one, as indicated by the heavy black dots (points of origin). Note that the curve almost always turns the corner between the point marking the number of genera with $\mathbf{3}$ species, and that marking the number with 5 (indicated by the dotted lines). The number after the name of the family shows the number of genera in it.

Not only so, but the biggest genera are in general in the largest families, i.e. in general the oldest families. If one take (from my Dictionary, as usual) the largest genus in each family, and avcrage them, one finds 


$\begin{array}{cc}\begin{array}{c}\text { Size of } \\ \text { family } \\ \text { (genera) }\end{array} & \begin{array}{c}\text { Number of } \\ \text { families }\end{array} \\ 1 & 54 \\ 2-3 & 45 \\ 4-6 & 38 \\ 7-13 & 32 \\ 14-23 & 28 \\ 24-38 & 25 \\ 39-63 & 22 \\ 64-100 & 20 \\ \text { over } 100 & 28\end{array}$

$\left.\begin{array}{c}\text { Average of } \\ \text { largest genera } \\ \text { in each } \\ \text { (species) } \\ 19 \\ 27 \\ 63 \\ 79 \\ 95 \\ 125 \\ 161 \\ 278 \\ 404\end{array}\right\}$

\begin{tabular}{|c|}
\hline $\begin{array}{l}\text { Size o } \\
\text { largest } \\
\text { genus } \\
\text { (species }\end{array}$ \\
\hline 600 \\
\hline 700 \\
\hline 1600 \\
\hline
\end{tabular}

again a hollow curve. One may even find the sections of this curve regularly arranged. The families with one genus show 12/1 (twelve with one species), 8/2, 6/3, 3/4, 3/5, 2/6-7, 3/10, 3/15, and so on to 290 (Symplocos). This result agrees absolutely with what has been said under Size and Space in Chapter xir.

There is no demonstrable difference between monotypes and genera of larger size, except in the smaller number of species, and (usually) smaller area occupied. Of the 4853 of them, 1037 occur only upon the islands of the world, usually only upon one; 887 occur in South America, usually only in small portions of it; 835 in Africa, 612 in North America. These four divisions of the world contain in all 3371 monotypes, or 69 per cent. of the total number in the world. But if one eount up the number of ditypes they contain, one finds it to be only 59 per cent. (or a much smaller proportion) of those in the world. The number of tritypes confined to these portions of the world is only 51 per cent., or a lesser proportion again, that of genera with 5 species 46 per cent., of genera with 1033 per eent., of genera with 5020 per cent., of genera with 100 species 10 per cent., and of genera with more than 100 species they contain only 3 per cent. of those in the world. It is clear that what was said above under Size and Space is in general correct, and that the larger genera tend to occupy larger areas in proportion to the number of species that they contain (for the proportions decrease with perfect regularity). Distribution about the world, and number of species, go mainly with Age. It is inconceivable that natural selection should group genera likc this.

This regular curve for the occurrence of genera not only shows with a large number, such as those just considered, but also with much fewer. If we divide the world into continents and larger areas, and enumerate for each region the genera confined to it, we get: 
Table showing, in each line, the percentages of genera confined to the Islands, Australia, etc., and containing 1, 2, 3, or other number of species. The percentage is of the total number of genera containing 1, or 2, etc., species, not of the total number of genera confined to the islands, etc. Thus 21 per cent. of all the monotypes are found upon the islands, 49 per cent. of the genera with 75-125 species occur in both Old and New Worlds.

Pereentages of Genera of different sizes (numbers of species)

\begin{tabular}{|c|c|c|c|c|c|c|c|c|c|}
\hline No. of species in genus & 1 & 2 & 3 & 4 & 5 & 10 & 50 & $\begin{array}{l}75- \\
125\end{array}$ & $\begin{array}{r}\text { Above } \\
125\end{array}$ \\
\hline Islands & 21 & 14 & 11 & $8 \cdot 9$ & $7 \cdot 8$ & $3 \cdot 6$ & - & - & - \\
\hline Australia & $4 \cdot 9$ & $4 \cdot 5$ & 5 & $4 \cdot 7$ & $4 \cdot 3$ & $1 \cdot 7$ & $1 \cdot 6$ & $1 \cdot 7$ & $1 \cdot 6$ \\
\hline Africa & 17 & 15 & 14 & 14 & 15 & 10 & 10 & $3 \cdot 4$ & $1 \cdot 6$ \\
\hline South Ameriea & 18 & 16 & 13 & 12 & 13 & 11 & $7 \cdot 3$ & 6 & $0 \cdot 5$ \\
\hline Tropical America & $2 \cdot 9$ & $5 \cdot 7$ & 9 & 11 & 11 & 17 & 14 & 13 & 10 \\
\hline North America & 12 & 13 & 12 & 10 & 9 & 8 & $2 \cdot 4$ & $0 \cdot 8$ & $0 \cdot 5$ \\
\hline N. Temp. Old World & 8 & 8 & 8 & 7 & 7 & 7 & $7 \cdot 3$ & $6 \cdot 3$ & $1 \cdot 6$ \\
\hline Tropical Asia & 9 & 10 & 9 & 11 & 12 & 11 & $6 \cdot 5$ & 4 & $2 \cdot 7$ \\
\hline Palaeotropical & $0 \cdot 7$ & $2 \cdot 9$ & 5 & 6 & 6 & 9 & 14 & 13 & $5 \cdot 9$ \\
\hline New and Old Worlds & $1 \cdot 3$ & $4 \cdot 2$ & $4 \cdot 9$ & 6 & 7 & 14 & 31 & 49 & 73 \\
\hline \multirow{3}{*}{$\begin{array}{l}\text { Miscellaneous, mostly } \\
\text { of large areas in Old } \\
\text { World }\end{array}$} & & & & & & & & & \\
\hline & $5 \cdot 1$ & $6 \cdot 6$ & 9 & $9 \cdot 3$ & $7 \cdot 8$ & $7 \cdot 6$ & $5 \cdot 8$ & $2 \cdot 7$ & $2 \cdot 5$ \\
\hline & & 100 & 100 & 100 & 100 & 100 & 100 & 100 & 100 \\
\hline
\end{tabular}

This is a very remarkable table. In the case of Islands, Africa, South America, and North America (with a slight exception at the monotypes), the proportions of genera of different sizes decrease regularly (allowing for the lumping of uncertain fours and sixes as fives). This fact seems to mc practically to exclude the idea of local adaptation, as well as that of relic nature, for the great bulk of genera, though there must of course be many exceptions to this rule. But if this be so, then the idea that plants have been guided in their evolution by natural selection must also suffer something of an eclipse. One cannot imagine natural selection producing genera in careful graduation of sizes (and areas) like this. One would get distribution almost exactly of this type by the simple operation of the "mechanical" principle of Age and Area ${ }^{1}$ as expanded by its corollary Size and Space. If these two worked alone, and absolutely, one would get this

1 As already several times explained, the general meaning of Agc and Area is simply that on averages and in the long run species and genera spread at a more or less uniform rate, interfered with by barriers, physical or ecologieal. On the older view it was imagined that distribution was so rapid that all forms had already reached their limits, and that many were in process of contracting their area of dispersal. 
type of distribution shown in minute detail; and working upon large numbers, one gets it shown quite clearly.

One may, however, go further than merely splitting up the world into continents. If one take the genera endemic to South America, and divide these up among the countries to which the bulk of them are confined, and then take, for example, Brazil, one finds that it contains $6 \cdot 8$ per cent. of the world's monotypes (genera of one species), but only $5 \cdot 5$ per cent. of the ditypes, 3.5 per cent. of the tritypes, $0 \cdot \tau$ per cent. of the genera with ten species, and so on. The other countries of South Amcrica show similar, but not quite so regular, results (on account of the smaller numbers). Individual islands, when they have sufficient endemic genera, also show the same. Thus Madagascar contains 3.9 per cent. of the world's monotypes, $\mathbf{2} \cdot \mathbf{2}$ per cent. of the ditypes, and 1 per cent. of the tritypes, the numbers afterwards becoming irregular on account of their insignificant totals, but none of them approaching the figure for the ditypes (the highest is $1 \cdot 4$ per cent.).

If now, returning to the table, one look at the figures for the largest area (New and Old Worlds), which includes in general genera that occur throughout the north temperate zone, the tropies, or the world, but also includes a number that are only found in eastern Asia and in North America (i.e. really quite a small area), one finds the figures to go in the reverse direction, from 1.3 per cent. of monotypes to 73 per cent. of the large genera. This agrees absolutely with what has been said above under Size and Space; the surprising feature is that the figures increase regularly.

If now one take the Palaeotropical region (tropical Asia and Africa, North Australia, Polynesia), one finds the proportions to increase up to about genera of 50 species, and regularly, and then to diminish regularly. Tropical America behaves in the same way, but the decrease begins sooner. In other words, genera of larger size tend to occur in both Old and New World tropics. In tropical Asia, a much smaller area, the falling-off begins much sooner, and so it does in Australia. In the north temperate regions of the Old World it does not begin till about the size of 50 species (the flora, however, is more herbaecous).

There are many very interesting points to be made out from the study of such statistics as these, and still more interesting features can be discovered by breaking them up, and studying individual regions, and families, or types of vegetation, in detail, 
but it must suffice to have drawn attention to them, and to the very elear way in which they show that on the large scale and in the long run distribution is a very mechanical process, i.e. that the various factors eausing it act at a very uniform rate, and that it is usually only stopped by actual barriers.

The individual area occupied by a monotype genus may vary enormously, but is usually rather limited. 1037 of them oceur upon islands, and when the island is of any large size are usually restricted to a portion of it. The great bulk of those mentioned as found -only in South or North America, or in Afriea, and the 241 of Australia, are similarly restrieted, and so are most of those in the other great regions of the globe. When one comes to genera found in both worlds, one finds that only 66 of them are monotypic, or a mere $5 \cdot 6$ per eent. of the genera that oceur in both. All but about 20 of these are found only in the north temperate zone, which by reason of its connections by way of the aretic regions, formerly passable for plants, is not really so large in proportion as it seems. Bolboschocnus, Brasenia, Hakoncchloa, Hippuris, Montia, and Zannichellia are more or less cosmopolitan, and of the remaining genera three are coastal plants carried by sea currents, and four are tropical American and West Afriean-countries united by a current that crosses in about three months. Pistia is a water plant, and some of the others are doubtful identifications, so that there remain a bare half-dozen that have a very large range, evidently acquired by land, or much less than $0 \cdot 25$ per cent. of the total of monotypes. These are Christiana, Eulophidium, Manisuris, Remirea, Rhabdia, and Sphenoclea. In fact, it is fairly evident that if one were to determine aceurately the areas of the 4853 monotypes, one wonld obtain the usual hollow curve, beginning with a great many of very small area. and tapering away to the other end as areas were reached of larger and larger size.

In any country in which there are many monotypes, their areas tend to overlap like those of the endemic species. Thus in New Zealand, in any zone of 100 miles from north to south on the main islands, there are never less than seren monotypic cndemic genera, though of the eighteen such genera six are northern, ceasing towards the south, and twelve are southern, two only of which reach the far north. Just as with the species, the genera show a maximum number about the eentre of New Zealand. What reason (in adaptation or relic nature) ean one find for the faet that one genus reaches from the far north to 
about halfway down New Zealand, while another begins there and reaches the remainder of the distance? Further, these monotypic endemics have an average range of about 446 miles, and in a varied country it is a little difficult to imagine conditions to which they can be just suited in such a range.

If one take the families in groups of ten, in order of their size in the world (as measured by the number of genera given in my Dictionary), one finds that the column of monotype numbers follows that of numbers of genera with wonderful closeness; the first exception comes only at the seventeenth group of ten families, a group including only 59 genera, or six per family. Even beyond this the numbers continue closely parallel, and there is only once an exception. 'The percentages also show clearly that (just as with endemies) the greatest proportion of monotypes is in the largest (i.e. on our hypotheses, in general the oldest) families, falling steadily from 40 per cent. in the first forty families to 30 per cent. in the final group of 131 very small ones.

Analysing from my Dictionary, as corrected to date, the proportion of monotypes in the various families, one finds that in the families with over 100 genera the percentages vary between 28 and 56, with three-quarters of the whole total between 33 and 44. Those below 100 genera vary between 11 and 68 per cent., or twice as much, with three-quarters between 23 and 50 . The percentage in the larger families is evidently a little higher, as has already been pointed out.

There is a fair amount of difference, therefore, between individual families. In the first ten, the largest percentage is in the Asclepiads (54 per eent.), the lowest in the Orchids (35 per cent.), but there is not the least reason to suppose the former to be a specially moribund family. Other families with more than 50 per cent. of monotypes are Burseraceae, Lythraceae, Menispermaceae, Portulacaceae, Saxifragaceae, Juncaceae, etc.

Explanations of the facts of monotypism have followed much the same lines as those of endemism, the genera being regarded as local adaptations or as relics, according to taste. But what has been pointed out above shows that there is a very definite arithmetical relationship between monotypes and genera of larger size, not only on the total, but also in very fair detail. This alone is almost a conclusive argument against either of the suppositions just mentioned as a general explanation, though of course there must be many individual exceptions, better 
explainable by their aid. How could local adaptations be graduated in this regular order, or how could there be a vast number at the last stage of reliedom, and fewer and fewer at the stages leading up to that, and that in every family or country?

Another great difficulty for the older explanations is provided by the inerease of monotypes, as of endemic genera and species, as one goes southwards and outwards. Why should New Caledonia, the Mascarenes, and Juan Fernandez require so many more per thousand square miles than the Sandwich Islands, Formosa and Cuba, in similar northern latitudes, especially as their non-endemic genera are in general very large and "suecessful" world-ranging genera? Why should Chile have about 100 local monotypes, while there are only about $\pi \tau$ in Europe, with more than ten times the area? Why should Western Asia require so many more than Europe? and so on.

The only reasonable explanation of the very striking facts that have been set forth in the last three chapters, so far as I can at present see, is that provided by Age and Area with its corollary Size and Space, that the smaller genera are as a rule the younger, that they are probably the descendants of the larger genera, that they gradually increase their area with their age, and that as the area increases, so does the number of species, these also increasing their area with their age. As a general explanation of the phenomena seen in the distribution of plants about the globe, this commends itself by its extreme simplieity, and by the fact that it explains what has hitherto been regarded as an insoluble problem. Distribution is an extremely slow process, allowing time for acclimatisation, and the effect of all the various factors that act upon it is to eause it to take place at a regular rate, so that it becomes a measure of age, or vice versa. Barriers alone interfere with it, but they may be of many kinds.

\section{SUMmaRY}

The monotypic genera are very numerous, being 4853 out of $\mathbf{1 2 , 5 7 1}$ in the world, or $38 \cdot 6$ per cent. The ditypes are also numerous, but are only 1632, or a drop of over 3000 from the monotypes, while there is another drop to the 921 tritypes, and then the numbers of genera of different sizes taper away in a long tail to Astragalus at 1600 species. The mono- and di-types inelude more than half of the total, and a very regular hollow eurve is formed. The individual families are arranged in the same way, 
each commencing with a great number of monotypes, and giving a hollow curve.

In the smaller areas of the world, like the single continents, one finds the proportion of monotypes very high, while that of ditypes is lower, and it falls off steadily to an insignificant figure for the larger genera. In the genera found in both worlds, on the other hand, the exact reverse is the case, and intermediate phenomena show in intermediate areas.

The area occupied by a monotype may vary enormously, but in general is small; only 66 of them oceur in both Old and New Worlds.

The greatest percentage of monotypes is in the larger families, and it diminishes steadily with the lessening sizes of the families, when these are taken in groups of 40.

This marked arithmetieal relationship of the monotypes to other genera shows that the usual explanations-that they are relies, or that they are speeial adaptations-are in general inapplicable, and that the explanation offered by Age and Area, with its implieations, that as a rule they are young beginners, and probably descended from the larger genera, must in all probability be correct for the great majority. 


\section{CHAPTER XVIII}

\section{THE HOLLOW CURVE OF DISTRIBUTION}

$\mathrm{B}_{\mathrm{Y}}$ far the most remarkable feature that stands out through all the work deseribed in the preceding pages is what may be termed the "Hollow Curve of Distribution." It was first noticed in 1912, when working up the flora of Ceylon for the first paper upon Age and Area (123). This flora of 1028 genera was composed of $573 / 1$ (573 genera of one species in Ceylon), 176/2, 85/3, 49/4, 36/5, $20 / 6$, and so on, the numbers becoming somewhat irregular after six, but decreasing fairly regularly if taken in twos (genera of 7 and 8 species, 9 and 10, ete.). Having already the knowledge, familiar to systematists, that genera of one and two species were the most numerous, it was thought that the regular decrease of the numbers might be accidental, and time did not then permit of comparisons with other floras ${ }^{1}$. The hollow curve, however, appeared again in 1916, in counting up the areas of distribution of the endemies of New Zealand. Unlike Ceylon, New Zealand was treated by actual measurement, and when the cndemics were divided into ten classes by area, it was found that the lowest elass, though it occupied much the smallest area (40 miles by length of New Zealand against 120 for most classes), contained much the largest number of species, having 168 out of 902 , while the ninth class came next with 128. The two classes contained 32.8 per cent. of the whole number of endemies (of New Zealand proper), although their area was only barely 15 per cent. of the total.

1 In actual fact, as may be quickly verified, all (or most) local floras show the same thing, with their genera arranged in hollow curves when grouped by the number of their (local) species. This is what one would expect if genera are produced from other genera at a more or less uniform rate, and in a more or less "casual" way. The subject will be treated in greater detail in another place, and it will suffice for the present to call attention to the fact that the hollow curve is regularly shown, as by the Ceylon local flora (above, and ef. curve 4 on p. 237). The British flora shows $223 / 1,90 / 2,35 / 3,32 / 4,16 / 5,15 / 6,5 / 7,7 / 8,2 / 9,6 / 10$, and so on to 71 , the numbers becoming rather irregular after 6 . 'The flora of Cambrifgeshire (Babington, omitting Rubus, Hieracium, and Salix) shows 210/1, 61,2,36,3, $21 / 4,14 / 5,6 / 6$, and so on (l.c. curve 6). That of Wicken Fen, which is only a very small area in the same county, is graduated in the same manner. The flora of Italy (l.c. curve 9) shows the same thing, and so do the floras of Greece, British India, New Zealand, the Bahama Islands, and others that have been tested. 
These results are shown on pp. 162, 237. The middle elass for New Zealand is rather high, but this is probably due, as I have elsewhere shown, to the oecurrence of Cook's Strait in the middle of New Zealand, and it is worthy of notiee, that New Zealand, from which such strong evidenee has been derived in support of my eontention that age is the main faetor in distribution, shows the most irregular eurve that has as yet been met with in examining many hundreds. The fact of the division of the islands by straits, and the probable oecurrence of several different invasions of plants $(\mathbf{1 2 7}, \mathbf{1 3 1})$ are likely enough to aeeount for this.

As both these eurves agreed in type, and as the figures for the endemics of Ceylon, though only estimates and not actual measurements, seemed to hint at something of the same kind, my attention was thus roused, and espeeially so when the next figures that I obtained, those for the distribution of the endemies in the outlying islands of New Zealand (129, pp. 329, 331), showed the same eurve, but in a reversed direction, the maxima being upon the largest areas. It was next shown by the endemics of the Hawaiian Islands, where $4 \tau$ per eent. were eonfined to one island, and 20 per eent. more to two (out of seven), and the numbers rapidly diminished upwards (p. 162, eurve 3 ); then by the speeies of Callitris in Australia (130) and their local distribution, and afterwards by other things.

Numerous instances of the hollow eurve have been given above, for example (in speeies first of all), in the distribution of the species of Ranunculus in New Zealand (pp. 153-6), in the general distribution of the speeies of Cyrtandra and their loeal distribution within the Hawaiian Islands (p. 160), the distribution of the Boraginaeeae in New Zealand (p. 161), of Olearia in that eountry (p. 161), of Doona in Ceylon, of Cyanea and Pelea in the Hawaiian Islands (p. 161), of the speeies of endemie and non-endemie genera in the Hawaiian Islayds (p. 163), of Exacum, Christisonia and Ebermaiera in India (p. 163), and so on. Innumerable instanees of its applicability eould if neeessary be produced. Most of these curves are shown on p. 162 .

In the same way, the curve applies to genera, and instanees have already been given, for example, in the geographieal distribution of the Polemoniaceae (p. 171), the Cistaeeae (p. 172), the Menispermaeeae (p. 172), and the Monimiaceae (p. 174).

The curve is thus a general feature of the distribution of species by areas occupied, and goes to show that age is of enormous importance in geographical distribution. In view of these 
facts, and of the striking way in which it has been found, in regard, for instance, to the flora of $\mathrm{New}$ Zealand, that predictions as to distribution may be made upon a basis of age only, and yet be reasonably accurate, it would seem probable that age is by far the principal factor in determining geographical distribution.

This of course simply means, as has already been explained, that the resultant effeet of the many factors that are operative upon any individual species (and still more upon any group of ten allied forms) is so uniform, when long periods of time are dealt with, that dispersal goes very largely with age. The great difference between this and the older view is that we can no longer look upon the dispersal of species as having reached its limits. Before the rise of the theory of natural selection, as has been pointed out on p. 3, the effeets of age were recognised, but in the last sixty years they have been more and more lost to view. The figures that have been given above, however, show that in reality they are perhaps the prineipal features that are apparent in distribution.

But Size and Space also enters into the question, and if we consider this principle also to be valid, as indeed seems shown by the many cases of its application that have been given above, then we shall expect that as Age, Size, and Space (or Area) go together, the phenomena exhibited by Size will be more or less like those exhibited by Space, inasmuch as Age is the only active factor of the three. Actual examination soon shows that this is the case, and that genera of one country, endemic or not, arranged by sizes, form a hollow eurve like those formed by species in order of area; they begin with many monotypes, and a good many ditypes, and taper off into a more or less long tail of larger gencra. This of eourse means that the hollow curve enters not only into geographical distribution, but also into evolution, for nothing but evolution could produce the size of a genus.

The hollow curve shows in the distribution into sizes of the endemic genera of all islands (p. 176), of the endemic genera of individual islands (p. 175), of those of Brazil (p. 176), and other countries. It shows again in the composition, by sizes of genera, of the floras of Great Britain, Ceylon, New Zealand, India, ctc., and shows in the division of these into portions of the eountry, single families of reasonable size, and so on; it shows again in the composition of the lists of genera with one, two, thrce, or more species. Once more it shows in the composition of the lists of gencra confined to larger areas of the world, such as single 
continents, and to the whole world (p. 185). It shows, and that very conspicuously, in the composition of the various families by sizes of genera (p. 186), as well as in the average size of the largest genus in each family (taking the families in order of size, p. 188). It shows in the four curves of percentages given on p. 181. And it shows, finally, with great regularity of expression in the curve for all the genera of flowering plants grouped by sizes (p. 185), and in other features. There is no limit to the number of instanees that could if needful be produeed.

Now this is really a very remarkable state of affairs, and that it has not been discorered at a much earlier period can only be attributed to the fact that the rise of the theory of natural selection diverted effort from the lines which it is clear (ef. p. 3) that it was beginning to follow in 1853. Until, however, the theory of evolution was firmly established, it seems doubtful if much could have come of any demonstration of the effects of age. The clear arithmetical relationships that exist between the various groups of plants, "wides" and endemies for example, are only explicable if one consider that they are mutually related. The Darwinian theory established for us the law of evolution, and it now remains to carry the work a stage further.

It is somewhat difficult to perceive why the now clearly demonstrated faet, that age is the most powerful element in the dispersal of species, should rouse so much opposition. That an older species should oceupy more area than a younger one that is closely related to it, seems almost axiomatic, and was evidently elearly reeognised by Lyell and Hooker (ef. p. 3). If two species $A$ and $B$ have much the same dispersal methods, and are suited to much the same soils and climates, then it is clear that if we call these three factors $a, b$, and $c$, the dispersal of these two species will be represented by the formula:

$$
\text { dispersal }=(a+b+c) \times \text { age. }
$$

If the dispersal is the same, therefore, the age will be about the same, while if the dispersal of $A$ is greater than that of $B$, its age will be greater. If we transfer age to the left-hand side of the equation, we get $\stackrel{\text { dispersal }}{\text { age }}=a+b+c$, showing that dispersal goes with age only. But age simply represents the total effect of the operative factors $a, b$, and $c$, which will be the greater the longer the time during which they have been acting.

For the last half century, however, we have been under the 
sway of the theory of natural selection, which demands origin of species upon large areas, as well as the occurrence of many species that are "going under" in the struggle for existence. The result has been, consequently, that the species of small areas have been regarded as the failures, and this has derived support from the fact that fossil botany shows that there are vast numbers of extinct forms. Most botanical work has been done in the regions that were affected by the last glacial period, which has left very many survivals in them (ef. p. 86 , footnote). It is not fully realised that though there may be perhaps a thousand of such survivals, they are completely lost in the crowd when one deals with the forms of limited area, or with the monotypic genera as a whole. It would be absurd to apply the explanation of relicdom in face of such facts as those given in Chapters $x v$ to xvir. Few people would now be found to express themselves in support of natural selection as a cause for origin of species, but though the premises of the argument are damaged or abandoned, they hold strongly to the deduetions that were made from them, chief among whieh, in the present connection, is that species have reached their limits of possible dispersal, and that those of small area are the defeated in the struggle for existence.

So long as such a view was taken of distribution, so long would it have seemed absurd to expect to get any result from statistical investigations. But the figures that have aetually been obtained, and of which many instances are given above, show that what we have called the hollow curve obtains throughout. It obtains, for example, in the grand total of genera in the world, and for the totals of genera in every single family: for the distribution of endemies, and of local floras, whether for areas oceupied by the species, or for the sizes of the genera; for animals as well as for plants. The hollow curve is apparently a universal prineiple of distribution, whether it be distribution in space-geographical distribution-or distribution in time-evolution. A species as it increases in age, expands its area, while a genus increases its number of species, the younger occupying smaller and smaller areas, usually within the area of the first species, until that becomes very large (and sometimes even then).

The very important bearings of this work upon the general theory of evolution must be left for later publications. It will suffice to have called attention to the facts. 


\section{CHAPTER XIX}

\section{APPLICABILITY OF AGE AND AREA TO ANIMALS}

$\mathrm{A}_{\mathrm{T}}$ an early period of my studies of Age and Area, when once I had found how universally operative it was in the Vegetable Kingdom, it seemed to me that in all probability it must also apply to animals, though perhaps with less force on account of their capacity for movement. Accordingly, I asked Professor J. Stanley Gardiner, F.R.S., for help, which was given in the most unstinted manner, and for which I take this opportunity of expressing my most grateful thanks. By his advice I investigated some groups of Land Mollusea-animals whose locomotive capacity is somewhat limited-and I found that their distribution agreed fairly closely with what would be expected under the hypothesis of Age and Area. One or two other groups that he also recommended showed the same thing. The great difficulty in applying Age and Arca to animals rests upon the fact that Professor Stanley Gardiner pointed out, that in very many groups either the systematic grouping or the geographical distribution is but imperfectly known, and that there are comparatively few groups in which our knowledge of both is fairly complete. And of course in applying a new prineiple like Age and Area to the Animal Kingdom one must be very sure of one's facts, and not leave it possible for any one to say that a more complete knowledge of the subject would yield quite lifferent results.

At this stage I left the subject for a while, being much occupied with the extension of its application to plants. At a later period Professor Stanley Gardiner recommended me to apply for help to Mr Edward Meyrick, F.R.S., the well-known investigator of the Micro-Lepidoptera, who had at his command all the known facts about the systematic grouping and geographical distribution of this group. Mr Meyrick was so kind as to furnish me with the figures of the numbers of species that occurred upon New Zealand and upon other islands, and the genera to which they belonged, and from these I was able to determine that this group also had closely followed Age and Area in its distribution; not so closely, perhaps, as the plants, but with sufficient approximation for the fact to be unmistakable. 


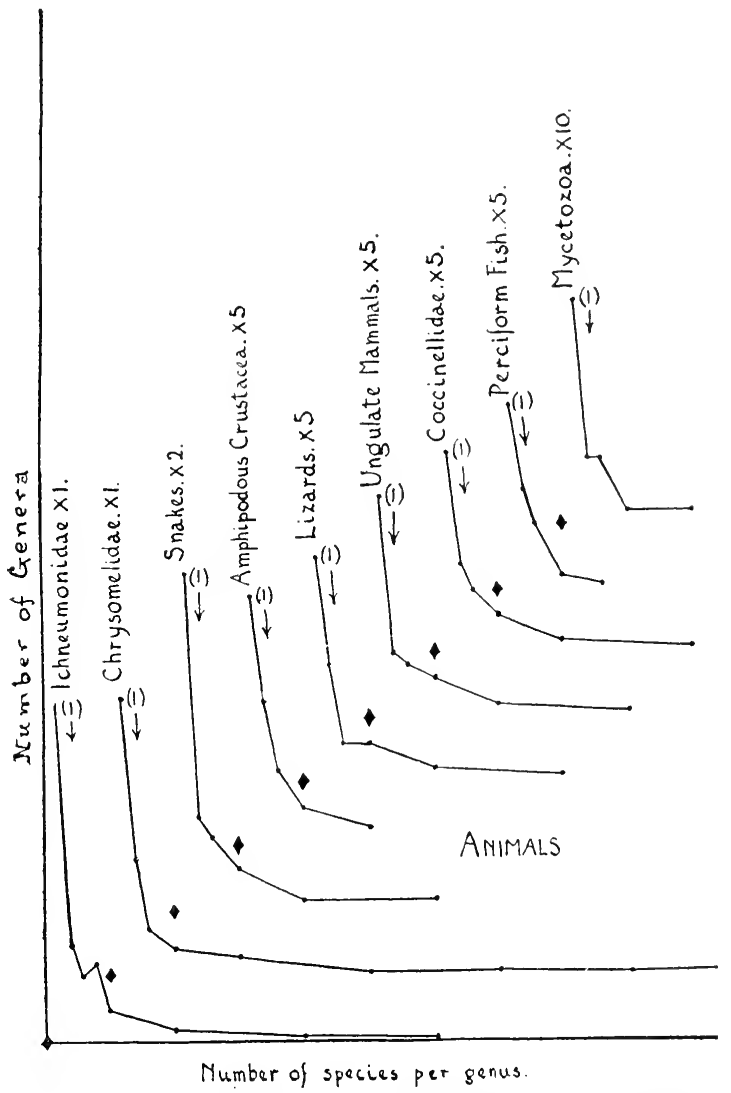

Hollow curves of distribution of sizes of genera in various families of animals, plotted in the same way as those for plants on p. 187. The almost exact parallelism of the eurves for both animals and plants may be scen in the fig. on p. 237 . 
It was thus becoming gradually clear to me that with perhaps rather greater deviations than in plants, Age and Area was also a rule for animals, and in the latter half of $1920 \mathrm{I}$ began to write a paper, which $I$ hoped might be published by one of the zoological journals, upon the application of Age and Area to such questions. But as about this time the work upon the "hollow curve," described above, began to show promise of very striking results, I decided that it would be better to leave the matter alone for the meanwhile.

Since finding that the hollow curve is practically universal in the distribution, and also in the actual evolution, of plants, and that it can be traced by merely adding up, and sorting into sizes, the genera that make up any group, the application of the theory to animals has been rendered a much more simple matter. Professor Stanley Gardiner once more came to my assistance, and gave me a start with the names of reliable catalogues of genera and species, such as those of Boulenger (Lizards, Snakes, Amphibia, Perciform Fish); and Miss Taylor, Librarian of the Balfour Library, Cambridge, showed me a number of others. Finally, Professor Stanley Gardiner recommended me to apply to Dr Hugh Scott, the Curator in Entomology, and an authority upon the Beetles. With his assistance, which was freely and liberally given, I have been able to enumerate a number of families of this group.

The result of all these enmmerations is to show that the "hollow curve" is as well marked in zoology as in botany, for I have found it to show elearly even in such small groups as the lizards and the snakes (fig. on p. 201), and it is as evident in the Ungulate Mammals (Lydekker, 1916), the Chiroptera (Anderson, 1912), the Amphipodous Crustacea (Bate, 1862), the Marsupials (Oldficld Thomas, 1888), the Mycetozoa (Lister, 1894), and even in such small groups as the Cyclostomatous Polyzoa (Buck, 1875).

Some of these curves are shown in the fig. on p. 201. As it might be thought that parasitic animals would show a different curve, I counted the Ichneumonidae (de Dalla Torre, Cat. Hym., 1901) upon Dr Scott's suggestion, and the illustration shows that this group also exhibits the hollow curve, though there is one irregularity shown at an earlier stage than usual. There are 60 with four species and only 50 with three, whereas the numbers usually do not show much irregularity till one comes down to about 20 . 
In the Beetles the curve shows clearly in all groups counted. For example, the Tenebrionidae (Gebien, Col. Cat. 15, 22, 28, 37, 1910-11) show 489/1, 154/2,103/3, 73/4, 40/5, 48/6, 32/7, 32/8, $24 / 9,10 / 10$, and so on; the same kind of figures are shown by the Coccinellidae (Gemminger and Harold, Col. Cat. 1876), and the Chrysomelidae $(I b, 1876)$, as well as other smaller groups that were counted. Unfortunately, I counted the Coccinellidae and Chrysomelidae from an old catalogue, and the new catalogue is not yet sufficiently complete to enable a comparison to be instituted. The result of comparing floras of different dates and by different types of systematists, however, leads one to suppose that the result would be very similar.

Not only does the curve show in general lists of the animals of the world, like these, but also, just as in the case of plants, it can be seen in local faunas. Thus taking Barrett's British Lepidoptera (London, 1905), one finds that the genera whose names begin with $\mathrm{A}, \mathrm{B}, \mathrm{C}$ or $\mathrm{D}$ show $62 / 1$ ( 62 of one species in Britain), $28 / 2,13 / 3,4 / 5$, and so on; those with E, G, II or L show $54 / 1$, $18 / 2,14 / 3,10 / 5$, and so on; those with $\mathrm{M}, \mathrm{N}, \mathrm{O}$ or $\mathrm{P} 63 / 1,15 / 2$, $9 / 3,8 / 5$, and so on; and those with $\mathrm{R}$ to $\mathrm{Z} 36 / 1,7 / 2,6 / 3,4 / 5$, and so on. The total shows $215 / 1,68 / 2,42 / 3,26 / 5$, and so on.

The British Echinoderms (Bell, 1892) show 39/1, 16/2, 5/3, and so on. Even so small a group as the British Spiders does its little best to follow the curve. It is clear that the rule holds as well for animals as for plants, as will be seen by examining the fig. on p. 237, where the eurves for animals and for plants, for local floras and for loeal faunas, etc., are mixed up together. The same rules have evidently guided the evolution and the geographical distribution of both groups, and the extraordinary parallelism of the curves goes to show that both crolution and geographical distribution were largely guided by factors that acted in a mechanical way. The very interesting suggestion has been made that the parallelism may be due to the fact that animals are (in the long run) a function of plants. But it does not seem to me that this is quite sufficient to explain, for instance, the fact that the Ichneumons show a curve parallel to the others. 


\section{CHAPTER XX}

\section{THE ORIGIN OF SPECIES}

No subject in biology has been the cause of such excited debate and controversy as has this, since the publication of Darwin's Origin of Species in 1859. Were it not that Age and Area seems to have some not unimportant bearings upon the subject, we should not bring into this book so thorny a matter of dispute.

If in this chapter or elsewhere I seem severely to criticise the Darwinian theory, it is not because $I$ do not appreciate its many strong points, nor is it that I am trying to throw contempt upon it. The theory is as legitimate a subject for criticism as is any other. It does not seem to me that it has been properly realised that the "Darwinian theory" has two separate sides. Darwin's immortal service to science lies in the fact that he established the theory of Evolution-until then regarded with contemptin an unshakeable position, which all subsequent research has only strengthened. But to establish it he had to invent some machinery by means of which it might be supposed to work, and for this purpose he devised the very simple and beautiful mechanism of natural selection. So strong was the a priori evidence in favour of this, and so well did natural selection seem to explain almost everything in animated nature. that within a short time it was accepted all round, and with it the theory of evolution, which is now established as the ruler of thought, not only in the scientific world, but outside of it. The mechanism of natural selection has, however, been for a long time subject to an increasing severity of criticism, and as a working theory is now becoming largely moribund.

No theory as yet brought forward in biology has been for so long a time a stimulant to research, nor has any proved so fruitful in educing valuable work. It may suffice to call attention to the very different position of biology in 1859, and at the present time. It is hardly too much to say that all, or nearly all, the work done during that time owes its inception, at least, to the influence of the Darwinian theory. Not only so, but it has produced the most far-reaching effects in all branches of human thought.

The literature in praise of the theory is already very bulky, 
and my present object is not to add to it, but to criticise certain aspects of the theory, and to show in what directions it has failed to give us satisfactory explanations of phenomena, or fruitful subsidiary hypotheses upon which to work. To suggest a doubt of its enormous value in the advance of knowledge would be to rank all the workers of the last sixty years as upon the intellectual level of the Bushman or the Esquimaux.

There can be little doubt, however, that during recent years the theory of natural selection has become what we may call a limiting factor in the progress of biology, and the time seems to me to have arrived when we ought to consider the advice given by Sir Joseph Hooker soon after his first acceptance of the theory:

"The advocate of creation by variation may have to stretch his imagination to account for such gaps in a homogeneous system as will resolve its members into genera, classes, and orders, but in doing so he is only expanding the principle which both theorists (i.e. special creationists and natural selectionists) allow to have operated in the resolution of some groups of individuals into varieties:... Natural Selection explains things better ...it is to this latter that the naturalist should look...holding himself ready to lay it down when it shall prove as useless for the further advance of science, as the long serviceable theory of special creations, founded on genetic resemblances, now appears to me to be."

Went (112, p. 270) has said that we ought to drop all teleological explanations, and not consider nature as having any aim. This may secm somewhat drastic, but as yet we are without any evidence as to what is the aim of nature, though the work that has been described above seems to show that she perhaps has one, for it seems evident that the evolutionary clock was wound up to run on a very definite plan. But for what nature is aiming in this definite way, we are completely ignorant, and it will, it seems to me, prove more wise, in the present state of science, to follow Went's advice, leaving out of serious account as yet any suppositions as to the ultimate aim of nature.

We have shown in the preceding chapters that the phenomena of distribution, whether it be distribution in space of species and genera, or distribution in time, as exhibited by the grouping of species into genera of various sizes, can be graphically represented by hollow curves, which could if required be produced in tens of thousands. It is clear that such a general phenomenon must have a general explanation, and that this must be largely 
mechanical. These phenomena, as has already been shown, cannot be satisfactorily explained by any of the many suppositions that have long been current, based upon natural selection. A differentiating cause like natural selection could not produce such uniformity of expression, and at the present time, the only feasible explanation in the field seems to be that provided by Age and Area, which explains the species and genera as developed in successive order and gradually expanding their area (and their number of species, in the case of genera) as time goes on.

But if this explanation be correct, it is clear that the smaller the area occupied by a species, the younger on the average will it be, in its own circle of affinity. The only logical conclusion to this is that in general the minimum area is that occupied by species just commencing their life as such. But, as already shown (pp. 54, 55), this may be very small indeed; a species may be easily limited to a dozen or two of individuals, if it does not actually begin witi one or the progeny of one ${ }^{1}$. It is clear that we cannot regard as the formative cause of the genesis of the species a struggle for existence resulting in the conservation of favourable variations, especially if these be of the kind that we understand as infinitesimal or fluctuating.

The new species just commencing will have to undergo a struggle for existence, usually of a very strenuous kind, immediately, and if in any way unsuitable to the conditions that prevail at the exact place and time of its birth, will at once die out, as a rule leaving no trace. If it survive, it may continue to spread so long as it finds conditions in which it can grow, and the ultimate area that it covers will depend upon that and upon its age (cf. de Vries, below, p. 227).

One of Darwin's innumerable services to the cause of science was to call attention to the struggle for existence. Even he, however, perhaps hardly emphasised sufficiently the intensity of that which probably takes place at the birth of a species, except upon more or less virgin soil. If in any way unsuited to the conditions obtaining at the time and place, it will be all but certain to succumb. Mere heredity, however, will tend to make it more or less suitable. But even if well suited, the new species

1 A few days before I left Rio, Dr Löfgren found, on a little island about three miles off the eoast, a new and very distinct Rhipsalis, of enormous size. He told me that there were only four examples on the island. I could only find, on the summit of Ritigala, about a dozen examples of Coleus elongatus (p. 54). And cf. Didymocarpus and Christisonia, p. 151. 
must probably have some degree of luck. It may not chance upon a spot where it can grow, the ground being already fully occupied by a closed association of plants; or it may easily be destroyed by a fire or a flood or other accident (cf. Didymocarpus and Christisonia on p. 151).

The older view, that species arose by gradual accumulation of infinitesimal or fluctuating variations (up and down variations, such as always show in any character, as when a leaf varies in length from one to one and a half inches on the same species), is now dying out in favour of mutations, or sudden alterations of form which have their origin in changes that have occurred in the material bearers of heredity. It is conceivable that any changes, however great, might be brought about by the accumulation of fluctuating variation, provided (1) that the variations were fully hereditary, (2) that they were not linear, showing the same character in greater or less degree, but differentiating, a simple leaf, for example, showing a tendency to compoundness, (3) that the necessary variations appeared, and (4) that natural selection should be able to act, i.e. that the appearance of the variation should give to the plant or plants possessing it such advantages as should ensure their survival in at least the majority of cases.

In regard to the first supposition, so far as we know, infinitesimal variation is not fully hereditary, but always regresses or falls back, so that while one may make great improvements by selection (as, for example, in the speed of trotting horses, or the content of sugar in the root of the beet) there always comes a point beyond which one cannot go. It is sometimes stated that the wonderful varieties of our cultivated crops owe their origin to the selection of infinitesimal variations, and that when left to themselves they go back to the wild form, but this is not the case, however; as Hooker long ago pointed out, the cultivated apple goes back, not to the crab, as is popularly supposed, but to crab types of cultivated forms.

These facts agree with ordinary observation, which gives no reason to suppose that continuous change is going on. Hooker (55 $a, \mathrm{p} . \mathrm{x})$ has so well put the argument in favour of the general permanence of species that it would be presumptuous to try to better it (I have shortened it).

"(1) The fact that the amount of change produced by external causes does not warrant our assuming the contrary as a general law. 
(2) The permanence with which widely dispersed species retain their characters, whether naturally or artificially dispersed.

(3) With comparatively few exceptions, plants are confined within well-marked limits; sporadies (discontinuously distributed) are rare. If they varied indefinitely, sporadic distribution would be the rule.

(4) A multitude of allied species of plants grow close together without any interchange of specific character.

(5) The individuals that inhabit the circumference of the area occupied by a species are not found passing into other species, but ceasing abruptly...may meet or overlap similar species.

[(6) A negative argument in favour of distribution from one centre.]

(7) The species of the lowest orders (now families) are not only the most widely distributed, but their specific characters are not modified by the greatest changes of climate.

(8) The fact that no plant has been acclimated in England within the experience of man."

A little consideration will show that these arguments, with the possible exception of the eighth and last, are as sound to-day as when they were written, and all the work and experience of Jordan (62), Johannsen (61), and the many ecological writers of recent years has but added strength to them. But the stronger they become, the greater is the argument in favour of sudden ehange by mutation.

The seeond and third provisos (about fluctuating variation) above given really go together, for we have no evidenee that differentiating variations can appear at all, unless so large and sudden that they are really mutations, not connected with the preceding form by infinitesimal stages. Fluctuating or infinitesimal variation is simply up and down in the same characters; one never finds a leaf rarying by imperceptible stages in the direction of a tendril, or of compoundness, or towards a pitcher.

A great difficulty for the theory of natural selection, though indeed it is no less for any other theory, is to explain the occurrence of correlated variations. Why, when a plant produces tendrils, or climbing leaves, should its stem at the same time be weak and flexible? Yet the one would be useless, if not disadvantageous, without the other. It often happens, in these correlated characters, that while one confers advantage, the other is disadvantageous. It is not altogether wise or reasonable to talk about advantage as having determined progress in nature. To take the single instance of Coleus elongatus (p. 151), its two 
most marked characters of difference from its allies are its peculiar inflorescence and different calyx. Neither could be "useful" under any conceivable circumstances, nor could any of the other characters of difference between it and C. barbatus, but neither can one say that any are disadvantageous. But to get the one calyx from the other means that one sepal must narrow, while the others broaden, and all experience of fluctuating variation shows that all homologous members vary in the same direction, so that nothing but a mutation can produce this difference.

There are so many characters in plants to which no amount of ingenuity can attach any quality of advantage or the reverse, that though at first the natural selectionists said that we did not know enough about them, it soon became crident that this would not serve as a general explanation, and it was then said that they were correlated with useful characters. Gradually, however, it has been realised that the bulk of morphological characters come under this head, and that the uscless structural characters in plants outnumber the useful by an enormous percentage.

Lastly comes the question under the fourth proviso above, whether natural selection can act upon the first beginnings of characters. While there are some cases in which it might be imagined to do so, there is no doubt that in the rast majority of cases, where no use can be even suggested for the mature charaeter, it could not take hold of the first rudimentary beginnings. Take, for example, at random, the pollen patterns in Acanthaceae (genus and subtribe characters), the adnation in Solanaceae (genus), the adventitious shoots in Podostemaceae (family), the translators of the pollen in Asclepiadaceae (family), the various aestivations of the corolla (genus and family), the dehiscent or indehiscent fruit (ditto), the monoclinous or diclinous flower (ditto), the ruminate endosperm of Anonaceae (ditto), the phylloclades of Asparagus (genus), the valvular opening of anthers in Berberidaceae (family), the septifragal opening of capsule (tribal), the "boragoid" inflorescence (family or genus), the tubers of potato, the bulbils of Agave, and hundreds more. One cannot conceive of natural selection getting any grip upon the early stages of these, and indeed, in great numbers of these and other characters, early stages are not conceivable.

Not only so, but many things that wcre once explained as adaptations to something or another are now proving to be in 
reality of little or no value to the organism concerned. It will suffice to recall to memory the controversies about Drosera and its insectivorous habits, the work of Kamerling upon xerophily, or the characters of the Podostemaceae and Tristichaceae (124), which are extremely striking and varied, though there are no differences in conditions to which to be adapted. Stomata with an outer pit entrance undoubtedly diminish transpiration, and were once considered an adaptation to that end, but one finds them on the inner wall of the fruit in the opium poppy, where transpiration camnot matter (112). Ant-plants were supposed to gain from their association with ants, but one may see the Cecropia flourishing without ants all over the forests of Southern Brazil, and the ants bring aphides, which must do much harm to the plants. Epiplyytes were supposed to be a particular adaptation, till Schimper showed that plants became epiphytic when they had three properties in common-easily dispersed seeds, elasping roots, and capacity to resist drought for long periods. And so on; the old adaptation explanation has been shown to be of service in many fewer cases than had been supposed the case.

There can be no doubt that the idea of adaptation was pushed to extremes, and that adaptations were found in many features that have since proved to be almost or quite indifferent. Went $(112$, p. 260) has treated this subject so fully that there is no need to repeat his eriticisms, and he has also pointed out that when real adaptation exists, it is chiefly in plants that live under extreme conditions, and that it is rare in mesophytie types, to which probably the bulk of plants belong. It is quite possible that it is in this way that one may explain the fact that in the Bahamas the local endemics are almost as widely distributed as the "wides" (p. 6t).

Another great difficulty for natural selection is that in many cases the distinguishing characters do not appear (119) until the struggle for existence is long over, for there is no doubt that the vast proportion of the mortality is among the young seedlings. What possible difference can it make to a plant that does not flower till it is thirty years old, to take a single instance, whether its calyx is smooth or ribbed?

The fact that allied species usually live near together is a strong general argument against the idea that adrantage has anything to do (in any important measure) with the origin of most species. Another is that for selection to produce any great 
effect, it should be between large numbers, whereas a plant cannot on the average have more than six like itself around it.

A consideration of the instances just given, or of still more "important" differences, such as that between the embryo in Dicotyledons and Monocotyledons, soon shows that infinitesimal or fluctuating variation, though it occurs in every character of every plant, is inconceivable as a means of effecting the great differences that actually exist in the vegetable kingdom. Infinitesimal variations would at once be lost by crossing with their surrounding unmodified neighbours, and only if all were modified in the same direction by the action of some definite cause, e.g. the environment, would there be any likelihood of the survival of the new form. And even then, it is hardly conceivable that such changes as those instanced above should take place in gradual stages.

The view that evolution is not directly guided by the need of response to the actual necessities of plants, but is a more mechanical process, going on in comparative indifference to them, but with the disadrantageous variations at once thrown out by natural selection, has been gaining in definition for many years, especially since the rise of the study of genetics on Mendelian lines; and the "hollow curve" observations, described above, seem to show clearly that it has followed a definite more or less determined course.

Nothing but mutation. understanding by that a change of measurable amount, hereditary, not connected by infinitesimal stages with the more "typical" form of the parent, and usually" differentiating, seems capable of explaining the bulk of the specific, generic, and family characters that at present exist.

Large mutations, often covering several characters of a plant. are by no means unknown, and go by the name of sports. Actual observation has shown that a great number of these are hereditary, as in the well-known instance of the cockscomb. But that such sports can give rise to new species has been strenuously denied, because no instance of their undoubted survival in nature has been recorded. But, so far as I am aware, no instance of the formation of even a small varicty by natural selection of infinitesimal or fluctuating variations has been recorded, and the theory was accepted on account of its a priori probability. When this difficulty is cast up to the supporters of natural selection, they insist that there has not been time enough for the formation of anything since man began to observe such things. But, as 
we shall endeavour to show, the same reply is valid in the case of mutation. To expect to see the formation of a new species, i.e. the survival of a mutation, in the short time since man began to observe such matters, is rather sanguine than reasonable, and especially in the north, where the adjustment of plant associations to the environment is probably very perfect, and where consequently the establishment of a new form is correspondingly difficult. Lord Rayleigh has estimated the period since the Eocene alone, which covers but a portion of that occupied in the evolution of the higher plants, at $30,000,000$ years. But if we suppose one mutation in 50 years to survive, we should get the whole of the existing 160,000 species of flowering plants in $8,000,000$ years, which is only 26 per cent. of that time. And this mutation, be it remembered, may appear upon any small spot any where in the world, most of which is not under sufficiently close observation for us to be able to say whether or not any of the many species that are confined to very minute areas has arisen within the history of human record. If Tribulus alacranensis (p. 152), or one of the other two Alacran species, has, as is possible, arisen in the last 50 years, then there is no necd for any more species to arise for 50 (perhaps 150) years to come, to keep up nature's average ratc of evolution.

When one considers how diffieult it is for seed to get a chance of germinating, growing, and surviving upon any given spot, well covered, as most spots are, with a dense association of plants that have already proved their suitability to the locality and its conditions, it is clear that a new form must have the most complete suitability at its birth to the local eonditions, to get any foothold. Not only so, but it must suit those conditions as they will be modified by its own appearance and addition to the association of plants already there. Clearly, therefore, to talk about advantage as having guided its evolution is to go somewhat beyond the warranty afforded by any of the facts as yet at our disposal.

Man can, and does, easily propagate a novelty ${ }^{1}$ by clearing the ground of rivals, but in nature this will rarely happen. It may be that the very common presence of young species upon islands and upon mountains is due to the fact that these places,

1 "We have no reason to suppose that we have violated nature's laws in producing a new variety of wheat-we may have only anticipated them; nor is its constitution impaired because it cannot, unaided, perpetuate its race; it is in as sound and unbroken health and vigour during its life as any wild variety is" $(55 b, \mathrm{p}, \mathrm{ix})$. 
being somewhat isolated, have comparatively small floras, which have not, therefore, been able as yet to form very elaborate plant societies suited to their various conditions, and into which, therefore, a neweomer may more easily enter. In the same way, the frequent, and apparently quite casual, appearance of young and localised species in the great forests may be due simply to the fact that the fall of a great tree has for the time so changed the conditions as to give the newcomer a better chance of establishing itself before the old conditions are completely restored. The further out one goes, the smaller on the average does the number of species per genus become, and perhaps therefore the plant societies may tend to be more open.

Whether a new form upon its appearance will or will not survive, will depend chiefly upon natural selcetion, for it will at once have a struggle for existence of the most remorseless kind. It will also depend appreciably upon mere chance (cf. Didymocarpus and ('hristisonia on p. 151). A fire or a flood may easily kill it out, however perfectly suited to its environment it may be.

As our object in the present work is simply to criticise some of the directions in which existing theories do not seem properly to meet the facts, and to suggest some directions in which it is conceivable that they may be improved, there is no need to go into any discussion of possible causes of mutation. If, as is not impossible, they depend immediatcly upon some chemical change that has somewhere taken place, one can understand why changes should be mutational, for chemical change does not usually take place by continuous variation.

On account of the insuperable difficulties in the way of erolution by means of the natural selection of infinitesimal variations, opinion has for a long time been steadily eoming round to favour the idea of change by mutation. Even the most enthusiastic supporters of infinitesimal variation now generally begin with a measurable change, improving it afterwards by the old method. A recent writer of this school, for example, cites a change from inches to feet as an infinitesimal variation.

The work upon Age and Area outlined in Part I provides, as has already been indicated, strong arguments against infinitesimal variation, and the further work given in the last few chapters, which seems to show that when one deals with large numbers and the long run evolution of new genera and species, and their distribution about the world, is very much a process which has 
gone onward in a mechanical way, and whose progress can to some extent be predicted from the laws of probability, supplemented by the principles of Age and Area, Size and Space, etc., provides a still stronger argument. If the "hollow curve" type of distribution of numbers of families in the world, of numbers of genera in families, of numbers of species in genera, of distribution of families, genera and species by area, of distribution of genera in a given flora, of the bulk of the phenomena of evolution and geographical distribution, etc., held only for grand totals, it might still be possible to say that natural selection had had much to do with the guiding of evolution, and that simply because one was dealing with very large numbers the final result came out more or less in accordance with the laws of probability and of compound interest. But when, as has been shown, this result is exhibited family by family, genus by genus, country by country, and in animals as well as plants, it secms clear that in general evolution and distribution, in some detail, have followed "mechanical" laws, some of which, perhaps, in the shape in which we have described them-as Age and Area, Size and Space, etc.-the work described in this book may have done something to bring into more clear definition.

One cannot imagine spccies or genera arising by gradual change, and producing such an arrangement of "wheels within wheels" as that shown in the figure upon p. 156, or such curves as those upon pp. $17 \%$ and 187, with the monotypes in a fairly definite relation to the ditypes, these to the tritypes, and so on, the curre practically always turning the corner between 3 and 5 . To produce such an arrangement by gradual variation, natural selection is evidently incompetent, and some definite law to guide it, at present inscrutable, is required. In this connection one must not forget that very strong evidence against such a supposition is provided by the fact that one finds very few continuous really intermediate stages, whether living or fossil, between spccies or between genera; in the enormous majority of cases they are discontinuous. One may easily find species that have say four characters of one genus and five of another. or varieties behaving in the same way between species, but really intermediate characters are very rare; and indecd, as we have pointed out above, they are frequently impossible.

We shall see in Chapter xxin that the hollow curve really represents an approximation to the compound interest rule, and one cannot imagine it to arise by continuous variation, though 
one can imagine a genus arising from another by sucecsive mutation of a large number of the characters of the latter.

But if crolution be thus to an appreciable, if not (as seems more probable) a very large, extent predetermined and governed in its unfolding largely by definite laws, or by mechanical considerations like age, then it is clear that it is no longer safe to consider that advantage to the species has had anything to do with the actual evolution of that species, though it will have determined to a very large extent whether or not that specics shall survive. It may have been directly concerned in the evolution, but it will be safer to leave it out of consideration, and to study evolution in much more detail before committing ourselves. This study must be especially from an experimental standpoint, perhaps largely Mendelian, and we must, it seems to me, work without any ulterior idca of any aim to which evolution may be directed (eren the very local one of immediate advantage to the species), until we really possess some facts upon which we may reconstruct a theory of its operations. The work described in this book is largely iconoclastic, and I do not propose, in the present volume, to try to substitute any new theory of evolution for that which has for so long held the ficld, but merely to suggest a point of detail in which the latter theory may in my opinion be altered with advantage, by the acceptance of the theory of mutation, whilst in a later work I shall attempt to bring forward some of the conclusions about evolution to which the latest extension of the work upon Age and Area has led.

If we remove advantage from the list of factors that may be operative in erolution-and it is clear that at most it can only be a small one-then it is evident that the mutations that distinguish species from one another cannot proceed in easy stages, unless there be, as is of course by no means impossible, some at present inscrutable law guiding them. The whole change, it would seem, must take place at once. And this brings us to the question of how large a mutation may be.

Size of Mutations. Many people think that a mutation must be very small, like the differences in the "Iordanian" species of Erophila verna which are so numerous in Europe, or in the British Rubi or II ieracia. My own opinion, which I have held for the last eighteen years, and have published on various occasions (especially in 123, p. 329), is that this is simply placing an unnecessary handicap, for which there is no positive evidence, 
upon the theory of mutation. We have no evidence to show that a Jordanian species will proceed further towards a Linnean species. One cannot imagine the 11 Doonas, or the 15 species of Stemonoporus in Ceylon (p. 152) arising in this way. The Jordanian varieties show the same phenomena of dispersal as do the Linnean species of Ceylon and elsewhere, and often occupy as large areas, while they still remain true-breeding, and show no sign of variation. As a general rule, it is not hard to place a Jordanian species in its proper "Linnean" aggregate.

In view of the large mutations that have been recorded, e.g. Capsella Heegeri (104) and others (ef. list in 39, p. 308), and upon general grounds of comparison of the characters used in systematic work upon the classification of the flowering plants, it seems to me that mutations may at times be of the necessary size to give rise at once to Linnean species. One cannot conceive of the many species of Ramunculus in New Zealand, for example, arising by the gradual separation of Jordanian varieties, especially when these breed true. We have no evidence to show that the intermediate forms, as would be necessary on this hypothesis, die ont. The struggle for existence comes at the moment of birth of a species, and if it survives it may spread.

The view that mutations are necessarily small rests upon the opinion, often put forward as if it were a general rule (e.g. 67), that a Linnean species consists of a great assemblage of microspecies, which breed true, as has been shown to be the case in Erophila verna, for example. But this opinion requires a complete revision in view of the facts that have been set forth above in regard to Age and Area. A species can only consist of such an assemblage, obviously, if it consist of many individuals, and occupy a large area of ground. Now in the north temperate zone, where most of our botanical research is earried on, this is in fact true of nearly all species; and only a few are localised, for instance in the Alps or the Rockies, or to a less extent in the plains, particularly of North America and West Asia. These localised species have been looked upon as relies or special local adaptations, and often disregarded from an evolutionary point of view. But the work that has been done upon Age and Area show's that such species, except to some extent within the range of the effects of the glacial periods, must be regarded as young beginners. Now in their case, where often the whole species is only represented by a few individuals, it is clear that unless every plant or two is different in hereditary characters, the spceies 
cannot be composed of many true-breeding micro-spceics, but that the formation of these must be later in the life of a species than the formation of the species itself, and that it is after it is formed that a species breaks up into micro-species, not that a species is formed by the accumulation of micro-differences. This agrees with what Bateson has said in his Presidential Iddress (6); and simply expresses what has long been an axiom with workers in ordinary systematic botany, that it is in large and widely distributed species that much variation is found. Working in regions where most speeies actually occupy fairly large areas, people have acquired an exaggerated opinion of the variability of Linnean species, and unless it can be shown, by genetic or other investigations, that local Linnean species, which exist in enormous numbers, especially in the south, are equally variable, we must prefer to go upon the positive facts shown by Age and Area, confirmed as they are by the ordinary experience of every systematist.

It has long been the fashion to sneer at the "more systematist," and to regard him simply as a useful hod-carrier for the real work of Botany, and this especially since the incoming of modern theories of evolution, of which, by a kind of instinct, he has rarely been a supporter in any enthusiastic way-in itself an offence to those who think that by this or that theory botany will at last come to an end of its difficult and slow beginnings. No great systematist has taken up, for example, the modern cult that the only species that are species, and that are worth consideration, are the minute varicties of Jordan and other writers.

It will be worth while, in this connection, to quote some of the axioms of the great systematists, as they are in danger of bcing forgotten in the enthusiasm for the study of micro-species. For example, Darwin uses as headlines in the Origin of Specics the following, which have never been disputed. "Wide-ranging, much diffused, and common species vary most." "Species of the larger genera in each country vary more frequently than the species of the smaller genera." "Many of the species included within the larger genera resemble varieties in being very closely, but uncyually, related to each other, and in having restrieted ranges."

From Hooker (55 $a$ and $b$ ) I take (order in his sense is now called family) "The varying species are relatively most numerous in those classes, orders, and genera, which are the simplest in structure." "As with species, so with genera and orders...upon 
the whole those are the best limited which consist of plants of complex floral structure." "Those classes and orders which are the least complex in organisation are the most widely distributed, that is to say they contain a larger proportion of widely diffused species.... This tendency of the least complex species to be most widely diffused is most marked in Acotyledons (Cryptogams), and least so in Dicotyledons." "The most widely distributed and commonest species are the least modified."

It is clear, after reading these axioms, that another explanation of the greater commonness of new (endemic) speeies upon islands, southern land masses, and mountains is thus opened, and one which may prove to be of great importance. Age and Area shows that these widely distributed forms, which are the most variable, are the oldest, and probably the parents of the forms of lesser distribution. But at the edge of the dispersal of any genus or other group, one will get, most markedly, the oldest types; these being the most variable, will be the most likely to give rise to new forms, and this, with the probable comparative openness of the associations, may be the simplest explanation of the frequency of endemies in the regions we have indicated. A cursory examination of a number of genera shows that this is rery probably a general rule, but it would lead too far to go into it in more detail at present; this must be left for later work.

There is as yet practically no eridence that several mutations are required to form a Linnean species. We have no reason to say that a new and strictly local species is appreciably better adapted, in the great majority of eases, than the older one, unless for the conditions in which it first finds itself upon its evolution. If species $A$ give rise to species $B$ at a certain point

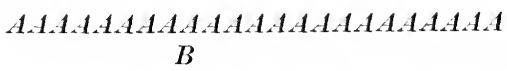

I

then, unless $B$ is suited to the conditions that obtain at that point in the year in which it was evolved, it is going to die out again. For the immediate conditions at $B$, then, it may be better adapted than $A$ (as for example, perhaps, the endemies of the Bahamas, p. 64 ), but when both speeies arrive at $X$, there is no reason why $B$ should be better adapted than $A$ to the conditions there. It will be mainly a matter of chance.

This being so, there seems no reason why intermediate mutations, if they were formed, should die out, especially as the 
original species, which we must look upon as the probable parent (e.g. Dillenia indica, p. 159), often survives in the same locality. A few cases like Acrotrema dissectum (Trimen's Flora of Ceylon, I, p. 9), where intermediate forms (possibly hybrids) occur, have been noticed, but more usually the loeal specics is fairly well distinguished from the wide-ranging form. And in some instances transitions are impossible, as, for example, with Coleus clongatus (detailed characters given on p. 152). I may quote here what has already been said about it in a paper of $1907(118)$ :

"The species is too entirely different from the other species of Coleus, whether we take C. barbatus or one of the others, for evolution by means of continuous variations to have bcen possible. To take some of the charaeters, especially those that are most prominent, how is the one type of infloreseence going to develop into the other by any possible continuous variation? The mind cannot conceive of such a process, unless it be by discontinuous variation. Still more, how is a calyx with one big tooth on top and four small ones below going to develop into one with five equal teeth? The study of infinitesimal variation shows that the maximum change to be expected in one generation would be a mere fraction of the width of a tooth, and how is this to prove of sufficient advantage or disadvantage to be of any material import in the struggle for existence? The question is equally hard if we suppose a common ancestor, for what kind of calyx or inflorescence will be intermediate?"

And ef. above, p. 209, as to ehanges in ealyx teeth.

In this case the speeies that one must regard as ancestral, C. barbatus, is also found in the same loeality; it is as frequent on the summit of Ritigala as $C$. elongatus, and grows in similar spots on the exposed rocks. Both suit the same eonditions, and if they have descended from a common aneestor, not one from the other, it is very remarkable that one should be confined to Ritigala, one common to tropical Asia and Africa.

Nearly seventy years ago, Lyell $(69$, p. 394) said "Might not the births of new species, like the deaths of old ones, be sudden?" and it appears to me, that when one puts together the facts of distribution as understood in the light of Age and Area, and the still more surprising faet of the agreement of the type of dispersal of species, both by area and into genera, and of genera by area and into families, etc., as more fully deseribed above, one can hardly arrive at any other conelusion. Adrantage as a cause in evolution seems to be ruled out with practical completeness, though it will determine whether the newly evolved form will survive or not; and if advantage cannot be adduced, then one can hardly conceive of the changes that distinguish one species 
from another having taken place gradually, whether by infinitesimal stages, or by small mutations, unless there be some at present inscrutable law that determines that such shall be the case. It will be much safer for the present, at any rate, to leave out of account such a supposition, and to work upon the idea that the whole distinction of a species may appear at once.

Now the new and distinct forms that have come into existence range from the minute varieties of the Drabas and Hieraciums of northern Europe to differences of well-marked Linneanspecific rank, and one must therefore suppose that mutations giving rise to such forms may be of similar variation in size.

It must not be supposed that this is being laid down as an absolute rule, but it would seem probable that it is a very general one. Individual forms may owe their origin to many canses, but in most cases it would seem to have been due (immediately) to a mutation small or large, which differentiated the new form from its predecessor, but there seems no reason to suppose that the new form is necessarily better adapted than its predecessor, and will kill it out in competition. The widely distributed, and presumably parental, Ranunculi of New Zealand are just as common in the south of South Island, where there is such a mass of endemics (fig. on p. 156).

Natural selection comes in, not as a causative and positive agent, but as a destructive and negative one. The new form will instantly have a most strenuous struggle for existence, so that, if not perfectly suited to the eonditions that obtain upon the spot where it is born, and at the moment of its birth, it will be remorselessly killed out. If it passes successfully through this competition, it may be regarded as eminently suited to that spot and those conditions, and may then spread as long as it can find suitable conditions into which to travel. Not infrequently it will meet with conditions that suit it cren more perfectly than those to which it was born, and we shall be liable to imagine it specially adapted to them, when really it is only they that are suited to it. Actual experience of the great changes in climatic conditions that go on from year to year shows that most species are really suited to a somewhat wide range of eonditions. This being so, there is little reason why the child should suppress the parent in competition. The latter will have proved its suitability to the conditions, and will probably have a much wider range, and the chance of a direct and severe struggle between the two is but small. Even if the child should suppress the parent in portions of its range, it will not be likely to overtake it over the whole, 
and the parent will probably survive in the outer portions of its range at any rate.

It is clear, if the Age and Area explanation of the facts of distribution be accepted-and as yet no other satisfactory hypothesis is forthcoming-that the endemics must in general be younger than the "wides," and it seems natural to suppose that they have been derived from the latter. But if this be so, then both parent and child occur together, or near together, in most cases, and if one push this consideration to its logical conclusion, one will see that there is no reason why the whole tree of the evolution of a genus (or even family) should not survive upon the earth at the present moment, as I have contended for the last fifteen years (120). Destruction such as that wrought by the glacial periods, or other geological convulsions, might of course kill out genera or families, but so long as conditions remain reasonably constant, there seems no reason why they, or intermediates, should be killed out.

If, as seems probable, destruction in the struggle for existence is to fall largely out of consideration as potent in the evolution that has gone on (except that it must have destroyed tens of thousands of incipient species, many of which might have been of great value had man been there to preserve and investigate them), we cannot regard Jordanian species as stages in the evolution of Linnean, for to get the localised Linnean from Jordanian species, wholesale destruction must have gone on, killing out altogether many of the latter.

Whilst the exclusion of advantage to the species as a serious factor in its evolution (though of great importance in determining whether or not it shall survive) practically compels us to accept the theory of mutation, and that such as may give rise at once to Linnean species, it also seems to me, when taken in conjunction with other phenomena which are now clearly visible, to involve other changes in our views. Chiefly important among these is the new view of erolution, first proposed by Guppy in 1906, and by the writer in the following year, that evolution did not proceed from individual to variety, from variety to species, from spceies to genus, and from genus to family, but inversely, the great families and genera appearing at a very early period, and subsequently breaking up into other genera and species. The final results of the study of Age and Area, with its demonstration of the universality of the hollow curve, seem to me at present almost to involve the acceptance of this riew, and the subject will be fully developed in a subsequent book. 


\title{
CHAPTER XXI
}

\section{AGE AND AREA AND THE MUTATION THEORY By Hugo de VRies, F.M.R.S.}

\begin{abstract}
The main principle of the mutation theory is that species and varieties have originated by mutation, but are, at present, not known to have originated in any other way. Originally this conception has been derived from the hypothesis of unit-characters as deduced from Darwin's Pangenesis, which led to the expectation of two different kinds of variability, one slow and one sudden.
\end{abstract}

Freed from the assumption of a transportation of gemmules through the organism, the conception of Pangenesis is the clear basis of the present manifold theories of heredity. An organic being is a microcosm, says Darwin, a little universe, formed of a host of self-propagating organisms, inconceivably minute, and numerous as the stars of heaven. In honour of Darwin, I have proposed to call these minute organisms pangenes, and this name has now been generally accepted under the shortened form of genes. They are assumed to be the material bearers of the unitcharacters of species and varieties.

This principle leads almost directly to the distinction of two different kinds of variation. For the first, no material change of the genes is required; they remain what they are. No two leaves on a tree are exactly alike; no two individuals of a species are the same in every detail. These two well-known propositions are the essence of what we now call fluctuating variability. In their visible features characters usually oscillate around a mean value, but this does not affect their material bearers. The researches of Quetelet and Galton have shown that such oscillations follow the law of chance. Starting from this idea, fluctuating variability of animals and plants has now become a main branch of biological study.

Besides these, changes may be expected, which involve the material bearers of heredity, or the genes, themselves. Some may be lost, either really or apparently, and new ones may be added to the stock, this latter process consisting probably in the transformation of old genes into new types. In consequence of such changes the external features of an organism may become 
altered, and these alterations are now generally ealled mutations. The theory assumes that these only are eomnected with the origin of species and varieties.

Darwin recognised both mutation and fluctuation as steps in the general proeess of evolution. For this assertion he mainly relied on his studies of the variation of animals and plants under domestication, since organisms in the wild eondition did not, at his time, afford a suffieient basis for controlling his coneeption. He assumed mutations to be of subordinate signifieanee, explaining the main lines of the evolutionary process on the assumption of individual or gradual variation. This variation he had shown to oceur everywhere, but as to its eapability of aehieving lasting changes, he had no faets at hand to give a definite proof.

In my book on the Mutation Theory I have given an elaborate "Review of the Faets," especially on the botanieal side, in order to show that fluetuating variability does not lead to durable changes in the hereditary composition of a type. Wherever such changes oecur they may be shown to be historieally, or at least probably, due to saltations. These eritical eonsiderations led to the proof that the eoneeption of mutations was in full harmony with our knowledge of the variability of plants, as it oecurs everywhere in nature as well as in hortieultural and agricultural breeding.

The mutation theory is intended to be a support and a eorollary of the seleetion theory of Darwin. There can be no doubt that Darwin correetly set forth the essential steps in the evolutionary process and that changes in his views mostly relate to those minor points, for which, at his time, the material of facts was not adequate to a eorrect deeision. The mutation theor: claims to remove many of the difficulties, inherent to the Darwinian doctrine, as e.g. the general oceurrence of useless eharaeters and the impossibility of explaining the first beginning of a seleetion on the ground of its usefulness.

In order to become generally aecepted this theory has to be considered from two main points of view. The contention that speeies and varieties originate by mutation is essentially experiniental in its nature. But the thesis that they camnot be shown to have ever originated in another way has to be studied in the field of systematic botany and zoology, and partly in that of palacontology. Mutations were well known to Darwin to oeeur from time to time, and of late numerous observations of speeial cases in animals and plants have been published. A list of them 
has been prepared by Gates in his new book on Mutations and Evolution.

In the fruit-fly Drosophila over two hundred instances have been studied by Morgan and his co-workers, and the evening primroses, or Oenotheras, have afforded some dozens, many of which differ more widely from their parent form than recognised wild species of this polymorphic genus do among themselves. On the other hand, no observations have been adduced of new forms originating experimentally from fluctuating variations.

The experimental work has not, however, ehosen for its scope the proof of the reality of mutations, but has preferred other lines of research. In the studies of Morgan the distribution of the genes along the chromosomes, as predicted from the prineiple of Pangenesis, has been the main aim. With Oenothera the prominent question was the search for a method of studying the internal and external causes, which induce mutations to occur repeatedly. A thorough knowledge of these causes must, in the end, enable us to produce artificially distinct ehanges, determined beforehand. In other words, it must afford the means of evolving arbitrarily new useful varieties of chosen qualities, in agrieultural and in horticultural plants.

In systematic studies it is now generally recognised that the characters used in the diagnostic distinction of related species are not such as would be expected on the ground of Darwin's selection theory. As a rule they relate to qualities, which cannot be explained on the assumption of an origin by the accumulation of infinitesimal steps on the basis of their usefulness for the species. They are not observed to increase the chance of success in the struggle for life. Most forms would thrive as well without their aid. This is espeeially the case with morphological characters, whereas adaptation to such environmental conditions as moisture or dryness, shadow or open field, physical and chemical constitution of the soil, etc., might far more easily be imagined to crolve slowly. But even here direct proofs are wanting.

It is a curious faet that most of the striking instances of beautiful adaptation to speeial forms of life are characters of genera and subgenera, or even of whole families, but not of single species. Climbing plants and tendrils, insectivorous plants, desert types of Cactus, Euphorbia, and so many others, submerged water plants, and numerous other instances could be adduced. Since we do not know when and where and under 
which external conditions those types have originated, all speculations concerning their evolution on the ground of their uses must be considered to be more of a poetical than of a really scientific nature. Wherever striking adaptations to the environment are met with, we will always have to grant that they did not originate under the conditions of the locality, where we observe them, but elsewhere and in long forgotten times, the environmental conditions of which are neeessarily unknown to us.

Hitherto systematic enquiry was obviously handicapped by the weight of such objections, and they were simply left out of consideration. No principle was known, which would enable us to decide the question, whether advantageousness to their bearers had played any rôle in the evolution of new eharacters. Later on, after many wanderings of a speeies into different new environments, a charaeter might prove to be useful in some of the new localities, and here induce a rapid multiplieation. Striking adaptations, such as those of desert plants, may be the consequence. But whether the characters have evolved under analogous or under quite different eonditions, we do not know.

It is at this point that the theory of Age and Area has come into the discussion. It showed that the dispersal of species, especially in the first period after their birth, is independent of their distinctive morphological eharacters. This phenomenon may be studied on a purely statistical basis without the aid of personal appreciations of biological qualities.

In the first place, the discovery that endemic species are, as a rule, the youngest in their country, has provided us with a means of judging the value of their characters in the struggle for life. But even here such a relation is not observed. The endemic forms of Coleus of Ceylon, and numerous other instanees, show their marks to be minute and of subordinate importance, although they are recognised by the best systematists as having full specific value. Many endemic species are still living in the same locality and obviously under at least almost the same conditions as those under which they have originated. But no relation of their new marks to any use in the struggle for existenee can be pointed out. They have inherited their adaptation to the environment from their ancestors, but are rarely known to have inereased it. Only in some eases they have suceceded in spreading rapidly and widely, and then, of eourse, an improrement in adaptation may be granted. But even here there is 
nothing to show that the evolution of the character was due to this cause.

The conclusion obviously is, that specific characters have evolved without any relation to their possible significance in the struggle for life. The facts are contrary to the main principle of the selection theory of Darwin. Moreover, intermediate steps between the endemic spccies and their parents, in the midst of which they are ordinarily still living, are wanting, and therefore must be assumed never to have existed. Endemic species must have appeared at once, by means of one or a few distinct steps, which embrace their whole differentiation from the parent type. Considered in this way, it is evident that their origin is in full accord with the principles of the mutation theory, and has to be considered as one of the best proofs of its applicability to evolution in general.

Starting from the endemic species, Willis has worked out his statistical methods of studying the relation of age to dispersal for larger and larger groups. Everywhere this relation is shown to be, in the main, independent of the specific eharacters. It obeys the same laws in widely different genera and families. Dispersal is not due to special adaptation, and often, as in the Podostemonaceae, the most beautifully adapted forms are the local ones, whereas the universally spread species of the same group show the smallest degree of specialisation.

In other words, the area oceupicd in a country by any given species depends upon the age of that species in that country, and not upon speeial characters. Of eourse this law applies to the common type of species, and exceptions may be expeeted to occur. For this reason the species are not studied singly, but in small groups of twenty or so, and on this basis the law has been formd to be everywhere the same in the animal and in the regetable kingdom.

Leaving the appreciation of the importance of this principle for pure systematic studies and for the construction of fanily pedigrees to other judges, I might here point out its bearing on the mutation theory. It affords a full proof that everywhere in nature, in geological periods as well as at present, the morphological characters of newly originated types have no special significance in the struggle for life. They are not known to aid them in their initial dispersal. They may afterwards prove to be useful or useless, but this has no influence upon their evolution. Obrious instances of usefulness occur, as a rule, only at much 
later periods during the wandering of the new forms, when unexpectedly they arrive in environments specially fitted for them.

The usual phrase, that species are adapted to their environment, should therefore be read inversely, stating that most species are now found to live under eonditions fit for them. The adaptation is not on the side of the species, but on that of the environment. In a popular way we could say that in the long run species choose their best environment. Favourable local conditions induce a rapid multiplication, whereas elsewhere the forms remain rare, or are seen to disappear slowly.

The general belief in adaptation as one of the chief eauses of the evolution of specific characters is thus directly contradicted by the statistical studies of Willis, which are independent of all personal appreciation or estimation of a supposed value. This result must be considered as the one great proof, which the mutation theory still wanted for its aceeptance in the field of systematic zoology and botany. 


\section{CHAPTER XXII}

\section{GEOGRAPHICAL DISTRIBUTION: GENERAL}

OUR general outlook upon biological problems has been, and to a great extent still is, principally governed by the theory of natural selection-the mechanism by whose invention, and by virtue of whose a priori reasonableness, Darwin was able to render the immortal service of establishing the theory of evolution. Few people nowadays would be found to give a complete assent to the doctrine of natural selection, but though the premises are therefore weakened or destroyed, the conclusions drawn from them are still accepted with little or no question. Somewhat to my surprise I have found many who no longer accept natural sclection as operative in evolution in a positive (rather than negative) manner, but who are prepared to fight to the death for conclusions that are essentially based upon it, such as that species of small area are usually relies.

When one comes to look at the history of the subject of geographical distribution, one soon realises that since the impulse which was first given to it by the aceeptance of the theory of natural selection has spent its force, little work of any importance $^{1}$ dealing with the broad general distribution of plants about the world (as distinguished from their local distribution into societies and associations occupying rarious types of habitat) has been carried on. The limiting factor in progress at the present time is the lack of a proper theoretical background from which fruitful hypotheses may be derived. The facts of distribution remain an insoluble problem so long as one endearours to explain them by the theory of natural selection, and the more that the attempt is made, the greater is found to be the incrompatibility between theory and practice. The serious study of geographical distribution has consequently been more and more neglected, whilst at the same time it has been admitted in a vague theoretical way that no theory of evolution can stand whech will not explain the facts of dispersal.

Chief among the deductions-consciously or unconsciously

1 The last important work was probably that of Gt.ppy $(44,46,47)$, and it is to be noted that this work has led him to conclusions (expressed in his Theory of Differentiation) diametrically opposed to the theory of Darwin. 
made--from the theory of natural selection, which are to-day strenuously supported, and the belief in which seems to me the chief preventive to further progress in the study of distribution, are perhaps the following:

(1) That distribution of species about the world has in gencral been rapid.

(2) That the present distribution of species and genera about the world represents the maximum possible to those species and genera, and that distribution is eonsequently a elosed chapter.

(3) That speeies and gencra now existing oceupy, as a rule, just those places to whieh they are suited.

(4) That speeies and genera oeeupying small areas are as a general rule speeies and genera that are dying out (relies). Natural selection could not produce them upon areas so small as are oceupied by a great many. It also demands that there shall be a good many moribund forms; and therefore these loealised forms are assumed to be dying out.

(5) That on the whole, in the same way, small genera (with few species) are to be regarded as relics, and as in process of dying out.

As regards the first two of these, we have seen in Chapters II to $\mathrm{v}$ that there is no reason to suppose that as a general rule dispersal in nature is anything but extraordinarily slow, the ground being usually fully oeenpied by societies or associations of plants, into which entry will be diffieult or even impossible. This is confirmed by ordinary observation, for if one remember the position of various clumps of plants from one's childhood. one soon realises that if man have made no alterations in the neighbourhood they will be found in the same places, without having extended their area exeept in very rare instanees. Dispersal may be rapid if there be (whieh is very rarely the ease) virgin soil available, or if man or other eause have made some great alteration in conditions, but usually it will be a matter of the most extreme slowness. The figures for areal distribution that have been given above, showing that the "hollow curve" is apparently a universal rule, not only for totals, but for individual families and genera, show elearly that dispersal follows a largely "mechanieal" eourse, and that if a speeies now oecupy a small area, it is in most eases beeause it has not had time to occupy a larger one. If the areas occupied had been determined by natural selection, it is inconceivable that they should have been thus graduated in sizes from many small to few large, with 
no breaks in the continuity of the figures, and that not only on the totals, but in individual families and genera. We have also seen that there is no need for rapid dispersal, when the time available is considered (cf. p. 33).

It is thus fairly clear that the existing distribution of species and genera, in probably the great majority of cases, represents only the dispersal possible in the time that has elapsed since their evolution. If one could return to the world after ten thousand years, one might find an appreciable extension of their area by existing species, but to expect it in a short time is more sanguine than reasonable.

The fact that the composition and distribution of the floras of the outlying islands of New Zealand can to a large extent be predicted from a knowledge of the distribution in New Zealand of the New Zealand flora (pp. 66-75) is a very strong argument indeed in favour of the view that dispersal depends chiefly upon age, i.e. that it is determined by various factors which when one deals with long periods are found to act at a more or less uniform speed, and that consequently the existing dispersal of species does not represent the end of the chapter, but only the point which has so far been reached.

If one accept the two suppositions under discussion, it is quite impossible to explain numerous facts in distribution which are easily explained by aid of Age and Area, for instance, the fact that the Auckland Islands have 45 per cent. of their flora monocotyledonous, the Chathams 31 per cent., and the Kermadees only 21 per cent.; or that the plants of the floras of these outlying islands (p. 67) are unusually widespread in New Zealand, and those of the Chathams much more so than those of the Aucklands and the Kermadecs. It is impossible with these suppositions to do any prediction about distribution at all, whereas nearly a hundred predictions have already been successfully made with the assistance of Age and Area, and have added considerably to our knowledge of the distribution of plants in the New Zealand area.

In regard to the third hypothesis (p. 229), the supposition that species and genera occupy just those places to which they are suited has usually been taken for granted, and a vast amount of energy has been devoted to the problem of finding out why they are suitcd. But, as has just been pointed out, we can no longer safely draw this conclusion. If a species is not suited to its location, it will probably die out, as is apparently happening with 
Cupressus macrocarpa at Monterey (p. 88), though this species is admirably suited to life in a climate a little damper. But it is stretching our imaginations somewhat to imagine that most localised species are suited only to the places in which they occur. Conditions change so much from ycar to year that unless a species is suited to a considerable range, it will not be able to survive at all. It would not obtain a greater change by moving to another locality not too far away. It is probable that the slow acclimatisation practised by nature will ultimately accustom species to widely different conditions, but long time must be allowed.

The arithmetical facts disclosed in this book are much opposed to any such supposition. It is almost impossible to suggest conditions to which the overlapping species in the map on p. 56, or the grouped species of varying size of area on p. 156 , can be suited. The point of view usually taken up on this matter has been very well put by Huxley (59, p. 123), who says:

"We are very much in the habit of tacitly assuming that because certain plants and certain animals exist only under certain climatal conditions, there is somcthing in what we vaguely call the 'constitution' of the plant or animal which binds them to these conditions, and renders it impossible for them to live elsewhere. I wish we could get rid of this word 'constitution'; for I take it to be one of the many verbal anodynes by which the discomfort of ignorance is dulled."

The arrangement of species in areas that are concentrated about particular points, as is shown in the curves and maps on pp. $79,80,153,156$, goes to show that local adaptation has had little to do with the dispersal. If not locally adapted, the species would die out without spreading at all; but once established they begin to spread, at an average rate determined by the various factors that act upon them. The fact that the northern invasion of New Zealand (cf. table on p. $\tau ;$, and curves on pp. 79 , 80) does not show any increase of local species at the region where the southern invasion shows its maximum, and vice iersa, is a strong proof against local conditions having anything scrious to do with multiplieation of species.

The fourth and fifth suppositions, that species of small area, and genera of one or few species, are dying out, are those most strenuously adhered to, but in view of the facts set forth in this book scem to form a very difficult position to uphold. It need not be entirely abandoned, but in place of supposing most such 
speeies and genera to come under this head, one must be satisfied with a small number; to the great bulk the contention is not applicable. We have seen, and seen it so strikingly in numerous instances that there can be no doubt that it is a general rule, that the species in a given country, endemic or not, are grouped there (according to the areas that they occupy) in a perfectly definite manner, whieh is always the same. The wides are found (when there are also endemics) with many in the class of largest area, and numbers decreasing downwards, the endemies arranged in the reverse direetion. This regular arrangement is completely opposed to the idea of relic nature, for how could there be many at the last stage of relicdom, fewer at the last but one, still fewer at the last but two, and so on? It is equally opposed to the idea of local adaptation, it may be worth while to point out, for why should there be many adapted to the smallest areas, with numbers steadily decreasing upwards. Still more difficult is it to explain, upon either of these suppositions, why the wides (if endemies oecur also) should be arranged in the reverse direction ${ }^{1}$. If there be special local adaptation, then the wides must be much better suited to the country than the locally crolved forms!

Inasmuch as all families and genera, of reasonable size, agree in arrangement, some meehanieal explanation is needed to aceount for the meehanical regularity, and the only reasonable one suggested is age (for youth ef. pp. $\$ 9,92$ ). Age in itself, as already explained, does nothing, but it allows time for the active factors in distribution to produce their effeet. To accept age as a meehanical explanation simply means that we regard these factors as producing a resultant or total effect which goes on at an average speed, so that age becomes a measure of dispersal. The dispersal is of eourse stopped sooner or later by barriers, physical or ccological, including the barrier imposed by the faet that a species has reached the extreme of temperature, dryness, etc., that it can withstand. The real difference between the old view of dispersal and that given by Age and Area is that under the latter we regard almost all species as in proeess of extending their areas of dispersal, not some as extending their areas and as many or more contraeting theirs (cf. footnote on p. 174). The exceptions to this-the real relics - are comparatively few and far between,

1 When, as in Britain, there are no endemies, the wides diminish upwards, but show considerable numbers in the most widely dispcrsed classes, owing to accumulation there of species that could not rise higher. 
forming perhaps 1-2 per cent. of the total of species of very restricted area.

Very many arguments against the old position have been brought up above, e.g. on pp. 58, 81, $88-94,141,161-6$, and 179. No one has yet attempted to reply to any of these, which have mostly been already published, but the position is obstinately held, and the facts brought out by the study of Tertiary floras are especially appealed to. These show that there are without doubt, in the north temperate zone, a number of forms, perhaps even as many as 600 to 1000 , rather widely separated from their nearest allies (when they have any such), and probably 'Tertiary relies; but it is not properly realised that these are a mere trifle when compared to the local species that occur south of the tropic of Caneer. Brazil alone has about 12,000 endemic species, usually well localised; even the little island of Ceylon has nearly 250 species of the most localised distribution possible, almost half of them occurring each on one mountain top only, and it has nearly 800 whose area does not exceed 4000 square miles $(63 \times 63 \mathrm{~m}$.).

In view of the facts that have been brought up above, showing the way in which not only the areas occupied by endemics, but those occupied by other species, are arranged in hollow eurves, and showing that this same type of arrangement also oceurs in the grouping of genera and families into sizes, the idea of relie nature, or of special local adaptation (except in so far as this is needful for all species, if they are to survive), must, it seems to me, be abandoned for the great majority of cases, and the mechanical explanation adopted in its stead, that area oceupied goes with age. Nearly all forms are to be looked upon as increasing their area, and only a few, not most, as moribund.

That this view is in all probability the right one to take of the phenomena of dispersal is shown very clearly by the way in which, accepting it, predictions as to distribution may be made, and have as yet been uniformly successful (in almost a hundred instances). Very strong evidence, and evidence based upon definite facts, not upon a priori reasoning, is now required to show that the hypothesis of Age and Area is unsound.

But not only have we seen reason to accept $A$ ge and $A$ rea, but also to aecept the similarly "mechanical" hypothesis of Size and Space (Chapter xir, p. 113), which asserts that when one deals with groups of allied genera the size of a genus depends largely upon the area that it eovers, i.e. ultimately upon its age. This follows almost of itself when one has once accepted Ige and 
Area with its implication that all, or nearly all, species are in process of enlarging their area of dispersal, not some enlarging and some contracting it. There is no need to quote the evidence a second time (ef. Chapter xil, and pp. 132, 164, 165, 174, 178, $188,190,197)$.

But if these new views be accepted, it is clear that a good many changes must take place in our mode of viewing the problems of distribution, which it must not be forgotten have hitherto been regarded as insoluble. One of the chief among these is the problem of Invasions of plants from other countries. If it be supposed that the dispersal of a species depends simply upon its age (representing the arerage effect of the active factors) and the barriers that it meets, and that when once it is established in any place it will rarely die out there except as the result of rather sudden or violent changes of conditions ${ }^{1}$, and further that only when these changes attack it at the margin of its area will they cause any diminution of total area "occupied," then it is clear that the problem of invasions can be studied with some hope of obtaining results. This has been illustrated in Chapter viII, which deals with the invasions of New Zealand. It was there shown that by taking the places at which the maxima of species, endemic and wide, occur, one may get a clue to the different invasions that have reached the country, and the dircetions from which they came. But in a country without any endemies at all. the same principles may be applied to its "wides." This has lately been done for Britain by Mr J. R. Matthew, whose work (74) gives great promise for the future (and $c f$. p. 11 )). Careful aceomt must be taken of the conclusions of geology, but if we get rid of the ideas that (proportionately) many species are necessarily dying out, and that most have reached their possible limits of dispersal, we can study invasion and spread with some hope of arriving at definite results, a proceeding which has been impossible under the older views of these matters.

If genera give rise to others in a casual way, and at more or less easual spots (as the way in which the endemic genera in any country occur at seattered points would scem to indicate), then it is clear that in any part of the world onc must expect to find a casual mixture of genera of different sizes, made up in much the same way as is the entire flora of the world, or one of the

1 E.g. the oncoming of excessive cold, heat, dryness, dampness ; clcarance, fire, submergence, etc. 
families of which it is composed (fig. on p. 187). A very little examination of local floras suffices to show that this is indeed the case.

If, for example, one take the flora of Britain (37), one finds that the families, by numbers of genera, are arranged in regular order, diminishing as the number of genera increases, thus: $33 / 1$ (33 of 1 genus), $17 / 2,9 / 3,6 / 4,3 / 5,2 / 6,2 / 7,2 / 8,1 / 9,2 / 10$, and so on in scattered numbers to 46 . The genera by numbers of their species in Britain are 223/1, 90/2, 35/3, 32/4, 16/5, 15/6, and so on. Until the numbers become small there is no break in the regularity. The first two or three numbers contain the great bulk of the total; 50 families out of 92 contain one or two genera, and 313 genera out of 512 contain one or two speeies. This will be found upon examination to be a gencral rule for all floras. In New Zealand, for example, one finds the gencra (total 329) to be $155 / 1,54 / 2,29 / 3,17 / 4,12 / 5,11 / 6,11 / 7,5 / 8,5 / 9,4 / 10$, and so on. In Ceylon (total 102 7 ) one finds $573 / 1,176 / 2,85 / 3,49 / 4$, $36 / 5,20 / 6,19 / \tau$, and so on. In Vol. I (only) of the Flora of British India one finds $173 / 1,70 / 2,33 / 3,19 / 5,7 / 10$, and so on. All form markedly hollow curves, with the great bulk of the genera in the first two figures, so that there is a very steep drop until the third or fourth figure is reached, and then a gradual tapering away to the larger genera. The larger the country, on the whole, the larger the size of the biggest genera.

One may push this type of distribution, shown in the hollow curve, into yet more detail, and find that not only the whole local flora of a eountry, say, for example, Britain, shows this curve, but also portions of that flora. The same curve is shown by the Monocotyledons and Dieotyledons of the British flora, and even by the individual families, when of reasonable size, the grasses for instance showing $24 / 1,13 / 2,1 / 3,4 / 4,1 / 5,2 / 6$, and 8 , 11,13 . The line is wary, but the numbers are small, and there is no doubt about the shape of the curve.

Or one may take portions of the country inhabited by more or less definite associations, or groups of associations, of plants, and find the same thing. Thus if we take Cambridgeshire, the Wisbech division of the county (fen), and the very loeal Wicken fen, from Babington's Flora of Cambridgeshire, we get the same type of curves (cf. eurve 6 in fig. on p. 23\%). One might expect certain genera to prove unusually suitable, and to be disproportionately represented, but this does not scem to be the case. 
In the Mixed curves on p. 237, the fourth curve shows the whole flora of Ceylon arranged in order, beginning with 573 genera of one speeies each, and forming the usual hollow eurve; the 6th curve shows the flora of Cambridgeshire (Babington), the 9th the flora of Italy. All the floras so far examined give similar results, and the same is the ease in local faunas, as the 10th curve (Birds of British India) and the 15th (British Echinoderms) illustrate. The eurve is exactly like the eurve given by other eombinations of animals or plants, as may be seen by eomparing them with the other eurves in the same figure, e.g. for the Compositae or the Chrysomelid beetles, the endemies of islands, or those of Brazil. The tails in the figure are of course cut short: their length depends in general upon the size of the flora; the larger it is, the larger size, as a rule, do its genera reach to.

Or if one take the flora of Ireland, one finds it to be, exeept for a few Iberian plants in the sonth-west, a redueed eopy of that of Britain, and the way in which age alone has been the chief determinant of what species shall oeeur there is very strikingly shown by the following figures, extracted from Moore's Cybele Hibernica.

The plants of Britain in the Cybele Britannica are grouped in hundreds aceording to degree of frequency in Britain (i.e. the number of Watson's vice-counties in which they occur). Of the first hundred all oceur in Ireland, of the seeond and third hundreds all, of the fourth 98 , fifth $9 \tau$, sixth 93 , seventh 84 , eighth 74 , ninth 63 , tenth 66 (the only exception), eleventh 13 , twelfth 26 , thirteenth 16 , and fourteenth 8 , a steady diminution from top to bottom.

But if size also depends upon age, then it is elear that in any loeal flora the genera, whieh as a rule will not be endemic, should be arranged in the same way. The genera arriving for example in Britain will not all arrive simultaneously, but some will arrive sooner than others, and these will tend to be the larger genera of the nearest souree of supply, for the larger genera will usually be the more widespread. The ultimate result will tend to be that these genera will not only arrive first, but will tend to be represented by more speeies, so that one will expeet the most widely distributed speeies in the large genera (i.e. large for the country in question, being represented there by many speeies) to be more widely dispersed than those of the small. This we have already seen to be the case in the most striking way (p. 114). But one may push this arithmetieal regularity further yet. If 
one take the number of speeies per family in the British flora, one finds it to inerease steadily with the number of genera; there are no breaks, as one would be inelined to expect. The families

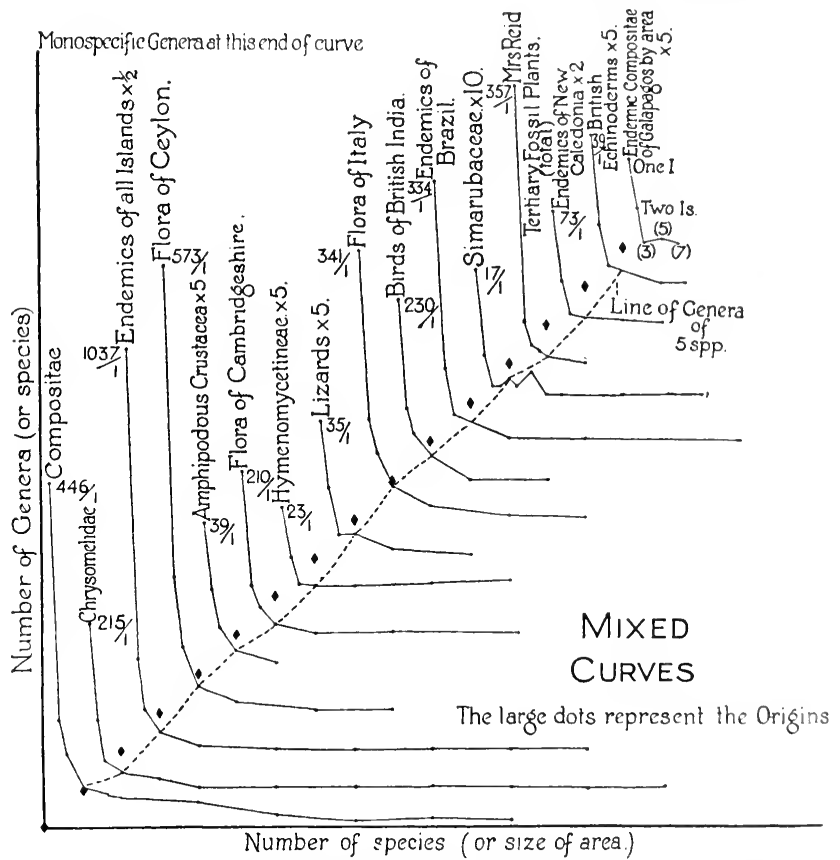

Mixed eurves, to show the elose agreement of the hollow curves, whether derived from families of plants grouped by sizes of genera (Compositae, Hymenomycetineae, Simarubaceae), families of animals (Chrysomelidae, Amphipodous Crustacea, Lizards), endemic genera grouped by sizes (Islands, Brazil, New Caledonia), local floras grouped by (local) sizes of genera (Ceylon, Cambridgeshire, Italy), local faunas (Birds of British India, British Fchinoderms), Tertiary fossils by sizes of genera, or Endemie Compositae of the Galapagos by area. [By courtesy of the Editor of Nature.]

with one genus show an average of $\mathbf{2} \cdot \mathbf{2}$ speeies per family, those with two an average of $8 \cdot 3$, with three of $10 \cdot \tau$, with four of $12 \cdot 3$, with five, six or seven genera of 15 , with eight, nine, or ten of 
40 , and with more genera than ten of 73 . The numbers increase regularly with the number of genera.

One may even find, here as elsewhere, that (as a general rule) the small families, which, as already explained under Size and Space in Chapter xis, will tend to be the latest arrivals, have fewer species per genus. While the families of one genus in Britain have $\mathbf{2} \cdot \mathbf{2}$ species per genus, those with more than one genus have a generic average of $3 \cdot 3$ species. If one take New Zealand, one finds the 34 families of one genus to average $2 \cdot 8$ species per genus, those with more $4 \cdot 3$.

One may even take the families of one genus in a country, and find that they are arranged in arithmetical order. In Britain there are $\mathbf{2 0}$ of these with one species, $\boldsymbol{\tau}$ with two, and six more with larger numbers. In New Zealand there are 18/1, 6/2, 3/3, and seven more. And this rule appears to hold everywhere. If one take the British families of two genera, one finds 12 genera with one species, 7 with two, 3 with three, and 12 others. In Ceylon the bi-generic families show $26 / 1, \mathrm{~S} / 2,3 / 3,2 / 4,1 / 5,1 / 6$ and 9,19 , and 20 species. Everywhere the arrangement of genera by species follows this simple arithmetical rule. forming hollow curves. Even the proportions of families and genera of different sizes in a comtry show some resemblance. In Britain 35 per cent. of the families are monogeneric, in New Zealand 37 per cent., in Ceylon 44 per cent. In larger and less isolated areas the proportions are smaller, and in the world they are only 18 per cent.

Another matter upon which it becomes needful to adopt a somewhat different view-point is the Struggle for Existence. We have seen that it ean no longer be regarded as an important determining cause in evolution, and that it is most strenuous for the individuals of new species that are just commencing. If they cannot succeed in this first struggle, they will simply die out and leave no trace, but if they do suceeed, they may be looked upon as having passed through the sieve of natural selection, and being, so to speak, certified as fit for existence in the region where they arose. Until they have spread to some little distance, however, they can hardly be looked upon as established, for they will be very liable to sudden extermination, whether ideally or badly equipped for life. A fire on the tiny summit of Nillowe-kánda in Ceylon (p. 55), for example, would probably exterminate the three species that are confined to it (and ef. Didymocarpus and Christisonia on p. 151). Once established on 
a reasonable area, only individuals, and not the species, will usually be affected by the struggle for existence. Only very rarely will a new form overtake its parent over the whole or the greater part of its range, and destroy it. We are no longer obliged to regard a new species as coming into existence at the expense of its ancestors.

Another important general result of the work upon Age and Area outlined above is to show that in any given country, and therefore in the world in general, the "wides," which occupy the largest areas (on the average), are the oldest forms, i.e. that they were the first to appear. The faets set forth showing the distribution of the varions classes are indisputable at the stage that the work has now reached, and they are wonderfully concordant from one country to another. No one has attempted to contradict them, but there has been much a priori reasoning to the effect that this or that has not been allowed for, that it is obvious that so-and-so must produce great effects, etc. None of this reasoning, however, has attempted to explain the faets, which are so striking and so eonsistent that they must have an explanation, and that a mechanical one, on aceount of their meehanical regularity. The only reasonable one is, as frequently pointed out, that the factors aeting upon dispersal produce in the long run a very uniform effeet, so that age forms a measure of dispersal.

But if this be so, there is no possible and reasonable explanation of the endemics, which in general are younger than the wides, and oceur beside or near them, except that they are descended from the wides, directly or through other endemies. But when a new endemie arises in this way, unless it is much better suited to a variety of eonditions than its parent, it will never overtake the latter, and we have seen that there is little reason to suppose a eombat $\grave{a}$ l'outrance between them. The parent will most often, probably, survive beside the child. At times it is possible that it may survive only beyond it; but the distribution, for example, of the Ranunculi of New Zealand, where the parcntal wides are just as eommon in the region where the crowd of cndemics oceurs, as in the far north where there are none (cf. map on p. 156), gives little evidence in favour of this latter supposition. In my various papers I have assumed that the wides give rise to the endemics, and have made nearly a hundred predietions upon this basis. As these predictions have 
always been successful, the assumption is therefore probably correct.

The endemics, then, of course with a good many exceptions, are in general to be regarded as derived from the wides that occur among them. In many cases, as we have seen, and those most often cases in which there is reason to suspect greater age than usual, a genus in any single country may have only endemic species (cf. pp. 95, 155), sometimes only one, sometimes more, and in these cases we may suppose some mutation, perhaps at once, in the first wide to arrive, or perhaps subsequently and en masse.

But now, if, in general, the appearance of a new form does not imply, as it did under the theory of natural selection, the disappearance of its ancestral forms, there seems little reason why both should not survive upon the earth, or, in other words, why the whole, or great part, of the tree of a family or genus should not survive. I have already worked out this question in regard to the Dilleniaceae (120), suggesting that Tetracera, a widespread and very simple genus, may have been the ancestral form from which the family was derived. In the same way the Polemoniaceae (p. 171) might have been derived from Polemonium, the Menispermaceae from Cocculus and Cissampelos, whilst in Cissampelos itself, C. Pareira (p. 159) might have been the parent of the other speeies, directly or indirectly. In Doona (p. 152), D. zeylanica may in the same way be looked upon as the probable parent, direet or indirect, of the other species, and so on.

It is elear that when once the general principle of Age and Area is established-and already the eridence in its farour is very strong-it may be called into service in the study of phylogeny. But if it be accepted, it is clear that Guppy's Theory of Differentiation (p. 221) must almost necessarily be accepted also. This subject will be dealt with in a later book upon Evolution generally, and can only be mentioned here.

Just as the endemics of small area are to be looked upon as descended from species of larger area, so also we have seen that the monotypic genera are to be looked upon in general as descended from larger genera. The way in which the numbers of genera, not only in the total, but family by family, are arranged (cf. p. 187) in hollow curves, with a great preponderance of monotypes and steady decrease to a few of large numbers, shows that 
there is a definite mechanical relationship betwcen them. If we imagine existing genera to give rise to new gencra, as they give rise to new species, by mutations at intervals, we shall then expect that genera as a whole will follow the law of compound interest. But if this be the case, then it follows that whilst the number of genera plotted to the numbers of species that they contain will give a hollow curve like those on p. 237, the logarithm of the number of genera plotted to the logarithm of the numbers of species that they contain will give a straight line ${ }^{1}$.

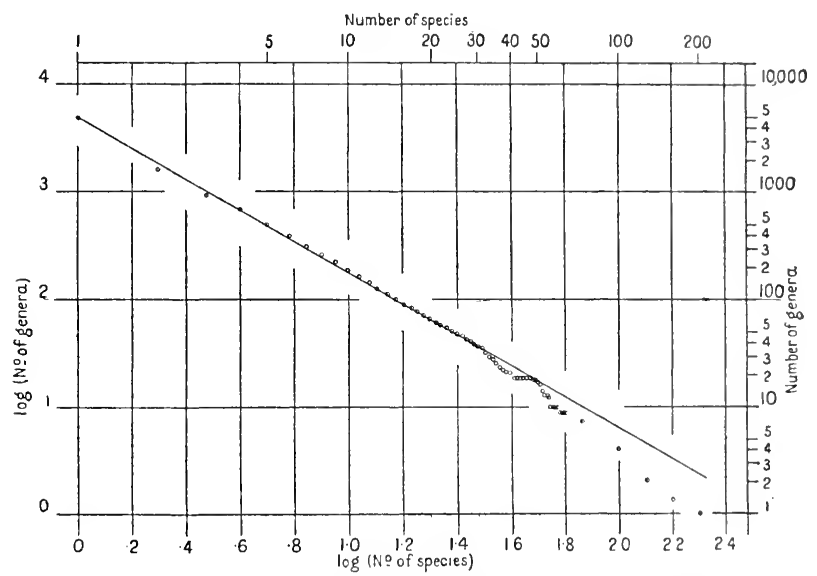

Logarithm curve for all Flowering Plants (from Willis, Dictionary).

(By courtesy of the Editor of Nature.)

That this is in fact very close to the actual truth when considerable numbers are dealt with is shown by the figures on pp. 241, 242, which give the logarithmic curves for all flowering plants, for the Rubiaceae, and for the Chrysomelid beetles. This subject must also be left for further consideration in a later book. Suffice it to say for the present that the evidence is decidedly in favour of the origin of new species and genera from old by mutation, which in the long run has followed a very definite

1 For this deduction I am indebted to my friend Mr G. Udny Yulc, C.B.E., F.R.S. 


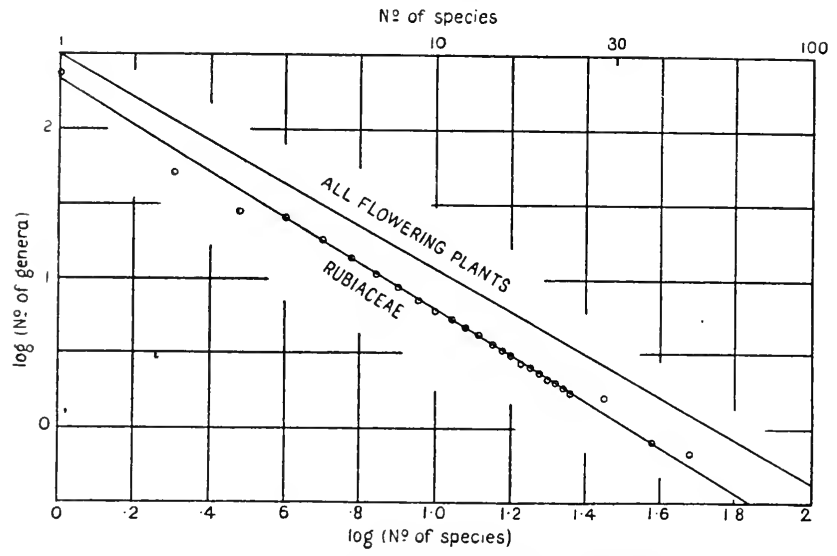

Logarithm curve for Rubiaceae (from Willis, Dictionary).

(By courtesy of the Editor of Nature.)

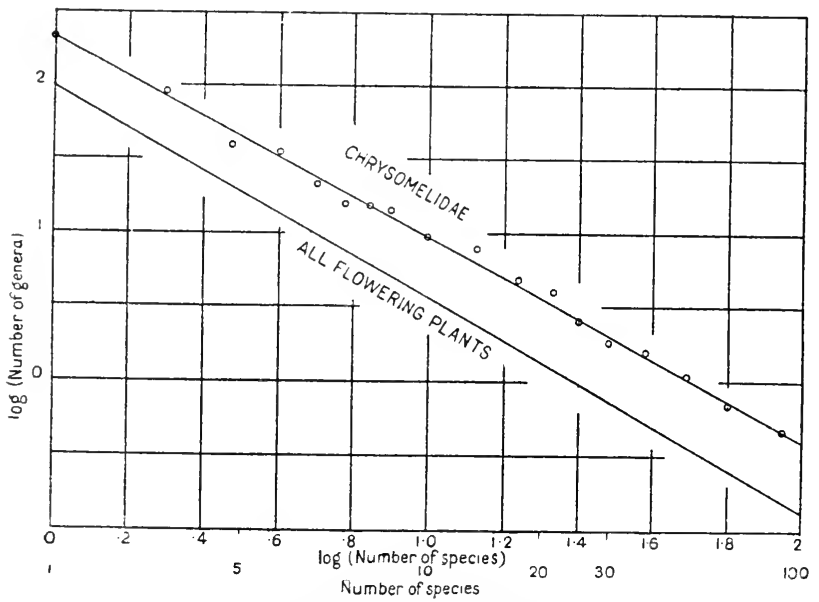

Logarithm curve for Chrysomelid beetles (from old Catalogue).

(By courtesy of the Editor of Nature.) 
plan, new mutations being cast on the average at a fairly definite speed, differing of course for different elasses of animals and plants.

The acceptance of the view that $B$ is the direct descendant of $A$, another living species, instead of both being the descendants of some hypothetical $\alpha$ (an ancestor which by the way has never been found in the fossil state, so far as I know, though on the current theory there should be hundreds of thousands of them) will make the work of tracing phylogenies easier, though if mutations may be of large size, this will not always be casy.

Except in cases where we have geological evidence of former greater spread, when of course the "fossil" area must be added to that occupied by the living plants, we may leave out of account the more local genera in tracing phylogenies, and it is clear that species or genera that are widely separated in space, and in whose case no fossils ean be found filling up the spaeial gap, cannot, withont great risk of error, be looked upon as necessarily closely related, however much alike they may be (cf. 130, p. 346 ). Their resemblance may be due to parallel mutation, and their ancestors may have been more widely separated than they themselves are.

In the same way, no fossil that is not of wide dispersal can safely be regarded as an immediate ancestor for anything that is of equal or nearly equal dispersal, and still less if it be of greater. Nor must widely separated fossils be regarded as nearly related without links. Nor is it safe to regard two layers as of the same horizon without a number of fossils in common; and so on.

Age and Area also throws light upon the question of Floral Regions, which are usually defined as marked out by containing large numbers and proportions of endemic forms, and as being the better marked and more natural the higher the rank of these. Great difficulty has always been encountered in defining such regions; and to make them agree with those of the zoologists is usually regarded as hopeless. In the accepted grouping of them, the southern regions are very much smaller than the northern, owing to the fact that endemies increase in number and proportion towards the south (p. 149). Thus south-west South Africa is regarded as a region equivalent to the Mediterranean region, which includes all the land around that sea as far as Beluchistan; and even to the whole of tropical America, including the West 
Indies, a region which contains colossal numbers of endemic forms. Other regions of absurdly small size are the Galápagos, Juan Fernandez, the Hawaiian Islands, Kerguelen, etc.

It is difficult to understand why so much energy and labour has been applied to the problem of differentiating floral regions, for one fails to perceive any object which is gained by defining them, for example, any progress in the study of geographical distribution. The term floral region may, it seems to us, be added to "constitution" in the extract from Huxley given on p. 231, as one of the verbal anodynes by which the discomfort of ignorance is dulled. When we say that Lactoris fernandeziana (which is now usually regarded as of family rank) is eharacteristic of the Juan Fernandez floral region, it sounds as if we knew more about it than if we simply stated the bald truth, that it oceurs upon the island of Juan Fernandez. In plain fact it is no more specially characteristic of that island than Centaurodendron dracaenoides, an endemic genus of Compositae, or Spergularia rubra, which is of enormously wide distribution.

What it really comes to is that as, on the whole, in recent periods of the world's history, migration of plants has been largely southwards (owing to the cooling of the north), and the subsequent northward migration has not yet had time to show very obvious results, the southern regions contain greater proportions of endemies. In the same way, the islands being at the edge of the dispersal that has gone on, where the oldest and most variable (p. 218) types oceur, and being also isolated, show great numbers of them. But, as pointed out on p. 170, it must not be forgotten that the larger regions of the world have greater proportions than the small.

Very little consideration is required to show that these divisions or floral regions are very arbitrary, but very little trial of the actual facts is needed to prove to an enquirer that it is a matter of extraordinary difficulty to improve upon them. The islands, by being clearly cut off from the rest of the world, are evident divisions to make, but to divide the continents, except to eut off a few such obvious regions as South Africa or West Australia, is quite a different matter.

The one thing that comes elearly out is that endemies are not a good test to apply, and with the new light that is thrown above upon the question of endemism, it would seem probable that this test will no longer be used. It gives a much greater proportionate value to small areas in the south or upon islands than 
they have any real right to possess. Of the 32 floral regions accepted in the latest work, 9 are upon islands, and 7 upon small southern areas, and $12 \mathrm{in}$ all are in the south, against only 14 for the very much larger land masses of the north.

The work upon Age and Area deseribed above makes it much more clear why these difficulties arise. No two genera, in all likelihood, will spread about the world at the same rate, so that it is evident that what may be a marked floral region for one genus of plants (or animals) will not be so for another, unless the region has been well isolated for a long time, when it will, as in the case of many islands, contain many endemies of many different families. The whole subject requires a complete reconsideration in the light of the results provided by $\mathrm{Age}$ and Area, before it will be safe to try to divide up the world in this manner. All that can be safely said at present is that regions with great numbers of endemies in many families can be regarded as regions that have existed for a long time, perhaps in comparative isolation.

Another thing that seems indicated by the work outlined above is that in general the floras of the world, including those of most of the islands, must have reached their present positions over land or narrow straits which would not seriously interfere with the passage of species. The arithmetical, systematic, and other relationships between them, are too complex, and too evident, to have resulted from transport over wide stretehes of sea, a process which would sift ont a very few from a comparatively large flora.

A way in which Age and Area may prove incidentally useful has been indicated above, and in a number of papers (126-134). For example, in New Zealand (127, p. 452) a number of widely distributed species, many more than would be expeeted, were found in the elass of smallest area. On examination, they proved to be, so to speak, the leavings of the flora. Twelve of 21 were Ionocotyledons, four were from the neighbourhood of Kaitaia, and so on; it was elear that many of them, though they perhaps appeared to be really native, were in fact introductions to the country. Pomaderris apetala proved to be a very marked exception among the plants of the Chathams in regard to its distribution in New Zealand (129, p. 332), and therefore was probably an introduction. The doubtful natives of Jamaica were 
picked out in the same way, through showing irregularities in regard to their distribution, judged by Age and Area (130, p. 337), and so on. Whenever a species is found whose distribution is markedly different from what one would expect under this hypothesis, that species is nearly always found to be an introduction, or of doubtful identification, or in some way irregular.

Sufficient has been said in Chapter xvin about the Hollow Curve of Distribution, and both this subject and that of Evolution will be treated of in fuller detail in a later book. It is clear that Age and Area becomes simply a corollary of the larger law that was indicated in what was said about Erolution.

There are many other directions in which Age and Area may prove to be a very useful hypothesis in dealing with problems of distribution, but in the present somewhat controversial stage in which the matter remains, it is better not to attempt too closely to define, or even to outline, new positions. The fact remains that Age and Area (with its subsidiary hypothesis of Size and Space) is strongly supported by very numerous facts which demand an explanation that is largely mechanical, and that the more inasmuch as the same type of facts is exhibited both by animals and by plants. It is also clear that in dealing with questions of Geographical Botany, the statistical method, which has remained almost untouched since Hooker long ago (p. 104) pointed out its uscfulncss, will probably play an important part. 


\section{LIST OF LITERATURE}

(1) Andrews, E. C. The Development and Distribution of the Legnminosae. Proc. R. S., N.S.W., xLvi1, 1914, p. 333.

(2) - The Development of the Myrtaceae. Proc. Linn. Soc., N.S.W., xxxvil, 1913, p. 529.

(3) Arber, A. On the Law of Age and Area, in relation to the extinction of Speeies. Ann. of Bot. xxxi1, 1919, p. 211.

(4) Water Plants. Cambridge, 1920.

(5) Bartlett, H. H. Mass Mutation. Bot. Gaz. Lx, 1915, 1. 125, and Amer. Nat. xxxix, 1915, p. 129.

(6) Bateson, W. Presidential Address, Brit. Assoe., Australia, 1914.

(7) Bentian, G. Notes on the Classification, History and Geographieal Distribution of the Compositae. Lim. Soc, Jl. xil, 1873, p.335.

(8) Bergson, H. Creatize Eiolution (Engl. trans.). London, 1914.

(9) Berry, E. W. A Note on the Age and Area hypothesis. Science, xuv, 1917, p. 539.

(10) Berer, R. ...Ueberpflanzen ausserhalb der Tropen. Abh. B. I'. Brandenb. xxxvi1, p. 105.

(11) Bцаск, J. M. The Naturalised Flora of South Australia. Adelaide, 1909.

(12) Blaringhem, L. et Viguier, P. Une nouvelle espèce...Capsella Jiguicri...née par mutation. Comptes Rendus, cL, 1910, p. 988.

(13) Breakifel, E. The Gramineae and the Age and Area hypothesis. Proc. Lim. Soc., N.S.W., xuII, 1917, p. 303.

(14) Buntt-Davy, J. Alien Plants...Transvaal. Rep. S. Afr. Ass. Adt. Sci. 1904 , p. 252.

(15) Chanderr, M. E. J. The aretic Flora of the Cam Valley at Iarnwell, Cambridge. Q. J.G. S. Lxxvi, 1921.

(16) Clements, F. E. Plant Succession. Washington, 1916.

(17) Copeland, E. B. Natural Seleetion and the Dispersal of species. Phil. Jl. Sci. xr, 1916, p. 147.

(18) - The Comparative Ecology of the San Ramon Polypodiaceae. lbid. 11, $190 \%$, p. 1.

(19) Cockayne, L. Observations eoneerning Evolution.... Trans. X. Z. Inst. XLIv, 1911, p. 1.

(20) Covlter, M. C. Reviews in Bot. Gaz. Lxil, 1917, p. 419, and Lxv, 1918, p. 116.

(21) Darwix, C. Animals and Plants under Domestication, 2nd ed. London, 1890.

(22) - Life and Letters, Ed. by F. Darwin. London, 1888.

(23) - Origin of Species. 6th ed. London, 1872.

(24) De Candolle, A. Gcographic Botanique. Geneva, 1855.

(25) De, Candolle, C. Momographiae Phancrogamarum. Paris, 1878.

(26) DE Vries, II. Die endenische I'flanzen von Ceylon mul die mul ierende Oenotheren. Biol. Ccutr. xxxvi, 1916, p. 1.

(27) L Lévolution des êtres organisés par santes brusques. Scientia, $\mathrm{xix}, 1916$, No. 1.

(28) - The Distribution of endemie spp. in New Zealand. Science, xLy, 1917, p. 641 .

(29) — The Mutation Theory (Engl. trans.). London, 1910. 
(30) DE VRIEs, H. The Origin by Mutation of the endemic Plants of Ceylon. Science, xuII, 1916 , p. 785.

(31) - The relative age of endemic species. Ibid. xlvil, 1918, p. 629.

(32) - Van Amoebe tot Mensch (with Engl. trans.). Utrecht, 1918.

(33) Drude, O. Manuel de Géographie Botanique (French trans.). Paris, 1897.

(34) Ersist, A. The new Flora of the Volcanic Island of Krakatau (Engl. trans.). Cambridge, 1908.

(35) Ewart, A.J. The Weeds...of Victoria. Melbourne, 1909.

(36) Farrow, E. P. The Ecology of Breckland. Journ. Ecol. 1916, et seq. (effects of rabbits, 1917, p. 1).

(37) Floras cmployed include Babington's Cambridgeshire, Bolle's Canaries, Britton and Millspaugh's Bahamas, Cheeseman's New Zealand, Clirist's Canaries, Engler's Natürlichen Pflanzenfamilien and Pflanzenreich, Hillebrand's Hawaiian Islands, Hooker's British India, London Catalogue, 8th ed., McNeill's Colonsay, Praeger's Clare Island, Reiche's Chile, Spence's Orkneys, 'Thwaites' and Trimen's Ceylon, and others.

(38) Gates, F. C. The revegetation of Taal volcano. Plant World, xx, 1917, p. 195 .

(39) Gates, R. R. The Mutation Factor in Evolution. London, 1915.

(40) Grisebach, A. H. R. Die Vegetation der Erde. 2 Aufl. Leipzig, 1884.

(41) Guppy, H. B. America's Contribution to the Story of the Plant World. Journ. Ecol. Ix, 1921, p. 90.

(12) - Distribution of Plants and Animals. Peterm. Mitt. 1910, Heft 2.

(43) - Fossil Botany in the Western World. Amer. Jl. Sci. xuix, 1920, p. 372 .

(4t) _ Observations of a Naturalist in the Pacific. London, 1906.

(45) - Plant Distribution from an old Standpoint. Trans. Fict. Inst., April, 1907.

(16) - Plant Distribution from the Standpoint of an Idealist. Linn. Soc. Journ. Xliv, 1919, p. 439.

(47) Plants, Seeds, and Currents in the West Indies and Azores. London, 1917.

(48) — The Dispersal of Plants as illustrated by...Keeling or Cocos Islands. Tiet. Inst. 1890.

(49) - The Island and the Continent. Journ. Ecol. vir, 1919, p. 1.

(50) The Testimony of the Endemic Species of the Canary Islands in favour of the Age and Area Theory of Willis. Ann. of Bot. xxxv, 1921, p. 513 .

(51) Hensley, W. B. In Biologia Centrali-Americana, London, 1879-88.

(52) - Insular Floras. Sci. Progr. 1894, p. 27.

(53) - Insular Floras in Rep. Bot. Challenger Exp. I, 1885.

(54) Hildebrand, F. Die Verbreitungsmittel der Pflanzen. Leipzig, 1873.

(55) Hooker, J. D. Botany of the royage..."Erebus" and "Terror." (a) II. Flora Nov. Zeal. 1853; (b) III. Flora Tasmanieae, 1860.

(56) - In Biologia Centr.-Amer. p. lxii.

(57) Life and Letters. London, 1918.

(58) - Outlines of the Distribution of Aretic Plants. Trans. Linn. Soc. xxiIr, 1860, p. 251.

(59) Huxley, T. H. The Gentians.... Journ. Linn. Soc. xxiv, 1888, p. 101.

(60) Jessex, Kxud. Moserundersogelscr i det nordostlige Sjaelland. Danmarks geol. undersog. II Raekke, no. 34.

(61) Johansien, W. Elemente der exacten Erblichkeitslehre (Germ. trans.). Jena, 1909. 
(62) Jordan, A. Diagnoses d'espèces nouvelles ou méconnues. Paris, 1864.

(63) Kryshtofovich, A. A new fossil Palm and some other Plants of the Tertiary Flora of Japan. Journ. Geol. Soc. Tokyo, xxvir, 1920.

(64) LeavitT, R. G. The Geographical Distribution of nearly related Speeies. Amer. Nat. xi.I, 1907, p. 207.

(65) Lotsy, J. P. Die endem. Pflanzen von Ceylon und die Mutationshypothese. Biol. Centr. xxxvi, 1916, p. 207.

(66) — Evolution by means of IIybridisation. The Hague, 1916.

(67) On the Origin of Species. Proc. Linn. Soc. 1914, p. 73.

(68) Lyell, Sir C. Antiquity of Man. 4th ed. London, 1873.

(69) - Principles of Geology. 9th ed. London, 1853.

(70) MacDougall, D. T. Review of Age and Area. Plant World, 1916, p. 79.

(71) MacLeod, J. List of literature relating to seed-dispersal. Bot. Jahrb. Gent. in. 1891, p. 192. And ef. Suall, no. 103, p. 182.

(72) Marr, J. E. An arctic Flora in Pleistocene beds, Barnwell, Cambridge. Geol. Mag. 1916.

(73) Massee, G. A revision of...Cordyceps. Ann. of Bot. Ix, 1895, p. 1.

(74) Matrhew, J. R. The Distribution of certain elements in the British Flora. Brit. Assoe. 1921; abstract in Journ. Bot. Jan. 1922, p. 26.

(75) Mrllspaugh, C. F. Flora of the Alacran shoal. Publ. Ficld Mus., Bot. II, 1916, p. 421.

(76) Morgan, T. H. Contr. to the Genctics of Drosophila. Washington, 1919.

(77) — Evolution and Adaptation. New York, 1903.

(78) Nationst, A. G. Contr. à la Flore Fossile du Japon. Acad. Roy. du Sc. Suede. Stockholm, 1883.

(79) - Zur fossilen Flora Japons. Palaeont. Abh. 1, part 3. Berlin, 1888.

(80) Oswald, F. The Sudden Origin of new Types. Sci. Progr. xix, 1911, p. 396.

(81) Pearson, H. H. IV. The Botany of the Ceylon Patanas. Linn. Soc. Journ. Xxxiv, 1900, p. 300.

(82) REID, C. The Plants of the late glacial deposits of the Lea Valley. Q. J. G.S. LxxI, 1916.

(83) Reid, C. and E. M. The pre-glacial Flora of Britain. Journ. Linn. Soc. xxxvil, 1908.

(84) _- The fossil Flora of Tegelen-sur-Meuse. Verh. k. Akad. Wctens., Amsterdam, xxil, no. 6, 190\%.

(85) - A further investigation of the fossil Flora of Tegelen-sur-Meuse. Ibid. Versl. Afd. Natuurk. pt. xix, 1910.

(86) - The Pliocene Floras of the Dutch-Prussian border. Med.Rijksopsporing v. Delfstoffen, No. 6, 1915.

(87) Rein, E. M. Two pre-glacial Floras from Castle Eden. Q. J. G. S. Lxxvi, 1920.

(88) — A comparative review of Pliocene Floras. Ibid.

(89) - Rech. sur quelques graines Pliocènes du Pont-de-Gail (Cantal). Bull. Soc. Géol. France, xx, 1920.

(90) Ridley, H. N. Endemism and the Mutation Theory. Ann. of Bot. $\mathrm{xxx}, 1916$, p. 551.

(91) - On the Dispersal of Seeds by Mammals. Journ. Straits As. Soc. 1894.

(92) - On the Dispersal of Seeds by Wind. Ann. of Bot. xix, 1905, p. 351 .

(93) Samuelsson, G. Ueb. d. Verbreitung ein. endem. Pllanzen. Ark. $f$. Bot. Stockholm, Ix, 1910, No. 12.

(94) Seward, A. C. Darwin and Modern Science. Cambridge, 1909. 
(95) Sinnotr, E. W. Comparative Rapidity of Evolution in various Plant Types. Amer. Nat. 1, 1916, p. 466.

(96) - The Age and Area Hypothesis and the Problem of Endemism. Ann. of Bot. xxxr, 1917, p. 209.

(97) - The Age and Area Hypothesis of Willis. Science, xuvi, 1917, p. 457 .

(98) Sinvott, E. W. and Balley, I. W. Foliar Evidence as to the Ancestry and Climatic Environment of the Angiosperms. Amer. Journ. Bot. 11, 1915, p. 1 .

(99) — The Origin and Dispersal of Herbaceous Angiosperms. Ann. of Bot. xxviri, 1914, p. 547.

(100) Suall, J. Geographical Distribution of the Compositae. Rep. Brit. Assoc. 1916, p. 509.

(101) - Modern Theories of Evolution. Pharm. Journ. xcvil, 1916, p. 612 ; xcvi11, 1917 , p. 3.

(102) — The Agc and Area Law. Science Progr. xir, 1918, p. 439.

(103) - The Origin and Development of the Compositae. New Phytol. Repr. xi. London, 1919. Cf. lists of literature on pp. 182 (seed dispersal), 214 (geographical distribution), and 242 (evolution).

(104) Solys-Laubach, Graf zu. Cruciferen-studien. Capsella IIegeri. Bot. Zeit. 1900, p. 16\%.

(105) Taylor, N. Endemism in the Bahama Flora. Anm. of Bot. xxxy, 1921, p. 523.

(106) Endemism in the Flora of the Vicinity of New York. Torreya, $\mathrm{xvr}, 1916, \mathrm{p}, 18$.

(107) Thellexg, A. Flore Adientize de Montpellier. Cherbourg, 1912.

(108) Townsend, F. Contr....Flora...Scilly Is. Journ. Bot. II, 1864, p. 102.

(109) Trecb, M. Notice sur la nouv. Flore de Krakatau. Ann. Buitenz. v11, 1888.

(110) Wallace, A. R. Darwinism. London, 1890.

(111) Island Life. 2nd ed. London, 1892.

(112) West, F. A. F. C. Ueb. Zwecklosigkeit in der lebenden Natur. Biol. Centr. xxrn, $190 \%$, p. $25 \%$.

(113) Wills, J. C. A Dictionary of the Flozering Plants and Ferns. 4th ed. Cambridge, 1919.

(114) - Agrieulture in the Tropies. 2nd ed. Cambridge, 1914.

(115) Catalogue of Ceylon Plants. London, 1911.

(116) Studies...Podostemaceae. Amm. Perad. 1, 1902, p. 267.

(117) - The Flora of Ritigala, a study in Endemism. Ibid. III, 1906, p. $2 \pi 1$.

(118) - Some Evidence against the Theory of...Nat. Selection of Infinitesimal Variations.... Ibid. 1v, 1907, p. 1.

(119) — Further Evidence. Ibid. p. 1\%.

(120) - The Geographical Distribution of the Dilleniaceae, as illustrating the Treatment of this subject on the Theory of Mutation. Ibid. p. 69.

(121) - Hill-Top Floras of Ceylon. Ibid. p. 131.

(122) - The Flora of Naminakuli-kanda. Ibid. v, 1911, p. 217.

(123) - The Endemic Flora of Ceylon.... Phil. Trans. B, Ccv1, 1915, p. 307, and correction in Proc. R. S. B, Lxxxrx, 1916.

(124) _ On the Lack of Adaptation in the Trist. and Podostem. Proc. R. S. B, Lxxxvir, 1914, p. 532 .

(125) - The Origin of the Trist. and Podostem. Amn. of Bot. xxix, 1915 , p. 299.

(126) — The Evolution of Species in Ceylon. Ibid. $\mathrm{xxx}, 1916, \mathrm{p} .1$. 
(127) Willis, J. C. Distribution of Species in New Zealand. Ann. of Bot. $\mathrm{xxx}, 1916$, p. 437.

(128) - Relative Age of Endemic Species. Ibid. xxxi, 1917, p. 189.

(129) - Distribution of Plants of the Outlying Islands. Ibid. xxxi, p. 327 .

(130) - Further Evidence for Age and Area. Ibid. xxxı, p. 335.

(131) - Sources and Distribution of the New Zealand Flora. Ibid. xxxi1, 1918, p. 339.

(132) — The Flora of Stewart Island. Ibid. Xxxm1, 1919, p. 23.

(133) - The Floras of the Outlying Islands of New Zealand. Ibid.p. 479.

(134) - Plant Invasions of New Zealand....Ibid. xxxiv, 1920, p. 471.

(135) - Endemic Genera of Plants. Ibid. $\mathrm{xxxv}, 1921$, p. 493.

(136) The Age and Area Hypothesis. Science, xum, 1918, p. 626.

(137) Willis, J. C. and Burkill, I. H. The Flora of the Pollard Willows near Cambridge. Proc. Camb. Phil. Soc. vin, 1893, p. 82.

(138) Willis, J.C. and Gardiner, J.Stanley. The Botany of the Maldive Islands. Ann. Perad. I, 1901, p. 45.

(139) Bews, J. W. Plant Succession and Plant Distribution in S. Africa. Ann. of Bot. xxxiv, 1920, 1. 287.

(140) —- Some gencral Principles of Plant Distribution, as illustrated by the S. African Flora. Ann. of Bot. Xxxv, 1921, p. 1.

(141) DE VRies, H. The present position of the Mutation Theory. Nature, CIV, 1919, p. 213.

(142) Hooker, J. D. On Insular Floras. Journ. Bot. 1867, p. 23.

(143) Harward, I. and Druce, G. C. The Adventive Flora of Treedside. Arbroath, 1919.

(144) Laxg, W. D. Old Age and Extinction in Fossils. Proc. Geol. Ass. xxx, 1919, p. 102.

(145) Willis, J. C. and Y YLe, G. U. Some Statistics of Evolution and Geographical Jistribution in Plants and Animals, and their Significance. Nature, 109, Feb. 9, 1922, p. 177. 



\section{INDEX}

Acclimatisation, 29, 45. And ef. Introduction

Acrotrema dissectum, with intermediate stages, 219

Adam's Peak, endemics of, 55

Adaptation, $19,55,57,59,87,148$, $209,210,220,224,227,229,230$, 231. And ef. Correlated variation, Endemic genera and species, Evolution, Intermediates, Local adaptation, Natural selection, Species, Struggle for existence

Advantage as a guide in evolution, $189.212,215,221,225$; ruled out, $215,219,221$

Africa, endemic genera, 170, 178: monotypes, 188, 189. And ef. Canary Islands, Madagascar, Mascarene Islands, St Helena

Age, effects of , 3, 4, 5, 6, 61, 62, 85, $99,174 n ., 196$; the most powerful factor, $6,197,198$

Age and Area, 4, 5, 6, 54, 61, 63 (statement of rule), 85, 103, 147, $150,189,206,221,225$; application to single species, 84,85 ; to animals, 200; to unallied forms, 86 ; and ecological results, 98 ; and palaeobotanical study, 137, 147; and the mutation theory, 222; confirmation by prediction, 66, $76,87,230$; in Australia, 64; in Ceylon, 54; in Compositae, 119; in New Zealand, 64; invasions, $76,139,234$; objections to, 70 , 84; position of the theory, 101; reservations, 63,70

Aim of nature, 205, 215

Alacran reef, endemies of, 152, 212

Allied forms only comparable under age and area, 62,85

America. See North America, South America, Tropical America. And cf. Alacran, Andes, Argentina, Bahamas, Brazil, Chinese, Eugenia, Galapagos, Jamaica, Juan Fernandez, Lactoris, Mexico, New York, Rio de Janciro, Sequoia

Andes, endemies of, 176

Animals, applicability of age and area to, 200

Anodynes, verbal, 231, 244

Anthemideae, 127, 135, 136

Antiquity and amplitude, 116

Anurádhapura, climate of, 43
Arber, Mrs A., 92

Aretotidcae, 126, 127, 136

Area, broken, 89; dillerences in, occupied, 2, 33, 55; early species gain in, on later, 34; fossil, 243; graduation of, $58,170,229$; increasing more rapidly with age, 33 ; increasing with size of genus, 114-18; large, due to spreading, 11; minimum, oceupied by commeneing species, 206; necessary for origin, 10; of endemic genera, 171 ; of endemic species, 56,150 ; occupied, 2, 11, 33, 55, 115, 150, 151, 170, 191; phenomena matelicd by those of size, 175 ; plants of smaller, the younger, 206: possible of occupation, 49 ; restricted, $5 \pi$; to which suited, 11. And ef. Age and Area, Dispersal, Endemie, ctc.

Argentina, spread of introductions in, 26

Argument of Part I, $\tau$; of Part II, 107

Asia, tropieal, endemic genera, 178 . And ef. Ceylon, Chinese, India, Krakatau, Maldives, Monsoons, Taal

Associations of plants, 20, 25, 30, 35, $50,51,229$

Astercae, 129, 130, 131, 134, 135

Auckland Islands, 66-74, 230

Australia, age and area in, 64; endenie generat of, 170, 190; cndemic species of, 150 ; grasses of, 64. And ef. West Australia, New Caledonia

Average generic area, 126 ; necessary in age and area, 61

Axioms of the systematists, 105.21\%

Bahama Islands, endemics of, 64, 150,210

Barriers to spread, 12, 13, 16, 20, 21, 36 ; especially Chap. v

Bateson, W.. 217

Bectles, hollow eurve in, 202, 203, 236; log:trithmic curve, 241

Birds, dispersal by, 12-18

Boraginaceae, distribution in New Zealand, 161

Brazil, endemics of, 150, 170, 190, 233 ; endemic gencra, 170,176 ; sizes of genera, 190. And ef. Eugenia 
Breakwell, E., 64

Britain and Ireland, and outlying islands, distribution in, 70,73 ; flora of genera and families by sizes, 235; Hieracia in, 160 ; invasions of, 234, 236; species per family, 237. And ef. Cambridgeshire, Clare, Colonsay, Ireland, Orkneys, Scilly, Wicken, Willow, ete.

Broken areas, 89

Burkill, I. H., 12

Cakile alacranensis, distribution of, 152

Calcutta climate, 43

Calenduleae, 126, 127, 134

Callitriche, distribution of, 92

Callitris, distribution in Australia, 157,64

Cambridgeshire flora, 235, 237

Campanula Vidalii, distribution of, 152

Canary Islands, flora of, 27,88

Caluses favouring or hindering dispersal, 32

Cenchrus insularia, distribution of, 152

Ceylon, age and a rea in, 54 ; catalogue of flora, 59 ; distribution of classes in flora by area, 59; distribution of species in, 59; dry and wet zones, 14 ; endemies, 54, 55, 56, $150,152,233$; endemics mainly in big genera, 165 ; endemic genera, 170 ; genera by sizes, 235 ; spread of introductions in, 25-6. And of. Adam's Peak, Anurádhapura, Christisonia, Coleus, Doona, Eugenia, Hakgala, Hinidun-kanda, Hortomia, Kandy, Ritigala, Schumacheria, Thwaites, Tithonia, Trimen

Change in living world, rate of, 3 ; of conditions, $39-44,51$; of temperature, 44; greater in greater time, 1.44

Characters, family and generic, 209 ; intermediate usually not possible, 209, 211, 219; often appear late, 210 ; rudimentary beginnings of, 209 ; usually evolved without reference to usefulness, 226; usually indifferent, 152, 209, 224, 225. And ef. Intermediates, Species, etc.

Chatham Islands, 66-74, 230; plants oldest in New Zcaland, 67

Cherrapunji climate, 43

Chinese-North-American flora, 88, 140,144

Christisonia, 151; distribution of, 159
Cichorieae, 130, 135, 136

Cissampelos, distribution of, 159, 172

Cistaceae, distribution of, 172

Clare Island, distribution of flora, 70

Classes by area, 60, 61

Clements, F. E., 20

Climate, 40; climatic boundary, 45; changes of, as barriers, 40 ; changes of, as directing forces in migration, 138

Closed plant-societies, 20, 30, 50, 51

Cockayne, L., 26

Coffee, Liberian, acclimatisation of, 29

Coleus, dispersal of Ceylon species, 2,54 ; C. elongatus, 2, 54, 151, 152, 208, 219

Colonsay, distribution of flora, 70

Commencing species, 10

Comparison of unallied forms, 86

Compositae, age and area in, 119; distribution of, $18,22,48,85$, Chap. xur ; evolutionary history, 132 ; of Madagascar, 175 ; size and space in, 132

Compound interest law, 241

Constitution of plant or animal, 231

Copeland, E. B., 5, 50

Correlated variations, 208, 209

Cosmopolitan genera, 21

Cromerian flora, 137-8

Cupressus macrocarpa, 88, 113

Currents, dispersal by, 14-17

Cyanca, distribution in Hawaii, 161

Cynara, spread of, 27; Cynareae, $127,134,135$

Cyrtandra, distribution of, 159 ; in Hawaiian Islands, 160

Darwin, C., 4, 10, 204, 217. 222; Darwinian theory, 102, 204

Destruction in struggle for existence, 113, 221

De Vries on Age and Area and the Mutation Theory, 222

Diagnostic characters usually indifferent, 152, 224, 225

Didymocarpus Perdita, species of two individuals only, 151

Differentiation, is, 103, 105, 221, $228 n ., 240$

Dillenia, distribution, 159, 219; Dilleniaceac, family tree, 240

Dipterocarpaceae, distribution of, $19,36,85,152$

Dispersal of plants, 10, 12, 24, 32, $85,101,228$; a measure of age, 61 , 197,230 ; by birds, explosions, mammals, sea, vegetative reproduction, wind, etc., 12-19; average 
rate probably very uniform, 99 ; causes favouring or hindering, 32 ; due to youth, 89,92 ; into virgin areas, 12, 14, 15, 19-21; mainly by land, 21, 182, 245; mainly conditioned by barriers, 48 ; mechanical, 21, 22, 36, 61, 229; methods, 12-22; of introductions, 24-27; of unrelated forms, 36 ; oldest types at edge of, 218 ; present, the maximum possible, $11,197,229,230$; rapid, 11,19 , $20,26,94,229$; rapid, not necessary, 33: reaclied possible limit, $11,27,229$; regular and irregular, 12 ; slow, 20, 30, 33-52; to sliort distance only, 14, 20, 32, 35; without alteration of conditions, 2.5

Distribution, 101, 228; a closed chapter, 11, 27, 230; detemined largely by time, 179; discontinuous, 11; general, 228; largely mechanical, 6, 61, 191, 203, 206, 214,229 ; due to interaction of many factors, $1,2,5,85,87$; limited, 3,4 ; of endemies, 54,58 , 163,166 : of rainfall and moisture, $43-1$; of wides greater than of endemies, 60 ; to what due, 1,5 ; vital factors in, 2. And ef. Dispersal, Endemies, Species, and the various count ries

Ditypes, 185

Doona in Ceylon, 94, 152, 161

Drosophila, mutation in, 224

Dying out $1,4,10,58,81,88,89,90$, $91,93,142,144,148,165,186$. 192-3, 229-34. And ef. Intermediates, Killing out. Relies, ete.

Early species gain upon later, 34

Ebermaiera, dist ribution in India .1 6:3

Ecology, 20; ecological barriers or aids to spread, $46,99,100$; results, and Age and Area, 98

Effects of barriers, 12, 13, and Chap. $\mathrm{v}$

Elodea, dispersal, and spread, 17, 26, 27,51

Endemic genera, 169 ; areas oceupied, 170; as local adaptations, $57-8,87,166,179$; as relies, 166 , 179,182 : as young beginners, 166 , 179,183 : belong chiefly to larger families, 182; distribution of, 169 ; explanations of, 179; of eontinents, 177-8; of islands, 175-83; number inereases with various factors, 169 ; and with increasing area, 169; phenomena paralleled by genera of larger area, 176; with small areas, 171. And ef. Endemic species, Evolution, and the various count ries

Endemie species, areas oecupied, 150 ; as local adaptations, 5., 87, 166,186 ; as relies, $58,81,88,93$, $141,1.48,166,186$; as young beginners, 165-7; belong chiefly to large genera, 91,165 ; commoner in the south, ete., 218; descended from wides, $61,71,77,86,153$, $221,239,240$; explanations, 218; families and genera to which belong, 164: increase to southwards, etc., 149 ; localities in which oceur, 149; of Bahramas, 64 ; Cevlon, 54 ; Galapagos, 150 ; Hawaiian 1slands, 150,164 (including of endemic and non-endemic genera, 163), India, 164; mountain tops, 54, 5.5, 58; New York, 64; New Zealand, or New Zealand and outlying islands, 64, 66-74, 164: North Ameriea, 86 ; resenblance to nonendemies, 161 ; relation to wicles, $61,77,86,198$; their distribution a special case, $16: 3$; types of distribution same as wides, 161 ; unrelated to wides. $86 n$; with maximum numbers at certain spots, $\tau \tau-8$; without differences in conditions, 88 ; younger than wides, 89,221 . And $\mathrm{cf}$. Age and Area, Dispersal, Distribution, Local adaptation, Relies, speeies

Endemism, 17, 54, 148, 166: a sign of age, 81; and distribution. (species) 148, (genera) 169: and isolation, 148-9; especially to the southwards, 149, 170; explanations of, 166; on continents. 1.49: on mountains, 149, 150. And ef. above, and Killing ont, Local adaptation. Relies, Wides, ete.

Epilobium, distribution in New Zealand, 155

Eugevia, in Brazil, 157, 165; in Ceylon, 58, 115, 157, 165

Eupatorieae, 126, 127, 134, 136

Europe, endemies of, 149. And ef. Britain, Italy

Europeans in the Tropies, loeations of, 24

Euryale, formerly of great extension. 141

Evolution. by infinitesimal variation, $2,10,20 \%, 213$; by differentiation, ef. I) ifferentiation: by mutation, ef. Mutation : guided ly advantage or natural selcetion, $189,212,214,215$; mechanical, 
203, 205-6, 211, 214; predetermined, 215; theory, 204; tree of, surviving to present time, 221; type of, 101 ; without adaptation, $57,58,221-6$. And cf.Adaptation, Natural selection, etc.

Exacum, distribution in India, 163

Exceptions to Age and Area, 67, 68, 84; exceptional species, $\mathbf{2 4 5}$

Expectation of life, 5

Explosions, dispersal by, 16

Extermination, 140, 238; regional, 140; specifie, 142. Cf. Killing out and Dying out

Extinction of species, 142-4. Cf. Killing out and Dying out

Factors in dispcrsal, ete.

Cf. Causes, 1)ispersal, etc.

Families to which endemics belong, 182; sizes of, in hollow curves, 186. And ef. Genera

Faunas, local, 203

Festuea on different types of soil 38 ; on the downs, 51

Fixity of vegetation at a given spot, 20

Fleshy fruits, 13

Floral regions, 243

Floras. Cf. under countrics, etc.; due to land connections, 182,245

Fluctuating variation, 207, 211, 213, 222

Foreign spccics, introduction and spread of, 24

Forest, $4.2,47,51$

Fossil areas, 243

Galapagos, endemies of, 150

Gardiner, J. Stanley, 14, 200, 202

Genera, as local adaptations, 189 ; as relics, 189 ; ditypic, etc., 185 ; endemic, 169; form more species with increasing area, 117; formed in a casual way, 234; gromped by number of species, 186 ; largest in largest families, 187; monotypic, 185 ; number of species in, related to variety of conditions, 115; of endemics only, $95,18,155$; of few species usually relies (?), 229 ; of one or more species, 185; of Old and New Worlds, 21; on both sides of a barrier, 39 ; percentage confined to various areas, 189 , 190 ; possible size increasing with increasing area, 178 ; sizes of, in hollow curves, $174,178,186$

Geographieal distribution. Cf. Distribution, Limiting factor, Progress
Geological changes, 1, 52, and Chap. xrv

Glacial period, 2, 172 n., 199

Gnaphalieae, 126, 128, 134, 135

Goats, effect of, upon vegetation, 26

Graduation, of areas of endemics and wides, 60,61 ; of areas of genera from small to large, 170; of areas of species from small to large, 58

Gramineae of Australia, 64

Great Britain. Cf. Britain

Gummera, distribution of, in New Zealand, 155

Guppy, H. B., 17, 49, 95, 101, 117 , 130 ; his theory of differcntiation, $18,103,221,228,240$

Gymnema, distribution of, 159

Iaastia, distribution in New Zealanci, 1.5:3

Ilabit, types of, effects upon dispersal, 49

Hakgala (Ceylon), 151

llawaiian Islands, age and area in, 64; Cyanea in, 161; Cyrtandra in, 160 ; cndemies of, $150,163,164$, $1 \% 0$; endemics of endemic and non-endemic genera compared. 163 ; genera above average world size, 164; Pelea in, 161. And ef. Waialeale

Helenieae, 126, 131, 134, 136

Heliantheae, 128, 134, 135

Inclieae, size and space in, 116

Herbs, shrubs, and trees, 46; herbaceous vegetation and drier climate, 42: advantages of, 48; younger than forest, 46

Hieracia in Britain, distribution of, 160

Hindrances to dispersal, 32-53; to progress, 228-9

Hinidun-kanda species, $\mathbf{5 5}$

Hollow curves, 155, 161, 163, 166, $171,174,176,180,185,186,187$, 188,195 (Chapter), 199, 202, 205, $211,214,229,235,236-7,240$

Hooked truit, 12

Hooker, Sir J. D., on age and area, 4; axioms, 21\%; on Botanical Geography, 6, 104; on dying out. 4; on natural selection, 205; on proportion of mono- to di-cotyledons, 22; on general permanence of species, 207

IIortonia in Cevlon, distribution of, 159

Huxley, T. H., 2, 231

Hydrocotyle, 46 ; acclimatisation to different climates, 30 
Increase of area occupicd, 33

India, endemic genera of, 170; genera by sizes, 235 ; genera above average world size, 164

Infinitesimal variation, evolution by, $2,207,211,213,214,222$

Interaction of factors in dispersal, 1 , 2,5

Intermediates, between diagnostic characters usually impossible, 209, 211, 219; between genera and species, not found, 214,226 ; in Acrotrema, 219 ; no need for them to die out, 218

Introduction of foreign species, 24 ; on continental areas, 25

Inuleae, 126, 134, 135; diphyletic origin, 126; limited, 126, 127, 136

Invasions, 20, 234; of New Zealand, 76,139

Ireland, flora of, 236

Irregular dispersal, 12-16

Islands and endemics, 148-50, 17583 ; monotypes, 188-9

Isolation, 17, 148, 169, 170

Italy, flora of, 236

Jamaica, age and area in, 64

Jordanian species, 215-21

Juan Fernandez, endemic genera of, 169- 70,244

Kandy climate, 43

Kermadec Islands, 66-74, 230

Killing out, 1, 157, 135, 142, 144

Krakatau, flora of, 15

Lactoris, distribution of, 244

Land connections, 21, 182, 245

Landslips, 37, 48

Large families and genera the successful ones, 113

Larger genera, 11\%, 185; on larger areas, 178

Largest families in the world, 21

Light, effects of, 45

Light seeds, 13

Limit of distribution, 4.5

Limiting factor in progress, 3,205,228

Linnean species, and splitting, 98 , $216,218,221$

Literature, 247

Local ataptation, 54, 57, 58, 87, 148 , 216,231 ; species, 50, 151, 217 (and ef. Endemic); distribution, 3, 4; faunas and hollow curve, 202; floras and hollow curve, 236; migration, $20,32,35$

Löfgren, A., 206

Logarithmic curves, 241

Lyell, Sir C., 3, 20, 219
Madagasear, endemic genera of, 175,178 ; sizes of endemic genera, 190

Maldive Islands, flora of, 14

Mammals, dispersal by, 19

Man, action of, 52

Mascarene Islands, endenic genera of, 169,170

Matthew, J. R., 234

Mechanical explanations necessary, $89,183,206,232,233$

Mechanisms for dispersal, 12; not imperative, 34

Menispermaceae, distribution of, 172

Mesophytic plants, dispersal of, 49 ; adaptation rare in, 210

Mexico, endemies of, 150

Meyrick, E., 200

Microspecies, 98, 216

Migration, 138

Mogi flora (Japan), 145-6

Moisture of air, distribution of, 43

Monimiaceae, distribution of, 174

Monocotyledons in islands off New Zealand, 230

Monotypic genera, 185; areas occupied by, 191; as relies, 186, 191-3; as special adaptations, $186,191-2$; descended from larger genera, 240 ; explanations of, 192 ; greatest proportion in largest families, 192; increase southwards and outwards, 193

Monsoons, 14, 41

Moribund species. Cf. Relies, and 148

Mountains, as agents facilitating migration, 37 ; as barriers, 36,40 ; as last resorts, 58; and climate, 40-12; and endemies, 5.5, 92, 149 ; endemies as relies, 92 ; endemic genera of, 176

Multiple origin, $11,47,105$

Mutation, 208, 211-21, 222 (de Vrics), 223; causes of, 213; large, 216; Lyell on, 219; parallel, 243 ; several, not necessary for formation of species, 218; size of, 215 ; small, 216; theory and age and area, 222

Mutisicae, 126, 12\%, 131, 135

Najas, distribution of, 159 ; fossil record of, 143

Natural selection, and explanations based upon it, 10, 58, 61, 104, 148, $188,198,199,204,206,208-14$, 220,229 ; a destructive and negative agent, 220; governing general outlook upon biological problems, 228

Nest making, 12, 13 
New and Old World genera, 190

New Caledonia, endemic genera of, 169,170

New forms at commencement of life, 212, 213; most frequent at edges of dispersal, 218 ; range from small to large, 220

New species, formation of, 34-5

New York, endemies of, 64

New Zealand, age and area in, 64; endemies of, 150 ; of, and islands, 69 ; endemies belong to large genera, 165; endemic genera, 170 , 171; flora of outlying islands, 66 , 72; genera above average world size, 164; genera by sizes, 235; invasions of, 76,139 ; predictions about flora of New Zealand and islands, 66-74; Ramunculus in, 153; species per family, 238; spread of introductions in, 26 ; the most irregular curve of all, 196. And ef. Aucklands, Chathams, Epilobium, Gunnera, IIaastia, Kermadee, Monocotyledon, Olearia, Outlying, Ranunculus, Stewart, Vegetation, etc.

North America, spread of introductions in, 26; endemics of, 86 ; monotypes, 188, 189

Objections to hypothesis of age and area, 70,84

Oenothera, mutation in, 224

Oldest and most variable types at edge of dispersal, 218; living species, 143

Olearia, distribution in New Zealand, 161

Open plant societies, 20, 2т, 50, 213

Origin of speeies, 10,204

Orkneys, distribution of flora, 70

Ontlying islands of New Zealand, flora of, 66

Pacific Islands, plants of, 17

Palaeobotanical study and age and area, 137

Palaeotropical genera, 190

Pangenesis, 222

Parent and child occur together, $219,220,221$

Pelea, distribution in Hawailan Islands, 161

Permanence of species, 207

Phylogeny, 240

Physical barriers, 36

Plant migration, 137

Plant societies or associations, 20, 50
Podostemaceae, 4; distribution, 57, 92 ; characters, 210

Polemoniaceae, distribution of, 171

Pollard Willow flora, 12

Polyphyly, 11, 47, 105

Pomaderris apetala, distribution, 67

Pont-de-Gail flora, 137, 143, 146

Prediction, 66, 76, 87, 230

Progress in knowledge of geographical distribution, 3, 228, 229. Cf. Limiting factor

Rainfall, 41-4; distribution of, 43

Rank and range, 105, 118, 130

Ranunculus, 153; distribution in New Zealand, 153, 163, 216, 220, 239

Rapid spread of introductions, 24, 25,94

Rayleigh, Lord, 33, 145, 152, 212

Regional extermination, 140

Regression, 207

Regular mechanisms for dispersal, 12-19

Reid, Mrs E. MI., 82, 137

Relies, 86, 88, 93, 186, 192-3, 199, $216,229,231-3$; explanation of endemism, 58-9. And cf. Dying out, Killing out

Reservations in regard to age and area, 63,70

Reversion, 20\%

Ridley, H. N., 18, 151

Rio de Janeiro climate, 43

Ritigala, and flora of, 14, 54.55

Rivers as barriers, 37

Rubiaceae, logarithmic eurve, 241

St IIelena, endemic flora, 150; spread of introductions in, 26

Salsola Kali, distribution of, 49

Schumacheria in Ceylon, distribution of, 159

Scilly Islands, distribution of flora, 70

Scott, H., 202

Sea, dispersal by, 14-17; as barrier, 36

Seed, quantity of, necessary for transport to a distanee, 32

Senecioneae, 126, 128, 134

Sequoia, formerly of great dispersal, 141

Sinnott, E. W., 95; and Bailey, I. W., 46

Size and space, $71,74,113$ (chapter), $115,171-2,174,178,185,188$, 190, 197, 233; in Britain, 113; in Compositae, 132 ; in Helobieae, 116

Sizes of families in hollow curves, 186; of genera in hollow curves, 174, 178; of mutations, 215 
Small, J., 18, 119

Societies, plant, 20, 27, 32, 50-2, 229

Soil as barrier or assistance to spread, 38

South America, endemies of, 190 ; monotypes and larger gencra, 188-90

Spartina, spread of, 26

Specialisation of plants, 49 (twice), 50

Species, best limited when of complex floral strueture, $217-8$; causes favouring or hindering dispersal, 32 ; commeneing life, 36 ; diagnostic characters usually indifferent, 224-6; dispersal, ef. Dispersal; early gaining on late, 34 ; endenism and distribution, 148; foreign, introduction and spread, 24; general permanence, 207; going under, ef. Relies; least complex that are most widely distributed, 218 ; local, 50, 216, and ef. Enlemies; oceupying just those places to which suited, 229,230 ; oceupying overlapping areas, 57; of large genera often resemble varieties, 217 ; on smaller areas in general younger, 206 ; per family or genus in local floras, 237-8; that vary most, 217. And ef. Endemicspecies, Evolution, Loeal adaptation, Relics, etc.

Specific extermination, 135

Splitting of Linnean species, 98

Sports, 211

Spread of introductions, 24; with alteration of conditions, 25-6; often rapid, 27

Statistieal treatment of geographical distribution, 6,246

Stewart Island, $7 \mathbf{7}, 72$

Stratiotes, suceession of species, 143

Struggle for existence, 50, 148, 206, $210,213,220-1,238$

Successful and unsuccessful species, 55

Suecession, 20, 51, 138

Survival of speeies, 142

Swamping, 95, 18

Systematist, the, 101, 105, 217

Taal voleano, revegetation of, 16

Taylor, N., 64

Temperature changes as barriers, 44

Tertiary flora, $2,34,49,88,137,233$

Theory of differentiation, 18, 103, $105,221,228 n$., 240

Thiselton Dyer, WV. T., 49
'Thwaites, G. H. K., 151

Time available for cvolution and dispersal, $33,145,152,212$

Tithonia, dispersal of , 17,26

Tree, ancestral, of genus or family, surviving, $20,24321,24$

Trces, of inultiple origin, 4\%. And cf. Herbs

Trees, shrubs, and herbs, 46

Treul, M., 15

Tribulus alacranensis, distribution of, 152, 212

Trimen, H., 54, 56

Tristichaceae, dispersal of, 92

Tritypes, 185

Tropical Ameriea, endemie genera of, 190; Asia, endemie genera of, 190

Type of vegetation, is barrier, 50-1

Unallied forms not comparable under age and area, $63,85,86$

Useless characters, 209

Variation a centrifugal force, 105 ; variations, eorrelated, 208; most common in genera simplest in structure, in species of larger genera, and in wide-ranging species, 217

Vegetation, of northern type in New Zealand, 40; type of, as barrier, $50-1$

Vegetative reproduction, 16

Verbal anodynes, 231, 214

Vernonieae, 126, 127, 136

Virgin soil, dispersal into, 12, 14, 15, 19-21

Vital factors in distribution, 2, 4

Waialeale, climate, 43

Water-plants, dispersal of, 49

Went, F. A. F. C., 205

West Australia, endemism in, 149 , 169,170

Wicken Fen flora, 235

Wides, 59; cndemies deseended from, $61,74,167,221,239$; first to appear, 239 ; most widely distributed in a country, 60; of wide dispersal, 84; oldest forms, 61, 72, 239

Widespread genera, 21

Willow, pollard, flora, 12

Wind, as barrier, ete., 45 ; dispersal by, $13-17$

World, endemic genera of, 178

Youth, greater distribution due to, 89,92

Yule, G. U., 241 
PRINTED IN ENGLAND

AT THE CAMBRIDGE UNIVERSITY PRESS

BY J. B. PEACE, M.A. 
This book is a preservation facsimile.

It is made in compliance with copyright law and produced on acid-free archival $60 \#$ book weight paper which meets the requirements of ANSI/NISO Z39.48-1992 (permanence of paper)

Preservation facsimile printing and binding by

Acme Bookbinding Charlestown, Massachusetts

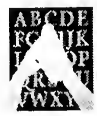

2006 




